Dysertacje

Wydziału Neofilologii

UAM w Poznaniu

\author{
Justyna B. Walkowiak
}

\title{
Personal Name Policy: From Theory to Practice
}

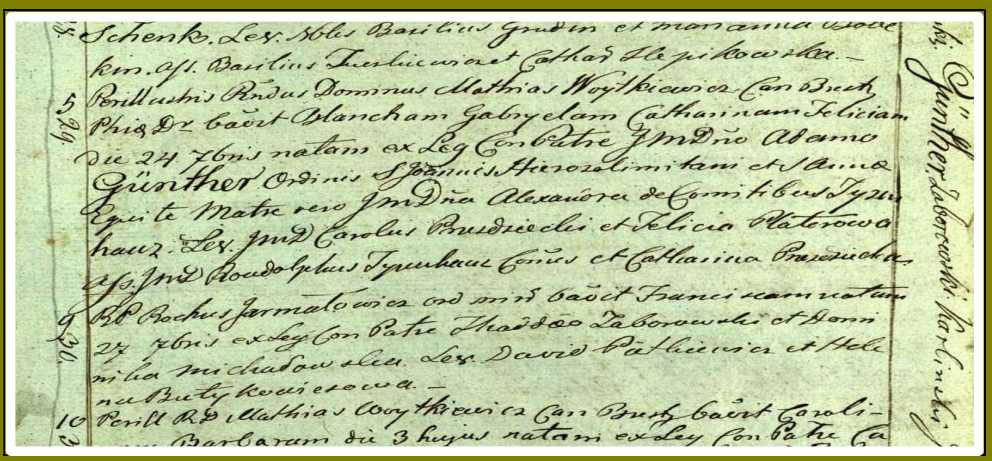

Wydział Neofilologii UAM w Poznaniu Poznań 2016 



\section{Personal Name Policy: \\ From Theory to Practice}





\author{
Justyna B. Walkowiak \\ Personal Name Policy: \\ From Theory to Practice
}

Wydział Neofilologii UAM w Poznaniu

Poznań 2016 
Projekt okładki:

Justyna B. Walkowiak

Fotografia na okładce:

(C) http://www.epaveldas.lt

Recenzja:

dr hab. Witold Maciejewski, prof. Uniwersytetu Humanistycznospołecznego SWPS

Copyright by:

Justyna B. Walkowiak

Wydanie I, Poznań 2016

ISBN 978-83-946017-2-0

*DOI: $10.14746 / 9788394601720 *$

Wydanie:

Wydział Neofilologii UAM w Poznaniu

al. Niepodległości 4, 61-874 Poznań

e-mail: dziekneo@amu.edu.pl

www.wn.amu.edu.pl 


\section{Table of Contents}

Preface

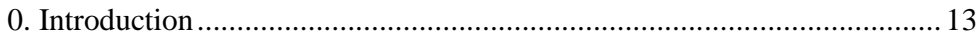

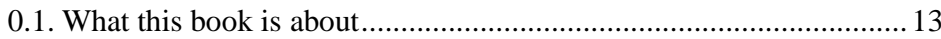

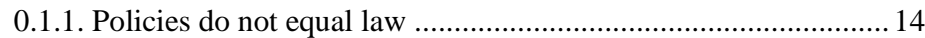

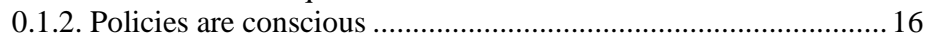

0.1.3. Policies and society ................................................................... 17

0.2 . Language policy vs. name policy ……………............................... 19

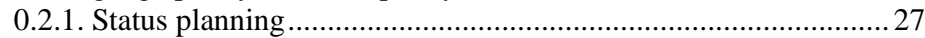

0.2.2. Corpus planning ..................................................................... 28

0.2.3. Technological planning .............................................................. 29

0.2.4. Dissimilarities between language policy and name policy ........... 30

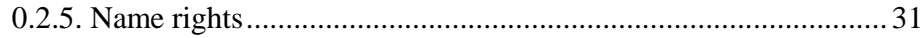

0.2.6. The choice of terms for personal names ....................................... 38

0.3 . Personal names and language policy - overview of literature............ 43

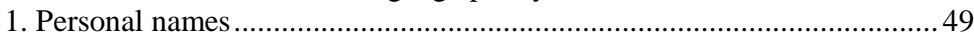

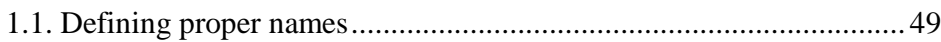

1.2. Defining personal names..................................................................56

1.3. Mill and beyond: the many meanings of personal names...................59

1.4. The meaning of personal names as motivation for name policies ..... 74

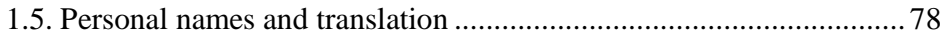

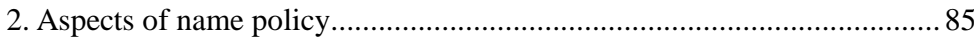

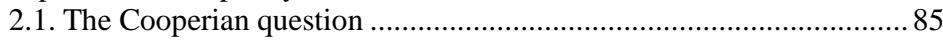

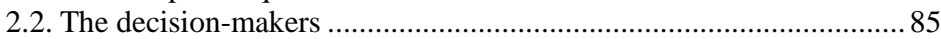

2.2.1. The state and the language regulators ........................................ 87



2.2.3. Low-level authorities ...............................................................94

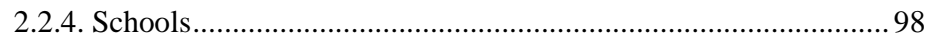

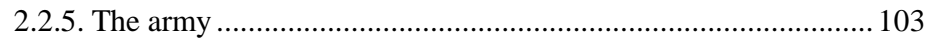

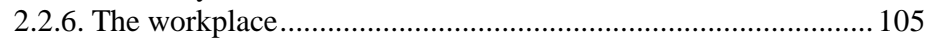

2.2.7. The influence of name calendars and name books .................... 106

2.3. The targets of name policies.......................................................... 110

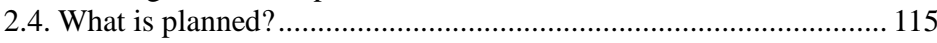

2.5. Motivation and objectives: name-related versus non-name-related

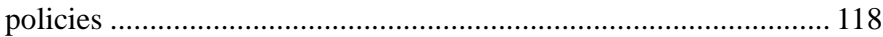

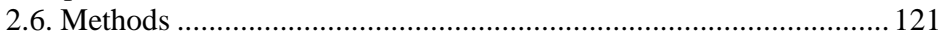

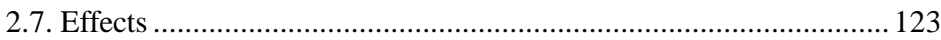

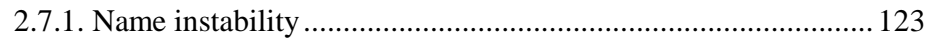

2.7.2. 'Duck-rabbit names'.............................................................. 125

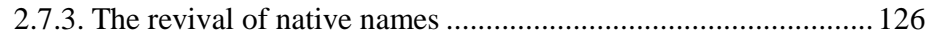

2.7.4. Repetitiveness of personal names ........................................... 127

2.7.5. Blurring the boundary between given names and surnames...... 128

2.8. Implied values and assumptions behind name policies .................... 131 


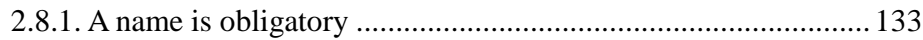

2.8.2. At least two names, each of a different type............................. 134

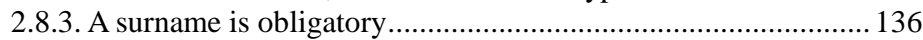

2.8.4. The same surname for the whole family .................................. 136

2.8.5. Only one surname .................................................................... 138

2.8.6. Surname variety is a value ..................................................... 140

2.8.7. Preference for a native name................................................... 141

2.8.8. A given name should look like one ......................................... 142

2.8.9. Not the same given name in the family ................................... 144

2.8.10. Gender-specific versus androgynous given name ................... 148

2.8.11. A given name should correspond to one's religion .................... 151

2.8.12. Civil law versus common law .............................................. 152

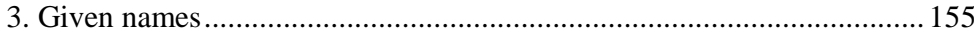

3.1. The laissez-faire approach - testing the limits ................................ 155

3.1.1. One-letter names .................................................................. 160

3.1.2. Numbers, symbols and other unusual names ........................... 162

3.2. Allowed given names and their lists.............................................. 164

3.2.1. Wartheland under Nazi German occupation.............................. 164

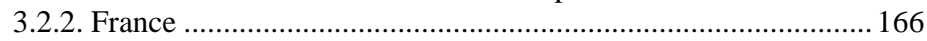





3.3. Forbidden names, by category and individually............................... 171

3.4. Given names promoted by the state ............................................. 175

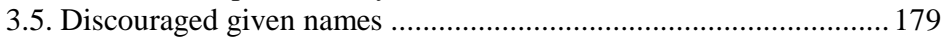

3.6. Obligatory given names ................................................................. 181

3.7. Hyphenation and number of given names ...................................... 182

3.8. Models of relationship between majority and minority

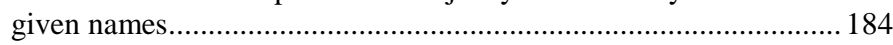



4.1. Compulsory adoption of surnames................................................ 189

4.1.1. Previous names as surnames with new given names .................. 201

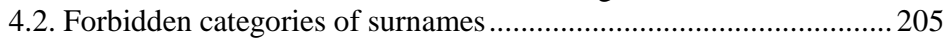

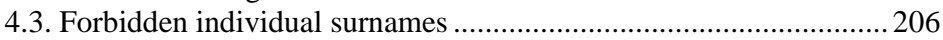

4.4. Discouraged surnames ................................................................. 206

4.5. Protected surnames ......................................................................... 207

4.6. The number and hyphenation of surnames.......................................208



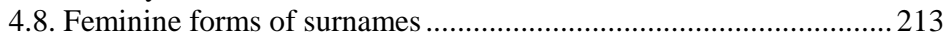



4.9.1. Reducing isonymy - enhancing surname diversity .................. 217

4.9.2. Limiting the number of bearers of popular surnames................ 220

4.9.3. Assimilationist versus segregationist surname policies ...............220



5.1. Voluntary name changes..................................................................223

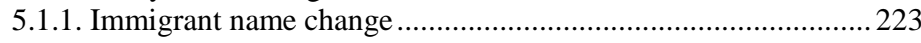






5.1.3. Pseudonyms assumed as surnames ....................................... 226

5.2. Encouraged change of name and name-changing campaigns .........2229

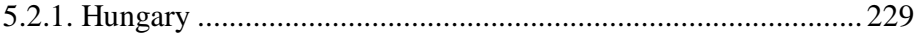

5.2.2. Finland …........................................................................... 231

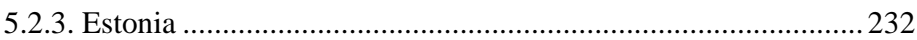

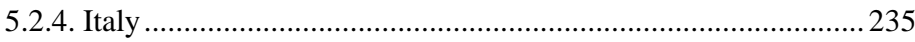

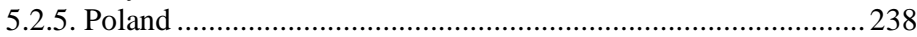

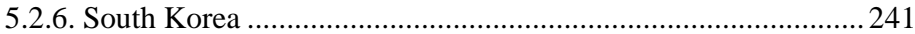

5.2.7. The patterns and directionality of surname changes................. 242

5.3. Enforced change of name ...................................................... 243

5.3.1. Lorraine ........................................................................... 243

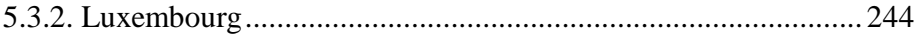

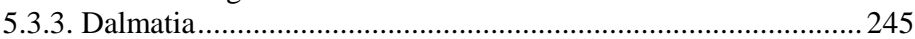

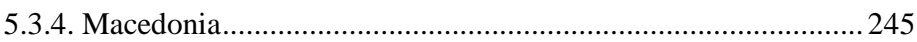

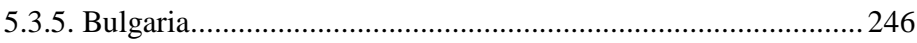

5.4. Voluntary vs. enforced changes ................................................ 249

5.5. Forbidden name change .......................................................... 252

6. Names and the law .......................................................................... 255

6.1. Domestic legislation in selected European states .......................... 255

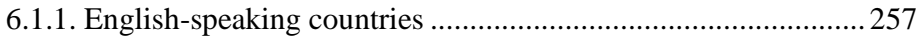

6.1.2. German-speaking countries............................................... 258

6.1.3. Nordic countries............................................................. 260

6.1.4. The Baltic states ............................................................... 268

6.1.5. Romance-language countries ............................................ 273

6.1.6. Slavic countries ................................................................. 278



6.2. The international level: European legislation ................................. 291

7. Case study: Lithuanisation of the personal names of Poles

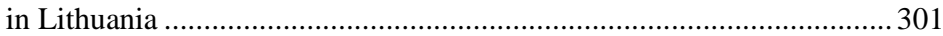

7.1. The identity problem: language - name - self-identification .......... 301

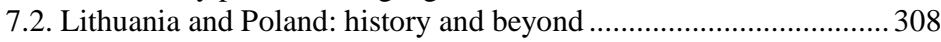

7.3. The emergence of contemporary Lithuanian spelling ................... 314

7.4. The surname-spelling conflict, its historical background and

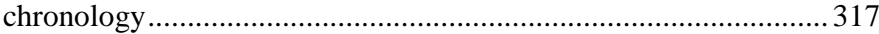

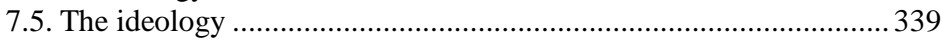





7.7.1. General remarks ............................................................. 348

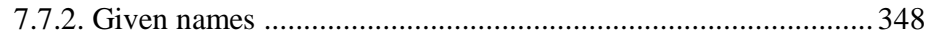

7.7.3. Surnames .......................................................................... 350

7.7.4. Non-Lithuanian letters and letter combinations in registered personal names ................................................................. 352

7.7.5. Names of historical persons and of foreigners ......................... 354

7.8. The Lithuanian context: names of companies ............................. 357 


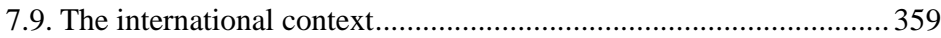

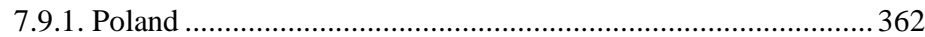

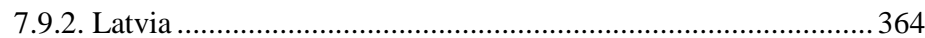

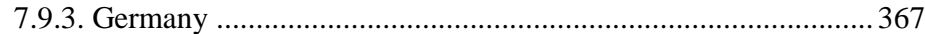



7.9.5 Technical problems in the recording of foreign names............... 373

7.9.6. The cases in supranational European courts ............................ 374



Personal name policies - a summary .................................................... 377

The types and the directionality of name policies ................................. 378

Perspectives for the future.............................................................. 385

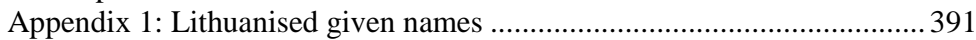

Appendix 2: Contemporary Lithuanised surnames ................................... 394

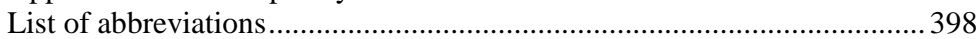

References ................................................................................ 401 
The creation of a word or a notation for a class of ideas may be, and often is, a scientific fact of very great importance, because it means connecting these ideas together in our subsequent thought. Jacques Hadamard

At the lowest level, a science is merely a new way of talking about familiar phenomena. Charles E. Osgood

\section{Preface}

If personal names are ever discussed in the context of language policy (as a scholarly discipline) or language policies (in the sense of the actual endeavours on the part of those in authority), they are typically treated as marginal. Both theorists and practitioners of language policy prefer to focus on discussing the relative status of languages on a particular territory, on the planning of the various strata of language, or on issues connected with language acquisition. Seldom is personal naming perceived in this context as worthy of mention.

Yet personal names are at the core of human identity and they are linked to identity in no lesser degree than languages. They are subject to control on the part of the state or of other agents. These two observations became the inspiration of this book. Name policies are around us. I wished to show that personal names constitute a legitimate field of interest and a valuable pool of data for language policy and planning $(\mathrm{LPP})^{1}$, as well as to categorise language policies in the sphere of personal names cross-culturally, seeking common denominators and recognisable patterns. To this end, numerous examples of specific policies, past and present, from various states, have been invoked and described.

It is usual to classify LP into status, corpus and acquisition planning. While useful, these categories cannot be the only organising principle for personal names. Despite the somewhat

${ }^{1}$ Henceforth for simplicity Language Policy (LP). 
blurred borderline between given names and surnames (especially, though not exclusively, in the Anglo-Saxon culture), the basic difference between given names and surnames is that the former are bestowed, whereas the latter are inherited. Consequently, policies targeted at given names should be treated differently from those targeted specifically at surnames, and both - differently from policies that are targeted simultaneously at both, such as for instance encouraged or enforced given name-cum-surname changes (usually motivated by ideologies related to national identity; in fact, such changes constitute the majority of policies targeted simultaneously at both given names and surnames). For this reason, the illustrative material presented has been classified under the following three broad categories: given names, surnames, and name changes.

Not all personal name policies can be perceived as a subset of language policies. Some policies that concern personal names are not related to language as such - beyond the obvious fact that personal names, being words, are always a part of some language. A case in point may be the admissible number of given names to be bestowed on an individual. However, sometimes it is relatively difficult to tell if a particular personal name policy is at the same time a language policy or not.

An integral part of this book is a case study which analyses in depth a name policy in the making. The object of the case study is the Lithuanisation of personal names of the Polish minority in Lithuania after 1991 and the resulting Polish-Lithuanian conflict over their official spelling. I analysed documents, including the legal acts of the Republic of Lithuania that pertain to personal names, the documents concerning personal names in Lithuania which have been issued by the VLKK, as well as bilingual lists of pupils and/or teachers of several Lithuanian schools and bilingual electoral lists (for details see Appendices). The media coverage of the issue, including Internet forums devoted to Polish-Lithuanian 
relations, proved informative too. The results of my own archival research concerning family history, conducted in the years 2011-13 on online archival material and in 2013 in the Historical Archive and State Archive in Vilnius, also enriched my understanding of the complicated Polish-Lithuanian history. So did the fact-finding interviews that I conducted in the autumn of 2013 during a study trip to Vilnius, for which I had been granted a monthly scholarship from BUWiWM.

Appendix 1 gives examples of contemporary Lithuanised given names of Poles: 48 masculine and 40 feminine ones. Appendix 2 contains nearly 300 Lithuanised surnames extracted from bilingual lists of teachers, pupils and politicians from the Polish minority in Lithuania.

Throughout the text, citations in conference languages have been left untranslated. Quotes from other languages (mostly Polish) have been translated into English - unless marked otherwise, the translation is mine. While scholarly literature on the topic, referred to in this book, is generally listed at the end of this book, incidental references and citations (especially of non-scholarly sources) are shown in footnotes. Citations that are marked by the year in brackets but without the relevant page number(s) come from electronic sources, which frequently lack pagination. This also applies to certain books published in electronic editions.

I wish to express heartfelt gratitude to Prof. Tomasz Wicherkiewicz and Prof. Alfred F. Majewicz for their invaluable assistance and professional expertise. My thanks for help, information and advice also go to the following scholars: Dr Andrea Bölcskei, Prof. Tamás Farkas, Dr Kinga Geben, Dr Milena Hadryan, Dr Milan Harvalík, Prof. Irena Kałużyńska, Prof. Katharina Leibring, Prof. Witold Maciejewski, Ms Maria Manova, Prof. Nicole Nau, Prof. Meilutè Ramoniené, Dr Mariann Slíz, Dr Iveta Valentová, Prof. Mats Wahlberg, Prof. Estera Żeromska and many more, too numerous to mention here. For the time devoted to answering my questions I am grateful to the members of the 
VLKK Jūratè Palionyte and Asta Kazlauskienė, as well as to the head of the Registry Office for the Vilnius Region Edvarda Časiene, two Lithuanian historians and genealogists Czesław Malewski and Albert Volk, the head of the Association of Poles in Lithuania Michał Mackiewicz and over a dozen members of the Polish minority in Lithuania. Many thanks to Mr Jacek Swędrowski and Dr Mikołaj Sobkowiak for typesetting the book. Last but not least, my family deserve sincere gratitude for their patience and support. 


\section{Introduction \\ 0.1. What this book is about}

This book is concerned with the presentation and classification - along various dimensions - of instances of various name policies, past and present, taken mostly from the European cultural circle. For me this meant Europe in a larger Council of Europe sense, i.e. comprising, alongside the countries of Europe, also Turkey and the states of the Caucasus: Armenia, Azerbaijan and Georgia. Apart from this European area sensu largo, examples are occasionally derived also from some other countries and regions outside Europe, mostly (though not exclusively) from those that came into contact with European cultures and were in various degrees onomastically influenced by them, such as the USA or the Philippines $^{2}$. A considerable number of examples come from my native language and culture, Polish, not only because I am well familiar with them, but also because they appeared only in Polish-language literature, whereas I considered them interesting enough to be accessible to the Anglophone reader too. Still, considering to what extent any theorising about proper names might be influenced by the researcher's own mother tongue and culture, I attempted to adopt as wide a perspective as possible.

Anthroponymic policymakers seldom operate singlehanded in a social vacuum. On the contrary, there is usually some degree of tacit or explicit support for their ideas at least in certain sections of society. In particular, many name policies are a reflection of societal cultural values, of tradition, of what is in very imprecise lay parlance sometimes referred to as

${ }^{2}$ Naturally, it would have been more fruitful not to limit oneself to situations where at least one party comes from Europe instead of "unfortunately falling prey to the traditional genetic bias" (Van Langendonck 2007: 3). For example, a very interesting policy called Sōshi-kaimei, connected with making or at least encouraging Koreans to adopt Japanese personal names during the Second World War, is not discussed here. 
'the spirit of a language' (however understood). These policies are mostly widely accepted and seldom contested, since they constitute a de facto codification of customs and traditions that permeate a given society. Other policies, however, might be more controversial and might even be strongly opposed by their recipients, i.e. by those affected - for instance when for reasons of bureaucratic efficiency old customs are eradicated. A case in point might be the obligatory superimposition of surnames upon the Jewish population of numerous European states in the $18^{\text {th }}$ and $19^{\text {th }}$ centuries.

\subsubsection{Policies do not equal law}

The book is not a regular presentation, country by country or culture by culture, of legal regulations, past or present, pertaining to personal names. It stakes no claims to being exhaustive even in terms of Europe, not to mention other continents; such a study would be far beyond the scope of a single scholar and would require specialised legal rather than linguistic background. Next, the focus of this book is primarily the shape of personal names, as opposed to their use. In concrete terms, this translates, for instance, into an interest in what a maiden surname of a woman looks like (especially that the feminine suffix - or the lack of it - might be an indicator of ethnicity, which might add an extra dimension to the discussion), but not, for example, in whether she is allowed or obliged to bear it following divorce ${ }^{3}$. Similar name-related phenomena which will be of no interest to the present discussion are for instance the way surnames are transmitted (or not) to legitimate or illegitimate offspring, what names to bestow on foundlings, what exactly the name-registering

${ }^{3}$ The diverse approaches by various legal systems to the question of which surname the spouses are to carry during their marriage are presented in International Encyclopedia Of Comparative Law, Chapter 17: Personal Effects Of Marriage 1986. Tübingen: J.C.B. Mohr, pp. 39-42. An exception has been made for Hungarian patterns of surnames for married women, since there not only the use, but also the morphology of surnames is involved. 
procedure looks like, etc. These issues belong elsewhere, for example in the area of family law or of administration.

A law-centred approach would reduce the present work to codified, de jure policies only, whereas language policy (LP) does not equal legal regulations. On the contrary, LP developed as a field of study separate from law, with its own apparatus and conceptual framework. Law is seen in LP as a possible tool for policy, and it is not to be overlooked that alongside de jure policies, there is a plethora of subtle, kid-glove methods of exerting de facto influence on names.

As an example one might take the situation in Azerbaijan at the time when it constituted part of the USSR. As Garibova and Blair pointed out, there was "no official policy" at the time with regard to personal names:

Though Russification of names was a logical outcome of the Soviet national policy, the government did not issue any official decrees or ultimatums relating to personal names. The choice remained highly expressive of the inherent values within the society. As deviation from established norms and practices in any society could possibly subject a child to rejection and discrimination, few parents would deliberately risk their own child's future (1996, emphasis added).

The naming power may lie in the hands of many diverse agents, including schoolteachers, army superiors, the clergy, immigration officers and many more. These agents might be motivated by time-honoured, established practice (or even idiosyncratic whim) rather than by written law. Furthermore, laws do not necessarily reflect the actual practice: they may be ineffective, dormant or hardly enforced at all. In real life a discrepancy between the law and the actual practice is frequently observed. An extract from the 2008 opinion on the implementation of the Framework Convention for the Protection of National Minorities in Ukraine may serve as illustration: 
Despite the existence of legislative provisions protecting the right of persons belonging to national minorities to use their surnames and first names in a minority language, and the right to have official recognition of them, there is reason for concern about continuing reports, including from representatives of national minorities, that the practice of imposing the Ukrainian form of names and surnames continues, including in personal documents such as passports ${ }^{4}$.

\subsubsection{Policies are conscious}

Certain developments in personal names are discussed below only to the extent to which they are the object of conscious shaping efforts by those in power/authority. To understand this limitation, let us consider the emergence of surnames. Their presence in today's Europe is for the most part due to their natural evolution over centuries, typically starting in the upper strata of society and gradually 'trickling down' along the social ladder (cf. Scott 1998: 64-71; Kohlheim 1996; on the development of surnames in Poland see, among others, Kaleta 1998). However, in certain cases this natural evolution of surnames had not been completed by the time the governments or monarchs saw it fit (for the purposes of military draft, tax-collecting, or land-owning), to require all their subjects to have fixed, transmittable surnames. This is where conscious policies stepped in. In fact, the policy of bestowing obligatory surnames on those members of society who hitherto had had no surnames was one of the earliest name policies ever implemented.

In a similar fashion there are naming taboos in many societies, which are observed for fear of supernatural consequences. This fact in itself does not yet constitute any explicit name policy. However, sometimes such prohibitions concerning names are backed by regulations and are enforced

$4 \mathrm{https} / / / \mathrm{rm}$. coe.int/CoERMPublicCommonSearchServices/DisplayDC TMContent?documentId=090000168008c384, accessed Dec. 2, 2016. Emphasis added. 
using the apparatus at the disposal of the state or the ruler. A case in point may be the 1985 Thai name law which makes it illegal to register a name resembling the King's name (cf. Jernudd 1995: 121). Similarly, when the Chinese emperor ascended the throne, all his subjects who happened to bear the same name had to change it or face severe punishment (cf. Creamer 1995: 911). One might refer by analogy to an old adage about language being a dialect with an army and a navy. In other words, where a taboo gets the support of the law, it is not a taboo any more, but a policy - be it a language policy or a name policy.

\subsubsection{Policies and society}

LP is usually construed as, if not part of, then at least somehow related to, sociolinguistics, possibly with considerable overlap between one and the other. Bastardas (2004: 193-194) convincingly made a case for this overlap:

The discipline that we have agreed to call «language policy and planning» sees to the study of decision-making processes and public intervention in the linguistic organization of society. It also studies the structures that such an organization may adopt and its evolutionary effects on sociomeanings and language behaviors, both public and private. Ideally, it would differentiate itself from sociolinguistics in the sense that sociolinguistics would project a global perspective on the phenomena being studied, while language policy and planning could be an applied, more pared down, perspective, specializing in the most political aspects of the situation. Thus, while in sociolinguistics we attempt to understand reality, making it intelligible to us, in language policy and planning we devote our efforts more to organizing, designing and changing certain parts of this reality. This is, however, a distinction among fields that dovetail, since one field is part of the other and the two are mutually interrelated.

However, one also needs to keep in mind the distinction made by many researchers between sociolinguistics and the 
sociology of language, the former being "the study of language in relation to society" and the latter "the study of society in relation to language" (Hudson 1996: 4; see also Hazen 2011: 28). While the methods used by the former are basically linguistic, the methods employed by the latter are essentially those used in sociology. Seen from that angle, the present study might be at least partly classified as confined within the realm of the sociology of language.

Various name policies invoked in this book include not only those laws and de facto policies that regulate naming in contemporary democratic states, but also what could be interpreted as violations of human rights in totalitarian regimes of the past. Nevertheless, upon closer inspection the latter appear to differ from the former in the degree rather than in essence. The difference is, more often than not, that of quantity rather than quality. As a case in point, let us compare two seemingly disparate policies in two European states. The historico-geographic context for one of the policies is a democratic European state which in 2008 applied to join the European Union; for the other - a communist regime east of the Iron Curtain in the 1980s. The object of the first policy, which from the 1950s to the mid-1990s was pursued in Iceland, was the names of immigrants, which at naturalisation were obligatorily assimilated to the form typical of the state language - Icelandic - including the replacement of family names with patronymics. The second policy, which was adopted in the People's Republic of Bulgaria under Todor Zhivkov, consisted in the compulsory change of the names of the Turkish minority to the form typical of the state language Bulgarian. Granted, there is a difference between the two respective groups subjected to assimilation, one of them being immigrants from various ethnic backgrounds and the other an autochthonous minority with many centuries of residence history ${ }^{5}$. Beyond that, however, it would be hard to identify

${ }^{5}$ In the context of human rights and LP in education, Skutnabb-Kangas noted: "So far, (im)migrant minorities have not had any linguistic rights in 
any other significant differences, as observed by de Varennes, who in mid-1990s likened the Latvia of the time to a totalitarian regime, writing that "Latvia provides, perhaps, the most recent and unfortunate example of an Article $27^{6}$ violation, having recently [1992 - JBW] adopted a language law which follows the same type of measures popular in oppressive regimes like Franco's"7 [emphasis added].

\subsection{Language policy vs. name policy}

The term policy is relatively wide in scope and may be used to refer to an array of diverse phenomena. There exist numerous policies on various levels and a special, rather practically oriented field known as policy studies has even developed. One of these policies is connected with language. Language policy (LP) has become a well-established field by now. An overview of the discipline - and also a discussion of the different approaches to it - may be found for instance in Schiffman 1996, Spolsky and Shohamy 1999, Spolsky 2004, Shohamy 2006 (more personal approaches), Ricento 2006 and

education to use and maintain their languages. The European Charter for Regional or Minority Languages, for example, explicitly excludes immigrant minority languages. So do the OSCE (Organisation for Security and Cooperation in Europe) and several other non-binding documents. Some of the UN documents (e.g. the UN Declaration on the Rights of Persons Belonging to National or Ethnic, Religious and Linguistic Minorities) are unclear/open to different interpretations as to whether (im)migrant minorities count as minorities. Should they have rights? When do they cease to be immigrants and become minorities? So far Hungary seems to be the only country which has defined this in law (after 100 years)" (1997: 62).

${ }^{6}$ Article 27 (of the International Covenant on Civil and Political Rights) states that "In those States in which ethnic, religious or linguistic minorities exist, persons belonging to such minorities shall not be denied the right, in community with other members of their group, to enjoy their own culture, to profess and practice their own religion, or to use their own language."

${ }^{7}$ Fernand de Varennes 1995/6. "The Protection of Linguistic Minorities in Europe and Human Rights: Possible Solutions to Ethnic Conflicts?" The Columbia Journal of European Law 2/1, 107-143, p. 127. 
a "state-of-the-field" collaborative effort, Spolsky 2012a. It should be stressed that numerous researchers understand LP as dealing not with any attempt at regulating language but with the relationship between majority and minority language(s), thus explicitly linking LP with minority studies.

When contrasted with the ambitious goals set for themselves by LP practitioners in the 1906s, when LP was still a budding discipline - such as solving the linguistic problems of "multilingual developing nations which had gained independence following the collapse of the colonial system after the Second World War" (Spolsky 2012: 23) - the questions of how many given names to bestow on a child might in comparison seem trivial and irrelevant. However, many issues connected with naming are not trivial at all.

First, many naming problems constitute part and parcel of the overall language policy. After all, names belong to language and are inseparable from language. If a state's policy marks one of the languages in use in this state as a state language whose use is mandatory in all official situations (as is the case with Turkish in Turkey, to the detriment of e.g. Kurdish, or with Lithuanian in Lithuania, to the detriment of Polish or Russian), then this privileged status is typically also extended onto personal names, which must be officially registered in this language form only (Kurdish personal names must not be registered in Turkey, just like personal names in their Polishlanguage version must not be registered in Lithuania).

Second, it must be borne in mind that contemporary LP is free from the somewhat naïve illusions that once accompanied its infancy. In the 1980s came the realisation that "all language planning assumes a specific practice of social change [...] and that the practice is political behaviour and it is subject to political analysis" (Spolsky 2012: 27). Linguists engaged in LP understood that "planning must consider the interests of various social groups, that politics is a fight over interests and that people have different values" (ibid.: 26). Similarly, naming is not a value-free, morally neutral and purely 
technical activity. Just the opposite: it can be a manifesto of convictions and a political or identity statement; restrictions on the scope or form of admissible names might have the weight of national policies.

Last but not least, our focus here is Europe, whose problems today differ from the problems facing post-colonial Third World countries of the 1960s. Hardly any contemporary European states are multilingual in the degree comparable with the multilingualism of India or Papua New Guinea. Hardly any language spoken in today's Europe lacks its codified written form. Also, illiteracy in Europe is marginal. There are, however, other problems on the agenda for LP in Europe today. Among these, especially the emancipation of various minorities, along with interest in minority rights, is reflected in the sphere of personal names. The struggle for the right to a minority personal name might be just as much of an identity statement today as the struggle for the right to use a minority language.

In fact, the two - language policy and name policy - have much in common. Historically, language policies were closely linked with religious ideologies, later to be superseded with nationalist ideologies (cf. Spolsky 2010: 375). So were name policies: restrictions on name choice and use were originally the domain of religious authorities, and later - of state authorities, which in nation-states contributed to linking name policies with nationalism.

In (personal) name policy personal names are perceived as part of language. It follows logically that any name policy is by implication also a language policy. Consequently, a mere substitution - personal names instead of language, with some details changed accordingly - should generate the desired definitions:

\begin{tabular}{|c|c|}
\hline $\begin{array}{c}\text { Language policy (after Spolsky } \\
\text { and Shohamy 1999: 39-40) }\end{array}$ & Name policy \\
\hline $\begin{array}{c}\text { A policy concerning language } \\
\text { status may take the form of laws }\end{array}$ & $\begin{array}{c}\text { A policy concerning the status of } \\
\text { names } \text { may take the form of laws }\end{array}$ \\
\hline
\end{tabular}


or regulations determining the permissible or required languages in certain situations. Proclaiming an official language is status policy or planning.

A policy concerning corpus sets out the approved forms of $a$ language. Preparing official lists of approved spellings or terms or grammatical rules, or new lexicon is corpus planning or policy. A corpus policy goes beyond general statements ('speak English' or even 'speak correct English') to quite specific regulations ("don't say ain't" or "spell honor without $<\mathrm{u}>$ "). or regulations determining the permissible or required names / permissible or required language versions of names. Proclaiming an official version of names is status policy or planning.

A policy concerning corpus sets out the approved forms of $a$ name. Preparing official lists of their approved spellings or grammatical rules for names, or new onomasticon is corpus planning or policy. A corpus policy goes beyond general statements ("give children Polish names" or even "give children correctly formed Polish names") to quite specific regulations ("give a child the name Agnieszka, not Inez" or "spell Ksenia with $<\mathrm{ks}>$, not $<\mathrm{x}>$ ").

However, in the case of acquisition policy and planning, merely substituting the word "name" for "language" does not produce any meaningful results. The obvious reason for this is that names are obviously not learned the way a language is. To allow for a meaningful analogy, one should perhaps consider what actually happens when a language is acquired by an individual or a group of individuals. The effect is a change (or at least a modification) in the distribution of speakers of a particular language (as a first or second language), i.e. redistribution. Applying the concept of redistribution to personal names one obtains a powerful tool in personal name policy: enforced or encouraged name changes.

By analogy, two more concepts concerning language and applicable in LP could also be adapted to personal names: language shift and bilingualism/diglossia. Language shift, 
understood as a process whereby a given language community shifts gradually to speaking another language, is clearly reflected in naming, where such a process could be tentatively termed naming shift. That certain developments in the sphere of personal names can indeed be viewed as shift is evidenced e.g. by Herbert (1997), who wrote of "typological shift" within African naming systems that was a result of culture contact with the European naming system. The analogy is justified and may provide for onomastics the benefit of the conceptual apparatus of those sub-disciplines of linguistics which deal with language shift (assimilation), language vitality and language death, such as the (socio-)ecology of language.

Albert Breton, quoted in O'Keefe (cf. 2001: 7), distinguished two steps in the process of linguistic assimilation: the first one consists in learning a second language, the second - in dropping the original one. This process, it is argued, spans at least two generations. It seems that a meaningful analogy can be drawn between, on the one hand, language assimilation thus characterised, and, on the other hand, what has above been termed naming shift. In the history of Europe (and often also in the history of countries whose naming systems were reshaped in contact with Europeans) a massive naming shift appeared, which in many cases led gradually to the partial or complete obliteration of the indigenous naming system, to the benefit of the so-called Christian names. Let us have a closer look at this shift.

The data from the English poll tax for the years 1377, 1379 and 1381 show that in eight of the ten counties analysed the two most popular given names for boys - John and William - accounted for well over $50 \%$ of the bestowals; in the remaining two counties those two names were given to almost half of the boys (cf. Redmonds 2004: 30-1). Similar phenomena were observed in other European countries of the time: "In medieval Languedoc, for example, only a few names (Guillaume, Bernard, Raimond, Pierre, Pons) might designate three quarters of the male population" (Scott et al. 2002: 14). 
The same phenomenon could be observed in medieval times in the Romance-speaking Europe:

There is no doubt about the decline in the name stock in Italy [...] By 1370, the three commonest names were borne by about a quarter of the population, and only 20 per cent of names were not shared [...] There was a big reduction in stock again by the early fifteenth century, when the eleven commonest names covered half the male population [...] The reduction of the name stock was slower to get started in France but then became more sharp and more comprehensive than in Italy [...] It does seem to have begun among Christian names, but it soon became an independent trend affecting all names. (Wilson 1998: 109-110)

Following the Council of Trent (1545-1563), Christian name-giving was enforced more strongly than before in many Christianised countries of Europe. Consequently, in $18^{\text {th }}$ century Croatia the disappearance of a multitude of traditional Slavic names, which were seen as pagan and thus unsuitable, led to the reduction of the entire system of given names to just 40 masculine names and as few as 20 feminine ones. In the same period almost 50 per cent of the inhabitants of the area in and near Dubrovnik (and 60 per cent of the women and girls) carried just 5 given names. It goes without saying that all of these names were Christian (cf. Šimunovič 2002: 373). In some areas this phenomenon persisted even as late as the end of the $19^{\text {th }}$ century, as Galley et al. (2011: 32) found about Scotland:

On Skye, John, Donald, Alexander and Angus - the top four names given to boys on birth certificates between 1861 and 1901 - account for 48.8 per cent of all male names appearing in the registers. The top four girls' names - Mary, Catherine (with spelling variations such as Catharine and Cathrine included), Marion and Ann - account for 36.5 per cent of all names given to girls during the same period. The name pool thus appears very restricted $[\ldots]$ 
Such a transition from a set of names derived from one language to a completely different set (taken from another language or from other languages) seems a good example of the above-postulated naming shift.

Just like the notions of bilingualism / multilingualism refer to the societal or individual possession of respectively two / more than two languages, so one might imagine analogous concepts of binominalism / multinominalism, i.e. the possession of two / more than two names. In the case of bilingualism, a bilingual person will "speak language A to members of group A and language B to members of group B" (Haugen 1979: 248). One might hypothesise an analogical situation with reference to names: name $\mathrm{A}$ is used in contacts with speakers of language $A$, and name $B$ - with speakers of language $B$. In fact a situation like this has been attested in North America in the $17^{\text {th }}$ and $18^{\text {th }}$ centuries, as Hanks observed:

It was quite normal for a person to have two surnames, one used in Dutch-, German-, or French-speaking contexts, the other one used in English-speaking contexts, often, the latter was a straightforward assimilation to an English name, either phonologically (Dutch Jansen became English Johnson or by translation (French Dubois became Woods or Swedish Eklöf became Oakleaf) (2003: 120).

There are further, more recent examples of what for the purpose of the present discussion will be termed binominalism $^{8}$. When after 1989 trade opportunities opened for Poland, entrepreneurs and consequently a plethora of Polish small businesses imported goods such as textiles from, among others, Turkey. Thus in the 1990s a whole sector of Turkish production for the Polish market developed. To endear Turkish partners to Polish wholesalers, many Turkish workshop-owners would flaunt business cards with Polish

${ }^{8}$ For the term used, cf. e.g. Thompson 2006. 
given names (combined with Turkish surnames) of Turkish businessmen: Andrzej Demir, Jurek Şahin, etc. ${ }^{9}$

In a slightly similar fashion, non-Chinese visitors to China, such as businesspeople, Sinologists or university students, are advised to get for themselves Chinese names. One of the commercial websites lists reasons why it is commendable:

1. When you do business with Chinese, your name plays a role in making a first impression, conveying an image, and expressing the quality of guanxi ${ }^{10}$ you will establish. [...]

2. Some Chinese decision makers you want to do business with may have difficulty remembering your non-Chinese name or knowing how it is pronounced. [...]

3. When more than one person writes about or refers to you, you can end up with several versions of your Chinese name. The different versions will confuse your clients. ${ }^{11}$

By contrast, the term diglossia (Fishman 1972: 74) ${ }^{12}$ refers to the use within a single society of two separate language codes, each of which serves a distinct function; these codes are complementary and not in conflict with each other. Their functional separation is most often along the lines of an $\mathrm{H}$ (High) language for religion, education, high culture etc. vis-a-vis an L (Low) language for everyday life, home, or lower work sphere. Along the same lines, one could imagine a phenomenon that, for lack of a more suitable term, one might

${ }^{9}$ Dariusz Walkowiak, personal communication.

${ }^{10}$ Guanxi is a romanised Chinese word for a cultural concept which is hard to define: it corresponds roughly to forging and maintaining reciprocal relationships / connections that often last a lifetime and help individuals to achieve their career or other goals by what by Western standards might be termed mildly 'pulling strings' or, more strongly, nepotism.

11 Good Characters. 2001-2011. http://goodcharacters.com/names /get_a_chinese_name.html, accessed Dec. 2, 2016.

${ }^{12}$ The definition is given after Fishman (1972: 74), who expanded the original notion introduced in 1959 by Charles Ferguson. While Ferguson referred only to complementary varieties of the same language, Fishman used the term diglossia for different languages as well. 
tentatively call dionimia ${ }^{13}$, consisting in the use of one name for official/public sphere and of the other for private sphere. In fact such phenomena do appear - for details see the chapter devoted to the effects of policies on names and other related phenomena - especially where a prohibitive state policy makes it impossible for a minority to use officially the minority variant of a name.

The postulated pair binominalism vs. dionimia as a mirror of the well-established pair bilingualism vs. diglossia is somewhat similar to a pair postulated by Saville-Troike, namely biculturalism vs. dinomia;

'Dinomia' [...], which translates roughly from Greek as 'two systems of laws' [...] may thus be defined as the coexistence and complementary use within the same society of two cultural systems, one of which is the dominant culture of the larger society and the other a subordinate and less prestigious subculture from within that same society (2003: 46).

\subsubsection{Status planning}

In a nation-state majority forms of names compete against non-majority forms, which could be minority versions or simply foreign names. Frequently preference is given to the majority (official, national) form. This preference may assume the shape of a law that facilitates unidirectional transfer from non-majority form to majority form, but perhaps makes it quite difficult or even impossible for names to undergo transfer in the opposite direction. Or it may be that foreigners upon naturalisation must change their names to the majority form. For instance, as already mentioned above, in the years 1952-1996 foreigners applying for Icelandic citizenship had to adopt an Icelandic name and until the 1970s also a patronymic in the place of a family name (cf. Jóhannesson \& Pétursson

${ }^{13}$ Maria Malec (2001: 81) uses the term 'polionimia' to refer to the possession by an individual of multiple names. 
2010: 2, 9-12). The 1996 amendment to the Personal Names Act abolished these requirements. The 1985 Finnish name law (with amendments up to 1991), in turn, finds it a sufficient reason for surname change if "the surname causes inconvenience due to its foreign origin" (Section 10.1). Conversely, in Section 11.2.1 of the said law it is stipulated that "a name cannot be approved as a new surname without a special reason if the name is in its form or spelling contrary to the Finnish naming practices" ${ }^{14}$. This relative status of rivalling forms may be said to amount to status planning with reference to personal names.

\subsubsection{Corpus planning}

Spolsky and Shohamy discussed obvious areas of interest for corpus planning in LP. First, with the exception of "a tiny handful of languages" (1999: 47), in the history of many languages of the world there was a time when the writing system had to be intentionally developed: the alphabet to be used had to be selected, and the orthography had to be agreed upon. Once developed, later the writing system could be changed or modified. Second, as times change, as a new signified appears, so a new signifier has to be invented, which phenomenon is known as lexical elaboration. Third, there is standardization, which might be manifested in the creation of normative works, such as dictionaries.

In parallel to the first outlined area, similarly in name policy there was a major task undertaken consciously in many countries in historical time: the assumption of surnames. Just like in some languages the writing system developed spontaneously and presumably in a gradual and piecemeal fashion, so there are countries where the surnames evolved naturally. Nevertheless, for a large part of states and / or cultures the acquisition of a writing system was a venture undertaken consciously (especially where the writing system

${ }^{14}$ http://www.finlex.fi/fi/laki/alkup/1985/19850694 accessed Dec. 4, 2016. 
was borrowed). Similarly, in many countries surnames were imposed on the populace as an organized top-to-bottom decision (especially where the very idea of a surname was borrowed).

The second area of interest for corpus planning, i.e. lexical elaboration, provides an even more convincing analogy. New names enter the onomasticon just like new words enter the lexicon. In the case of new words it is the pressure of the changed reality - the need to fill a yawning lexical gap - that leads to the enlargement of the vocabulary. In the case of new given names it is the bottom-to-top pressure of the (potential) name users, whereas in the case of new surnames it might be the need for more precise identification, felt either by those in authority or by those at the bottom. Even the ways to remedy the perceived problem are analogous between language policy and name policy. New words may be borrowed from another language or created from the available native language material, with the latter option favoured by numerous language-planning bodies. In the same vein new names are borrowed (and possibly adapted morphophonetically) or created using the linguistic elements available (e. g. by analogy) - in this way artificial surnames are created.

\subsubsection{Technological planning}

This is a recent addition to the traditional three-way division of LP and it is concerned with the use of technology, such as speech recognition systems and text editors, in the support of language. An interesting example of the use of computer technology in the sphere of personal names comes from Sweden:

The need for variety impelled the Swedish government to draw up a list of 900,000 unique new surnames by having a computer randomly combine syllables [...] The problem that the computer was intended to solve is that there are too few Scandinavian family names because many of them were 
originally patronyms, limited in variety by the small number of popular masculine given names on which they were based. Consequently a few names like Olson, Hanson, Gustafson, or Swenson occur with confusing frequency, even more so than comparable names like Thompson, Johnson, and Jones in British and American society (Algeo 1973: 6).

However, for minority personal names technology is a dubious boon. On the one hand, with the advent of new technology minority personal names in official documents may be rendered more faithfully to the original version (using the language-appropriate diacritics, or even using a minority script if different from the script of the majority/state language). On the other hand, Internet URL's (and occasionally also e-mails and text messages) seem to be promoting the basic Latin script, devoid of any diacritics, to the detriment of practically all languages but English ${ }^{15}$. The latest developments in the field, however, seem promising: new IDN system will in the future allow for the potential use of the 100,000 characters of the world's languages in Internet domains ${ }^{16}$.

\subsubsection{Dissimilarities between language policy and name policy}

A typical policy statement, if verbalized, would include a word like 'should': "It is the use of the word 'should' that distinguishes policy (what people should do) from practice

${ }^{15}$ As a Polish daily reported, "Russians pay twice as much for a text message written in the Cyrillic script than for the same message in the Latin alphabet $[\ldots]$ The problem resulted from the norms for text message coding adopted in the 1980s. One letter of the Latin alphabet requires 7 bits [...] while for one letter of the Cyrillic script as many as 14 bits are necessary." („Cyrylica droższa niż łacina” [Cyrillic script more expensive than Latin script] 2011. Dziennik Gazeta Prawna, Aug. 11.)

${ }^{16}$ Cf. Lance Whitney 2009. "ICANN approves non-Latin domain names.” Oct. 30. http://news.cnet.com/8301-1023_3-10387139-93.html?tag =mncol;txt, accessed Dec. 2, 2016 . 
(what people commonly do)" (Spolsky and Shohamy 1999: 39). In that particular respect language policies are somewhat different from name policies, insofar as personal names, once officially registered, are hardly negotiable. Granted, one might use for private purposes a name different from the officially registered one - and this is indeed what is actually done (see below in the section devoted to the effects of name policies) but that is about the limit of the choice, apart from the downright sabotage of the names that have been, or should be, conferred by the officialdom, In fact, the above-mentioned sabotage is rare and immediately conspicuous for its rarity. In one such case, following the parents' decision to give them Breton rather than standard French names, six children of a Breton family were reported to have been pushed into a limbo of legal non-existence ( $Q u^{\prime} y$ a-t-il dans un nom? 1966). A similar fate befell the girl in Iceland whose mother gave her the name Blaer. Although Icelandic, the name was rejected by the authorities on the grounds that it was not unequivocally feminine. As a result, until 2013, i.e. for the first fifteen years of her life, Blaer Bjarkardottir in communications with officials was referred to as "Girl" only ${ }^{17}$.

\subsubsection{Name rights}

Apart from LP, another possible framework within which to analyse name policies comes from the relatively new field of Linguistic Human Rights. In drawing analogies between LHR and NP, the grid devised by Skutnabb-Kangas and Phillipson (1995: 79-80) will be useful for the present discussion. The grid helps capture the important dimensions of language rights. On its vertical axis, the degree of overtness is presented: by this parameter the authors understand the extent to which laws or covenants are explicit in relation to the rights

17 [Gudjon Helgason] 2013. "Blaer Bjarkardottir, Icelandic Teen, Wins Right to Use Her Given Name" https://24tanzania.com/blaer-bjarkardottiricelandic-teen-wins-right-to-use-her-given-name/, accessed Dec. 2, 2016. 
of minority languages in education. The other dimension is the degree of promotion, which shows the extent to which a language is prohibited, tolerated or actively promoted (the horizontal axis). Both dimensions are seen as continua. The grid is presented below:

ASSIMILATION-ORIENTED

MAINTENANCE-ORIENTED

Overt

I

I

Prohibition -- Toleration -- Non-discrimination -- Permission -- Promotion prescription

I

I

Covert

The grid may also be used in relation to personal names. Just like languages, also personal names can be prohibited, permitted, or even actively promoted. While Skutnabb-Kangas and Phillipson place on the grid specific legal acts, individual personal names or their whole sets may be superimposed on it as well.

Name policy (NP) will be understood here as the sum total of legal regulations and administrative procedures, as well as of the actual de facto practices by any agents (such as administration clerks, schoolteachers, employers, clergymen and other people in the position to exert power) who make decisions about the shape and use of personal names. Somewhat contrary to the spirit of Cooper (cf. 1989: 37), who identifies agents of LP as low down as on the family level, it is proposed in the present work that individual naming decisions - such as choosing a given name for one's baby or changing one's own name - will not be included here. The rationale for such a decision needs to be explained.

It goes without saying that parents exercise naming power over their newborn babies. This fact in itself, in my opinion, obviously does not constitute any name policy as such. However, it might be claimed that occasionally parents do 
something more than merely name their child. For instance, they might follow some self-imposed underlying principle regarding the choice of the names for their children. As a case in point one might take the regionally well-known Polish family of mountain dwellers going by the double-barrelled surname of Bachleda-Curuś. One of its members, Adam, a former mayor of the town of Zakopane in the Tatra Mountains, decided to bestow all his children with names that start with the letter $A$ so that their resulting initials could be $A B C$. Thus his children are called Albert, Adam Jr., Antoni and Andrzej; Andrzej's own children in turn have been named Angelika and Andrzej Jr. ${ }^{18}$ It might be argued that such a family-level phenomenon as the "ABC" principle described above is a special case of a name policy. Also given names bestowed on babies as patriotic manifestos could illustrate the point. The common denominator in both cases would be the position of power that the namer has over the named. In other words, the namer and the named are not one and the same person - in contrast with situations where an individual is selfrenamed to manifest his or her political convictions or religious beliefs (as in the case of converts). However, even such low-level "name policies" raise doubts as to their status. After all, while the result of such a "policy" is official, it is nevertheless easily overridden by its object (the child) once the child comes of age and parental responsibility is no longer exercisable: a grown-up child may officially change his/her unwanted name; this is usually not as easy (or is even impossible) with official name policies.

More importantly, such low-level (i.e. family-level) decisions frequently constitute an effect of a NP: in their individual naming decisions people either comply with the official (state) regulations or do exactly the opposite, challenging or bypassing them. For all these reasons, I believe, it is policies on levels higher than that of a family that are the

${ }^{18}$ Katarzyna Świerczyńska 2010. "ABC książąt Podhala” [the princes of the Podhale]. Wprost [weekly, Warsaw] 52 (1455), pp. 68-73. 
proper object of the present analysis. In that respect many of the LP domains identified by Spolsky (cf. 2009: vii-ix) religious institutions, the workplace, the schools, the military and government (i.e. policy on the state level) - are also valid domains of NP. In fact, each of them is known to have influenced names.

Name policy also comprises those aspects which have nothing to do with language policy in the strict sense. As a case in point a very common and frequently codified principle might be proposed that a name is not to subject its bearer to ridicule. That commonsense idea, which aims at protecting the infant against its parents' flights of fancy, and allows the change of an embarrassing, inherited surname, as a matter of principle has no connection with the language policy in a given state ${ }^{19}$.

Name policy is frequently connected with symbolic power exercised in the symbolic domain. The idea of symbolic power has been proposed by Bourdieu in reference to another notion that he introduced, viz. that of symbolic capital. As Bourdieu noted,

the patrimony of a family or lineage includes not only their land and instruments of production [which Bourdieu sees as capital in the narrow sense of the word] but also their kin and their clientele $[\ldots]$, the network of alliances, or, more broadly, of

${ }^{19}$ A formal excuse for not accepting officially a minority name, though, might be the argument that it might expose its bearer to ridicule. Such an argument has in fact been used. A 1945 Polish law allowed the change of surname if it was degrading, humiliating or out of keeping with human dignity, or if it did not sound Polish. As Rajkowski explains, apparently merging two separate reasons for surname change into one, in pre-war Poland "non-Polish surnames were effectively 'bad' surnames (and perceived as such by a part of their bearers), since they facilitated ethnic discrimination" (1955: 49-50). By non-Polish surnames were to be understood the surnames of minorities: Ukrainians, Jews, Belarusians, Ruthenians, Germans. The declared rationale behind the law in question was that it was permitted to change foreign-sounding surnames (i.e. mostly minority names) not because majority names were preferable, but because minority names were by definition 'bad' - degrading or humiliating. 
relationships, to be kept up and regularly maintained, representing a heritage of commitments and debts of honour, a capital of rights and duties built up in the course of successive generations and providing an additional source of strength which can be called upon when extra-ordinary situations break in upon the daily routine [...] [S]ymbolic capital, which in the form of the prestige and the renown attached to a family and a name is readily convertible back into economic capital, is perhaps the most valuable form of accumulation in a society in which the severity of the climate $[\ldots]$ and the limited technical resources [...] demand collective labour (1993: 178-179).

Even though Bourdieu's observations refer directly to and were inspired by the Kabyle people, an ethnic group in Algeria which Bourdieu studied, they are more universal and applicable to various ethnic/national groups, past and present. What is the relevance of the above citation to name policies? These policies are frequently connected with a power struggle whose tools are names. More importantly, it is the power struggle in which the dominant ethnic/national group symbolically appropriates the minority territory, making it seemingly - its own. People who are forcibly given majority names, or whose minority names are modified so as to make them look as if they were majority names, are perceived by outsiders as part of the majority and thus in the eye of the beholder they seemingly lose their original minority identity exactly as intended by the dominant group. What is more, chances are that with time the minority might increasingly conform to its external, distorted, assimilated image and actually change self-identification, in this way eventually joining the majority. The same mechanism, incidentally, is operative when place names are changed or modified, by which process the dominant group and symbolically labels territory as its own (naming a territory and thus claiming it). The "national" agenda in naming can be followed in a variety of ways ranging from subtle to radical, such as: 
- facilitating and encouraging name change towards the national-language name form (absence of formal obstacles or administrative fees, procedural simplicity);

- the requirement that surname changes must be unidirectional (always to a native name), as is the case in Estonia $^{20}$;

- the requirement that minority names be spelt in documents using the majority spelling on the basis of pronunciation (cf. the case study in the present work, concerning the names of Poles in Lithuania);

- the requirement that the foreigners (especially at naturalisation) adapt their names to the national-language form;

- the requirement that foreign given names are not to be bestowed on newborn and either native equivalents are to be used instead, or a foreign name is to be assimilated to the national/dominant language.

However, some policies are not easily interpreted within the framework of symbolic power and symbolic domain. Just on the contrary, on the surface they seem rational and guided by practical considerations rather than symbolic ones, and the theoretical notion that might be employed is that of 'citizen legibility' (cf. Scott 1998: 65). Examples include:

- the requirement that a person in Germany is not to have more than five given names (cf. Willms 2011: 8);

20 "On 15 April 1999 the Minister of Internal Affairs, by his directive, dismissed to the request of Marika Arendi for changing her name. M. Arendi wished her new surname to be Arendi Elita von Wolsky [...] According to M. Arendi she descends from the family the surname of which was Elita von Wolsky. The complainant also requested that $\S 11$ of the Surnames Act be declared unconstitutional. The complainant found that the restriction established in this section that persons who are of Estonian origin or have an Estonian surname may not request a non-Estonian surname, discriminates on the basis of national origin against persons who are of Estonian origin and is thus in conflict with $\S 12$ of the Constitution" (http://www.nc.ee/?id=436, accessed Dec. 2, 2016; emphasis added). 
- the requirement that the two parts of a double surname should be linked by a hyphen;

- $\quad$ the requirement for given names to be visibly distinct from surnames;

- the requirement for given names to be easily recognisable as such (e.g. by a prohibition of given names that look like appellatives, or by the imposition of a list of allowed names);

- limitations on the number of surnames per individual;

- limitations on the number of characters that can be used to write names (in Japanese or Chinese);

- limitations on the number of letters in a name (this is often connected to the amount of space on ID documents).

It is difficult to interpret the way in which the official forms and other documents shape reality (by requiring certain information: the second surname in Spain, the patronymic in Russia, or the middle name in the USA). Are such "default settings", indicative of the suggested/ preferable name shape in a particular cultural context, meant merely to make bureaucracy more efficient, or is their aim to promote the national-language name forms?

On the surface "default settings" seem commonsense and devoid of any hidden agenda. After all, a limit on the number of names seems rational; so does the hyphenation (it helps recognise the surname as such and thus not confuse its first part for a second given name) or the name list (which might prevent confusing the given name for a common noun). However, underneath the surface doubts remain. Why set the limit of given names at five and not at two, as in Poland or Hungary? Why hyphenate surnames, if Spain functions perfectly well without obligatory surname hyphenation? Finally, why is it that the British and Americans do not feel the need for any sort of name list - on the contrary, it seems that practically any existing appellative or a new coinage can be assumed as a given name, and how is it possible that this fact does not lead to the destruction of the naming system? 
A useful concept that might be introduced at this point is that of doxa. The term denotes all experience that is taken for granted, implicit, unformulated, unquestioned. In Bourdieu's words,

what is essential goes without saying because it comes without saying $[\ldots]$ The adherence expressed in the doxic relation to the social world is the absolute form of recognition of legitimacy through misrecognition of arbitrariness [...] The truth of doxa is only ever fully revealed when negatively constituted by the constitution of a field of opinion, the locus of the confrontation of competing discourses (1993: 167-168, emphasis in the original).

To put it differently, many arbitrary traditions disguise themselves as rational, efficacious, culturally-neutral solutions. This corresponds with what Scott has to say about the issue, albeit without explicitly resorting to the concept of doxa:

Some of the categories that we most take for granted and with which we now routinely apprehend the social world had their origin in state projects of standardization and legibility [...] The invention of permanent, inherited patronyms ${ }^{21}$ was, after the administrative simplification of nature (for example, the forest) and space (for example, land tenure), the last step in establishing the necessary preconditions of modern statecraft. In almost every case it was a state project, designed to allow officials to identify, unambiguously, the majority of its citizens. When successful, it went far to create a legible people (1998: 64-5, emphasis added).

\subsubsection{The choice of terms for personal names}

The issue calls for clarification, since the English language seems to channel the thinking about personal names

${ }^{21}$ Under this not very fortunate term Scott understands surnames (in the sense of family names). The term is not fortunate since it must be borne in mind that not all surnames originated from patronyms. 
into certain moulds, perhaps somewhat in the spirit of (a weak version of) the Sapir-Whorf hypothesis. Polish, my native language, provides a relatively clear-cut distinction between the contemporary imie ('given name') and nazwisko ('surname', 'family name'), although the situation has not been as clear-cut historically (cf. Bystroń 1938, 1993, Kaleta 1998, Malec 2001). English, by contrast, has several names for both, and sometimes they are not used consistently. First and foremost, there is the term name, which could be a substitute for any of the two above mentioned Polish terms or for both of them in combination (in the sense of a full name). This ambiguity neatly corresponds to the contemporary confusion, especially in the USA, where names may freely cross the category border between what the Polish language calls imie and nazwisko (for instance, there could be a Morgan Stanley as well as Stanley Morgan, or Winston Taylor alongside Taylor Winston) ${ }^{22}$.

In relation to what corresponds to the Polish term imie, in the present work I will use the term given name. The term first name, similarly to forename and - for surnames - last name, implies the so-called Western order with the given name preceding the surname. It is opposite to the Eastern order of, for example, Hungarian, Romanian ${ }^{23}$, Chinese, Japanese, Korean or Vietnamese, where the surname comes first.

${ }^{22}$ It should be stressed that while Polish still has surnames equal to given names (Roman, Marian, Abraham, Justyna), including some diminutive forms of given names (Jurek, Kazik, Franek, Magda), the opposite phenomenon - surnames that may be chosen as given names - is non-existent in Polish. In order to avoid ambiguity, however, the official policy to a degree discourages the use of such surnames: possessing a surname equal to a Polish given name is sufficient reason for granting surname change.

${ }^{23}$ Introduced in Romania in the years 1947-1989; after the fall of communism there was a return to the Western order. Also in Basque has a brief period of the Eastern order (with a suffix after the surname) been witnessed - nationalist leader Sabino Arana promoted this order and it was used for some time unofficially. As R.L. Trask noted, "this practice was very prominent among Basque writers during the first two-thirds of the 20th century, but it now appears to be all but dead". José Ignacio Hualde [\&] 
Similarly the term Christian name is inaccurate as a potential synonym for given name. Christian names are of various kinds but they are generally a subset of given names as such. Among Christian names in the literal meaning of the word, several types can be distinguished:

- those that are semantically associated with Christianity: Faith, Hope, Grace, Renata ('reborn'), Fürchtegott, etc. The names of the various attributes of Virgin Mary, such as Dolores ('sorrowful') or Mercedes ('merciful'), might be treated as a subgroup of them. It seems that what Wilson (1998: 87) termed "mystical" names may be considered another subgroup. Among the "mystical" names, Wilson distinguished two kinds: augurative (Bonaventura) and theophoric, i. e. containing the name of God (Amadeus). Some augurative names were, as he noted, "implicitly rather than explicitly Christian" (1998: 87);

- the names of personages from the Bible, especially the Old Testament;

- names that happen to have been borne by saints, regardless of the origin of names (Hebrew, Greek, Latin, but also Germanic, Slavic and other) and of their etymology;

- a special, albeit exceptional, category: Puritan baptismal names in the form of whole clauses, such as the one of an $18^{\text {th }} \mathrm{c}$. Rhode Island dweller by the surname of Clapp: Through-much-tribulation-we-enter-into-the-kingdom-ofheaven (cf. Smith 1970: 5).

It is sometimes not clear to which of the above four categories a particular name belongs. Thus Eve is both an Old Testament name and the name of a 13th-century saint from Leodium - today Liège in France (Fros \& Sowa 2002: 218). John was a saint, but at the same time its Hebrew source was a theophoric name.

To what extent the term Christian name might be inappropriate as a synonym for given name is visible in the

Jon Ortiz de Urbina (eds.) 2003. A Grammar of Basque. Berlin: Walter de Gruyter, p. 163. 
fact that in 2010 the name Mohammed (together with its spelling variants) was the most popular given name bestowed on baby boys in Great Britain ${ }^{24}$. While being a given name, it is certainly not Christian in any of the above-mentioned senses of the word. Nor does it seem appropriate to use the term Christian name when referring to the given names of Lithuanian or Crimean Karaites, Balkan Muslims, or to Jews. It might be added that the term personal name is also occasionally used in scholarly literature with the sense of 'given name' (for such usage, cf. e.g. Mac Giolla Easpaig 1995: 29, or Krăsteva-Blagoeva 2006: 70). In this book, however, personal names are used to refer to the broad category that includes given names, surnames, patronymics, bynames, nicknames, stage names, pen names (noms de plume), noms de guerre, etc. And since only the first three of these are objects of official regulation ${ }^{25}$ in the so-called Western cultural circle, wherever the term 'personal names' is henceforth used, it will refer (unless explicitly otherwise stated) to given names and surnames only, with the occasional inclusion of middle names (usually analysable as surnames) and patronymics.

As a possible English equivalent of the Polish nazwisko, the term 'family name', in turn, suggests it is shared by a family, or, as a minimum requirement, that it is transmitted from parent(s) to their offspring, a notion obviously not true in the case of Iceland, where surnames are patronymics and as such they are not shared by all family members ${ }^{26}$. Granted, this

${ }^{24}$ Jack Doyle 2010. "Mohammed Is Now the Most Popular Name for Baby Boys Ahead of Jack and Harry." Mail Online, last updated Oct. 28. http://www.dailymail.co.uk/news/article-1324194/Mohammed-popular-baby -boys-ahead-Jack-Harry.html, accessed Nov. 30, 2016.

${ }^{25}$ Interestingly, some forms of unofficial naming may greatly diverge from official forms - cf. multipart bynames composed of chains of given names, used informally in the town of Wilamowice in southern Poland (Wicherkiewicz 1997).

${ }^{26}$ For instance, if a man by the given name of Garðar has a daughter, her surname (in fact a patronymic) will be Garðarsdóttir, while a son's surname will be Garðarsson. Garðar's wife (and at the same time the mother 
is not the only reason why the term surname might be perceived to be slightly ambiguous. Van Langendonck (cf. 1996: 1228) proposed a classification of personal names that, for more clarity, has been presented graphically below:

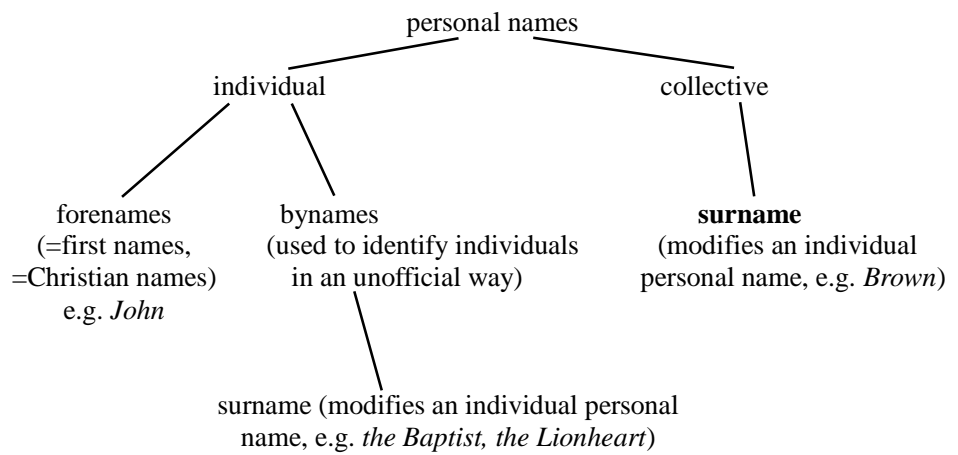

"In most European systems", Van Langendonck (1996: 1228) has noted, "a family name can function as a collective name, but also as a byname. Moreover, a family name is a typical surname, as Brown in John Brown. In John the Baptist, the Baptist is a byname that functions as a surname."

This said, the term surname will nevertheless henceforth be used. In the graph above it is, of the two identically termed elements of the graph, the surname in boldface. The term surname will here refer in most cases to a family name, with the exception of Iceland, where it will equal a patronymic instead, and of the countries like Russia, where the surname functions within the tripartite naming system and is made up of a patronymic and the family name.

of Garðarsson and Garðarsdóttir) will bear the surname formed from her father's (or sometimes mother's) given name with the suffix -dottir, daughter. Thus there is no surname common to both parents and children, especially that women do not take their husbands' surnames after marriage. A logical consequence of such a naming system is the fact that Icelandic names are listed alphabetically according to given names, not surnames. 


\subsection{Personal names and language policy - overview of literature}

Language policy as a discipline is now a well-established field. However, personal names do not figure prominently in LP. The reason is perhaps not so much the lack of data as such but, rather, the conviction that decisions about names belong elsewhere, for example in the realm of history, law or cultural studies. Consequently, the relevant data are hardly contained in books on language policy. They can be found instead in such diverse sources as historical or socio-political analyses, studies on identity, nationalism and on the emergence of nation-states, anthropological research, legal studies, memoirs, reportage-type writing, even the press (including the electronic media). Some of these data pertain to history, while others describe policies and practices in the making. Naturally, successful or unsuccessful attempts to control and influence personal names are also described in anthroponomastic studies, but there LP is seldom explicitly mentioned.

Another factor that possibly contributes to the scarcity of scholarly studies that make an explicit connection between LP and the sphere of personal names may be the exceptional and by the same token somewhat unclear status of onomastics, of which anthroponomastics is a part. To this day there is no unanimousness among scholars on how best to treat onomastics. Does it constitute a legitimate subfield of linguistics, or is it, by contrast, a highly multidisciplinary scholarly endeavour? On this question Cieślikowa wrote:

The controversy over placing onomastics among other disciplines may be reduced to the following question: Does an onomastic system exist and to what extent is it different from the system of language in which it is functioning? This controversy, both historically and contemporarily, has assumed various forms, ranging from statements that exclude onomastics from linguistics, through granting onomastics far-reaching 
autonomy, to statements about a complete subordination of onomastics to the system of language (2000: 21 ).

Bauer (1995) listed many areas of research which may be said to be closely connected with onomastics: history (including archeology, the history of literature and the study of cultural space), geography and related sciences, religious studies, natural sciences, engineering sciences, economics, legal studies, social studies, linguistics, literary studies and art studies. What is more, such special fields of interest as for example one-name studies add to the obfuscation. Onomastics as a field of scholarly research is highly interdisciplinary:

Onomastic studies comprise not only synchronic and diachronic research based on and constituting a part of linguistics; there is an intensive and enriching methodological and factual give-andtake between the study of names and many other disciplines. This makes onomastics a complex, but certainly not peripheral, area of study, as is sometimes assumed - regrettably even in the academia (Bauer 1995: xii).

One of the few notable exceptions to the general neglect of personal names as objects of LP was the November 2007 issue of CILP, devoted exclusively to names (not only personal) and featuring articles by Shouhui Zhao and Richard B. Baldauf on language planning, naming and character use in China, by Chun Huang on the situation in Taiwan, by Wendy D. Bokhorst-Heng and Lionel Wee on language planning for naming in Singapore, by Noriko Watanabe on the politics of Japanese naming practice, by Meilutè Ramonienè on language planning and personal naming in Lithuania, and an article by Busi Makoni, Sinfree Makoni and Pedzisai Mashiri on naming and language planning in Zimbabwe. While Jernudd (1995) links personal names with linguistic human rights only, and the word 'policy' (language policy or otherwise) is not explicitly mentioned anywhere in his article, the names of editors and contributors, which include Tove Skutnabb- 
Kangas, Robert Phillipson, Mart Rannut and Joshua A. Fishman, as well as the titles of articles, ensure the spirit of LP studies that permeates the volume.

A themed volume of the journal Onoma of 2012 (released 2015), on the topic "Names and law", also deserves a mention here, even if the concept of policy is present only in some of its contributions. Twelve of the articles deal with regulations in the sphere of personal naming. The countries covered are mostly Hungary (Tamás Farkas, Judith Raátz, Erzsébet Fercsik) and the Nordic countries (Sweden - Staffan Nyström and Linnea Gustafsson, Norway - Ivar Utne, Finland - Sofia Kotilainen, Iceland - Gudrún Kvaran, Denmark vs. Sweden Kendra Willson), but single contributions are also devoted to France (Pierre-Henri Billy), Poland (Justyna B. Walkowiak) and Austria (Axel Linsberger).

The phenomena under consideration occasionally appear under different labels, such as onomastic colonialism or political onomastics (cf. Alia 2009), the politics of personal naming (cf. Herbert 1997), as one of the aspects of a national policy (cf. Garibova and Blair 1996), or as onomastic regulation (cf. Bering 1992: 43). Names are also mentioned by Skutnabb-Kangas and Bucak (1995) in the context of linguistic human rights. There exist works wherein an explicit link between proper names and politics has been made, such as a 2008 volume of conference proceedings Namen und ihr Konfliktpotential im europäischen Kontext ${ }^{27}$. It is no coincidence that naming is also frequently linked with power. "On the surface," Alia noted, "naming is simply a way to classify people and their environments; [...] It is much more a form of social control, a political activity, a key to identity maintenance and transformation... It always signifies a change in power relations" (2009: 174). Rannut (2008) made a similar observation, stating that "language policy may simply be defined as an application of power to language".

${ }^{27}$ For details see Wenzel 2008. 
In his book Language Policy, a classic introduction to the discipline, Spolsky devoted to the topic of personal names merely half a page in a 250-page volume:

Personal names might seem at first glance to be a private matter. Many of us have more than one: the official name registered with the government, the name used in religious ceremonies, the name our siblings used for us, the name by which we were addressed in school or in the army, the name that our spouse or other loved one selects for us and the "ineffable name" by which we know ourselves. All this seems to be a matter of language practices, but Jernudd (1995) noted that it was often controlled by governmental language policy. In Bulgaria, until 1989, ethnically Turkish people were obliged to avoid Turkishsounding names and use Bulgarian ones. In Indonesia, there was pressure on ethnic Chinese to avoid Chinese-sounding names. In Japan, there is a limitation on the characters that may be used for writing names. In Singapore, parents are pressured to base Romanization on Mandarin rather than the Hokkien or Cantonese dialects that most of them use. In Sweden, since the beginning of the twentieth century, the government has been trying to persuade people to adopt family surnames rather than employ the older practice of using the father's first name followed by the suffix '-son' (2004: 20).

This citation provides the reader with some points to ponder. For one thing, what Spolsky termed 'language practices,' in fact covers both practices of personal nature (the name used by siblings or by oneself) and the official use of name in society (by government registration officials, by the church, by the army, by the school). In this book only the latter, official use of names will be dealt with, in contrast with some authors who at least theoretically consider the possibility of language policies as low as on the microlevel of the family unit (cf. Cooper 1989: 37-38, Spolsky 2004: 42ff). Secondly, the five examples given by Spolsky are quite diverse in nature. In some, names simply mirror majority-minority power struggles for status between languages (Bulgaria, Indonesia) or dialects (Singapore), while 
in others (Japan, Sweden) the problems are language-internal. It is noteworthy that all the examples invoked by Spolsky have been drawn from one source: the 1995 article by Jernudd, which may indicate how few authors have ever written about the personal name aspect of LP.

In the above, only English-language literature has been cited - to the detriment of my native language, Polish. It is so because language policy (polityka językowa) in Poland is not only a relatively recent field of interest for scholars ${ }^{28}$ and decision-makers but also (and more importantly), it would appear, a differently defined field. As Pawłowski (cf. 2006: 7-8) aptly remarked, Polish history, in which most of the past two centuries were spent defending Polish national identity against military aggression and/or cultural indoctrination from both the East and the West, led to a different understanding of the notion of language policy. In effect language policy in Poland came to be synonymous with protecting the national language, sometimes bordering on language purism. This led to the narrowing of the horizons to prescriptive and stylistic issues and proper language standards, as implied by the term kultura języka, literally 'language culture'. This approach is not particularly applicable to the present discussion, which focuses on describing various policies rather than on prescribing a specific course of action. It must be nevertheless admitted that the description offered in the present work is not completely free from the element of evaluation - and, moreover, negative evaluation. After all, some policies violate even the most modestly defined linguistic human rights (cf. Skutnabb-Kangas \& Phillipson 1995).

Of Polish works relating onomastics explicitly to language policy, two need to be mentioned: Chłądzyńska (2010) and Walczak (2010). Interestingly enough, the focus of both are toponyms and not personal names. The former article is noteworthy for its explicit reference to polityka nazewnicza

${ }^{28}$ A remarkable exception is Władysław Lubaś 2009. Polityka językowa. Opole: Uniwersytet Opolski. 
('naming policy'), perceived by the author as part of language policy, as specified by her in the introduction to her article:

By language policy I will understand a group of activities, coordinated and planned, whose aim is influencing both a language with its development, and its users' attitudes towards this language. It is an attempt to control the development of the language and to shape the attitudes of its users on the assumption that such an attempt is possible and necessary in society. The naming policy of the state is subsumed in the larger issue of language policy (Chłądzyńska 2010: 84).

The latter article is notable for the author's honest realisation that

probably each nation - to a greater or lesser degree - tends to judge its own actions and behaviours by different standards than the actions and behaviours of other nations. Poles will deem it only natural that they use traditional exonyms (such as Brema, Drezno, Lipsk, Monachium ${ }^{29}$ ) when referring to German geographical objects, but at the same time [...] they will hold a grudge against Germans for the fact that Germans refer to Polish geographical objects using German exonyms: Bromberg (Bydgoszcz), Breslau, Danzig, Landsberg (Gorzów), Oppeln, Posen or Warschau ${ }^{30}$. This attitude can be observed even in the works of onomasticians (Walczak 2010: 268).

Walczak's observation constitutes a remarkable departure from the Polish language-centred, puristic attitude traditionally present in many Polish works. The realisation that language policies in the service of particular nation-states are contradictory to one another is important insofar as it enables a more impartial perspective on the issue, one that I will try to maintain in this book.

${ }^{29}$ Their corresponding German names are Bremen, Dresden, Leipzig and München respectively.

${ }^{30}$ Their other Polish names are: Wrocław, Gdańsk, Opole, Poznań, Warszawa. 


\section{Personal names \\ 1.1. Defining proper names}

As Algeo aptly pointed out, "in the present state of onomastic study there is no consensus on how to define the object of the discipline"; consequently, "as long as there is no clear sense of what the term proper name means, onomatologists are in the position of not knowing what they are talking about" $\left(1973^{31}: 3,4\right)$. Algeo was basically doubtful about the possibility of formulating a single universal definition of the proper name (and, as his later work suggested, also about the chance of constructing a theory of names ${ }^{32}$ ). Van Langendonck, on the other hand, believed a theory of names to be possible, and in fact proposed one himself, taking proper names in a rather liberal, wideencompassing sense, though the languages on which he based his work were mostly Dutch, English, German and French. A valuable element of his proposals was the inclusion of neuropsychological evidence to prove the reality of proper names as a category. The tenets of Van Langendonck will be discussed in more detail in the further part of the book.

Algeo (cf. ibid.: passim) listed the following properties of proper names as suggested by various scholars:

1. orthographic: proper names are capitalised;

2. morphosyntactic: proper names have no plural forms; they are used without articles; they do not accept restrictive modifiers;

3. referential: proper names refer to single unique individuals;

4. semantic: proper names do not impute any qualities to the objects designated and are therefore meaningless; they have a distinctive form of definition that includes a citation of their expression.

${ }^{31}$ Even though this opinion was expressed in the 1970s, it appears no less valid in the second decade of the $21^{\text {st }}$ century.

32 John Algeo 1985. "Is a Theory of Names Possible?" Names 33/3, pp. 136-44. 
Of these criteria, only the morphosyntactic and semantic ones, it seems, were admitted by Algeo as valid, and even those not without reservations ${ }^{33}$. The orthographic and referential criteria, Algeo claimed, define other sets of words, only roughly coterminous with proper vs. common names (i.e. capitalised vs. uncapitalised words, and singular vs. general terms respectively).

In a similar vein, Valentine et al. (2002) listed the following three commonly given features of proper names:

1. a proper name designates a particular being or thing (as Valentine et al. observe, typically authors cite in this context names of persons and of places);

2. proper names have a capital initial letter;

3. proper names are not used with determiners in the same way as common names are.

Still, some of the other characteristics invoked by Algeo and by Valentine et al. are largely culture-specific. That the capitalisation criterion for classifying a noun as proper does not apply without exception is admitted by Valentine et al. themselves: they note that in English ethnic or national adjectives are capitalised though they are not proper names. However, there are more arguments against the capitalisation criterion than they invoke. What the researchers do not mention is the fact that among the languages that use the Latin script, in German all nouns are capitalised, and in Danish the same spelling convention was followed until the language reform of $1948^{34}$. Even more importantly, many non-Latin scripts lack the contrast between capital and lower-case letters (i.e. they are unicase systems). This refers among others to the

${ }^{33}$ Algeo made a finer distinction between proper names and proper nouns. However, discussing this difference falls outside the intended scope of this book.

${ }^{34}$ What is marginal to the present discussion, though interesting, is the fact that also in English capital letters were once (in the Old English period) used only at the beginning of sentences. 
Arabic, Chinese, Devanagari, Georgian, Hebrew, Hangul and Kana writing systems.

The existence (or, rather, non-existence) of articles as a criterion for deciding whether a name is proper is useless e.g. in Slavic languages, which do not have articles at all. Equally problematic is the number contrast: in many languages there are proper names in the plural, such as the Philippines, the Alps, the Netherlands (for more in-depth discussion of that problem, see Valentine et al. 2002: 18-19). It is probably such considerations that have led Nicolaisen to make the following cautious disclaimer about the culture-specificity of proposed definitions of proper names:

Nor will this exploration of one of the most complex and vexing verbal expressions of two closely associated grammatical categories [viz. name and appellative] be capable of reaching conclusions which might be generally applicable to all language families. Even two cognate languages like English and German whose vocabulary feeds largely on the same sources show certain differences, particularly in their surface features, in the treatment of these two notions. Far from being intended to produce universally accepted or acceptable principles, this account will be chiefly devoted to the problems as they present themselves to users of English, since even translations from other languages involve the risk of misunderstanding and unwarranted assumptions (1995: 384, emphasis added).

What is more, in view of the first feature brand names (sometimes treated as synonymous with chrematonyms though other researchers consider brand names to be just one type of chrematonyms) present a methodological problem too, since

[t]hey do not designate a unique object. It could be argued that in fact a brand name designates a unique object that is simply replicated in a number of identical exemplars. This can be the case, for instance, of drugs [...] or beers [...] where each exemplar designated by the label is a perfect clone. But this is 
not true of all brand names. For example, we know a lot of different cars called 'Volkswagen' or even 'Golf' and the different exemplars of Golf we know are not pure clones. They differ from each other in colour, power of the engine, year of the model and so on. In fact, brand names like 'Golf' and 'Volkswagen' designate categories of objects rather than unique objects (Valentine et al. 2002: 5).

Last but not least, there are cases where one referent has more than one equally legitimate proper name to refer to it. Thus the second largest city in Switzerland may be referred to by its inhabitants as Genf (in German), Gèneve (in French), Ginevra (in Italian) or Genevra (in Romansh), to say nothing of the exonyms in languages other than the four national languages of Switzerland (consider e. g. Genewa in Polish). This existence of multiple exonyms is not in itself a violation of the definition, yet it detracts from the clarity of the definition $^{35}$.

The thesis that a proper name only denotes, but does not connote) is clearly related to the famous statement by J.S. Mill, who claimed that proper names are devoid of meaning; or, more accurately, that their apparent meaning does not have to be true. For instance, a town by the name of Dartmouth may or may not be at the mouth of the Dart river:

If sand should choke up the mouth of the river, or an earthquake change its course, and remove it to a distance from the town, the name of the town would not necessarily be changed. That fact, therefore, can form no part of the signification of the word; for otherwise, when the fact confessedly ceased to be true, no one would any longer think of applying the name (1882: 36).

While Mill was right in pointing out that the literal meaning of certain proper names might contradict reality -

${ }^{35}$ In terms introduced by philosopher Gottlob Frege, such a variety of proper names would equal to the various senses (Sinne), while all of them refer to the same reference (Bedeutung). Each sense offers some information on the angle from which the city's identity is viewed. 
a good example being the world-famous Dakar ${ }^{36}$ Rally, which since 2009 has actually taken place in South America - this fact does not necessarily differentiate proper names from appellatives. First of all, regarding the fact that the apparent meaning of proper names does not have to be true, it must be emphasised that this feature might characterise certain common nouns as well: in Polish świnka morska ('guinea pig'; literally 'little marine pig') is neither marine nor a pig. Another example is the expression ślepe ryby (literally 'blind fish') in the regiolect of the inhabitants of Poznań, which means 'potato soup obtained by boiling potatoes until very soft $\mathrm{t}^{37}$. In a similar fashion, in mincemeat nowadays there does not have to be any meat, its chief ingredient usually being dried fruit, though originally as a matter of principle the dish did contain meat finely chopped, as the name implies.

Moreover, Mill seems to have accepted only a binary truth value for the example he gave (Dartmouth either is or is not at the mouth of the Dart), whereas in fact there could be an intermediate option: Dartmouth is on or near the Dart, yet not exactly at its mouth. In a similar fashion, in the Polish expression zimne nózki ('meat jelly made with ham hock', literally 'little cold legs') there is a grain of truth: the main ingredient for the dish is ham hock, so indeed the meat carved from a pig's leg, and he dish is indeed served cold.

Šrámek (cf. 2010: 24-25) mentioned another feature that distinguishes proper names from common nouns (appellatives): the fact that the former reflect reality only partially. To put it differently, not all that creates reality is granted a proper name. Which phenomenon / element of reality will be given a proper name is decided by extra-

${ }^{36}$ Dakar is a town in Senegal, West Africa. The rally originally (19792001 ) bore the name the Paris-Dakar Rally, yet even then in some years it started in Granada (Spain) instead of Paris, and ended in Cairo or Cape Town instead of Dakar.

37 Monika Gruchmanowa, Małgorzata Witaszek-Samborska [\&] Małgorzata Żak-Święcicka 1987. Mowa mieszkańców Poznania [the speech of the inhabitants of Poznań]. Poznań: Wyd. Poznańskie, p. 43. 
linguistic factors: social (including political, economic, legal and other considerations) as well as factors to do with communication. Thus reality, Šrámek argued, must first be divided into its non-proprial component and its proprial component. In his opinion, from this proposal three statements result. First, proper names constitute the so-called second stratum of language. Second, there exists a category of the socalled onymic objects. Third, proprial meaning is not the same as the semantic meaning of appellatives; nor can it be equalled with the etymological meaning of the proper name: e.g. Czech surname Noha, Polish surname Noga, Czech place name Noha and Polish place name Noga have only the etymological meaning of 'leg' in common. Šrámek also stressed the individuality of a proper name. There is only one Wrocław ${ }^{38}$, for example, he argued, and went on to note that a proper name can function only when its meaning is connected with a single object and when this meaning does not have the characteristics of a concept (ibid.: 27). Šrámek also listed three functions of a proper name - if all the three of them are not simultaneously present in a word (lexeme), then this word is not a proper name:

1. the individualising function: the proper name delineates this section of reality (e.g. a newly built street) that will be granted an own name;

2. the differentiating function: it enables one to single out from among many objects of the same type a particular one (e.g. Mr Noga); the combined effect of the above two functions becomes the basis for the referential function;

3. the localising function: the named reality is located within the geographical (toponyms), social (anthroponyms ${ }^{39}$ ), economic-cultural, political, historical (chrematonyms) etc. context.

${ }^{38}$ A big city in south-western Poland, capital of Lower Silesia.

39 The actual term used by Šámek is bionimy (bionyms), i.e. the names of living organisms - humans, animals and plants. However, his reference to animals and plants as placed in a social context is surprising. 
While discussing various aspects of proper names, Srámek did not seem to strive towards an explicit definition of a proper name, a definition that could be applied to the present discussion. The three functions that he listed merely imply such a definition.

Even attempts at defining proper names as objects of onomastics by listing their subsets (definition by enumeration) only seem to lead to further dilemmas. Van Langendonck (2007) classified proper names into prototypical (personal names, animal names, names of hurricanes, place names, names of astronomic objects, names of buildings / ships, names of organizations / associations) and non-prototypical. The latter, rather wide, category was further subdivided into countable names (temporal names, names of works of art / books / journals / films, names of institutions connected with buildings, trade / brand names, names of currencies, names of numbers and letters) and uncountable ones (names of languages, colours, diseases). As can be seen, especially the uncountable group is quite large. The problem is, how can the methodology employed in the analysis of place names - which mostly developed spontaneously and evolved naturally over centuries - be the same as in the case of brand names, which are historically a relatively recent phenomenon, and which are comparable rather to artificial surnames than to naturallyevolved surnames or given names? What is more, the existence of brand names is owed largely to a fairly sophisticated naming process backed by powerful marketing research ${ }^{40}$ with all its apparatus and tools.

To sum up, it must be admitted that arriving at a consistent universal (i.e. cross-cultural) definition of a proper name is not easy and perhaps even impossible. One has to be content with the intuitive understanding of proper names especially official personal names - as outlined above. More precisely, the makeshift working definition that will have to

${ }^{40}$ See for instance http://www.thenameinspector.com/10-name-types/ (accessed Dec. 2, 2016). 
suffice for our purposes will be a very modest proposal: proper names is an umbrella term (hypernym) for linguistic items that include, among others, place names and personal names. It is the latter group (which includes given names and surnames) that will be the object of interest here and that will be discussed in the following section.

\subsection{Defining personal names}

It goes without saying (and research in the production and recognition of human names, such as Valentine et al. 2002, appears to support that view) that in many cultures the category of personal name is a psychologically real category and that people are intuitively aware of what a personal name is (cf. Alford 1988: 2). What is more, this intuitive awareness seems extendable also onto personal names from outside the culture in question, and it appears to be gradable rather than binary.

To illustrate the point: any Pole knows that Kowalski is a surname. What is more, it is quite likely that some Americans are aware of this fact as well, the likelihood probably higher in the case of those Americans who have had some exposure to Americans of Polish descent (or to those that have seen the play A Streetcar Named Desire, or the film Vanishing Point, since they both feature characters by that surname). By claiming that the awareness of surnames is gradable it is meant that many (though certainly not all) of these Americans might also be aware of the fact that any capitalised word ending in -ski is highly likely to be a $\left(\mathrm{Polish}^{41}\right)$ surname. Of these, an even less numerous group might also classify -cki-ending capitalised words (such as Konwicki) as surnames,

${ }^{41}$ Judging from the ending -ski, also possibly Macedonian - but the number of Macedonian Americans is estimated at roughly 60 thousand, whereas there are almost 9 million Polish Americans in the USA; consequently, in the case of encountering such a -ski-ending surname it is a more likely guess for an American that the surname is Polish. 
and so on. Naturally, this process of recognition is not as smooth and problem-free as it might seem from the above example. For instance, in the case of the Polish surname Moskwa the guessing might not be so easy as this surname is homonymous to the placename meaning 'Moscow' (should any American be aware of this fact), and worse still, it does not end with -ski. Van Langendonck (cf. 2007: 9-10) offers more examples of such "proprial lemmas ${ }^{42}$ like Zeppelin or Sandwich [which] are semantically and syntactically ambiguous on the level of established linguistic convention in that they are able to designate either a person or an object." As mentioned above, they are usually the results of an intra-onomastic shift (cf. Nicolaisen 1995: 388). Thus Zeppelin as the name of an airship is derived from the surname of Count Ferdinand von Zeppelin, a German inventor, whereas the surname Sandwich comes from a placename.

In answering the question of how best to define personal names, the fundamental study by Van Langendonck (2007) will be referred to, albeit not without reservations. As he stressed, personal names belong - together with animal names, place names and a few others - to the most important (prototypical) of the four major classes of proper names. At the same time they are the least marked category, displaying the most diversified constructional patterns. As such, they constitute the most salient category of names. Van Langendonck went on to note that in order to classify personal names, one must first decide what criteria to use: semantic, pragmatic or morphosyntactic? His decision was to apply semantic-pragmatic criteria for universal generalisations, and a morphosyntactic analysis for a language-specific standpoint. Consequently, he proposed the following parameters to classify personal names: primary vs. secondary and official vs. unofficial. Thus Van Langendonck arrived at a pragmatic trichotomy of personal names:

${ }^{42}$ I. e. onymic dictionary entries. 
1. primary official personal names - further broken down into first names (including their diminutives and augmentatives) and family names; he noted that "the borderline between these two categories [i.e. first names vs. family names] can vary from culture to culture" (ibid.: 190);

2. secondary official personal names, among which he counted family names when used as individual names (Johnson was a former president), as well as pluralised family names to refer to the whole family (the Johnsons) and what he termed official identificatory epithets (e.g. the Fifth in the name of a king);

3. secondary unofficial personal names, which comprise on the one hand bynames (i.e. names given by others) and on the other pseudonyms, Internet chat names, etc. (i.e. names that one gives to oneself). The reason for the existence of only three and not four categories is that unofficial names are by definition secondary.

Intersecting the above tripartite division of personal names, there is another division - this time a dichotomy (ibid.: 187):

1. individual names (first names and most bynames 'nicknames');

2. collective names (inhabitant names, certain bynames and especially - family names).

In both of the above divisions, the treatment of family names seems to be the most controversial. In particular, it is difficult to account for the apparent inconsistency in categorising family names: why should they be counted twice in the trichotomy, and treated as more collective than first names (after all, most first names have many bearers) in the dichotomy?

Therefore it appears advisable to refer to the commonsense intuitive idea of given names and surnames, which would in practice amount to applying neither semantic/pragmatic nor morphosyntactic criteria but, rather, functional criteria. This idea appears to be backed by some 
sort of psychological reality. More importantly, there is a lot of evidence in support of the claim that personal names do carry a meaning in a particular sense of the word. The issue of meaning will be dealt with in the following section because it has a direct bearing on how numerous policies are related to personal names.

\subsection{Mill and beyond: the many meanings of personal names}

In Mill's classic definition, a proper name is "a word which answers the purpose of showing what thing it is we are talking about, but not of telling anything about it" (1882: 36). Since Mill, many philosophers ${ }^{43}$ have dealt with the topic of meaning in proper names and have had to grapple with Millean tenets. However, as Van Langendonck (2007: 2) emphasised, "proper names have been attracting a lot of attention from philosophers ever since the Ancient Greeks [...] but only in the $20^{\text {th }}$ century from theoretical onomasticians." Today proper names are in the sphere of interest not only of philosophers but also of historians, anthropologists, and - most importantly, naturally - onomasticians. The data collected by all these scholars indicate that "philosophers have not always confronted their analyses of proper names with the whole range of proper names and [...] some accounts can be falsified simply by considering a wider sample" (Valentine et al. 2002: 31).

${ }^{43}$ Notably Gottlob Frege (Sinn und Bedeutung), Bertrand Russell (On Denoting) and Saul Kripke (Naming and Necessity). Nevertheless, as Algeo (1973: 8) wrote referring to Russell, they were perhaps "talking logic and not onomastics" and therefore their reasoning does not appear directly applicable to solving practical onomastic problems. Consequently, Algeo's words that "[w]ith the special uses of the term proper name in logic and other branches of philosophy this study will not be concerned" (ibid.) are applicable here too. An overview in English of the various standpoints vis-à-vis the question of meaning can be found e.g. in Van Langendonck (2007: 71-86). 
Lévi-Strauss, among others, was doubtful of Mill's radical rejection of the notion of meaning, even though the French structuralist's professed concern was more ethnological than linguistic in nature. As Lévi-Strauss noted,

[1]es noms propres ne forment pas une simple modalité pratique des systèmes classificatoires qu'il suffirait de citer après les autres modalités. Plus encore qu'aux linguistes, ils posent un problème aux ethnologues. Pour les linguistes, ce problème est celui de la nature des noms propres et de leur place dans le système de la langue.

Pour nous, il s'agit de cela, mais aussi d'autre chose, car nous nous trouvons confrontés à un double paradoxe. Nous devons établir que les noms propres font partie intégrante de systèmes traités par nous comme des codes: moyens de fixer des significations en les transposant dans les termes d'autres significations. Le pourrions-nous, s'il fallait suivre l'enseignement des logiciens et de certains linguistes, et admettre que les noms propres sont, selon la formule de Mill, 'meaningless', dépourvus de signification? (1962: 227-228, emphasis added).

As Valentine et al. rightly emphasised, "psychologically speaking, proper names have a range of possible meanings" (2002: 28). In line with this observation, some modern approaches to Millean tenets rest on the realisation that

[a] name is the result of a complex mental process [...] With an approach like that, it would be counterproductive to state that names do not have meaning [...] In fact a constant interplay takes place between the proprial part of our mental lexicon (the onomasticon) and the non-proprial part (the common words), which makes even the idea of lexical meaning more complicated and more important than it appears" (Nyström 2016: 40).

Nyström goes on to identify several types of meaning of proper names. For example, one can speak about their lexical vis-a-vis proprial meaning, and the two depend on each other: 
for names that are non-opaque semantically, there are "open, working connections to the living vocabulary, the mental lexicon" (ibid.: 42). Other possible kinds of meaning include categorical (which consists in mentally dividing objects and other phenomena into categories), associative (some associations are personal, others - shared by large groups of people) and emotive (involving positive or negative connotations).

Can such layers of meaning be identified for personal names? There are two reasons for such a formulation of the question. First, the object of the present study is personal names only, not all proper names. Second, proper names constitute such a broad and disparate category that what is true of personal names might not be equally true of the other subsets of proper names.

Many examples that could be invoked in support of the view that personal names may have lexical meaning come from outside the so-called Western cultural circle. As a particularly telling name one might quote the name of a Congolese (Zairean) president and dictator. He was born Joseph-Désiré Mobutu, but as part of his 'African authenticity' campaign, which consisted among others in Africanising place names and personal names, he changed his name to Mobutu Sese Seko Kuku Ngbendu Wa Za Banga. This name is usually translated as the all-powerful warrior who, because of his endurance and inflexible will to win, will go from conquest to conquest leaving fire in his wake ${ }^{44}$. There can be no doubt about the intentionality of such a name change and about the intended effects of the name on whoever is confronted with it. It certainly is meaningful.

A plethora of evidence can be invoked for categorical meaning as described by Nyström. Even in the Western

${ }^{44}$ Cf. Mark R. Lipschutz [\&] R. Kent Rasmussen 1989. Dictionary of African Historical Biography. Second Edition, Expanded and Updated. Berkeley - Los Angeles - London: University of California Press, p. 275. See also: Francesca Davis Di Piazza 2007. Democratic Republic of Congo in Pictures. Minneapolis: Twenty-First Century Books, p. 34. 
cultural circle, where so many personal names are semantically opaque, in many cases they nevertheless provide information about their bearers, thus in fact telling something about them. In other words, they may serve as social devices which enable people to be classified e.g. in terms of parental, social, ethnic or geographical group (cf. Valentine et al. 2002: 16). In particular, their categorical meaning may also refer to gender. For example, Alford (1988: 66) found in his crosscultural study that in a sample of 60 cultures from all over the world, in nearly three-quarters of them given names (usually or always) distinguish sex. For Europe the proportion is probably much higher, given that in many European states laws explicitly prohibit given names that do not allow sextyping.

On the plane of associative meaning, personal names may express religious identity:

[I]n a study of some villages in the Scottish Highlands, three surnames were shared by over three-quarters of villagers, and furthermore [...] first names were often drawn from a small set of biblical names. Thus, from their names, people were readily identified as coming from the area and as being Christians [...] (Valentine et al. 2002: 17).

As another example one might take a married couple in Sarajevo $^{45}$ : Amer, a Bosnian Muslim, and Nina, a daughter of Serbo-Croatian parents. In Bosnia and Herzegovina in the times of the socialist Yugoslavia "one's name didn't matter" and "nobody paid any attention to what one's name was and whether one celebrated Bajram or Christmas". When Amer confessed to his parents that he had found a woman he would like to marry, he drew enthusiastic responses until he mentioned his fiancée's name, which alone sufficed to identify

45 These two people were the hero and the heroine of a reportage by Krystyna Żukowska, entitled "Pomieszani Amer i Nina" [mixed-marriage couple Amer and Nina]. Gazeta Wyborcza - Wysokie Obcasy. Mar. 19, 2011, pp. 58-65. 
her religion and ethnicity. The situation in Nina's family was similar: "it soon turned out that there was someone in her family who minded her future husband's name." In fact, the mixed-marriage couples described in the article declare that "name or religion do not matter to them, what matters is if one is a good person." Consequently their children "have double names and celebrate Bajram alongside Christmas" [emphases added].

Onomastic studies describe communities characterised by a high predictability, on the basis of the name of a person, of the religion to which that person adheres. For instance, the data from the parishes of Amsterdam indicate that in the year 1898 as many as 58 per cent of Catholic children - and only 5 per cent of the Protestant ones - were bestowed with the name Maria (cf. Majewska 2015: 208). Certain given names may be associated with a particular denomination, which is especially important in a conflicted society, such as that of Northern Ireland:

People employ several important coping strategies in their everyday spatial negotiations. The first of these involves the practice of not using or changing certain names: Irish first names such as Mairead and Séan identify people as Catholic, just as English names such as Sammy and Billy are more commonly Protestant. These names rarely cross the religious divide. Hence the act of changing or not using names in particular spaces can be seen as a deliberate strategy to offset the possibility of ethnic identification ${ }^{46}$.

Very important information potentially present in personal names is the ethnicity or nationality of their bearers:

It is obvious upon reflection that if we know that someone is called Mr Baker, it is likely that the name refers to an adult

46 Karen Lysaght [\&] Anne Basten 2003. "Violence, fear and the 'everyday': Negotiating spatial practice in the the city of Belfast". In: Elizabeth A. Stanko (ed.) The meaning of violence. London: Routledge, 124142 , p. 233. 
male, it is rather likely that he speaks English, and we may be prepared to guess that he likes apple pie, and may expect him to have heard of Oscar Wilde. On hearing the names Michio Yamato, Natalia Todorova and Björn Bergström, you are likely to be right in assuming that the ethnic origin of these people is Japanese, Slavic and Swedish respectively [...] The information is of variable precision. It will sometimes allow one to classify a person as from a particular culture with certainty, and at other times to narrow it down to a certain part of the world, and still others to be completely misleading (Valentine et al. 2002: 29).

An example to illustrate this idea can be invoked on the ground of the Polish language and culture. The titles of two books by Janusz Korczak ${ }^{47}$ : Mośki, Joski i Srule and Józki, Jaśki i Franki are not mere lists of random masculine names in the plural; they bring to mind Jewish boys and Polish boys respectively, exactly as intended by the author, since the first three given names are Jewish and the other three - Polish.

That personal names help identify people as members of particular ethnic groups is evidenced, among others, by Article 16 of the Romanian Draft Law on National Minorities and Autonomous Communities (Nov. 14, 1993) which states that "it is forbidden to question the belonging of any person to a national minority by the etymological analysis of his or her name or by any other means; it is forbidden to influence any change of his or her freely chosen affiliation."

Even examples of people whose names are in contrast with their professed ethnicity show how strongly the form of the personal name shapes stereotypical expectations about the ethnicity of its bearer. Liulevicius (2000: 34) cited an example of the "three Smiths" in the Lithuanian town of Marijampole $\dot{e}^{48}$

47 Pen name of Henryk Goldszmit (1878-1942), Polish-Jewish pediatrician, author, director of an orphanage in Warsaw, renowned for his humanistic views on pedagogy. He died with the children from his orphanage in a Nazi extermination camp in Treblinka.

${ }^{48}$ Industrial city in southern Lithuania and capital of the eponymous county (Marijampoles apskritis). Liulevicius uses the Polish name Mariampol; the town was handed over by Poland to Lithuania in 1920. 
around the time of the First World War: Heinrich [sic!] Schmidt, a nationalist Pole and a Roman Catholic; Kowalski, an Orthodox Russian; and Kusnjetzow ${ }^{49}$, a genuine German and a member of the Evangelical community. "Surnames were not reliable indicators of what a person's hotly professed identity would turn out to be," Liulevicius concluded. In a similar way, as an anecdote from the time of the Silesian Uprisings ${ }^{50}$ has it, in the Conciliation Commission ${ }^{51}$ the spokesmen for the Polish cause were named Kaufmann, Lachmann and Neumann (which are German surnames), while the spokesmen for the Germans were called Brończyk, Jonczyk and Pietrzyk (these in turn are typically Polish surnames) ${ }^{52}$.

Individuals are frequently forced to come to terms with the associations that their personal names invoke - what Puskás (2009) calls "the ethnic game with names": one assumes ethnicity on the basis of the name. Thus names, inadvertently or intentionally, become identity markers. In Slovakia the surname Böszörményi, Puskás argued, infallibly marks its bearer as alien, if not for any other reason, then at least by virtue of the fact that it contains letters alien to the Slovak alphabet. The same fate awaits the bearer of a Slovaklooking or Slovak-sounding name in a Hungarian milieu:

I write my family name with Slovak $\check{c}$ (unlike the Hungarian that has a 'cs' form), this is clearly a Slovak sign, I have never considered writing it differently, but my name caused great frustration when I learned to read (in the Hungarian school) because my classmates' names, even if they sounded Slovak, did not include Slovak letters. [...] I had to show twice as much as them that I am Hungarian (ibid.: 165).

\footnotetext{
${ }^{49}$ So in Liulevicius; in the original spelling Кузнецьов.

${ }^{50}$ Three Polish uprisings against German rule in Upper Silesia (1919-

${ }^{51}$ In Polish Komisja rozjemcza.

52 Cf. Henryk Borek 1986. Wśród śląskich nazw [Silesian names]. Opole: Instytut Śląski w Opolu, p.69.
} 1921). 
Ethnic identification by means of a name is so natural that it motivates the members of ethnic groups, on the one hand, to conceal their ethnic identity by name-changing, on the otherto manifest their identity by consciously choosing an ethnic given name as a manifesto. The bestowing of "programmatic names" (cf. Walkowiak 2014) or even voluntary individual name change is in fact a common phenomenon in times of national or ethnic revivals, when people feel compelled to prove their patriotism / ethnic self-identification by giving their children names that show their national / ethnic identity. This is an example of associative, but perhaps also emotive meaning, to refer to Nyström's layers of meaning.

Sometimes such 'patriotic' names are not easily found and have to be created rather than merely revived. Thus many users of Internet forums devoted to Kashubian culture, for instance www.naszekaszuby.pl, inquire online about "typically Kashubian" given names. Partly in response to such inquiries the Kashubian Language Board (Rada Języka Kaszubskiego) published in its 2008 bulletin (cf. Breza 2008) a list of standardised Kashubian names, some of them historical names of Pomeranian dukes or names of legendary characters, seldom used by the general populace.

The fact that some names have emotive meaning may even result in tangible economic consequences, as proven in 2013 by Rubinstein and Brenner. They analysed a sizeable sample from the 1995 Israeli census and found that workers with Sephardic surnames, other factors being equal, were far more likely to be discriminated against in terms of earnings than those with Ashkenazi surnames ${ }^{53}$. Similar results

53 The researchers compared "the wages of individuals who are similar in all respects that are relevant to labor market performance and differ only in how labor markets perceive their ethnicity, as signaled by their inherited, ethnic-sounding family names." Their findings were that "labor markets discriminate based on surname [only] when those names provide additional information about ethnicity. When a person's skin tone provides a clear signal of ethnicity, surnames do not explain residual wages." (Yona Rubinstein [\&] Dror Brenner "Pride and Prejudice: Using Ethnic-Sounding 
regarding the effect of surnames on the job market have been obtained in the USA by Bertrand and Mullainathan, who sent fictitious job applications with randomly assigned AfricanAmerican- or White-sounding names in reply to help-wanted ads in Boston and Chicago newspapers. As it turned out, White-sounding names yielded 50 percent more invitations for interviews ${ }^{54}$. The research conducted in 2015 in Denmark ${ }^{55}$ revealed than bearers of non-Danish sounding names must make 27 per cent more inquiries before they can find housing than those with Danish-sounding ones.

Let us return once more to two kinds of meaning listed by Nyström: categorical and/or associative (it might be difficult at times to distinguish the two). The list of parameters that personal names can be indicative of is not limited to gender, religion, or ethnic/national identity. For instance, given names can also inform about their bearers' age, as visible in the following review of a theatrical play. Introducing the heroine and the hero of the play, the reviewer remarked: "Wiktoria and Leszek - by their names it is possible to guess in which year they were born and on which side of the barricade their fathers fought." ${ }^{56}$ Naturally, deciphering this kind of cultural code requires some background, though the reader is somehow helped by the title of the review, which sets the scene. One must know, for instance, that the 'barricade' is an allusion to the 1980 fight in Poland for freedom against the communist system; that the male name Leszek is reminiscent of Lech, the

Names and Inter-Ethnic Marriages to Identify Labor Market Discrimination". The Review of Economic Studies. OUP. Posted on September 1, 2013. http://www.restud.com/accepted-papers/, accessed Jan. 23, 2014)

${ }^{54}$ Marianne Bertrand and Sendhil Mullainathan 2004. "Are Emily and Greg More Employable Than Lakisha and Jamal? A Field Experiment on Labor Market Discrimination." American Economic Review 94/4, 991-1013.

55 "Danish housing market rife with discrimination". The Local, April 24, 2015. http://www.thelocal.dk/20150424/discrimination-rampant-in-danishhousing-market, accessed Dec. 10, 2016.

56 Izabela Szymańska 2012. "My, rocznik 80." [us, born in 1980] Gazeta Wyborcza-Wysokie Obcasy, May 26, p. 8. 
given name of Wałęsa, the legendary leader and co-founder of Solidarity, Polish independent trade union of 1980; finally, that Wiktoria refers to the expected victory over the hated communist system ${ }^{57}$. Sudden popularity of certain given names is also due to the popularity of soap operas, films, books, as well as to the names of popular celebrities and their children. As a case in point one might take the sudden emergence in Poland of the female name Izaura / Isaura. Its first bestowals date back to the years 1981-1990, when the name was given to girls 58 times. The years $1991-1994^{58}$ were marked by a sharp drop in the name's popularity - only 8 bestowals (Rymut 1995: 184, 187). This unexpected rise and decline in the frequency of the name is not surprising if one considers the motivation behind the naming. Isaura was namely the heroine of a Brazilian telenovela Escrava Isaura ('Slave Isaura'), which was broadcast on Polish television in the mid-1980s and enjoyed quite high popularity at the time.

Naturally, the fact that the choice of given names may be indicative of the name-bearer's age is observed not only in Poland. As an American blogger living in Denmark observed,

Danish first names are extremely generational, and cracking the code means you can pretty much guess who will be across the table from you in a business meeting or blind date without knowing anything else about them. If the man you are meeting is named Flemming, Preben, Henning, or Bent, he is at retirement age or near it. His wife, sisters or the lady-next-doorhe-is-running-away-with will be named Bente or Birthe. His buddies are Ole or Finn. Nobody involved knows what Twitter is. If the invitation says Mette, Pernille, Anja, Lene, or Tine, you will be meeting a lady in her 30 s or 40 s. Her partner people in Denmark don't get married much any more, even after several children - will probably be named Morten, Martin, Lars, Søren, Steen, Rasmus or Nicolai. Nicolai/Nikolai/Nikolaj was

${ }^{57}$ It also became the name of Wałęsa's daughter born in 1982; this fact, however, obvious to theatre-goers today, would not be known in 1980 .

${ }^{58}$ No later data for all of Poland are available. 
a 1970s favorite, to the extent that the financial market commentators on Danish business TV seem to be one eternal Nicolai, with varying last names and neckties. There was a brief trend in the 1960s to give boys Americanized names, such as Johnny, Tony, Kenneth, Alan, or Brian. These names are now a huge burden to the middle-aged men who bear them, since they are associated with working-class troublemakers ${ }^{59}$.

The above example with personal names implying the age of their bearers proves that sometimes it is difficult to tell if the meaning is associative, categorical, emotive or even lexical (as in the case of the name Wiktoria).

Yet another type of information that a given name may provide is connected to the circumstances of the child's birth or even conception. Since that kind of information requires the appellative character of the given name, and European given names today are seldom semantically transparent, few contemporary European examples can be invoked. However, in many European countries foundlings and children born out of wedlock were once bestowed with given names or even surnames indicative of their unclear or illegitimate roots. Even in more recent times such traditions have not disappeared completely. Reportedly "during World War II, when there were many American and British soldiers in Iceland, many babies were being born to Icelandic women with the last name 'Hermatthson' or 'Hermathsdottir.' In Icelandic, 'hermaður' is the word for soldier" ${ }^{\prime \prime 0}$.

Some celebrities were rumoured to have named their child Paris after the city where the conception took place. A similar motivation stands behind the Greek name Tsambikos / Tsambika:

${ }^{59}$ Kay Xander Mellish "Danish names: Why it's bad to be Brian." http://howtoliveindenmark.com/stories-about-life-in-denmark/danish-nameswhy-its-bad-to-be-brian/, April 13, 2013, accessed Dec. 3, 2016.

${ }^{60} \mathrm{http}: / /$ namesacrossnations.blogspot.com/2012_07_01_archive.html, accessed Dec. 3, 2016. 
[T]he summit monastery of Panayía Tsambíka ${ }^{61}[\ldots]$ is unremarkable except for the happier consequences of the September 8 festival, when barren women make the climb sometimes on their hands and knees - to pay homage to an eleventh-century icon and (later) ingest a small piece of the wick from one of the shrine's lamps. Any children born afterwards are called Tsambikos or Tsambika $[\ldots]^{62}$

However, conferring names that describe incidents at the birth of the name recipient was far more frequent in Europe in the past than today. In Ancient Rome, for instance, a child could be named Octavius ('the eighth one'), Sextus ('the sixth one'), Postumus ('the last one'), depending on the birth order. Among cultures outside Europe such naming patterns are still quite popular. Names indicating birth order are used to this day among the Fulani of West Africa, among the inhabitants of South Java and of Bali, among the Japanese and in other cultures (cf. Dzharylgasinova \& Kryukov 1986). In some cultures, birth order is not reflected directly in numeral-like names, but can be indirectly inferred:

The first son of a Highland Scot couple is named after paternal grandfather, the first daughter after the maternal grandmother, the second son after the maternal grandfather, and the second daughter after the paternal grandmother. An identical system exists among the Santal, an agricultural people living in West Bengal in India: first and second sons and daughters are named after paternal and maternal grandparents, and third sons and daughters are named after paternal and maternal great uncles and great aunts (Alford 1988: 42).

Some Zambian names commemorate events having taken place in the community around the time a child was born: Solstice, Solstina, Eclipso, Sky Shadow, Blindness refer to the

${ }^{61}$ On the mountain called Tsambíka, $26 \mathrm{~km}$ south of Rhodes City, Rhodes, Greece.

${ }^{62}$ Marc Stephen Dubin 2002. Rough Guide to the Dodecanese and East Aegean Islands. London - New York: Rough Guides, p. 123. 
solar eclipse in Zambia which took place on June 21, 2001, while such names as Pollingday, Ballotbox or Voted are reminiscent of the presidential elections of December 17, $2001^{63}$. Traditional names in Ghana include day names (indicating, for each sex separately, the day of the week on which a child was born), as well as positional names that mark the birth order within the family (Reisœter 2012: 226). Alford (1988: 60) found that in his sample of 60 societies, given names connected with some birth incident had been reported in 18 cases.

Lévi-Strauss invoked a plethora of instances of baby naming where the name conferred was highly informative:

[D]ans une [...] tribu de l'Uganda, les Lugbara, [...] l'enfant reçoit son nom de sa mère assistée parfois de la belle-mère (mère de mari). Sur 850 noms recueillis au sein d'un même sous-clan, les trois quarts se rapportent à la conduite ou au caractère de l'un ou autre parent: En-paresse, parce que les parents sont paresseux, Dans-le-pot-de-bière, parce que le père est ivrogne, Donne-pas, parce que la mère nourrit mal son mari, etc. Les autres prénoms évoquent la mort, récente ou prochaine (d'autres enfants des mêmes parents, des parents eux-mêmes, ou d'autres membres du groupe), ou bien encore des attributs de l'enfant [...] Ainsi, chez les Lugbara: Ejua pour un jumeau, Ejurua pour une jumelle; Ondia pour le fils, Ondinua pour la fille d'une femme supposée stérile; Bileni ('pour la tombe') nom du premier survivant après une série de mort-nés. Ces noms préexistent donc aux individus qui les portent, et ils sont attribués à cause d'une condition qui est objectivement la leur, mais où d'autres individus peuvent également se trouver, et que le groupe tient pour chargée de signification [...]

Les Dogon du Soudan suivent une méthode très stricte pour attribuer les noms propres, puisqu'elle consiste à repérer la position de chaque individu d'après un modèle généalogique et mythique où chaque nom est lié à un sexe, à une lignée, à un ordre de naissance, et à la structure qualitative du groupe de

${ }^{63}$ Mwizenge S. Tembo 2006. Zambian Traditional Names. Lusaka: Julubbi Enterprises Ltd., p. 6-7. 
germains où l'individu est inclus: jumeau lui-même; premier ou deuxième né avant ou après des jumeaux; garçon né après une ou deux filles, ou inversement; garçon né entre deux filles, ou inversement [...] (1962: 237-9, 251).

Cultures in which name is not stable and where its change marks the attainment of various stages in life, names can also reflect personality traits. For instance, such a name change among the inhabitants of Zambia in the south of Africa

provides an individual with an opportunity to acknowledge some of his or her extreme typical personality characteristics or quirks as others see the person in the family, village or community. Are you too quiet, humble, or too talkative? Do you complain all the time about life? Are you too frugal? Do you buy things if only they are cheap? Are you very poor or very prosperous? Are you too generous? Do you always like to wear clothes that are very fancy? Do people say walk with a certain pride in your step? Are you short-tempered? Do you like to always say exactly what is on your mind? Do you say what is on your mind only when you have had a drink ${ }^{64}$

To sum up, it has been demonstrated that what can be possibly inferred from personal names about their bearers includes - among others - their gender, their national/ ethnic/religious background, their age, their parents' political convictions, sporadically (in Western cultures) or commonly (in other cultures) even the circumstances of conception or birth, including the birth order. In those societies where name change at a later age is customary, the new name may additionally reflect personality traits of its bearer.

All that shows that personal names are not completely devoid of meaning. Rather, one has to admit many possible types of meaning that a name can have. At the same time it must be remembered that the meaning explored by

${ }^{64}$ Ibid., p. 5. 
psychologists is simply different from the meaning that philosophers discuss. As Valentine et al. emphasise,

proper names have different meanings to different subjects, according to levels of expertise with different categories [...] Theories of proper name meaning often do not capture the full variety of types of meaning that they can have [...] People's names can carry meaning in that it may be possible to make educated guesses about a limited range of a person's characteristics from knowledge of their name alone, although such information is not always reliable (2002: 30-32).

An even more interesting phenomenon involves thinking in the opposite direction: how such inferences ("educated guesses") may be consciously shaped, even manipulated, by the name bearers. There are not many examples of such shaping, but nevertheless some can be invoked. J.S. Bystroń mentions Polish Jesuits, who in 1820s settled in Italy and assumed Italian surnames "so Italians are not surprised that they are being taught by barbarians" (1993: 179). Thus a Pole by the name of Suszyński took on the surname Aridini (both names are semantically related to 'dryness'), while Rytto became Grillo (this time phonetic similarity was decisive in the choice).

There also exist contemporary instances of such conscious shaping of the connotations evoked by personal names. Asked in an interview if he feels pigeon-holed as a representative of magic realism ${ }^{65}$, American writer Jonathan Carroll once revealed:

Some literary critic once wrote that the sale figures of my books would go up if I assumed a pen name that would be composed of three Spanish given names. It is enough for a writer to be called Felipe Miguel Gonzales Carroll and suddenly the appearance of a talking dog in a realistic novel is not surprising any more. Unfortunately, it was too late for me to put this advice into practice. ${ }^{66}$

65 Aesthetic style often associated with Latin American writers.

${ }^{66}$ Wojciech Orliński 2012. "Kobieta, która wyszła za chmurę. Jonathan 
A similar gimmick has been not only considered but actually implemented by Jarosław Świerszcz (b. 1960), Polish playwright self-renamed Ingmar Villqist:

From the very beginning he was hiding under a Norwegian pen name, because his dramas are marked by a strong influence of psychological, Scandinavian style of writing for the theatre. In his literary output critics would find spiritual affinity with Henrik Ibsen, August Strindberg or Ingmar Bergman ${ }^{67}$.

Incidentally, this kind of name styling, in which names are treated as products, is very close to the phenomenon known in marketing as foreign branding. ${ }^{68}$

\subsection{The meaning of personal names as motivation for name policies}

As shown and exemplified above, various types of meaning may be ascribed to personal names. The reason why so much space has been devoted to the numerous meanings

Carroll: Uważaj, co przy mnie mówisz" [interview with Jonathan Carroll]. Gazeta Wyborcza, June 14, p. 12.

${ }^{67}$ [Monika Mokrzycka-Pokora] 2009 (updated 2016). "Ingmar Villqist (Jarosław Świerszcz)”. http://culture.pl/pl/tworca/ingmar-villqist-jaroslawswierszcz, accessed Dec. 3, 2016.

${ }^{68}$ Foreign branding means using a foreign or at least foreign-sounding name for a product to create in the mind of the customer the image of a particular culture (e.g. Italian names for frozen pizza to imply original Italian recipes, French names for hairstyling parlours to allude to style and good taste, German names for household appliances to suggest reliability and technological excellence, etc.). An interesting example in the sphere of music is the so-called metal umlaut: the use of 'umlauts' in the names of heavy metal and punk rock bands to evoke a tough, macho (as if Teutonic) image or to create Gothic rock associations. Cf. Bruce Campbell, no date. "Would You Like Umlauts With That?" www.clicknation.com/snoof/stuff /umlaut.pdf, accessed Dec. 3, 2016. See also: Mark Liberman 2005. "The Modish Macron.” Aug. 29. http://itre.cis.upenn.edu/ myl/languagelog /archives/002433.html, accessed Dec. 3, 2016 and Joeri Van den Bergh \& Mattias Behrer 2011. How Cool Brands Stay Hot: Branding to Generation Y. London: Kogan Page. On foreign branding in Poland, see Walkowiak 2013. 
and connotations personal names may have is that, arguably, most name policies can in fact be linked to these particular types of meaning. Indeed, this link is possible precisely because names are not merely empty labels which could freely be exchanged for different ones. After all, if all personal names were absolutely meaningless, assigned completely at random and interchangeable at will, there would be hardly any reason for authorities and other policy agents to intervene and exert any kind of control over personal naming. More often than not, however, there is at least some (state or otherwise) control in that respect.

As emphasised, names do have their meanings and connotations. For instance, they are often good indicators of ethnicity. For precisely that reason so many states favour native/majority personal names over foreign/minority ones. In practical terms, it might be that citizens are encouraged to express their patriotism by assimilating their names, or immigrants are forced to change their name at naturalisation. There may also be asymmetry between the status of minority and majority/foreign names, so that it is easy and inexpensive to assimilate one's name to the majority form, but often far more difficult and/or expensive to do the opposite. In less common cases, minority to majority name change is forbidden so a minority can easily be identified and not confused with the majority (which, perhaps, enjoys more rights or higher social status, jealously guarding their privileges against "usurpers"). There may also occur enforced personal name assimilation whose objective is to create the impression of an ethnically uniform state ${ }^{69}$. All these forms of control would not make much sense if personal names did not indicate ethnicity.

${ }^{69}$ Such policies could be termed "domesticating" - this term refers to the distinction between domesticating vs. foreignizing translations (cf. Laurence Vanuti 1995. The Translator's Invisibility. A History of Translation. New York: Routledge, passim). It is no coincidence that concepts taken from the theory of translation should be adopted here, even though proper names, which include personal names, are traditionally not perceived as translatable. After all, as further argued in this book, personal names can be and in fact 
In a similar way religious connotations of personal names are linked to name policies. For instance, it is often expected of followers of a particular denomination that they would name their children according to its principles - thus in a particular socio-geographical environment it is relatively easy to tell on the basis of one's name what his or her religion is. Such a policy may take on various forms: from the provision in the Catholic Canon Law that priests should only baptise babies with Christian names, to the expectation that converts at conversion adopt new names appropriate to their new religion. Also lay persons embarking on consecrated life are typically required to change names. Granted, at times the change might be seen as effected merely for the change's sake (for instance, when Angelo Giuseppe Roncalli became Pope John XXIII, his change of name could hardly be described as one from a less religious to a more religious name; after all, Giuseppe is a highly respectable name of the foster father of Jesus, and Angelo invokes angels). However, in other cases the difference is easily visible - for instance many Polish nuns assume unusual monastic names that are practically never used by lay women in Poland (e.g. Immaculata, Jukunda, Konsolata, Paschalisa, Cherubina, Anuncjata ${ }^{70}$ ). It is thus easy to identify a woman as a nun on the basis of her name only. Even though such a name change is seldom, if ever, effected administratively, the new name is nevertheless used in public life: Mother Theresa was a name many people recognised, whereas few people, especially outside Albania, knew who Anjezë Gonxhe Bojaxhiu was.

That in numerous cases a personal name is not semantically opaque, so that (the vestige of) the semantic meaning of a name remains and is projected onto the name's referent, is visible in the fact that some names (mostly

\footnotetext{
are translated in a certain sense of the word (but in a no less psychologically valid way than appellatives).

70 Agata Puścikowska "Siostra niejedno ma imię" [nuns have many a name]. Gość Niedzielny 4/2010, Jan. 28, 2010.
} 
surnames, though not exclusively ${ }^{71}$ ) are treated as offensive and humiliating for their bearers (such as the French surname Trognon 'stump, butt end', or the Polish surnames in use today: Burdel 'brothel', Fiut 'penis' or Kupa 'poo'). For this reason legislation in many states allows name change if this name is pejorative $^{72}$. Not to be confused with this situation is another one, when the name evokes negative associations with some (in)famous person - historical (Hitler, Adolf, Ned Kelly ${ }^{73}$ ) or even literary (Alfons ${ }^{74}$ ), and when its bearer is therefore allowed to change it.

Another example of the link between name policies and the meaning of personal names is the existence of sex-typing in given names: many states allow their citizens to use only such given names (and sometimes such surnames too) which make it possible to recognise if the bearer is male or female. If given names was merely meaningless labels, they would not include this information. In addition, in some states (e.g. Lithuania ${ }^{75}$ ) separate surname forms for married vs. unmarried women are still used and in others (e.g. inter-war Poland) such separate forms were once obligatory.

Polish law considers a request for surname change justified if the surname in question is homonymous with a given name. This is yet another indication that names are

${ }^{71}$ In 1993 Japanese parents unsuccessfully attempted to name their newborn son Akuma ('devil'). Cf. Minoru Kuniya and Mami Oyama "Unwritten Legal Codes", p. 45. http://data.nistep.go.jp/dspace/bitstream/1103 5/713/1/NISTEP-PS001-FullE.pdf, accessed Dec. 11, 2016.

72 Cf. e.g. Tadeusz Kisała 1996. Nasze nazwiska [our surnames]. Warszawa: Ludowa Spółdzielnia Wydawnicza. The book contains a long list of surnames in use in Poland (at the time of writing the book) which for semantic reasons might be perceived as offensive and whose bearers, in Kisała's opinion, are justified in requesting surname change.

${ }^{73}$ More on Ned Kelly is to be found further in the book.

${ }^{74}$ Monsieur Alphonse, a procurer, was a hero of the 1873 play by Alexandre Dumas fils by the same title. Under the influence of the play the colloquial eponym alfons ('pimp') emerged in Polish, which fact has drastically limited the use of the given name Alfons in Poland to this day.

75 Only in 2003 have women in Lithuania been allowed by law to assume surnames that do not carry information on marital status. 
much more than mere labels, and, more specifically, that from the point of view of policymakers there may be "better" and "worse" surnames, the latter in this case being the surnames which look like given names.

\subsection{Personal names and translation}

The issue of the potential meaning or meanings of personal names ${ }^{76}$ is closely linked to another question, namely: are personal names translatable? The traditional answer to this question is negative: it is one of the major differences between proper names (including personal names) and appellatives that the latter are translatable whereas the former are not, and are best left intact as far as possible (though historically the translating practice used to be different $-18^{\text {th }}$ or $19^{\text {th }}$ century translators freely translated or adapted morphophonetically personal names in texts).

However, in what follows it will be argued that personal names in fact may be translatable, in varying degrees and depending on a particular case; but the possibility of translation is certainly not to be ruled out. What is more, language users are frequently aware of the existence of two (or more) parallel forms of a personal name and of their mutual equivalence ${ }^{77}$. In making the case for the (conditional) possibility of a translation of personal names, it is necessary to resort for a brief moment to a sphere seemingly marginal to the present discussion, viz. to literary onomastics.

76 The remarks about the meaning and translation are applicable not only to personal names but, given the appropriate context, also to toponyms and perhaps occasionally even to some other subclasses of proper names, such as chrematonyms. Cf. e.g. German Opel vs. English Vauxhall; Polish chocolate bar Prince Polo vs. Islandic Prins póló or Ukrainian Siesta; the gear shift lock Niedźwiedź ('bear') Lock in Poland vs. Bear Lock in Poland and many other countries). However, since the focus of this book is personal names, chrematonyms will not be discussed further here.

${ }^{77}$ A disclaimer is in order that this term is used here rather loosely and does not necessarily reflect all the senses attributed to it in various theories of translation. 
It goes without saying that personal names can be and in fact sometimes are or in the past used to be translated in literature. It is so today especially in children's literature and in the films for children (naturally such practice is nowadays definitely frowned upon in adult literature). One may consider for instance Eeyore, one of the characters in "Winnie-the Pooh" by A. A. Milne. This name has been rendered as Bourriquet in French, as Ih-Oh in Italian, as Ijáček in Czech, as Kłapouchy in Polish, as Bisonho in Portuguese, Tussi in Norwegian (bokmål), Füles in Hungarian, etc. Given the immense number of languages into which the famous Winniethe-Pooh books have been translated, one may safely assume that this fictional English name has a plethora of equivalents. Is literary onomastics - especially as regards children's literature - the only subfield of onomastics where such a special instance of polyonymy ${ }^{78}$ is possible?

In fact, one encounters a similar phenomenon in the sphere of Christian given names, the major difference being that literary names are frequently invented while Christian names developed naturally over centuries. The most popular of these names, such as John, has numerous equivalents in other languages: there is Ivan in Belarusian, Juan in Spanish, Jan in Polish, Giovanni in Italian, Johann(es) in German, Jonas in Lithuanian, Evan in Welsh, and many more ${ }^{79}$. The existence of numerous equivalents of popular given names in various languages facilitates their spontaneous translation in real-life language contact ${ }^{80}$. Actually, migrants are known to "translate"

${ }^{78}$ In its classic sense, the term denotes the use of various names for one thing (Mirriam-Webster Dictionary and Thesaurus, 2012 online version, http://www.merriam-webster.com/dictionary/polyonymy, accessed Dec. 3, 2016).

79 The portal http://www.behindthename.com/ gives over two hundred of equivalents of this name in various languages of the world (accessed Dec. 3, 2016).

${ }^{80}$ Ricardo, my student from Portugal, was frequently addressed by his Polish fellow students as "Rysio", which is a diminutive of his name's Polish cognate Ryszard (Aleksandra Mrozińska, personal communication). 
their given names in this way, which indicates the psychological reality of such a transposition.

Such a given name translation as the above, where Christian given names (usually borrowed from Hebrew, Latin, Greek or Aramaic) have undergone different phonetic and morphological development in various languages of Europe, is easiest to accept. Nevertheless, as instances of what for the purpose of this work shall be called name translation ${ }^{81}$, also the following cases will be included:

- customarily accepted and linked with each other, though not genetically related equivalents ${ }^{82}$, such as Polish Wojciech and English Adalbert ${ }^{83}$;

- arbitrarily chosen, though phonetically motivated equivalents; for instance Polish immigrants in the USA by the name of Stanistaw often change it to Stan or Stanley as these are phonetically similar (in particular, the onset of the word is preserved), later functioning as Stanley to Americans and as Stanisław to Poles;

- semantic translations: thus the given names $\Theta \varepsilon o ́ \delta \omega \rho o \varsigma$ (Greek) and Bogdan (Polish) are semantically equivalent and they both mean 'given by God'; similarly Latin Felix and Polish Szczęsny are semantically equivalent, both with the meaning of 'happy, fortunate, lucky'. This category might include also mistranslations, such as the case of the Polish male name Żegota, perhaps wrongly identified with the Latin Ignatius on the assumption that the latter is

${ }^{81}$ The diverse processes by which a personal name from one language is rendered in another come under various terms: adaptation, transformation, conversion, transposition, name transfer (cf. Abramowicz 1998, Citko 1998).

${ }^{82}$ Algeo (1973: 60) uses in such cases the term functional equivalence. Alhough he exemplifies this notion by toponyms (both etymologically related ones, as Florence - Firenze or Vienna - Wien, and ones with no etymological connection, as Suomi - Finland, or Germany - Deutschland), his findings are similarly applicable to anthroponyms.

83 The Polish name of the Czech saint is traditionally translated into English as Adalbert since the latter is believed to have been the saint's monastic name. This and other etymologies in this section are given on the basis of Fros \& Sowa (2002). 
motivated by the Latin word for 'fire' (this etymology is probably incorrect - it is generally assumed in Polish onomastics that the Polish Żegota probably developed independently);

- equivalents resulting from sound substitutions: here one might include the so-called 'phonetic translations' of Western personal names into Chinese ${ }^{84}$. Incidentally, equivalents of Christian names in various languages may be perceived as having in the past resulted from a similar kind of process.

The above examples refer to given names. Name translation in the case of surnames is less obvious, yet also conceivable, comprising the following possibilities:

- semantic translations, e.g. Latin-based Kantor and the Polish Śpiewak ('singer'); English Stevenson and Gaelic MacStiophain ('son of Steven'); German Bronstein and Hebrew Shaham ${ }^{85}$ ('brown stone'), Yiddish Hersz [Hirsch] and Polish Jeleński ${ }^{86}$ ('deer/of a deer'), etc.

- $\quad$ transposition of a surname derived from a placename in a given language into a surname derived from the equivalent of this placename in another language, e.g. Hung. Görgei $>$ Slovak Harhovsky ${ }^{87}$ (cf. Farkas \& Slíz 2013: 9)

- equivalents obtained by regular suffixation - quite often bilingual language users produce the desired equivalent automatically: e.g. Polish Kozłowski, Malinowski have

${ }^{84}$ Cf. e.g. Tracey Wilen-Daugenti 2007. China for Businesswomen: A Strategic Guide to Travel, Negotiating, and Cultural Differences. Berkeley: Stone Bridge Press, p. 21: "Some businesswomen also suggest using a Chinese name so that your name can be easily pronounced and remembered. Most English names can be phonetically translated into Chinese. For example, Jenny could be Zhenni, and Katie could be Kaidi." Internet forums (e.g. http://www.chinese-tools.com/names/forum.html, accessed Dec. 3, 2016) are full of requests like "Can you translate Mackenzie into Chinese?"

85 Cf. http://www.columbia.edu/cu/record/archives/vol20/vol20_iss26 /record2026.28.html, accessed July 29, 2012.

${ }^{86}$ Cf. Bystroń (1993: 193).

${ }^{87}$ Hung. Görgö, Slovak Harchov, German Gorg, today Spišský Hrhov, a municipality and village in Slovakia. 
their Lithuanian equivalents Kazlauskas, Malinauskas ${ }^{88}$. Interestingly, the stems of the surnames in this example remain untranslated and thus the derived name is semantically opaque.

'Name translation' as defined and exemplified above certainly differs from translation in the usual sense of the word. Name translation can be observed contemporarily or historically in several situations:

1) Language contact in mixed language areas whose inhabitants typically have two (or even more) parallel names each - the situation typical of border regions. Quite often one of these languages is the majority (state, official) language and the other $-\mathrm{a}$ /the minority language. For example in Communist times Hungarians in Slovakia often had two versions of the name: a Slovak one (e.g. Juraj Ďurčik, Zlatica Duuráčová) for work and for the records, and a Hungarian one (e.g. Gyurcsík György, Gyurács Aranka) functioning in informal settings, such as at home or among friends (cf. Satinská 2015: 105).

2) Language contact between two distant linguistic cultures, where for the ease of communication the "alien" name has to be adapted, especially in view of the difference in the respective scripts used by two distant languages in question. As mentioned above, frequent or long-term foreign visitors to China often decide to assume Chinese names; in this way their Chinese hosts, business hosts, university teachers etc. will remember their names better. Typically the Chinese name thus acquired by visitors has little or nothing to do with the semantic meaning of their original name but there is usually some phonetic similarity.

3) The admission during the Renaissance by many European writers or philosophers of Latinate or - sometimes - Greek

${ }^{88}$ It is noteworthy that no semantic translation is involved here: Kozłowski is motivated by the Polish appellative koziot 'male goat', in Lithuanian ožys; Malinowski is semantically related to Polish malina 'raspberry', in Lithuanian aviete. 
or Hebrew versions of their names, which lent them more prestige among the literati: Maciej Kazimierz Sarbiewski ${ }^{89}$ - Mathias Casimirus Sarbievius, Mikołaj Kopernik Nicolaus Copernicus, Philipp Schwartzerdt ${ }^{90}-$ Philipp Melanchthon. The first two examples are the effects of Latin suffixation (with Latin equivalents of Polish Christian names Maciej, Mikołaj, as discussed above), while the third is an actual translation of the surname into Greek. Examples from Hungary include Kovács 'smith'> Lat. [Faber >] Fábry, Molnár (or German Müller) 'miller' > Molitoris, Zsámboky 'from Zsámbok' János > Johannes Sambucus (cf. Farkas \& Slíz 2013: 6). Somewhat similar is the contemporary practice in mainland China (especially, though not exclusively, Hong Kong), Taiwan and Singapore to assume English given names alongside Chinese surnames (Jackie Chan, Anthony Wu). It is similar insofar that, like Latin in Renaissance Europe, also English in today's world, including China, enjoys high prestige ${ }^{91}$.

\footnotetext{
${ }^{89}$ Polish poet (1595-1604).
}

${ }^{90}$ German theologian (1497-1560).

91 "When I moved to Shanghai about a year ago", a Chinese New Yorker recollected, 'I figured my name would finally seem 'normal.' No longer would it be the albatross of my childhood in Utah - making me stand out among the Johns, Steves, and Jordans. But when I introduced myself, I was met with blank stares, double takes, and requests for my English name. [...] My company almost didn't process my paperwork because I left the box for "English name" blank. "You don't have an English name?" the HR woman gasped. "You should really pick one." She then waited for me to do just that, as if I could make such an important existential decision on the spot; I told her I'd get back to her. People - Chinese people - had trouble recalling my name. One guy at work, a Shanghai-born VP, called me 'Steve' for almost three months. At my workplace, which is 90 percent mainland Chinese, just about everyone I interacted with had an English name, usually selected or received in school. The names ran the gamut, from the standard (Jackie, Ivy) to the unusual (Sniper, King Kong), but what really struck me was how commonly people used them when addressing one another, even when the rest of the conversation was in Chinese" (Huan Hsu 2009. "The Name's Du Xiao Hua, But Call Me Steve.” Slate, Apr. 27. http://www.slate .com/articles/arts/culturebox/2009/04/the_names_du_xiao_hua_but_call_me_s teve.html, accessed Dec. 3, 2016). See also: Rachel Edwards 2006. "What's in a Name? Chinese Learners and the Practice of Adopting 'English' Names". Language, Culture and Curriculum 19, pp. 90-103; Laurie Duthie 2007. 
4) Within one culture that uses two languages; a case in point may be Ashkenazi Jews, whose religious language was Hebrew and everyday language was Yiddish. It was customary to translate Hebrew names into Yiddish, leading to name pairs linked by common semantic meaning. Abramowicz 2002, discussing the names of Białystok Jews, gave several such pairs: Cewi (Cwi) - Hirsz ('deer'); Aria - Lejb, Lew, Lewe ('lion'); Ze(e)w - Wolf ('wolf'), Dow - Ber 'bear'.

It is evident that at least some of the above examples involve what might be called endoanthroponyms (personal names which are self-names, i. e. ones reflecting internal identification) vis-à-vis exoanthroponyms (personal names given by others, i. e. those which express external identification), terms that I coined on the basis of the wellestablished concepts endonyms and exonyms, of the relatively common analogical pair endoethnonyms / exoethnonyms, as well as of the practically non-existent endolinguonyms / exolinguonyms (used, to the best of my knowledge, only by Skutnabb-Kangas and Phillipson, cf. 1995: 109). In example 1) above, exoanthroponyms are the majority names; in 2) - the foreign visitors' Chinese names; in 3) - the Latinised names.

\footnotetext{
"Western Names for Chinese Identities: The Acquisition and Use of Western Personal Names among Chinese Business Professionals in Foreign-Invested Corporations". Asian Anthropology 6/1, pp. 53-80.
} 


\section{Aspects of name policy 2.1. The Cooperian question}

In his book Language Planning and Social Change, Cooper cited twelve definitions of language policy/planning and then formulated a basic question to serve as guidance for analysing language policies: "Who plans what for whom and how" (1989: 31). In the further part of his book, this question was expanded to include the activities on the part of agents other than governments: "What actors attempt to influence what behaviors, of which people, for what ends, under what conditions, by what means, through what decision-making process, with what effect" (ibid.: 98). In what follows, this series of questions will now serve as a point of departure for analysing (personal) name policies.

\subsection{The decision-makers}

Just like LP, also name policy can be divided into two broad categories: de jure and de facto policies. In discussing them, it would be fruitful to refer to the conceptual framework developed by LP. It must be stressed that some LP researchers - as for instance Crawford - do not perceive the latter as legitimate language policies:

Language policy [is] what government does officially - through legislation, court decisions, executive action, or other means to (a) determine how languages are used in public contexts, (b) cultivate language skills needed to meet national priorities, or (c) establish the rights of individuals or groups to learn, use, and maintain languages. ${ }^{92}$

Other scholars, however, understand language policies in a broader sense. As Shohamy noted,

92 James Crawford 2000. http://www.languagepolicy.net/archives/lang pol.htm, accessed Dec. 3, 2016. Emphasis added. 
the study of LP should not be limited to formal, declared and official policies but rather to the study of the powerful mechanisms that are used in most societies nowadays to create and perpetuate 'de facto' language policies and practices. [...] Moreover, these devices, which on the surface may not be viewed as policy devices, are strongly affecting the actual policies, given their direct effects on language practice (2006: xvi).

A similar stance was taken by Schiffman who stated that "[o]vert and covert policies are like an iceberg: the tip of the iceberg is the overt part; the underwater part is the covert part. $" 93$ In the opinion of Cooper,

[i]t would seem [...] that to restrict language planning to the work of authoritative institutions is to be too restrictive.[...] It must be admitted [...] that most scholars of language planning are reluctant to include decisions by small-scale social units such as individual schools, workplaces, churches and families as instances of language planning [...] It seems to me, however, that to exclude such small-scale instances [...] is to impoverish the field (1989: 38).

It is this broad, Cooperian approach that I will adopted here to PNs. De jure name policies are naturally adopted by the state legislators and/or language regulators and subsequently implemented by the authorities who see to it that the laws are put into effect. Agents of de facto name policies, on the other hand, include clerks, schools, churches, the army, and even the authors of calendars with the names of saints. The following sections discuss and exemplify all these types of policy agents.

93 Harold F. Schiffman, 2005. "LING 540: Language Policy: Introductory Remarks". Last modified Sept. 20. http://ccat.sas.upenn.edu/ $\sim$ haroldfs/540/polintro/polintro.html, accessed Dec. 10, 2016. 


\subsubsection{The state and the language regulators}

In many states of Europe there are special scholarly bodies that give their opinions on names and establish principles for name choice and use. Some of them actually make decisions, while others merely offer advice ${ }^{94}$ but their verdicts are not legally binding. Some function on state level, others are active only regionally. In some states the same body is responsible for both the language and the name registration, while in others the responsibilities of the language board do not include name registration, which is dealt with by another institution. The decision-making bodies include:

- Poland - Polish Language Board (Rada Języka Polskiego) and the Anthroponymy Section of the Polish Language Institute (Pracownia Antroponimiczna Instytutu Języka Polskiego PAN ) in Cracow (cf. Rzetelska, Cieślikowa and Duma 2002: 263).

- Kashubia - Kashubian Language Board (in Kashubian Radzëzna Kaszëbsczégò Jãzëka, in Polish Rada Języka Kaszubskiego).

- Basque names in Spain - the Onomastics Committee of the Royal Academy of the Basque Language (Euskaltzaindia)

- Germany - Association for the German Language (Gesellschaft für deutsche Sprache)

- the Czech Republic - Czech Language Institute, Academy of Sciences of the Czech Republic, Department of Onomastics (Ústav pro jazyk český, Akademie věd České republiky, oddělení onomastiky)

- Hungary - Research Institute for Linguistics of the Hungarian Academy of Sciences (Magyar Tudományos Akadémia Nyelvtudományi Intézete)

- Lithuania - State Commission of the Lithuanian Language (Valstybine lietuviu kalbos komisija)

94 A good example was the Welsh Language Board, which on its website used to offer advice in the form of a list of Welsh names to choose from (http://twfcymru.com/yourtoolkit/advice/welshnames/?lang=en, accessed Jan. 27, 2014). 
- Latvia - State Language Centre (Valsts valodas centrs)

- Wales - until 2012 Welsh Language Board (Bwrdd yr Iaith Gymraeg), then its powers were transferred to the Welsh Government and the Welsh Language Commissioner

- Finland - Language Planning Department of the Institute for the Languages of Finland (Kielitoimisto)

- Iceland - Icelandic Naming Committee (Mannanafnanefnd)

- the Faroe Islands - Faroese Language Committee (Foroyska málnevndin)

In some other states the naming decisions are made by other bodies. Such states are for example:

- Denmark - the National Social Appeals Board (Ankestyrelsen), the Ministry of Ecclesiastical Affairs (Kirkeministeriet) and the Danish National Church (Den Danske Folkekirke) $)^{95}$

- $\quad$ Sweden - the Swedish Tax Agency (Skatteverket)

- Norway - the National Registry (Folkeregisteret)

In these states the basis for the decision may be legal rather than related only to language correctness. Interestingly, while such regulatory bodies as language boards are sometimes perceived negatively as restrictive and limiting parental freedom, their existence may be a boon for others namely, for registry clerks or priests in that function, who may always shift onto them the blame for their own decisions, as the following quotation indicates:

My last interview ${ }^{96}$ was with Auður Eir, who happens to be Iceland's first female priest [...] For Auður, the naming committee

95 The Danish Act on Names of 2006 mentions also the Minister for Family and Consumer Affairs; however, as of 2014, this ministry does no longer exist, its responsibilities shared by two other ministries.

96 The author of these words, Nell Bang-Jensen, in the years 2011/12 researched naming in seven countries on a Watson Fellowship. http://namesacrossnations.blogspot.com/2012_07_01_archive.html, accessed Dec. 3, 2016. 
is a gift. She told me that before it formed, she had to act as an informal committee herself.

"Before, I had to be the one to tell parents yes or no about whether they could have a name. I had to read the law and decide whether I could baptize a baby with that name or not." She was ordained in 1974, 17 years before the foundation of the naming committee. "It was really hard to face the parents and tell them I couldn't baptize the baby with that name, but it was my responsibility as an official."

A few times, if she refused, the parents decided to go to another priest instead (some of them tended to be more flexible than others). She told me that in a few heartbreaking cases, she had been baptizing babies in a family for years, but then when someone came to her with a name she thought didn't meet the standards, she had to refuse them. There have been three cases that she remembers where this happened and the family stopped speaking to her. She remembers every one.

The committee makes her job easier. There is a higher authority that approves or rejects a name, and she can turn to them to ask whether a name will go through-it is not up to her interpretation of the law alone.

\subsubsection{The church}

For centuries, in view of the absence of state registries, churches fulfilled the role of registering births. In some states of Europe, only relatively recently did the non-confessional institutions take over this function (e.g. in Sweden as late as 1991), though in Europe there are still exceptions, such as the Lutheran Church in Denmark. In Poland under partitions, for instance, the transition from parish to state registration was gradual and took place at a different time under each partition. Thus under the Prussian partition civil registration was introduced in 1874; in Austro-Hungary it started as early as 1784 (with parish priests becoming simultaneously state registrars); in the short-lived Duchy of Warsaw (1807-15) Napoleon introduced civil registries; and in the semiautonomous, Russia's puppet state known as the Congress 
Kingdom of Poland (1815-67) church registers functioned as state registers ${ }^{97}$. In Russia before the October Revolution registering a birth and giving a name was possible only in the Orthodox church, which demanded the choice from the calendar of the Orthodox saints' names, usually of the saint whose feast was on the child's day of birth.

Obviously the people in charge of registering births used to wield (or even still wield) enormous power of shaping personal naming patterns. From their decision there was usually no appeal, especially if the people whose names were registered were illiterate or did not know the language of the records, as the following citation shows:

German expansion in Bukovina, a province of Austria-Hungary, was manifested in numerous areas of life, such as economics, culture, and even religion. A German priest in villages inhabited by Ukrainians, Poles or Romanians was not uncommon. Beside his ministry, he propagated German, instilled respect for the culture of the German-speaking area and promoted modern lifestyle. Taking advantage of his considerable standing, he became a spokesman for positive changes in the country, but in keeping with German policy. It was visible, among others, in name-giving at baptism, where - especially in Polish families there appeared on a mass scale hitherto little-used names, such as Wilhelm, Leopold, Otto, Fryderyk, Matylda, Gertruda. Such a priest did his best to avoid typically Slavic names. ${ }^{98}$

Sometimes, however, the actions of the priest did not lead to such a partial 'naming shift' but merely to increased or decreased name diversity. For example, the Kashubs' pool of given names in active use was traditionally limited (Jan and Józef for boys, Anna and Marianna for girls being the most

97 Cf. Małgorzata Nowaczyk 2005. Poszukiwanie przodków: Genealogia dla każdego [searching for ancestors: popular genealogy]. Warszawa: PIW, p. 95.

${ }^{98}$ Barnard Najdek 2007. „Na zielonej Bukowinie” [in Bukovina a historical region in the Carpathians that now belongs partly to Ukraine and partly to Romania]. Akant 9 (126). 
common choices). Also Slovincians ${ }^{99}$ are said to have been using very few names - chiefly Martyn, Pawet, Michat for boys, and Katarzyna, Stańca/Stanka (Konstancja) and Eliszka (Elżbieta) for girls. This was accompanied by a limited selection of surnames. Hieronim Gołębiewski (1845-1918), a parish priest in the Kashubian village of Jastarnia, wished to remedy misunderstandings, so he instructed his flock to bestow on the newborns each time the name of the saint whose feast was on the day of the child's birth. Since his parishioners complied, in the first decade of the $20^{\text {th }}$ century the names of Jastarnia's children were already quite diverse (cf. Bystron 1938: 31) ${ }^{100}$.

Yet another, if somewhat unusual, instance of a de facto policy on naming exerted by the (Catholic) church (with the accompanying language ideology) comes from Lithuania after the uprising of $1863-1864^{101}$ :

In the church, exclusively Polish words echoed. [...] [The priest] believed the noble Polish language would appeal more to God than the peasantish Lithuanian. He only chatted to villagers in Lithuanian believing that Polish was only the due of the nobleman, and the servants of the Church, so he even Polonised the names of the organist and the sexton. Šakutis the organist was christened Sakiewicz, and Bolis the sexton to Boliński. "God's servants cannot bear such peasant names" (Bojtár 1999: 199).

It is understandable that religious institutions used to wield the most power regarding (given) name control before the era of civil status registration. However, they exerted some influence on naming and renaming even later. For example, as Krăsteva-Blagoeva observed, during the first wave of the

99 A Slavic people, today practically extinct, that used to live in the region of Słupsk (German Stolp) in Pomerania (Poland) and speak Slovincian, classified either as an independent language or as a dialect of Kashubian.

100 Cf. also: Jerzy Treder (ed.) 2002. Język kaszubski. Przewodnik encyklopedyczny [encyclopaedic handbook of the Kashubian language]. Gdańsk: Wyd. Uniw. Gdańskiego Oficyna Czec, p. 89.

101 The Polish name is Powstanie styczniowe (the January Uprising). 
forcible Bulgarization of Muslim names in Bulgaria (19121913), "the acquiring of a Christian name was traditionally an element of [...] real baptisms. Of particular importance in that case was the active involvement of the priests, who, naturally, preferred 'the most powerful' Christian names" (2006: 64). By contrast, later waves of forcible name-changing were not motivated by religion or accompanied by any conversions. In fact, in the 1940s the traditional Christian names were consciously avoided.

A recent attempt on the part of religious authorities to exert naming influence by curbing the bestowals of unChristian (and usually celebrity-inspired) names has been the preaching of Pope Benedict XVI of January 2011. The Pope urged the faithful to return to tradition and to turn to the Bible for inspiration in name choice. In line with this teaching, Andrew Faley, Assistant General Secretary of the English and Welsh Catholic bishops' conference, stressed that "[n]aming children after perfumes, bicycles and countries is putting a limit on their potential. They are not merchandise or commodities."102

It should finally be noted that in certain cases it is difficult to distinguish between church authority and state authority, since both might be merged into one. A case in point may be the Protestant republic of Geneva under John Calvin (15361538 and 1541-1564), in which Calvin was both a political and a spiritual leader:

The ministers wanted to ban in Geneva certain given names which they considered to be vestiges of Catholic superstition. They hoped to eliminate names associated with the Godhead, such as Jesus, as well as names for feast-days, for example, Pentecost. They also suppressed names which they considered unbiblical such as Gaspard, Melchior and Balthazar, the names of the Wise Men. Finally, they wanted to prohibit names associated with local saints such as Claude and Martin. They

102 Nick Squires 2011. "Pope rails against rise of un-Christian names." The Telegraph, Jan. 11. 
wanted to eradicate Claude especially, as the saint's shrine was near Geneva, although it was the third most common name for boys and girls in Geneva. ${ }^{103}$

Other forbidden names were Suaire, Claude, Toussaint, Dimanche and Sepulchre, as well as nicknames (such as Monet for Simon, Tyvan for Estienne) and "bad-sounding" names such as Mermet, Sermet and Allemand. The name Chrestien was forbidden too ,pour ce qu'il est commun à tous” (Eire 1986: 316). Calvin's 'baptismal policy' (in Naphy's wording) was fiercely opposed by the local population:

A father presented his son at the font. When the minister was given the name 'Claude' for the child, he baptised it 'Abraham'. A riot then erupted ${ }^{104}$. The magistrates asked for a list of forbidden names and the ministers complied. However, they continued to make ad hoc decisions at the font when they deemed it necessary. ${ }^{105}$

Nevertheless, the policy turned out to be highly effective. As Naphy pointed out, the pre-reform number of saints' names bestowed on newborns was on average about 43 per cent for boys and 49 per cent for girls. At its lowest ebb (the years 1560-1570) the respective percentages were only 3.2 for boys and 1.8 for girls.

An interesting contemporary instance of the intertwinement between the decisions of religious and secular (state) authorities comes from Italy, where in 2008 a couple was banned by court from naming their son Venerdì (Friday). Even though the court invoked a (secular) law that prohibits "names which are ridiculous, shameful or may create discriminatory situations and difficulties of integration," 106 by

103 William G. Naphy 2003. Calvin and the Consolidation of the Genevan Reformation. Westminster: John Knox Press, p. 145.

104 On August 26, 1546.

105 Donald K. McKim 2004. The Cambridge Companion to John Calvin. Cambridge: CUP, p. 31.

106 "Chiamarono il figlio Venerdì, per la Cassazione diventa Gregorio" 
the court order the boy was to be renamed Gregorio, after the saint of the day of his birth. Interestingly, however, before the court verdict was passed, the boy had been baptised Venerdì in church.

\subsubsection{Low-level authorities}

The authority may assume the shape of an ordinary clerk, especially if there are no unequivocal regulations and the clerk wields de facto naming power. Such a phenomenon has in fact been named desk-clerk law in the sense of "what the person at the desk tells you the law is', and although such assertions are often incorrect, they routinely remain unchallenged" (Larson 2011: 164).

The following quotations depict the situation of a helpless individual facing an omnipotent figure of this embodiment of authority. The first quotation comes from the memoirs of a member of the Lemko minority in post-war communist Poland:

According to my birth certificate my name is Symeon Madzelan, born on the $18^{\text {th }}$ of February 1922 in the village of Binczarowa in the Grybów municipality, Nowy Sącz province. On this certificate in Latin and Ukrainian there is an elliptical stamp in Cyrillic script, which says: The Greek Catholic Parish of St Dimitrij in Biłcarewa. In 1946 without my consent I was renamed Szymon and I've been using this name ever since in contact with administration as well as among Poles. My parents and my kinsmen called me the Lemko way - Seman, while teachers and the priest - the Ukrainian way, Semen. These two tiny differences I didn't mind, but with 'Szymon' I haven't come to terms yet as it's been forced on me. ${ }^{107}$

[they named their son Friday, to the Court of Cassation he becomes Gregory] 2008. Il Secolo XIX, Oct. 22. http://www.ilsecoloxix.it/p/genova/2008 /10/22/ALQXoEAC-chiamarono_gregorio_cassazione.shtml?url=/p/genova /2008/10/22/ALQXoEAC-chiamarono_gregorio_cassazione.shtml\&offset $=0$, accessed Dec. 6, 2016 .

107 Wojciech Sitek (ed.) 1996. Mniejszość w warunkach zagrożenia. 
The following two citations illustrate the situation of the Polish inhabitants of Greater Poland under Prussian (and since 1871 - German) rule in the latter half of the $19^{\text {th }}$ century:

My father was born and raised in a village in Greater Poland [...]. It was before Poland regained independence. He was baptized Szczepan, but when the child had to be officially registered, it turned out that no German clerk would be able to pronounce the name. So he was entered in the register as Stephen and he remained Stefan till the end of his life ${ }^{108}$.

[The war against Germanisation] was also waged in registry offices, which demanded that the names of newborns be registered in German. Thus Polish boys by the name of Franek, Michał or Andrzej were officially entered in registers as Franz, Michael and Andreas. In order to avoid such practices, parents did their best to bestow on their children names which were either Slavic or Polish with no German equivalents, such as Grażyna, Aldona ${ }^{109}$, Zdzisław, Mściwoj; those in turn were subsequently challenged on the pretext that they do not figure in a Catholic calendar ${ }^{110}$.

De facto practices of registry clerks may be in contravention of the law. In the pre-war Opole Province,

Pamiętniki Łemków [a minority in danger. The memoirs of the Lemkos]. Wrocław: Wydawnictwo Uniwersytetu Wrocławskiego, p. 99.

108 Bogusław Witek 2008. „Nacjonalista” [short autobiography of B. Witek]. Sekrety ŻARu - Kwartalnik Kulturalny Klubu „ŻAR” nr 1(20). http://www.pzn-mazowsze.org.pl/kultura/klub_zar/sekret20/sek_20.html \#laurproza, accessed Dec. 3, 2011.

${ }^{109}$ The author of these memoirs is mistaken as to the origin of those two names. In fact Grażyna (in Lithuanian Gražina) was coined in 1823 by the Polish poet Adam Mickiewicz on the basis of the Lithuanian appellative gražus 'beautiful', and to this day this name is more popular in Poland than in Lithuania. The etymology of Aldona is unclear. The name, borne by a daughter of the Lithuanian Grand Duke Gediminas (c. 1275-1341), might have stemmed from Old Prussian or Ruthenian (cf. Fros \& Sowa 2002: 255, 80).

110 Zygmunt Karpiński 1971. O Wielkopolsce, złocie $i$ dalekich podróżach [memoirs of a Polish pre-war bank manager, pertaining to the years 1860-1960]. Warszawa: PIW, p. 120. 
which belonged to Germany, Poles were a recognised minority, to whom the regulations of the Upper Silesian Convention applied. According to this convention (also known as the Geneva Convention), signed on May 15, 1922 under the auspices of the League of Nations, Poles as a minority were guaranteed the freedom of association, as well as the right to use Polish, to organise Polish schools and to publish Polish newspapers ${ }^{111}$. The right to use Polish comprised also the right to choose a Polish name for the child. However, administrative practice was different:

Practice usually did not agree with the theory. When parents arrived in the Registry to register a newborn, they were shown a German list of given names and strongly urged to choose one of them. There were cases of children who remained nameless for months until their fathers litigated the issue and were granted, on the basis of the Upper Silesian Convention, the right to a free choice of name.

However, fathers and mothers were mostly not so determined. A peasant or a labourer seldom had the courage to oppose the laconic statement of a clerk: 'It's not on the list - pick a name that's in use in Germany.' If they were reluctant, the clerk would persuade them that 'it would be easier for the kid to finish school, that the kid would be accepted as a bricklayer's or locksmith's apprentice, or even into secondary school, that a Stanisław or a Tadeusz ${ }^{112}$ would not easily find work or inherit land, that the parents of a child with a foreign-sounding name would have problems obtaining a child benefit... anyway, we're living in the state of Germany and as citizens we have to respect official recommendations.'

To exert that influence, authorities resorted to using - apart from registry clerks - also German teachers, tax collectors,

111 These freedoms remained in force until July 15, 1937 (cf. Beata Łabutin "Opole w przeddzień wybuchu II wojny światowej" [Opole shortly before the outbreak of the Second World - an interview with historian Adriana Dawid of Opole University]. Gazeta Wyborcza Aug. 31, 2009. http://opole.gazeta.pl/opole/1,35086,6986225,Opole_w_przeddzien_wybuch u_II_wojny_swiatowej.html, accessed Dec. 10, 2016.

112 Polish names. 
mayors of towns or rural communes, even priests (Osmańczyk 1954: 167-8).

It should be emphasised that despite appearances (and popular myths) to the contrary, the influence of clerks in registry offices and similar state institutions was not always so great. For instance, a commonly held misconception about how names of immigrants were changed upon their entry into the USA is not accurate. There are numerous anecdotes and jokes about how an American immigration clerk at Ellis Island, ignorant of languages other than his own, misunderstood and consequently distorted the names given by immigrants who did not know English. In one such story, the bewildered newcomer to the island is asked the name by an Irish immigration officer and replies in Yiddish: "Sheyn fergessen!" (or, in a different version, in German: "Schon vergessen"), thus earning himself the name Sean Ferguson (cf. Zax 2008). In another story the immigrant, asked the name, just nods and smiles, upon which the clerk records the surname Smiley. What is more, so the story goes, many of these immigrants were illiterate, which prevented them from checking what had been recorded in writing. While it was obviously true that many immigrants could not read or write, in fact they did not need literacy to get their names intact:

Folk myth in America has it that Americanized forms of European family names were created at Ellis Island as a result of linguistic confusion between immigrants and U.S. Immigration officials. This is largely nonsense [...] the majority of family names survived the immigration process there relatively unscathed (Hanks 2003: 141).

The officials at Ellis Island typically did not record what they heard (or misheard) but had at their disposal the ships' manifests ${ }^{113}$ with lists of passengers compiled in the

113 A ship's manifest is a transport document with the names of passengers and the information on their port of embarkation and 
immigrant's homeland. Moreover, the immigration clerks were frequently immigrants themselves, with a working knowledge of European languages - and if deemed necessary, the Ellis Island officials would even summon interpreters of rarer languages (cf. Zax 2008, Powell 2012). How then can name changes in the USA be accounted for? Powell (ibid.) explained:

This is not to say that the surnames of many immigrants were not changed at some point after their arrival in America. Millions of immigrants had their names changed by schoolteachers or clerks who couldn't spell or pronounce the original surname. Many immigrants also voluntarily changed their names, especially upon naturalization, in an attempt to fit better into American culture. Since the documentation of name changes during the U.S. naturalization procedure have only been required since 1906, the original reason for the name change of many earlier immigrants is lost forever. Some families even ended up with different last names since everyone was free to use the name he or she preferred. Half of the children of my Polish immigrant ancestors used the surname 'Toman' while the other half used the more Americanized version 'Thomas' (the family story being that the name change was suggested by nuns at the children's school). The family even appears under different surnames during different census years.

\subsubsection{Schools}

By their very nature, i. e. by virtue of their ability to influence people at an early age, to record personal names in the way they see fit, and to effectively enforce compliance in the degree unattainable in the case of adults, also schools are powerful name-givers. In that capacity they might either act as "transmitters" - i.e. implementers of the policies of state authorities - or they might develop their own policies.

disembarkation, prepared for the immigration authorities. 
Regarding the first possibility, a frequent case is the assimilation of a minority group to the state culture. Here are the recollections of a woman born 1918 in Bochum, Germany, to a couple of Polish economic migrants, who, following Poland's regaining independence, returned to the Polish Pomerania:

I went to primary school in 1927. [...] My name was changed by my teacher. When I introduced myself as Greta, he said that from that moment I was to be called Małgorzata and that's how I was entered in the school register. He did not even talk about it to my parents. For the many years to come I was to be Greta in some documents, and Małgorzata in others. ${ }^{114}$

Her case was an instance of Polonisation that affected a German name. A contrary example of forced Germanisation of Polish names in school comes from Racibórz ${ }^{115}$ :

In 1913 the head of a German school in Racibórz, Hoppe, said to me:

'Wawrzynek, you are a good pupil, it is not becoming that your surname should be so conspicuously Polish. Starting tomorrow, you are going to sign yourself Wawrzinek'.

I didn't say anything to that; returning home after school I asked mother for 50 pfennig, I ran to the Registry and demanded my birth certificate. On the next day I told the headmaster that according to my birth certificate I must be spelled Wawrzynek and I handed him the certificate. He went red in the face with anger and hit me on the bottom with his cane several times, shouting:

'So you are a Pole!' (Osmańczyk 1954: 269)

114 Justyna Błaszczyk et al. (eds.) 2006. Zachować od zapomnienia. Rozmowy o przeszłości z Pomorzanami [conversations with Pomeranians about the past]. Gmina Chełmża: Stow. Homo Homini, p. 32.

${ }^{115}$ A town in Southern Poland, in the Silesian Voivodeship. At the time referred to in the citation it belonged to Germany. It became part of Poland in 1945 . 
A particularly poignant tale of a school-enforced identity and the resulting double self-identification comes from a Silesian writer ${ }^{116}$ :

This story is set in 1927 in Upper Silesia, in a big suburban village that has been within the borders of Poland for five years now, in Rybnik county [...] In the village works a teacher, young and full of enthusiasm [...] She came to exotic Silesia to teach things Polish and the Polish high culture. After all, Silesian children had no high culture of their own, they could breathe the words of either Goethe or Mickiewicz, no other option was available. I'm writing this with regret but without sarcasm, since it's true. On the other side of the border similar Kulturträgerin[nen] ${ }^{117}$ brought their own high culture, from Wrocław or from Berlin, and they were as full of noble enthusiasm $[\ldots]$

One of [the] boys is called Jorg ${ }^{118}$. He's seven, so he was born in the Silesia which was at the time in a state of flux, of fire, the Silesia that was everybody's and nobody's at the same time. In his birth certificate his name has been recorded as Georg and in the baptismal register he is Jerzy - or the other way round, I don't know [...] One day the teacher asks him his name. He replies that his name is Jorg. She asks again and gets once again the same answer. She has him stretch out his hands and hits him on the hands with a ruler, asking again. The boy doesn't know what he's been punished for, though the punishment itself does not seem to him in any way unusual. He replies again that he's Jorg. The teacher hits him again. I don't want this to sound like martyrdom [...] The teacher was not a sadist who might relish the pain of a child. Until the end of her life she was respected $[\ldots]$ and the respect resulted from her personal merits but also from the fact that in Silesia teachers have always been powerful figures, just like priests and clerks; their cultural foreignness

116 Szczepan Twardoch „Chłopiec, który się rozdwoił” [the boy that got split in two]. Polityka 43 (2880), Oct. 24-28, 2012, p. 77.

${ }^{117}$ A Kulturträger is someone who transmits culture; here this term is used figuratively and ironically in the sense of a forcible assimilator.

118 The name Jorg is a Silesian form of the German Georg and of its Polish equivalent Jerzy (dim. Jurek). 
was natural - in our situation a previous cultural foreignness being simply replaced by a new one [...]

I don't know if at last [the boy] guesses or if someone whispers the answer, anyway he finally says he's called Jurek, though he's never thought of himself in that way and nobody has ever addressed him so. 'Now you'll know', the teacher says [...]"

I could write about this in terms of symbolic violence or of the spirit of history, I could also treat it as a contribution to the anatomy of twentieth-century nationalisms, but all these words, true in the context, would only distract us from what is the most important: from a boy who got split in two.

Schools, especially state schools, frequently act hand in hand with state authorities in naming and renaming campaigns. A case in point might be the enforced Bulgarization of Muslim names in Bulgaria in the 1970s. An informant, a school pupil at the time, recollected: "We stayed at school until five in the afternoon, and finally, they would come with the list and would tell you what your name would be" (Krăsteva-Blagoeva 2006: 71).

In Israel it has been widespread and accepted practice for many years to bestow new Hebrew names on immigrants, but Israeli schools in particular are known to have been mediating in this process, often without any regard for the wishes of the renamed person. Stahl (cf. 1994: 280ff) gives numerous examples of renamings. The teacher typically did not even ask the children or their parents for their opinion but simply announced the new name. In one described case the teacher rejected a pupil's name as likely to expose her to ridicule because of phonetic similarity to the word meaning 'stinking', only to learn later from the girl's irate father that the name in fact appears in the Pentateuch ${ }^{119}$ and is thus a perfectly acceptable Hebrew name. Somewhat similar situations take place even today. In Israeli kindergartens the language of instruction is Hebrew - consequently, Palestinian children,

119 The Torah (the first five books of the Jewish Bible, comprising Genesis, Exodus, Leviticus, Numbers and Deuteronomy). 
similarly to immigrants' children, are addressed by Hebrew names (cf. Spolsky and Shohamy 1999: 123).

In South Africa there even evolved what came to be known as a "school name": a European name given to children by teachers when children went to mission schools. Its existence for most of the $20^{\text {th }}$ century gave rise to a double (or even multiple) name system: an African (later also European) name given at birth, the other - European - for school use (cf. Herbert 1997).

Also China has a tradition of the so-called "school name" ( $s h \bar{u}$ ming), in the past bestowed on male children when they entered school (cf. Creamer 1995: 910). "When a boy first goes to school, his milk-name is practically replaced by a shu ming or ch 'eh ming, 'book-name', also called hioh ming, 'study-name or school-name', which the teacher selects"'120. Thus teachers were frequently posited in the role of naming decision-makers: "All my three grandchildren's school names were given by school teacher," an elderly informant told the researcher in 2011 in Gansu (north-west China) ${ }^{121}$.

Educational institutions can also influence names within the same ethnic circle - not only minority names. The first president of Turkey, Kemal Atatürk, was in fact born Mustafa; he owed the name Kemal ('perfection') to his math teacher to distinguish him - accounts vary - either from the teacher himself or from another student by the same name.

A name change effected by a school may serve to ease identification where many pupils bear the same name. A Slavicist from Pennsylvania who embarked on searching for his family roots recollected:

${ }^{120}$ J[an] J[akob] M[aria] de Groot 1910. The Religious System of China. Vol. VI. Un document produit en version numérique 2007 à Chicoutimi, Québec. http://classiques.uqac.ca/classiques/groot_jjm_de/religious_system_of _china/volume_6/groot_religious6.pdf, accessed Dec. 3, 2016, p. 216.

121 Hong Yanbi 2013. Between sacred and secular knowledge: rationalities in education of a Muslim village in Northwest China. Ph.D. Thesis. The University of Hong Kong. http://hub.hku.hk/bitstream/10722 /188261/1/FullText.pdf?accept=1, accessed Dec. 3, 2016, p. 108. 
My Stockholm correspondent, Bertil Magner, explained his surname as follows: "My father, Olaf, and his two brothers, Edward and Nils, were born around 1900 with the family name Olsson. This, as you know, is a very common name in Sweden. About 1910 the boys were asked in school to change their family name. They considered many suggestions from the Svensk namnbok ${ }^{122}$ and chose their name from this list. They wanted an internationally suited name and also the connection to the name Magnus. When they received the name, it was also given to a second family (by mistake, I understand) but taken from the same list of suggestions. Other families in Stockholm have the name Magnér but this is not in any way connected in origin or by family connections." It may seem strange to an American to picture a schoolroom scene with the teacher and pupils seriously creating new family names but it is a fact that, because of the plethora of -son names (Eriksson, Andersson, Johansson and the like), name-changing has been encouraged in Sweden. ${ }^{123}$

\subsubsection{The army}

Similarly to the school, also the army is a potential agent in the process of personal name planning. In the United States during the Second World War, enlisted Jewish refugees from Europe were officially encouraged to change their surnames as a means of protection. Should a soldier with a Jewishsounding name be captured by Germans, his fate would be far worse than in the case of a prisoner of war with an AngloSaxon name. Returning to the original name after the war, however, turned out to be disappointingly complicated (cf. Maass 1958: 160)

Nevertheless, the best example of army-induced naming are the so-called soldier names in Sweden. In the Swedish army and navy, since the end of the $17^{\text {th }}$ century (although the first surnames in later years known as 'soldiers' surnames were

${ }^{122}$ Swedish book of names.

123 Thomas F. Magner 1999. "The Origin of the Magner Surname." http://www.magner.org/surname.htm, accessed Dec. 3, 2016. 
recorded as early as 1541 in Stockholm), enlisted soldiers received surnames which had to be unique in a particular company. Many of those names were monosyllabic (so as to sound well during the roll call) and often conveyed military or nautical connotations: Granat 'grenade', Strid 'battle', Sköld 'shield', Svärd 'sword', Modig 'brave', Ankare 'anchor', Segel 'sail', Köl 'keel'. In his novel Raskens ('The Rasks') Vilhelm Moberg ${ }^{124}$ describes such an act of naming. The hero of the novel, a Swedish peasant Gustav Karlsson, on joining the army shows his fighting skills, breaking a bone in the thigh of a blacksmith; in this way he earns himself the soldier name Rask ('swift, brisk, quick, fast'), later to become his family name.

Some of the Swedish soldier names came from the world of nature: Örn 'eagle', Ros 'rose', Räv 'fox' (perhaps referring to hair colour), or were adjectives relating to soldiers' traits: Frisk 'healthy', Trätdryg 'quarrelsome', Klein 'small'. The surnames connected with military qualities and with plants or animals seem to have been the most popular. However, there were also other types of surnames, some similar to traditional 'civilian' surnames (Bergman, Akerlund), some fairly unusual (Adjö 'good-bye'125, Alltså 'therefore', Körpå 'drive on!', Venus, Apollo, Bonjour, Pardon).

A new soldier who in a company replaced a discharged or killed one might 'inherit' his predecessor's soldier name. However, it was also possible for a soldier to change his name, if he so wished, and it would seem from the preserved records that the permission was often granted to change the name 'inherited' from the predecessor. Though after the period of their service the soldiers reverted to their original surnames, in several cases (especially in the $19^{\text {th }}$ century) the new surnames remained for life, replacing the previously used patronymic. Today it is hard to establish with certainty which and how

124 Swedish writer and historian (1898-1973).

125 As Wahlberg (1990) pointed out, this may have been the name of the last soldier at the roll-call (there is also the name Först 'first'). 
many soldier names actually gave rise to present-day Swedish surnames. However, on the list of over a hundred most popular contemporary Swedish surnames, all except for those ending in -son, which originated as patronymics, can also be found on the soldiers' lists.

Interestingly, the Swedish example seems to have been followed to some extent in the middle of the $19^{\text {th }}$ century by the Finns of the battalion of Turku, who at the time assumed similarly motivated surnames in the Finnish language ${ }^{126}$.

\subsubsection{The workplace}

The power of the working environment is not to be underestimated when it comes to making decisions about names. The benefits of a name which would be easier for the boss or colleagues to pronounce are and have always been appreciated the world over. For instance, when in the second half of the $19^{\text {th }}$ century innumerable Polish workers from Schlesien (Silesia), East Prussia and Posen (Poznań) migrated to the Ruhr District in search of work, they frequently wished to enhance their job prospects by assuming German-sounding names:

Viele Polen nutzen nach 1904 die Möglichkeit des Namensänderungsgesetzes. Seit der Germanisierungswahn ihnen in ihrer Heimat den Grunderwerb extrem erschwert, siedeln sich viele im Ruhrgebiet an und bleiben. Mit deutschen Namen wollen Sie sich und ihren Kindern Diskriminierungen ersparen und ähnliche Chancen wie die Einheimischen haben ${ }^{127}$.

Not all employer-induced name changes were voluntary. Stahl (cf. 1994: 281) mentioned an Israeli housewife who

${ }^{126}$ Per Clemensson [\&] Kjell Andersson 2004. Your Swedish Roots: A Step by Step Handbook. Provo, UT: Ancestry Publishing, p. 44. See also Wahlberg 1990.

127 1880. Polen im Ruhrgebiet. http://www.deutsche-und-polen.de/ /ereignisse/frames/content_lang_jsp/key=ruhrpolen_1880.html, accessed Dec. 3, 2016. 
employed as domestic help a girl from Yemen and changed her name from the Arabic Rumiyah (meaning 'the Roman') to the Biblical Hebrew Moriyah, evocative of the Temple Mount in Jerusalem. A similar story comes from the novella Tefarik by Krikor Zohrab ${ }^{128}$ :

We called her Miriam. My mother did not approve of any other name for a servant; in fact, though, her name was Ashkhen. This foreign name in a foreign house became for her, as it were, a break with the past, the renouncing of her own personality. Even her name is not accepted! Strangers blithely and indifferently deprive the servant of her own self, impose on her new expressions in conversation, a new style of clothes, force her to give up all her rural ways and habits.

It is not easy to come to terms with such humiliation. Ashkhen, the favourite name among the youth of her home village, did not find favour with the inhabitants of Instanbul. Her movements, her dresses endeared Ashkhen to her young compatriots, while here she had to renounce everything that used to be her feminine charm. ${ }^{129}$

This literary account of the plight of an Armenian domestic in Istanbul offers some insight into the situation of a person deprived of identity. Name is at the core of one's identity; name is identity. Forceful change of one's own name equals trauma comparable to dispossession. Where even the name is taken from one, there is no more homeland, the last enclave of one's identity is gone.

\subsubsection{The influence of name calendars and name books}

The role of such publications consists in aiding parents in their choice of name for the newborn child. In today's Europe

${ }^{128}$ Also Latinised as Grigor Zohrap (Qphqnp Qnhpuu). Armenian writer, politician and lawyer (1861-1915).

${ }^{129}$ Nowele ormiańskie [Armenian novellas] 1950. Warszawa: Książka i Wiedza. Translation into English from the Polish translation - JBW. 
name calendars and similar publications are usually secular; seldom so in the past. Calendars were once meant to enlighten the laymen about the range of available names to bestow on children, as well as to advise them of the so-called dies natalis $^{130}$ on which to commemorate the patron saint. Fros \& Sowa (cf. 2002: 51-63) discussed in detail the calendars of saints in the history of Christianity, their origin and development, as well as the Polish calendars of saints. It seems that in Christianity the first such lists of the names of saints date as far back as the $4^{\text {th }}$ century. Due to the additions of names of the newly canonized saints, with time such calendars grew bigger and bigger, with for instance as many as over two hundred saints' days at the end of the $12^{\text {th }}$ century, until around the $15^{\text {th }}$ century the burning need for the reduction of too many calendar commemorations was acutely felt. It was not until the 1960s, however, that visible changes were introduced, which resulted in 170 commemorations of saints in the liturgical year. It should be nevertheless borne in mind that the actual number of names in use is not as high since some names are repeated. Suffice it to say that Catholicism recognises several hundred saints by the name of John ${ }^{131}$, although, naturally, not all of them were included in the 1960 s calendar. Moreover, more recent canonizations and beatifications hardly ever add new names to the Christian stock, as even Asian or African saints are typically known by traditional Christian rather than indigenous names: among about 140 Japanese saints, there is not even one Japanese given name (the given names of Japanese saints include Michael, John, Anthony, Louis, Mary, Thomas, etc. $)^{132}$.

${ }^{130}$ Literally 'the day of birth' - in Roman and Orthodox Christianity the day of the death of a saint, understood as the day when the saint was born to a new, eternal life in heaven. In Catholic countries this date became the nameday. 2016.

${ }^{131}$ Cf. http://www.catholic.org/search/saints/?q=john, accessed Dec. 3,

${ }^{132}$ Cf. http://www.catholic.org/saints/japanese.php, accessed Dec. 3, 2016. 
As could be expected, calendars do not constitute such a powerful tool for name policy as lists of allowed names do. Yet, given favourable conditions, their impact can still be quite strong. As Superanskaja (cf. 1995: 815) pointed out, from 1930 until the 1960s no calendars with names had been published in the Soviet Union. Consequently, over that period the number of given names in use dropped significantly. In the 1950s just three female names - Yelena (Елена), Irina (Ирина) and Tatyana (Татяна) - were borne by 35 per cent of the female population, and three male names - Sergey (Сергей), Alexandr (Александр) and Andrey (Андрей) - by the same percentage of males.

Regarding Polish calendars, until 1820s most of them included chiefly Judeo-Christian names. If any Slavic names were to be found, they were mostly the names of the few wellestablished Polish saints, such as Stanisław or Wojciech. In 1827, however, in keeping with the national revivalist spirit of the time, a revolutionary saints' calendar was submitted for publication in Lwów ${ }^{133}$. Its title was Nowy kalendarzyk czyli Światnik Lwowski na rok przestępny 1828 [a new calendar, or holiday book of Lwów for the leap year 1828] and it was compiled by Franciszek Siarczyński, a Catholic priest and a zealous propagator of purifying the Polish language of foreign words. He advocated translating the well-known names of saints into Polish and did so, proposing such replacements as Żegota, Spytek, Bieniasz, Lassota, Czesna, Olech, Gryfina, Pałachna, Wicien, Szczęsny, Bożenna, Dobrogost for the names Ignatius, Rogatianus, Benedictus, Sylwester, Honorata, Alexander, Agrippina, Pelagia, Vitalis, Felix, Beatrix and Bonaventura respectively (cf. Bruchnalski 1926). The book did not gain church acceptance and therefore was ultimately never published, but the very idea at the time constituted an unprecedented effort to revert the 'naming shift' from native to foreign given names, the shift which had started

${ }^{133}$ Today in Ukraine. Ukrainian name Lviv, German Lemberg. 
many centuries earlier and was accelerated by the Council of Trent in the $16^{\text {th }}$ century.

About the same time (1828) another calendar of Slavic names worthy of mention was published. Its author was Tadeusz (self-renamed Władybóg) Wojewódzki. As Taszycki 1927 cogently showed, Wojewódzki's work was full of mistakes and inaccuracies. Some names (e.g. Błażej, Janusz, Jerzy, Sebastian) were not Slavic at all, but entered the Polish onomasticon from Latin, ancient Greek or Hebrew, whereas some others were German or Lithuanian. The most noteworthy about this calendar, however, was its use by the Nazis over a century later. In 1940 a list was prepared on the basis of Wojewódzki's work that included names considered by the Nazi occupants as sufficiently Slavic to be given to Polish children of Wielkopolska and the region of Łódź ${ }^{134}$, to the exclusion of traditional Christian names, reserved for German children only (cf. Sarnowska-Giefing 2003, Umińska-Tytoń 1988).

It should be emphasised that to a certain extent telephone directories, once introduced, occasionally served the same purpose for surnames as calendars did for given names. In his article on name-changing among Jewish immigrants to the USA in 1930s, Maass (cf. 1958: 151) gave examples of name changes inspired in that way.

Today name dictionaries are of two distinct types: prescriptive (the more common kind) and descriptive, such as for instance Rymut 1995. It seems that while the former type by definition serves to influence the naming choices, the latter type might influence the policymakers themselves, since descriptive dictionaries may provide feedback, showing how remote the policies sometimes are from the actual practice. A similar role was played in Lithuania by the data revealed in 2012 by the European Foundation of Human Rights. It suddenly became clear that names that violate the principles

134 These two regions jointly made up the Nazi region of Warthegau. 
of name Lithuanisation as set by the Lithuanian state are markedly more frequent than could be expected ${ }^{135}$.

\subsection{The targets of name policies}

Name policies may affect all citizens or only particular sections of the population (e.g. along ethnic or religious lines). Specific policies on names may also be targeted at immigrants. Nevertheless, it may also be the case that, conversely, foreigners and/or minority members may be the only ones exempt from specific name policies that are otherwise binding for the (national, ethnic) majority. For example the rules regarding the choice of given names in Poland are applicable only to Polish citizens of Polish nationality (cf. Zalecenia 1996). A similar situation exists in Denmark, where state restrictions on given names for newborn babies only apply if at least one of the parents is Danish ${ }^{136}$.

An American visitor to France recounted his ordeal of trying in vain to register his newborn son there under the Greek name Calix:

A couple of minutes later [the registry clerk] arrived with her superior, who explained that our choice of names would be limited to the official government list.

Once again I protested. My impatience betrayed even more than usual my foreign accent, upon which the official asked me if I weren't a foreigner.

Responding in the affirmative, I learned that I, as a foreigner, had a right to call my child anything I wanted to. ${ }^{137}$ [Emphasis added.]

${ }^{135}$ http://www.efhr.eu/2012/12/28/w-na-litwie-jednak-zgodne-z-prawem/, accessed Dec. 5, 2016.

${ }^{136}$ Liza Alvarez 2004. "Jens and Vita, but Molli? Danes Favor Common Names." The New York Times International. Oct. 8. http://www.nytimes.com /2004/10/08/international/europe/08names.html, accessed Dec. 3, 2016.

${ }^{137}$ Marc Mailloux 2006. God Still Loves the French. Adventures of a Missionary to France. Maitland: Xulon Press, p. 106. 
Also in today's Hungary children from minorities, if they are not given a Hungarian name, are named on the basis of specially drawn minority name lists. However, before 2004, as Raátz noted,

there were no laws in force restricting the registration of ethnic names requested by the members of the officially recognised thirteen ethnic minorities. In other words, if somebody considered himself to be a member of an ethnic minority, he was free to register any kind of first name [i.e. not necessarily an ethnic one] without applying restricting spelling rules (2008: 10, emphasis added).

It would appear that a kind of legal vacuum rather than a consciously adopted policy is responsible for the abovementioned phenomena. In certain cases - such as the two examples above (Hungary before 2004 and France) - justified doubts as to the nature of that kind of minority/foreign culture protection may emerge. The problems are frequently resolved in registry practice by referring to foreign name books; in fact, laws of some states even contain the provision that in order to be accepted (also as a name for a majority child), the questionable name must be in actual use in some country.

However, there still remains the question whether a given name should be accepted as a name for a minority child on condition that it is an attested minority name (as it is the case in the Hungary of today), or solely by virtue of the fact that it is not a majority name (as the practice used to be in Hungary before 2004). The following example from Russia shows that this question is not only academic.

In 2006 the opinion of the Advisory Committee on the implementation of the FCNM in the Russian Federation voiced the concern that "certain Bureaus of Civil Status Acts have refused to accept names chosen by Roma parents for their children on the grounds that they are 'unusual', and are 
forced to adopt traditional Russian equivalents." ${ }^{38}$ In fact the given names used by the Roma are not homogeneous and it is therefore not clear what is meant by 'unusual' in the cited opinion. On the one hand, the names of the Roma include names from the Romani language, such as Kalo ('black'), Cikňi ('little'), Šuki ('slender'), Papin ('silly'), Pušomori ('little flea') ${ }^{139}$. On the other hand, names given by the contemporary Roma to their children in many European countries come from broadly taken pop-culture, including soap operas and TV commercials: Sandokan, Angelika, James Bond, Izaura, Ricardo, Tarzan, Winetu, Totuś ${ }^{140}$. In a similar vein, in Great Britain some recently recorded given names of the Roma included: Belcher, Dangerfield, Neptune (for men), and Britannia, Cinderella, Freedom, Ocean, Reservoir, Unity (for women) ${ }^{141}$. Rumanian examples of similar naming patterns include Obama, Beckham, Elvis, Pamela (after P. Anderson), Bruzli (from Bruce Lee), Superman, Zor(r)o, Romario, Ambasador, Cosmos, Semafor, Televizor, Paracetamol, Nutella, Palmoliviu (cf. Felecan 2012: 138 and 140, who makes a distinction between conventional and unconventional naming of the Roma). While protecting original Romani names would seem desirable (just as in the case of any cultural heritage), it is doubtful if such protection should be extended onto cases where minority names differ from majority ones merely in their eccentricity.


TMContent?documentId=090000168008c2bd, accessed Dec. 3, 2016.

${ }^{139}$ Milena Hübschmannová "Names of Roma", Rombase January 2003. http://ling.uni-graz.at/ rombase/cgi-bin/art.cgi?src=data/ethn/topics/familynames.en.xml, accessed Dec. 3, 2016.

${ }^{140}$ Ibid.; cf. also: Elżbieta Jakimik "Identyfikacja osobowa Romów i Sinti w Polsce" [personal identification of the Roma and Sinti in Poland]. In: Romowie 2009: między wędrówka a edukacją. 2009. Barbara Weigl (ed.). Warszawa: Wydawnictwo Szkoły Wyższej Psychologii Społecznej "Academica". The name Totuś is derived from a brand of toothpaste, whose name included the component Total.

${ }^{141}$ Louise Broadway "From Where I Stand Now." Last updated August 2003. http://www.bbc.co.uk/devon/community_life/features/romany.shtml, accessed Dec. 3, 2016. 
Another type of policies seen from the point of view of those affected by them are 'retroactive' policies, understood here as policies that influence people - the famous or just ordinary citizens - who have long been dead. In consequence, their names are changed in documents, in the press, on tombstones, in street names, etc. For example, massive renaming campaigns in Bulgaria at the time of Todor Zhivkov (1980s) involved erasing Turkish names even from tombstones. Similarly, in Greece the tombstone of the grandfather of Nikola Gruevski, a Macedonian politician who in 2006 became Prime Minister of Macedonia, was replaced by the Greek government

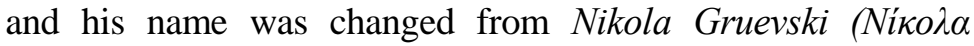


commemorative plaques or historical books devoted to eminent figures can become the tools of such policies. For example, since it is standard practice in Lithuania to Lithuanise all foreign and minority language names, this includes also Polish names of historical figures, who did not bear such names while living (e.g. Adam Mickiewicz and Emilia Plater, who signed herself Emilia Platerówna, become in the Lithuanian history books and in the press Adomas Mickevicius and Emilija Pliaterytè). Klemperer gave several instances of such name changes or even deletions in the Third Reich:

Every possible attempt was made to protect German national comrades (Volksgenossen) entirely from names of this kind [i.e. names from the Old Testament, which were equated by Nazis with Jewish names]. In September 1940 I saw a church advertisement on poster columns: 'A Hero of the People: Oratorio by Handel ${ }^{143}$. Below was printed in timorously small type and in brackets 'Judas Makkabaeus; new edition.' At around this time I read a historico-cultural novel translated from English: The Chronicle of Aaron Kane. Rütting \& Loening, the

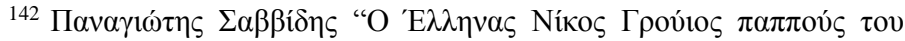
Гкрои́єфбкі" [the Greek Nikos Grouios, grandfather of Gruevski]. July 17, 2008. http://www.zougla.gr/news.php?id=4828, accessed Dec. 3, 2016.

${ }^{143}$ So in the original; correct spelling: Händel. 
same publishing house that had produced the great Beaumarchais biography by the Viennese Jew Anton Bettelheim! - the publisher apologized on the first page for the fact that the biblical names of the characters stemmed from the puritanism current at that particular time and in that particular country, for which reason it was not possible to change them. Another English novel - I can't remember the author any more $^{144}$ - bore the German title Geliebte Söhne (Beloved Sons). The original title, printed inside in tiny letters, was $O$ Absalom! In the Physics Department the name Einstein had to be hushed up and the 'Hertz' unit of frequency also not be referred by its Jewish name $[\ldots]$

Was Joseph too Catholic a name, or did they simply want to make space for a Romantic painter, one who was thus more emphatically German? Be it as it may, the Josephstraße in Dresden became the Caspar-David-Friedrich-Straße, despite the fact that it led to a not insignificant postal conundrum; when we lived in a Jews' House in this street we repeatedly received letters addressed to 'Friedrichstraße c/o Mr Caspar David' (2006: 72-75).

To conclude, sometimes laws and/or de facto practices in theory targeted at the population at large affect only a particular ethnic / religious / linguistic minority. For instance, at the end of the $18^{\text {th }}$ and in the $19^{\text {th }}$ centuries the laws were passed in many European states which introduced compulsory surnames for all the population. In theory they concerned everybody in an equal measure; in fact, however, the regulations affected mostly the Jewish population as that was usually the only group which at the time did not yet have hereditary surnames (family names). A similar outcome of a policy could be observed in Fascist-governed Italy of the year 1927:

In theory, all deformed names - German, Slovene, Hungarian, Croat, Serb, Turkish - fell equally readily to the fascist pen.

144 The novel was in fact written by a Welsh novelist and journalist Howard Spring (1889-1965). 
But, given the preponderance of ethnic Slovenes and Croats in the region [of Trieste] and the fascist insistence that clerks serving in the Habsburg lands had deliberately Slavicized names that were originally Italian, Slavic names commanded the commission's attention (Hametz 2012: 87).

\subsection{What is planned?}

Personal names comprise given names, also called in English first names, Christian names or forenames; surnames, also called last names or family names (though these terms are not necessarily synonymous); patronyms (also called patronymics ${ }^{145}$ ); nicknames (sometimes difficult to distinguish from bynames - for more details cf. e.g. Van Langendonck 2007: 192-4 and N. Felecan 2014) and on the distinction between the Polish equivalents of these terms, i.e. przezwiska and przydomki respectively - Wicherkiewicz 1997: 310) with a similar (sub-)category of Internet chat names; pseudonyms; pet names; noms de guerre; stage names; finally pen names, also called noms de plume. Less common are matronyms / metronyms, i.e. surnames derived from the mother's given name. One more example from outside the European and European-influenced countries are teknonyms in the Arab countries (Crystal 1997: 112), that is names for adults derived from the names of their children. This list would be even longer if those cultures from outside Europe were to be included in which a name is transient and illustrative of one stage in life only (then school names might be included, for instance). Of all these, in Europe and those countries from outside Europe whose naming systems have been influenced by European conventions, only given names and surnames are typically and commonly subjects of official regulation.

There are exceptions, however. On the one hand, in Russia and the areas influenced by Russian culture - such as

145 Some authors use the term 'patronymic' in the sense of 'surname' (e.g. Maass 1958: 139; this use can also be found in state-specific opinions of the Advisory Committee on the FCNM). 
Bulgaria or many of the former republics of the USSR patronyms are the third element of a personal name. How the existence of a patronym or its lack means much more than merely a means of identification is evidenced by the example of Ukraine, where, following the regaining of independence from the USSR in 1991, Ukrainians programmatically rejected their Russian-style patronyms, treating this rejection as a political act ${ }^{146}$. On the other hand, there is Iceland as the only European country with a system of two-part names in which the function of surnames is performed by non-inheritable patronyms. However, by virtue of their very nature (i.e. their dependence on the name of the father), patronyms are not so easily controlled in any way other than their conscious introduction into a system that traditionally did not contain them or, conversely, their removal from a system that traditionally contained them. Other above-mentioned types of name (nicknames, pseudonyms, pet names, stage and pen names) are perfectly able of exclusively functioning if not exactly in private life, then at least in the officialdom-free zone ${ }^{147}$.

There remains a separate category of personal name: the middle name (Ashley 1996 comprehensively discusses the concept, including the difference between second names and middle names). Middle names are quite popular in the USA and Canada. Since in these countries in general there is hardly any explicit, codified personal name policy, middle names in particular hardly deserve a mention as objects of de jure

146 Tomasz Wicherkiewicz, personal communication.

${ }^{147}$ An interesting exception comes from Bulgaria, where, "until the beginning of the 20th century, forms issued by the central and local community administrations had sometimes a 'nickname' entry column. Nicknames were in general use and institutionally accepted during the past centuries. A nickname was attributed by the community to a clan, family, or an individual. Its substance did not follow any particular rule. It could be related with certain skills, with one's appearance, peculiar characteristics, or occupation. Today nickname usage is mainly limited to informal communication." ("Traditional and Modern Names Among the Bulgarian Population." 2011. Wonderland Bulgaria. Last updated Feb. 6. http://old .omda.bg/engl/narod/BULG_IME_en.htm, accessed Dec. 3, 2016.) 
policies. The only exception might be the requirement of some institutions, such as the American army, to include middle initials in documents. The failure to do so results in the default insertion of the acronyms $N M I$ (No Middle Initial) or $N M N$ (No Middle Name), as in Henry NMI Smith.

Contrary to Ashley's claims, the middle name as such, i.e. not just another given name, functions in some other European nation-states, e.g. in Iceland, where it has recently fulfilled to some extent the role of a surname:

The millinöfn [middle names] which have been registered since this law [of 1996] took effect are generally similar to the fixed surnames already in existence in Iceland [...] The indeclinable, gender-neutral family name may have been readmitted by the back door" (Willson 2002: 150).

The middle name is also known in Sweden, where it functions as "more of a secondary surname than a given name" (Dacey-Fondelius 2007). It goes by the term mellannamn, as used in the Swedish Name Law of 1982.

The category of middle names in English-speaking countries is somewhat confusing. Middle names function there either as second given names or as surnames, therefore their inclusion in the present analysis as a separate third category does not seem necessary. Still, a note on the causes of potential confusion is in order at this point. As an example the name Lloyd will be taken, which in the English-speaking world can function as both a given name (cf. Lloyd Bridges, American actor) and a surname (cf. Harold Clayton Lloyd, American silent film actor). There lived or still live a number of famous people with the middle name Lloyd. Of these, four shall be considered here:

- $\quad$ Andrew Lloyd Webber, British composer;

- David Lloyd George, British politician;

- $\quad$ Alan Lloyd Hodgkin, British scientist and Nobel prize winner;

- Frank Lloyd Wright, American architect. 
Though all these names seem deceptively similar, the middle name Lloyd functions as part of the surname for David Lloyd George and for Andrew Lloyd Webber, whereas in the case of Alan Lloyd Hodgkin and Harold Clayton Lloyd it is in fact the second given name. The situation is the most complicated in the case of Frank Lloyd Wright, who was actually born Frank Lincoln Wright. His parents were William Carey Wright and Anna Lloyd Jones. When Frank was a teenager, as a sign of respect to his mother's family, the Lloyd Joneses, he changed his middle name to Frank Lloyd Wright ${ }^{148}$. However, for him the middle name Lloyd functioned as the second given name. Consequently, in an encyclopaedia his name is listed under the letter $W$, not $L$. The names of the above-mentioned people would thus be ordered as follows:

- Hodgkin, Alan Lloyd;

- Lloyd George, David;

- Lloyd Webber, Andrew;

- Wright, Frank Lloyd.

\subsection{Motivation and objectives: name-related versus non-name-related policies}

Regarding the objectives of a policy, Cooper (cf. 1989: 98) made a distinction between overt, language-related as opposed to latent, non-language-related behaviours of policy agents (among which he identified the satisfaction of interests). In a similar fashion, some policies on names may have objectives that are not related to names as such, but serve other purposes. For instance, the official motivation behind the name rePolonisation law of November 10, 1945 in Poland emphasized a break with the pre-war tradition and was a reflection of the new social policy:

148 Meryle Secrest 1998. Frank Lloyd Wright: A Biography. Chicago London: The University of Chicago Press, p. 79. 
Our assessment of the importance of the surname has in the present system changed considerably. The surname is a means of citizen identification, and not a proof of ancestry or a symbol of family ties. In 1919, when the previous law was passed, the old traditions, still lagging behind, treated the surname as the property of the family that bore it - as a hereditary trait indicating better or worse ancestry, hence gentry surnames, peasant surnames, bourgeoisie surnames, Jewish surnames. That is how surname protection originated, as well as the right to effective objection (Banach 1946).

Naturally, every conceivable name policy may bring about the desired result (represented in the table below as number 1), or it may inadvertently lead to completely different and unexpected results (number 2). Conversely, a different (unrelated to names) policy may nevertheless have an effect on names - on their use, distribution, number etc. (number 3). Obviously, as the fourth logically possible outcome, there may also exist a policy which is both unrelated to names and has an effect likewise unrelated to names - but this option is of no interest here.

\begin{tabular}{|l|l|c|c|}
\cline { 3 - 4 } \multicolumn{2}{c|}{} & \multicolumn{2}{c|}{ Policy adopted } \\
\cline { 3 - 4 } \multicolumn{2}{c|}{} & Name-related & $\begin{array}{c}\text { Other (non name- } \\
\text { related) }\end{array}$ \\
\hline \multirow{3}{*}{ Result } & Name-related & 1 & 3 \\
\cline { 2 - 4 } & Other /side effect & 2 & \\
\hline
\end{tabular}

In fact, most of the policies mentioned in the present work belong - as regards their effects - to category 1 in the table, i.e. they bring about the expected result. Nonetheless, there are also interesting cases which belong to categories 2 and 3. For example, in medieval times in the Orthodox church in Russia, monks used to rewrite the church books, adding names of new martyrs. These names gradually found their way into lists of names used for baptising children, so that while calendars in 
the $11^{\text {th }}-13^{\text {th }}$ century contained approximately 400 names, today they include as many as about 1150 names (cf. Superanskaja 1995: 814). Thus a religious policy had inadvertently a considerable effect on names (category 3 ).

What is more, a name policy never exists in a social, political or cultural vacuum and seldom, if ever, is not accompanied by any other, related policy. In particular, name policies tend to be spin-offs of more comprehensive language policies, and the latter - of even more-encompassing national policies. A case in point may be Breton given names: when they were forbidden in France, it was just an aspect of a larger policy of eradicating regional languages from France that originated at the time of the French Revolution and remained in force until relatively recently. For instance, for many years, by force of Loi d'éducation française of 1851, children in France were punished at school for speaking Breton. Only exactly a century later, under Deixonne Act ${ }^{149}$, could Breton be taught in $\operatorname{schools~}^{150}$ (cf. also Liberman 2008).

Other policies accompanied the assumption of surnames by Russian Jews in the $19^{\text {th }}$ century. Under the reign of Nicholas $I^{151}$, Jews were not only to take surnames but also to become enlightened and civilized, as well as "to wear clothing that did not differentiate them from those individuals with similar civil status" (Avrutin 2005: 150), so they would assimilate to their non-Jewish environment. In the years 184451 decrees expressly forbade such traditional elements of the East-European Jewish attire as yarmulkes ${ }^{152}$ for men or wigs for women (cf. ibid.).

${ }^{149}$ A law that permitted limited teaching of regional languages in state schools in France. Passed in 1951 but implemented about a decade later.

${ }^{150}$ Vergonha, no date. Wikipedia http://en.wikipedia.org/wiki/Vergonha \#Late_19th_century_-_Policies_and_legacy_of_Jules_Ferry, accessed Dec. 3, 2016. See also: William R. Beer, James E. Jacob 1985. Language Policy and National Unity. Totowa: Rowman \& Allanheld, p.120.

151 Born 1796, Russian Emperor (Tsar) in the years 1825-1855.

152 Today better known as kippahs or kipas. 
A name policy may also be a part of a larger ideological campaign. When in 1967 Albania was proclaimed by Enver Hoxha to be the first atheist country in human history, one of the aspects of its secularization was the prohibition to give children religious names. In the ethnically Greek southern regions of Albania, villages named after Orthodox saints were renamed. In 1975 two administrative decrees (number 5339 and 5354) on changes of personal and geographical names made it obligatory for the citizens to change their names (both given names and surnames) if they were contrary to the political, moral and ideological principles (cf. Couretas 2008; Bašić 2001: 511). In a similar spirit, in Communist Bulgaria it was forbidden to celebrate name-days in schools (birthdays were promoted instead), which policy went hand in hand with enforcing a list of permissible given names for children (from which many Christian names were excluded) and with promoting as given names new coinages derived from the surnames of the Communist regime elite (cf. Selimski 1998).

A highly unusual policy regarding given names - or, more accurately, just one male given name, Ignacy (details are discussed in the section devoted to favoured given names) was implemented in Poland before the Second World War, a country where over 30 per cent of citizens were of nonPolish ethnic origin. It was in fact a pro-Polish and pro-family policy in the disguise of a name policy.

\subsection{Methods}

The very fact that given names and surnames differ in character and serve different purposes justifies analysing each of these categories separately. The discussion of the various methods by which personal names are controlled by those in authority follows in the chapters devoted to given names and to surnames respectively. Let it be briefly mentioned at this point that given names may be bestowed on children in (at least seemingly) unrestricted manner, as in the case of the UK, the USA, or Canada. Further, the authorities may require 
parents to be guided by official or semi-official lists of acceptable given names, sometimes also accompanied by 'negative lists', i.e. the lists of unacceptable names. Certain names may be forbidden - either as individual items, or en masse (a particular category, especially names characteristic of a particular ethnicity). There may be favoured or disfavoured names, with subtle instruments, including material incentives or social pressure, for promoting (or, conversely, discouraging) the use of particular given names (this fate befell "revolutionary" names in France and in the USSR). Finally, in an extreme case, there may be obligatory names. Authority intervention extends also to the decision regarding the maximal number of given names.

In the case of surnames, historically the first policy was probably making them obligatory for all citizens. This could be done in at least two ways: by creating surnames and adding them to the (given) names already in use, or, alternatively, by transforming the hitherto used names into surnames and adding given names. One of the possible ways of creating surnames for everybody might be by fossilising patronyms or bynames and making them inheritable. Since the compulsory acquisition of surnames was motivated by the need for more accurate identification by authorities, once acquired, the pool of surnames could then be modified further in an effort to create "legible people" (Scott 1998: 65). This may be done by enlarging the surname pool, if it is not sufficient to ensure precise identification, or by limiting the number of bearers of popular surnames, with the same result. Also the older and/or more prestigious surnames tend to be protected crossculturally. Although it is not as obvious as in the case of given names, certain surnames may also be forbidden - either as individual items, or as a whole category. Finally, there may be a limit on the number of surnames per individual, as well as there may rules guiding their compounding. 


\subsection{Effects}

\subsubsection{Name instability}

While every name change potentially results in some degree of name instability, some cases are exceptional in that respect. An example may be the story of Hasan, a Pomak from the village of Bachkovo ${ }^{153}$ in the Balkans. As Neuburger recounted,

His saga began during the First Balkan War when Bulgarian troops occupied his village. Hasan, along with his family and all the Pomaks of his village, was forced by the Bulgarian authorities to change his Turco-Arabic name to a Slavic name, in his case "Dragan." A change in politics after the Second Balkan War in 1913 opened the door for Dragan to change his name back to Hasan; so he did. During World War II, however, he was again compelled to change his name to Dragan, in line with the wartime Law on Names. After the Communist takeover in 1944, Dragan was able to change his name back to Hasan when the Fascist policy was reversed. But with the movement toward national integration in the 1960s, Hasan was obliged, yet again, to change his name to Dragan. After the fall of Communism in Bulgaria in November 1989, Dragan was allowed to resume his original name, Hasan. In his one lifetime, Hasan, along with the rest of Bulgaria's Pomak population, changed his name six times, as Muslim names moved in and out of Bulgarian national focus (2004: 142).

Another example was described by Gauß:

Dem aromunischen Maler Nikola Martin ist in Kruševo ${ }^{154}$ ein eigenes museum gewidmet. Als die Stadt 1913 an Serbien fiel, wurde der aromunische Maler sogleich zu Martinović serbisiert.

${ }^{153}$ A village $10 \mathrm{~km}$ to the south of Asenovgrad, a town in southern Bulgaria, in Bulgarian Бачково.

${ }^{154}$ A mountain town in the Republic of Macedonia (in Macedonian Крушево), today inhabited by a Macedonian majority and an Aromanian minority. At the beginning of the $20^{\text {th }}$ century it had a numerous Bulgarian and Aromanian population, with an Albanian minority. 
1916 besetzten die Truppen des mit Österreich-Ungarn und Deutschland verbündeten Bulgarien das gebiet. Den Verfechtern eines großbulgarisches Reiches, in dem das Erbe des historisches Mazedonien aus der Zeit Alexanders des Großen wiederaufleben sollte, waren die Aromunen wie die slawischen Mazedonier gefährliche Separatisten, die es streng zu observieren galt; während Tausende von ihnen deportiert wurden und in Lagern jämmerlich zu Tode kamen, wurde aus Martinović der verdiente bulgarische Maler Martinov. Als nach 1945 im föderativsozialistischen Jugoslawien die Teilrepublik Mazedonien erstand, wurde Martinov zum Großen mazedonischen Künstler Martinovski, der nacheinander Serbe, Bulgare, Mazedonier gewesen war, aber niemals der sein durfte, der er war: ein Aromune, Abkömmling der lateinisch-romanischen Bevölkerung des Balkans (2003: 219).

It is noteworthy that both of the above examples are connected with people who happen to be living in multi-ethnic areas whose political, religious and cultural identity has been questioned, negotiated and challenged many times in history. Nevertheless, a similar situation results also when people change their domicile, especially migrating more than once. In a family memoir telling the story of a Jewish family migrating from post-war Poland to settle first in France and later in Canada, the author mentions her brother Stanley, born Sholem, "though at that time he was Simon and had already been Stanislaw and Szolam". Incidentally, the writer herself, who figures on the book cover as Lisa, had been born Elżbieta. This incessant transition from one name to another (even the author's maiden surname being now Borensztajn or Borenstein, now Borens) is paralleled by the family's switching among languages: "A sentence would begin in Polish, merge into Yiddish, migrate into French or stumbling English and go back again with no pause for breath" 155 .

${ }^{155}$ Lisa Appignanesi 2001. Losing the Dead. Toronto: McArthur, pp. 12, $18,112$. 
Similar problems arise among migrants. In order to ease integration into the Spanish society, especially in view of the fears instilled in Europe after September 11, a family of Bulgarian Pomak migrants to Spain gave their son "a safer Spanish name" Michael. Upon returning to Bulgaria, they met with societal ostracism:

Today, many older people are deeply unhappy at the thought of Muslim Bulgarians again adopting Christian names, this time under economic rather than political pressure. One way they can resist the trend is by not attending the ceremonies of 'infidels'. Another is by banning burials in local cemeteries of people lacking Turkish or Arab-sounding names (Kulov 2007).

\subsection{2. 'Duck-rabbit names'}

Karagiannis (cf. 2005: 158-159) described a naming custom in the Rhodopes which is a direct consequence of the Bulgarian name policy The term 'duck-rabbit names' (EnteHase Namen in the German original) used for a certain category of names alludes to Wittgenstein ${ }^{156}$, who used an ambiguous picture of duck-rabbit as an example of seeing (something) as a rabbit/duck rather than seeing that something is a rabbit/duck. A similar ambiguity is connected with some given names bestowed on the children of the Pomak community. For instance, the name Manjo may be interpreted as derived from the Muslim Osman as well as from the Bulgarian Manol. Similarly the originally Thracian and now also Bulgarian name Velizar through its diminutive Veli can at the same time belong to the Muslim onomasticon. Bulgarian as a majority language enjoys relatively high prestige in Bulgaria, but even more prestigious there are Western European languages. For that reason are Muslim names chosen

156 Cf. Ludwig Wittgenstein 2009. Philosophical Investigations. The German text, with an English translation by G.E.M. Anscombe, P.M.S. Hacker and Joachim Schulte. Chichester: Wiley-Blackwell, p. 205. [Orig. title: Philosophische Untersuchungen] 
which could be interpreted also as West European. For example Deniz (Turkish for 'sea') resembles the French or English Den(n)is, just like the name Selvi is referred to as 'Turkish-French-Italian'.

\subsubsection{The revival of native names}

The phenomenon of returning to the roots is not typical of contemporary times only. Before the establishment of the Irish Free State in 1922, users of Irish names were discriminated against, and as a consequence, many Irish used to Anglicize their surnames, for instance by respelling them and by dropping the word-initial $O^{\prime}$ or Mac. After 1922 here was a marked return to the original Irish Gaelic surname forms (cf. Hanks 2003: 133-134).

Maass (cf. 1958: 161) mentioned young Jewish refugees who, having emigrated to the US in Nazi times, felt so conscious of their roots that they wanted to assert them even more by adopting Hebrew surnames: Freund was changed to Yadede ('friend' in German and Hebrew respectively), Goldmann - to Gilead, and Markovitsch - to Ben-Awi ('son of my people').

More recently, in many European nation-states where regional and minority languages experience a revival and more favourable conditions for development than before, there has been a marked tendency among minority members to revert to the original minority given names. Sometimes it is a top-tobottom process initiated by minority organizations, minority language councils, etc.; in other cases, grassroots initiatives are undertaken.

Thus the city council of Mieres in Asturias in Spain offers a service for citizens, businesses and associations, which is intended to promote the use of Asturian ${ }^{157}$. Among the

157 "El Serviciu de Normalización Llingüística ye un serviciu que l'Ayuntamientu de Mieres ofrez a los ciudadanos, empreses y asociaciones pa promover l'usu de la llingua asturiana y da-yos l'asesoramientu que 
materials made available on the SNL website, there is a section devoted to Asturian given names and surnames, offering practical advice on how to proceed in order to bestow an Asturian name on a newborn, how to change a given name from Castilian to Asturian, and how to revert from Castilian to the original Asturian form of a surname. ${ }^{158}$

Another example of a top-to-bottom activity is the 2008 publication by the Kashubian Language Board in Poland of an extensive list of Kashubian given names as well as of the Kashubian variants of Polish names (cf. Breza 2008).

The ultimate in grassroots initiatives appears to have originated in the Basque Country. In 1910 Sabino Arana, called the father of Basque nationalism, published a list of Basque variants of Christian names which he had himself compiled, practically inventing them almost ex nihilo, violating the rules of the historical development of the Basque language (Gorrochategui 1995 discussed the violations and "the antihistorical conception" of Arana's derivations, which were created "in a spirit more suited perhaps to Esperanto than to a language with its own history").

\subsubsection{Repetitiveness of personal names}

Certain name policies have led to the undesirable repetitiveness of personal names. This phenomenon has already been discussed above in relation to the introduction of Christian names, which in Croatia and in Scoland (e.g. the Isle of Skye) led to a drastic reduction of the number of given names bestowed on newborn babies. Also the situation in Turkey, following the Surname Law of 1934, may serve as a case in point. Since those affected by the new law often had a considerable degree of influence over the choice of surname,

necesiten pa ello."

158 "Nomes y apellíos n'asturianu" [Asturian given names and surnames]. Serviciu de Normalización Llingüística. No date. http://lingua.ayto-mieres.es /serveis_projectes_detall_1/_CAFjuKR7gbWJ3oqqSVpE4A-MBKgN_0osniQg 0Fgapeyo6R3pt777TFAQ0D0Z_heC, accessed Dec. 3, 2016. 
obviously some surnames were in more demand than others. Such fate befell, for instance, the surname Yild $z$, meaning 'star'. As a consequence, in Turkey nowadays there are many people with that surname, frequently not related by blood. Coupled with a popular given name, such as Mehmet, this may lead to serious problems with identification ${ }^{159}$.

\subsubsection{Blurring the boundary between given names and surnames}

As already mentioned, a relatively free transition between the categories 'given name' and 'surname' is quite commonly encountered in Anglo-Saxon countries, but such situations happened much earlier. "Surname names" were already known in Ancient Rome. "Towards the end of the Empire", Sheard (2011) noted, "the old naming traditions broke down, and first names, family names and surnames were bestowed freely in any order" 160 . Among the contemporary given names that originated as surnames, there are the well-known Adrian, Anthony, Justin, Lawrence, Paul, Sebastian, Vincent, Camilla, Cecily, Clare, Emilia, Julia, Marcia, and Valeria. By contrast, in Anglo-Saxon countries this phenomenon appears relatively recent: in medieval England, given names and surnames were basically separate sets (cf. Rose 2005). Several reasons contributed to the later blurring of the distinction. First, there were legal problems with inheriting land:

Historically, there has been a strong connection in peoples' minds between a family inheritance (especially of land) and the

159 That, in fact, was the point of departure of a 2009 installation project entitled 203 Mehmet YILDIZs by the artist Ahmet Ogut, which was based on an idea of a soccer match between two teams, each composed solely of players by the name of Mehmet Yıldız, and refereed likewise by men of the same name.

${ }^{160}$ K. M. Sheard 2011. Surname names: In defense of putting last names first. Posted Sept. 1. http://nameberry.com/blog/surname-names-indefense-of-putting-last-names-first, accessed Dec. 3, 2016. 
family name. So sometimes when a child would be inheriting land associated with a different surname, he would be given that surname for a first name to show the connection. An early example is Warham St. Leger ${ }^{161}$, whose mother was heiress of the Warham family (ibid.: 168).

Two more reasons listed by Rose are the need for more new names - especially compelling where one in every five men was called John - and the emergence of middle names. As Rose noted, "[o]nce the idea of middle names became established and people were using them both as a second first name and to include a second surname, it was only natural for names to cross the boundary that way." Some of the surname names (e.g. Avery, Cole, Emery, Wyatt) were originally given names, later in history to become surnames, and finally to be adopted anew as given names. In most cases, however, surname names have no such cyclical past. Other "surname names" include Ashley, Ashton, Aubrey, Austin, Bailey, Bentley, Blake, Braxton, Chase, Clayton, Connor, Corey, Evan, Evelyn, Hailey, Howard, Jordan, Kay, Kennedy, Kimberl(e)y, Leslie, Lloyd, Morgan, Owen, Paige, Riley, Spencer, Stetson and many more.

Similar phenomena appear - though to a decidedly lower degree - also in other European cultures. Selimski (1998: 107) mentioned Soviet surnames that in post-war Bulgaria became given names: Lisenko $^{162}$, Mičurin $^{163}$, Mikojan $^{164}$, Timošenko ${ }^{165}$

${ }^{161}$ English soldier (abt.1525-1597).

162 Trofim Denisovich Lysenko (1898-1976, Rus. Трофим Денисович Лысенко, Ukr. Трохим Денисович Лисенко) - Soviet biologist and agronomist of Ukrainian descent, known for his rejection of mainstream genetics and for unsuccessful attempts to increase crop yields in the Soviet Union. Due to the high offices he held and to the extermination of the scholars who opposed his views, his ideas ("lysenkoism") dominated Soviet agricultural research for many years.

${ }^{163}$ Ivan Vladimirovich Michurin (1855-1935, Rus. Иван Владимирович Мичурин) - Russian horticulturist. His scholarly ideas, known as "michurinism" and later developed as "lysenkoism", negated "Western" genetics based on Mendelian inheritance and attributed a major role to the 
and Totbuchin ${ }^{166}$. In some countries, however, the borderline between given names and surnames was (or still is) observed and required by the law, as illustrated by the 1932 official directive on registering names in Austria:

It is true that there is no actual law confining the choice of name which it is permissible to give to children to those which are recognized as in daily use. Yet it cannot on any account be permitted that existing surnames should be given to children as Christian names, for the Christian name is given as a distinction within the family, while the surname serves to distinguish one family or tribe from another (Rennick 1969: 206).

Today European states that explicitly prohibit the use of surnames as given names include, among others, Germany, Austria, Sweden, Norway, Finland, Lithuania, Italy and Slovakia. In several other countries - such as Denmark, Iceland, Portugal, the Czech Republic or Hungary - lists of officially acceptable given names are prepared to prevent the use of surnames as given names. This is not to say, however, that the lack of an explicit legal prohibition implies consent. In some countries - such as Poland - surnames differ so much in

environment. However, using a process of agricultural selection he did have some success in developing a number of fruit tree hybrids suitable for polar climate zones. In 1932 he became the namesake of a town in the south of Russia where he lived and died, and in 1950 - of a seaside resort in Bulgaria (in 1951 renamed Tsarevo).

164 Anastas Ivanovich Mikoyan (1895-1978, Rus. Анастас Иванович


Communist politician of Armenian descent, Politburo member and the holder of highest positions of power in the USSR (such as chairman of the Presidium of the Supreme Soviet).

165 Semyon Konstantinovich Timoshenko (1895-1970, Rus. Семён Константинович Тимошенко, Ukr. Семен Костянтинович Тимошенко) Soviet military commander of Ukrainian descent. Marshal of the USSR (highest military rank).

166 Fyodor Ivanovich Tolbukhin (1894-1949, Rus. Фёдор Иванович Толбухин) - Soviet military commander, Marshal of the USSR. 
form from given names that hardly anyone would even think of using them as given names.

\subsection{Implied values and assumptions behind name policies}

Cooper (cf. 1989: 98) enumerated several types of conditions as the background of policies: situational, structural (political, economic, social/demographic/ecological), cultural, environmental (influences from outside the system), informational. While situational and structural conditions are not easily generalised and are best described individually caseby-case, cultural factors show certain universal tendencies. It is so because laws, including name laws, imply the existence of certain values, which are either shared by the people (and then merely reflected in the legislation) or only desired by legislators (and then promoted by the legislation). In a given culture some assumptions and values might seem to be taken for granted, so much so that they become invisible and often equal customary law or become the source of codified law. They may also be assumed to correspond to what Bourdieu, using Husserl's term, called doxa and defined as what "goes without saying because it comes without saying" (Bourdieu 1993: 167) - i.e. popular beliefs which are taken for granted and never contested. These are basically the same elements that Schiffman listed in his definition of linguistic culture: "ideas, values, beliefs, attitudes, prejudices, myths, religious strictures, and all the other cultural 'baggage'" (1996: 149).

One of the elements listed by Schiffman is myths. Smith et al. (cf. 1998: 176-92) divide myths about language into language-extrinsic and language-intrinsic ones and propose a classification of language-extrinsic myths into the following five types:

- our language is the parent of all related languages / the original language of mankind / the language spoken in Paradise [sic!]; 
- $\quad$ our language is the chosen language;

- our language expresses the extra-linguistic reality better than others (is more 'natural' than others, its words reflect reality more adequately);

- in its sounds, vocabulary and structure our language reflects our national character in a unique way;

- our language is so wonderful / interesting / unique that foreigners want to study it (or foreign scholars take interest in it) for its own sake (i.e. not because of the expected profits or prestige).

There are also four language-intrinsic myths:

- our language sounds more beautiful than others;

- the concepts of our language are impossible to translate adequately into other languages;

- our language has the richest vocabulary;

- unlike other languages, ours has been handed down by our ancestors in its pure, uncontaminated form.

Schiffman's notion of linguistic culture seems to correspond roughly to what Spolsky and Shohamy (cf. 1999: 31-2) defined as language ideology of a language community: its generally accepted beliefs about language and language use. "They can be a basis for policy, or a policy can be intended to confirm or modify them [...] Put simply, language ideology is something like language policy with the policy maker left out, what people think should be done" (ibid.: 34).

Language policy, as Schiffman observed, is culturespecific. In the same vein it might be said that so are the convictions about personal names shared by people within a culture, though some of these are shared by so many cultures that to a layman these convictions might seem universal. To illustrate this point, a seemingly obvious and universal belief is that everybody should be known by his or her own name and not by someone else's. Yet the traditional (and going out of use) way of addressing a married woman in English - Mrs John 
Smith, Mrs Peter Brown - stands in stark contrast to this seemingly commonsense principle. Such a practice could give rise to quite serious cultural misunderstandings. ${ }^{167}$

The implied assumptions about personal names are manifested on the level of both given names and surnames. On the one hand, name laws reflect values held dear by lawmakers and expressed in state policies. On the other, people also hold certain convictions about names, which do not necessarily coincide with those of the legislators. In what follows some of the assumptions and values that appear to underlie respective policies will be presented.

\subsubsection{A name is obligatory}

"The right to a name," Valentine et al. emphasised, "is one of the most basic rights of human beings" (2002: 5). The cited authors went on to list international acts safeguarding this right, including the International Covenant on Civil and Political Rights (1966), the UN Declaration of the Rights of the Child (1959), and the Convention of the Rights of the Child (1989). Regarding naming, the furthest-reaching seems the American Convention on Human Rights of 1969, which in Art. 18 states that

[e]very person has the right to a given name and to the surnames of his parents or that of one of them. The law shall regulate the manner in which this right shall be ensured for all, by the use of assumed names if necessary.

${ }^{167}$ In fact it does, as evidenced by an article in a national Polish newspaper whose author so misunderstood the convention reflected in the name Mrs Vladimir Nabokov (which the writer's wife Vera used to sign letters with) that he engaged in psychologising about her alleged complete identification with the famous husband. Cf. Aleksander Kaczorowski 2005. "Vera Nabokova. Portret małżeństwa, Schiff, Stacy." Gazeta Wyborcza, Oct. 5. 
Whether or not the name is stable is another matter. In the so-called Western cultural circle a name composed of the part bestowed at birth or relatively shortly thereafter and of that inherited at birth is, more often than not, stable. There are basically two categories of exceptions: first, the change of surname at marriage (or the resumption of maiden name at divorce), and, second, the permitted - usually with its limitations and conditions - name change upon request. The former is in many countries a cultural (if not legal) default and it is culturally (if not legally) associated with the woman as its passive object ${ }^{168}$. The latter enjoys the status of an exception rather than default, implies active participation of the individual concerned, and is not culturally or legally associated with gender.

\subsubsection{At least two names, each of a different type}

Naming traditions vary across Europe, let alone the world. Thus the rule of at least one given name (in the sense of a name bestowed on a child by its parent/s upon its birth), combined with at least one surname (in the sense of an inherited name that identifies a child as a member of a particular family, or in the sense of a name acquired at marriage that indicates its bearer's relationship to the spouse) is by no means universal. On the contrary, there still exist countries and regions where a single (given) name is the official norm. These include for instance parts of Southern India, Malaysia and Indonesia (cf. Ishida 2011). Similarly Mongolians traditionally use only given names, though nowadays, under Russian influence, these are supplemented by patronymics, written before the given name (cf. Dzharyl-

168 The Lucy Stone League, founded in the USA in 1921, fought for women to be allowed to keep their maiden name at marriage. A similar, more recent initiative is the Center for a Woman's Own Name. Cf. C.R. Snyder [\&] Howard L. Fromkin 2012. Uniqueness: The Human Pursuit of Difference. New York \& London: Plenum Press, p. 130. 
gasinova and Kryukov 1986: 211). Also in China's autonomous regions of Inner Mongolia (where nearly one-fifth of the population is Mongol) and of Xinjiang are mononyms in use. When written in Chinese, they constitute more than one ideogram, therefore China's authorities accept them ${ }^{169}$. On official forms they are treated as given names, with the surname field left blank.

In the so-called Western cultural circle, however, an individual must possess at least two names as defined above: a given name and a surname. In other words, mononyms (oneword names) are as a rule excluded. Even under common law, which is the most liberal in that respect, cases of officially registered mononyms are exceptionally rare and result only from common-law name changes (i.e. newborns are not registered with mononyms). Two of the few publicised cases are Mitch, a Wisconsin lawyer whose successful litigation won him the right to use a mononym in lieu of a personal name ${ }^{170}$, and an American magician and comedian Raymond Joseph Teller, who legally changed his name to the mononym Teller. Most instances of mononyms are connected with artistic names (e.g. stage or pen names) of artists (Cher ${ }^{171}$, Sting, Prince $^{172}$, Madonna ${ }^{173}$, Björk ${ }^{174}$, Liberace ${ }^{175}$, etc.), which do not have to be legally recognised.

${ }^{169}$ Alfred F. Majewicz, personal communication.

${ }^{170}$ Cf. University of Wisconsin Law School / Faculty and Staff / Mitch. 2016 (updated). http://law.wisc.edu/profiles/mitch@wisc.edu, accessed Dec.3, 2016. See also http://ask.metafilter.com/176533/What-are-legal-aspects-ofchanging-ones-name-to-a-mononym-or-employing-multiple-legal-aliases, accessed Dec. 3, 2016.

${ }^{171}$ In fact a diminutive of the artist's real given name, Cheryl.

172 The artist's real given name.

173 The artist's real given name.

${ }^{174}$ It is in fact the Icelandic singer's real name (and, short of patronymic, the only one).

${ }^{175}$ It was the real surname of the artist. 


\subsubsection{A surname is obligatory}

It is generally assumed, at least in the so-called Western cultural circle, that everybody must have a surname in the form of a patronym and/or a family name. Deviations from this seemingly obvious norm are instantly visible. In the experimental city of Auroville ${ }^{176}$, children - just like everybody else there - had no surnames, which was to prevent them from inheriting the social position of their parents ${ }^{177}$. That a surname is by default transmitted by parents to their offspring is not as obvious in the Western cultural circle. Scandinavian countries, for example, introduced fixed, inherited family names only relatively recently, with Iceland still following the patronymic/matronymic system.

\subsubsection{The same surname for the whole family}

Historically looking, this principle is by no means obvious. In Poland first instances of a surname comprising all of the family go back to as early as the first half of the $14^{\text {th }}$ century, but generally only in the case of the gentry, and of these - only in the case of those surnames that stemmed from appellatives (cf. Kaleta 1998: 125). Names formed after toponyms at the time did not follow that rule. Thus two sons inheriting a different village could have different surnames, with each name derived from the respective inherited village,

${ }^{176}$ Utopian community founded in 1968 near the city of Pondicherry in the state of Tamil Nadu in South India, as a project of the Indian philosopher, freedom fighter, yogi and guru Sri Aurobindo. It was intended as an embodiment of peace, harmony and human unity regardless of race and religion. Its population is currently about two thousand, although the original plans envisioned as many as fifty thousand inhabitants. The community is largely economically independent and it is governed by a foundation controlled by India's government.

177 Stanisław Tokarski 1987. Jogini $i$ wspólnoty. Nowoczesna recepcja hinduizmu [yogis and communities: the modern reception of Hinduism]. Wrocław: Ossolineum, pp. 217-218. 
and possibly also different from the surname of the father. Moreover, the practice has been sometimes followed of inheriting surnames "after the farmstead" ${ }^{178}$, where the husband would take his wife's surname if upon marriage he moved into her house. The surname change could also accompany the purchase of a farm, as the following account from Upper Silesia indicates:

As long as the old times lasted, in the vicinity - especially in our parish - there was a custom of naming a farmstead with the family name of its first owner. And even if a new owner with a completely new surname were to take it over, still the locals would call it using the name of the original owner, in whose family this farmstead used to be passed down. Strangers who settled in the village did not know the surnames of the original owners and therefore called the farms with the names of their present proprietors. Thus locals gave the farms the names of the previous owners, whereas the newcomers would call them using the new owners' names. In this way double surnames were created, which at first glance seems somewhat unusual [...] Tobór v. Rasiek (1790), Sadłów v. Tayer, Wilk v. Reder, Nowak v. Kuna, Grunt v. Tobór, Bubola v. Cebula, Kuś v. Miś, Hart v. Frej. The letter " $v$ " does not, however, stand for the German nobiliary "von" [...] but for the Latin "vulgo", or "commonly called". Today this old custom disappeared completely $[. ..]{ }^{179}$

For many centuries the instability of the surname was characteristic of various European countries. One of the first attempts in Europe to address that problem was the 1787 imperial decree issued by Joseph II in the Habsburg Empire, which made it obligatory for all family members to have the

178 Pol. "po chałupie" - cf. Krzysztof Raniowski 2006. Rody ziemi wolsztyńsko-babimojskiej [families of the region of Wolsztyn and Babimost in western Poland]. Wolsztyn: Biblioteka Publiczna Miasta i Gminy, p. 16.

179 Józef Knosała 1926. Parafja Radzionkowska: Jej dawniejsze i dzisiejsze stosunki [the parish of Radzionków (a town in Silesia), past and present]. Katowice: Nakładem Księgarni i Drukarni Katolickiej, 41-42. 
same surname (cf. Bering 1992: 35). Naturally, this stabilisation fostered the patrilineality of surnames:

Children used to inherit their father's name as proof they were not born out of wedlock, so any inheritance could be legitimately claimed. Until the mid-nineteenth century, laws in the UK required a married woman to have her husband's name before she could take out a line of credit. This was known as coverture, and children inheriting their father's name was a natural part of the process. ${ }^{180}$

Even though many European states promote gender equality by allowing the married couple to assume as their common surname the premarital surname of either spouse (or each spouse may retain his/her premarital surname), this principle is not universal. Thus in 2015 a Japanese court ruled that a $19^{\text {th }}$-century law making married couples use the same surname does not violate the constitution. Although there is not official requirement that the common surname must be the husband's, in practical terms it so happens in Japan in 96 per cent of cases ${ }^{181}$.

\subsubsection{Only one surname}

Many European states as a general rule adhere to that principle. There are exceptions, though. In Spain two surnames are customary and, consequently, allowed: the

${ }^{180}$ Sadie Levy Gale "Are we heading for a generation of kids with quadruple-barrelled names?" The Telegraph, Nov. 20, 2015.

181 "'Names are the best way to bind families,' Masaomi Takanori, a constitutional scholar, told NHK public television in the run-up to the verdict. "Allowing different surnames risks destroying social stability, the maintenance of public order and the basis for social welfare." In practice, many women continue to use their maiden names at work and their legal, married surname in official documents. They include the internal affairs minister, Sanae Takaichi." https://www.theguardian.com/world/2015/dec/16 /japanese-court-rules-married-women-cannot-keep-their-surnames, accessed Dec. 10, 2016. 
father's surname and the mother's maiden name, traditionally in this order, although this order may be reversed. Portugal allows up to four surnames, i.e. one of each grandparent, even if often only two of these are actually used in everyday life. These multiple surnames are written as separate words without hyphens, but traditionally with the conjunction $y$ (in Spain) or $i$ (in Portugal), which in both cases mean 'and'.

Historically, the use of multiple surnames was connected with inheriting property and therefore implied the muchcoveted upper-class status. At the heyday of the doublebarrelled surnames in English-speaking countries, a New Zealand newspaper columnist wrote:

When things have reached this length, what can our old nobility do but "go them one better" by assuming a quadruplet? Surnames are now threatening to be no longer double-barrelled, but positively to develop into perfect six shooters. MontaguDouglas-Scott and Twistleton-Wykeham-Fiennes won't satisfy the ambition of our newest creations. I believe I am right in saying that at one time the member for Westminster was correctly described as $\mathrm{Mr}$ Ashmead-Bartlett Burdett-CouttsBartlett-Burdett-Coutts $[\ldots]^{182}$

As a matter of principle, the legislation of the inter-war Poland allowed double-barrelled surnames only exceptionally. This changed after the Second World War, though a commentary to the 1945-46 laws stresses the fact that applications for double-barrelled surnames should be rejected if the only motivation for their adoption is snobbery. Article 15 of the Decree on Determining Given Names and Surnames (November 10, 1945) states that surnames which originate after the decree comes in force are to be no longer than two parts (cf. Rajkowski 1955: 70-1, 75-7; Banach 1946). However, if the surname originated before that time, its bearer was entitled to it in its full length. In Poland, apart from the landed gentry,

182 “Double-Barrelled Surnames.” Evening Post, Wellington, June 29, 1895. 
double-barrelled surnames have traditionally been popular in Kashubia - examples include Kossak-Głowczewski, ObrachtProndzyński, Żmuda-Trzebiatowski, Baska-Borzyszkowski and in the Podhale ${ }^{183}$ : Bachleda Curuś, Gasienica Byrcyn, Karpiel Bułecka, Gut Mostowy ${ }^{184}$. What is noteworthy, in both regions they were not the result of joining the surnames of spouses in marriage but of combining a surname with a traditional byname (Pol. przydomek).

\subsubsection{Surname variety is a value}

Diversification of surnames is frequently considered desirable. A case in point might be France, where this was reflected in a 1993 law stating that (sur)name change is justified if the name would otherwise have died out:

Toute personne qui justifie d'un intérêt légitime peut demander à changer de nom. La demande de changement de nom peut avoir pour objet d'éviter l'extinction du nom porté par un ascendant ou un collatéral du demandeur jusqu'au quatrième degré. ${ }^{185}$

Also the Dutch law allows surname change when a name is so common that it has lost its distinctive character. More such initiatives are discussed below in the section devoted to reducing isonymy.

${ }^{183}$ A mountainous region in the south of Poland.

184 Alfred F. Majewicz and Tomasz Wicherkiewicz, personal communication. Interestingly, the Polish Language Board recommends spelling the compound surnames from Podhale (which are not the result of combining the surnames of spouses but indicate descent) without hyphen, which spelling is contrary to the Polish norm. Cf. "Zapis nazwisk dwuczłonowych" [the spelling of compound surnames] 2002. http://www.rjp.pan.pl /index.php?option=com_content $\&$ view=article \&id=1044:zapis-nazwisk-dwu czonowych\&catid=44:porady-jzykowe \&Itemid=5, accessed Dec. 3, 2016, and: Mirosław Bańko 2011. "Alicja Bachleda Curuś." Dec. 4. http://poradnia .pwn.p/lista.php?id=12618, accessed Dec. 3, 2016.

${ }^{185}$ Article 61-1 of the Law 93-22 of Jan. 8, 1993. La législation française sur les prénoms. No date. http://www.affection.org/prenoms/loi.html, accessed Dec. 3, 2016. 


\subsubsection{Preference for a native name}

A very common assumption in European states (and also elsewhere) is that the native version of a personal name is preferable to a foreign one. In many of these states, the native version equals the official/majority versions, possibly to the detriment of foreign or minority language versions. This implicit assumption comes to the surface in legal regulations which either encourage and facilitate or expressly enforce a change of a foreign-sounding name. Thus in Iceland in the years 1952-95 all foreigners applying for Icelandic citizenship had to take Icelandic names (cf. Willson 2009). The issue has been discussed in more detail in the section devoted to name changes.

The opposite change from a native name to a foreignsounding one is less common. Typically, it is neither encouraged nor easy. In the 1980s, two native Dutch citizens of the Netherlands were refused a change of names from Dutch to Hindi ones. They claimed that "for individuals wishing to study and practice the Hindu religion and to become Hindu priests, it is mandatory to adopt Hindu names" and that "if the surname is not legally changed and appears on official identification documents, they cannot become legally ordained priests." 186 Without going into the intricacies of the legalese and the outcome of the legal procedures, it has to be stressed that the Dutch law allows a change of surname of a naturalized citizen if it is not Dutch-sounding, so the permitted change is unidirectional: from a foreign name to a Dutch name.

186 UN Report of the Human Rights Committee, Vol. I, General Assembly Official Records - Fiftieth Session Supplement No. 40 (A/50/40), New York 1996. http://www.un.org/documents/ga/docs/50/plenary/a50-40 .htm, accessed Dec. 3, 2016. 


\subsubsection{A given name should look like one}

In contrast with the Anglo-Saxon culture, many states of Europe do not permit creativity in name-giving. In Germany, for example, the first name needs to be seen as a first name. Therefore, neither surnames nor appellatives like "phone" or "railroad" are allowed as last names. ${ }^{187}$

It must be stressed that such legal regulations do not exist in a vacuum but frequently coincide with attitudes deeply ingrained in a culture. An analysis of the posts in a Polish forum, in answer to the question what the forum users think about calling a newborn boy Nexus, shows interesting tendencies. Of the 48 net surfers who between July 10, 2007 and July 30, 2008 wrote posts in reply, only one thought that it is trendy to have an unusual name and that it is good rather than bad when others pay attention to you. All the rest, with the exception of one slightly off-topic comment, were strongly opposed to the idea. One of their main arguments was that Nexus is a name more suitable for a dog (although one person wrote: "I wouldn't call that even a dog") or some other animal, a robot, a cyborg, or "at best a space object" than for a human being, and it is strange-sounding as well ("What kind of name is that? From the Netherlands, or what?"). Forum users also expressed their dislike for Polonised names, such as Brajan ${ }^{188}$ and listed newfangled (in their opinion) names unacceptable to them, among which they included Ariela, Olgierd, Isaura, Agrypina, or Fulbert. They also criticised celebrities like Michał Wiśniewski ${ }^{189}$, who called his children Xavier, Fabienne, Etiennette and Vivienne. "Bożydar is more human [than Nexus]. And how original!," one forum user commented sarcastically. ${ }^{190}$

${ }^{187}$ Namensrecht. No date. http://www.beliebte-vornamen.de/522-recht .htm, accessed Dec. 3, 2016.

188 Polonised version of the English Brian.

${ }^{189}$ Polish pop singer and the leader of the pop group Ich Troje, born in 1972.

$190 \mathrm{http}: / /$ nastek.pl/forum/viewtopic.php?f=99\&t=16701\&sid=a3cbaa5e a7562e00281695d501cf7f8f\&start=45, accessed Jan. 26, 2014. 
Many users advised the person, who started the thread, to "find an ordinary Polish name", especially that "there are so many beautiful Polish names." The names recommended by forum users included Adam, Alan, Aleksy, Arkadiusz, Cyprian, Damian, Dawid, Emil, Eryk, Filip, Florian, Franek [Franciszek], Igor, Jakub/Kuba, Jasiek [Jan], Kamil, Karol, Krzysztof, Łukasz, Maciej, Marcin, Mateusz, Michał, Nikodem, Oluś [Aleksander], Patryk, Paweł, Piotr, Przemuś [Przemysław], Radek [Radosław? Radomir?], Romek [Roman], Szymon, Tomasz, Wiktor. With the exception of Alan, all of them are long-established, mostly Christian names, which have been present for years in Polish calendars. The opinions on this forum seem to reflect the "linguistic culture", in Schiffman's wording, which lies behind Polish name regulations. Interestingly, these regulations are at present more tolerant of unusual names than their corresponding linguistic culture, which, so to speak, lags behind.

That this conviction about the postulated recognisability of a given name as such does not extend to surnames is visible in a name policy whereby previous (single) names are changed into surnames, and new names selected from the pool of longestablished (usually Christian) names are added as given names. This policy will be dealt with in more detail later.

A related issue is the blurred distinction between given names and surnames, characteristic of the common-law countries - especially the USA, where generally any surname may be bestowed on a child as a given name. In Europe this phenomenon is observed for instance in Scotland:

In the Scottish context the distinction between forenames and surnames is less than usually significant, since so many of the latter derive from the former, e.g. Macdonald, Douglas, Ferguson. Indeed the interchangeability of forenames and surnames in Scotland is quite characteristic, such formations as Reid Jack and Grant Adam being almost as usual as Jack Reid and Adam Grant (Dorward 1996: 1285). 
Such naming practice - in absence of any state policy to counteract it - frequently leads to misunderstandings and doubts such as the following:

Chelsea's most puzzling player provokes two obvious questions. The first is to satisfy pedants: what, once and for all, is his name?

Mikel John Obi, John Obi Mikel, Obi John Mikel, John Mikel Obi? 'His first name is John, Michael is his confirmation name and the family name is Obi,' says the player's father, Michael. Mikel - the name that is emblazoned across the back of his Chelsea and Nigeria jerseys - first appeared as a typo on a teamsheet [...] 'He considers that his football name,' says his father. ${ }^{191}$

In order to avoid such confusion, in many European states there exist laws that help keep these two categories (given names and surnames) separate. In the Netherlands, for instance, it is forbidden by the Dutch civil code to change one's surname to one equal to an existing given name ${ }^{192}$.

\subsubsection{Not the same given name in the family}

Regarding given names, an underlying assumption is, or might be, that a given name must not be shared by a family member. Thus the Italian regulations, for example, explicitly state that it is forbidden for a child to have the same name as that of the living father, brother or sister ${ }^{193}$. There is a similar prohibition in Portugal ${ }^{194}$.

191 Paul Doyle 2010. "Passenger or Driving Force? The Enigma of Mikel John Obi." The Observer, Oct. 3, 2010.

192 Article 4.2. of the Burgerlijk Wetboek 1992, Boek I. Personenen familierecht. http://www.wetboek-online.nl/wet/BW1.html, accessed Dec. 3, 2016.

193 D.P.R. 3 novembre 2000, n. 396 (1). Regolamento per la revisione e la semplificazione dell'ordinamento dello stato civile, a norma dell'articolo 2, comma 12, della L. 15 maggio 1997, n. 127. http://www.esteri.it/MAE/doc /DPR396_2000.pdf, accessed Dec. 3, 2016.

194 http://www.irn.mj.pt/IRN/sections/irn/a_registral/registo-civil/docsdo-civil/dar-o-nome/, accessed Nov. 3, 2013. 
Despite its seemingly overwhelming logic, it is by no means obvious that such a principle should be universal. In Ancient Rome females had no praenomen ${ }^{195}$, as well as, originally, no cognomen, and were officially known only by the feminine form of their father's nomen, later also of his cognomen (cf. Rix 1995). Consequently, sisters typically bore the same name, which for everyday communication might be modified by Maior ('the older one'), Minor ('the younger one'), or by numerals. Jan Długosz, a famous $15^{\text {th }}$-century Polish chronicler, is said to have had several brothers by the same given name and family name (cf. Bystron 1938: 29).

In the Middle Ages the practice of bestowing the same given name on siblings was certainly not limited to Poland. "Giving living siblings the same forenames was once a relatively commonplace practice," Galley et al. (2011: 15) maintain. Using census and vital registration data, the researchers have proved that same-name living siblings (even same-name twins!) were once widespread in Scotland:

Kenneth and Catherine McPherson, for instance, registered the births of seven sons between 1889 and 1901. The first two were both called Peter, the third and fifth were called Alexander and the sixth and seventh were registered as Roderick. The older Peter died before the second Peter was born, but all the others survived to be registered in the 1901 census (ibid.: 16).

The research by Galley et al. seems to indicate that this practice persisted in Scotland for a longer time - at least until the end of the $19^{\text {th }}$ century - than in England. In the case of England, controversy centres on the issue of timing rather than on whether name-sharing among siblings appeared at all:

195 The praenomen was the first element in the classical tripartite Roman naming convention, equivalent to the first name. It was bestowed on a child a few days after birth. The nomen was the second element, indicating the family clan and roughly corresponding to today's family name. The cognomen, basically absent before 100 B.C, served to distinguish individuals with the same praenomen and nomen and was often related to its bearer's personal characteristics. 
[T]here is little agreement about the significance of name-sharing among siblings. Indeed, this issue has been a battleground for rival ideologies regarding the history of the family. Lawrence Stone has argued that during the Middle Ages and the sixteenth century the practice of giving a child the same name as an elder sibling was common, particularly in instances in which the name was also the traditional name for the head of the family [...] The end of this form of naming practice in the late eighteenth century was taken, by Stone, as an indication of the growing awareness of each child's individuality, a view strongly challenged by Ralph Houlbrooke. Instead, Houlbrooke claims that the practice of giving a child the same name as an elder sibling became much less frequent from the sixteenth century onwards, and owed more to what he termed the 'weakening of customary restraints and obligations and the availability of a wider choice of suitable names' after the Reformation. (SmithBannister 1997: 71)

Another instance of this phenomenon comes from the milieu of Moroccan immigrants to the Netherlands. As Gerritzen (2007: 123) noted ${ }^{196}$,

It is not unusual for brothers to be called Mohamed: The 7.166 boys named Mohamed have 348 brothers also called Mohamed (plus 61 Mohammed, 18 M'hamed and some other variants). The 3.114 boys named Mohammed have 322 brothers also called Mohammed (plus 61 Mohamed, 43 Mohammad and some other variants).

Naming a child after a living parent (typically providing additional means of identification: Robert Downey Jr., Oliver Barrett $I V$ ) is still practised in the USA. The boxer George Foreman's five sons all received the same given name (George Jr, George III, George IV, George V, George VI). Such a naming pattern is mostly an upper-class tradition. To what

196 The data refer to Moroccan Dutch citizens of all ages. Given the size of the Moroccan community in the Netherlands, that would mean that approximately one in 15 males bears the name of Mohamed or its variant which is likely, considering the popularity of the name among the followers of Islam in the world. 
extent it is associated with elites was shown in a 1983 study by Herbert Barry III, who found that the fathers of $33(85 \%)$ out of 39 American presidents each had a son (the President or a brother) who had been given the same first name (cf. Kaplan \& Bernays 1999: 220). Since the study appeared, America has had five more presidents ${ }^{197}$, all of whom fit the above pattern, thus raising the overall percentage to 86 per cent.

The motivation behind the medieval and early modern ${ }^{198}$ practice of bestowing the same names on living siblings might be complex. First, the stock of Christian names, which in various European countries in varying degree gradually replaced the native ones, was relatively limited. Second, there seem to have been no prohibitions in that respect on the part of those registering births in parishes. Third, children were frequently treated as little more than movable property, not as human beings in their own right ${ }^{199}$. Fourth, given the high mortality rate, same-naming might have been treated as a reasonable means of safeguarding the transmission of the father's name onto at least one son (the Scottish data seem to indicate that boys were the objects of such practices more often than girls). As Galley et al. (2011: 20) observed,

${ }^{197}$ George (Herbert Walker) Bush was the father of George W. Bush and a brother of Prescott S. Bush, named after their father Prescott (Sheldon) Bush. Bill Clinton, who later took the surname after his stepfather, was in fact born William Jefferson Blythe III to William Jefferson Blythe, Jr., who died in a car accident before his son was born. Barack Obama is a son of Barack Obama, Sr. Donald Trump's father was called Fred, which was also the name of one of Donald's brothers.

${ }^{198}$ Early modern times are usually assumed to have ended around the time of the French Revolution.

${ }^{199}$ French medievalist and historian of childhood Philippe Ariès wrote: «Cependant, un sentiment superficiel de l'enfant - que j'ai appelé le 〈mignotage > - était réservé aux toutes premières années, quand l'enfant était une petite chose drôle. On s'amusait avec lui comme avec un animal, un petit singe impudique. S'il mourait alors, comme cela arrivait souvent, quelques-uns pouvaient s'en désoler, mais la règle générale était qu'on n'y prît pas garde, un autre le remplacerait bientôt. Il ne sortait pas d'une sorte d'anonymat » (Philippe Ariès 1973. L'enfant et la vie familiale sous l'Ancien Régime. Paris: Éditions du Seuil). 
[s]ibling name-sharing has generally only appeared as a footnote in the academic literature, a situation partly due to the sparsity of records which might allow the phenomenon to be observed and systematically studied [...] From a twenty-first century perspective naming a newborn child after a living sibling may seem a highly unusual practice, but understanding why previous societies did not take this view may help us better to understand their demography, and should prove an interesting challenge.

It goes without saying that today, in the age of national identification numbers or of social security numbers, the same combination of the given name and surname would not be so serious a problem for officialdom. Nevertheless, in many countries such practice is frowned upon, and in some explicitly forbidden (the same given name for siblings is forbidden e.g. in Finland, Germany, Slovakia, the Czech Republic and Portugal). Moreover, it appears that societal pressure towards the relaxation of baby-naming restrictions, observable in many states, does not generally tend to go in that direction.

\subsubsection{Gender-specific versus androgynous given name}

Whether a given name should be gender-specific or not is another cultural tradition which may be reflected in a regulation or its absence. Italian laws state that the name given to the baby should correspond to its gender ${ }^{200}$. The Icelandic law on names says that "a boy shall not be given a girl's name nor a girl a boy's name" (cf. Brylla 2002: 358). Genderspecificity of given names is obligatory in other Scandinavian countries: Finland, Sweden, Norway, Denmark (cf. Willson

${ }^{200}$ D.P.R. 3 novembre 2000, n. 396 (1). Regolamento per la revisione e la semplificazione dell'ordinamento dello stato civile, a norma dell'articolo 2, comma 12, della L. 15 maggio 1997, n. 127. http://www.esteri.it/MAE/doc /DPR396_2000.pdf, accessed Dec. 3, 2016. 
2009). Also laws in Austria, Estonia, Hungary, the Czech Republic, Slovakia, Poland, Italy, Spain and Portugal require given names bestowed on children to correspond to gender (in the case of Portugal this refers to the first of the given names only). This principle, though not codified by law, is in practice observed also in several other states of Europe, for instance in Greece or in Lithuania.

In Germany a given name must be gender-specific (cf. Willms 2011: 8); in case of doubt another name must be added $^{201}$. Theoretically the only exception is the name Maria, which can be added as a second given name for boys. The practice somewhat diverges from the theory. On December 5, 2008, the German Federal Constitutional Court ruled, rather surprisingly, that constitution gives no basis for such a farreaching intrusion on the parents' right to name their children as the requirement that a name should be gender-specific. The case involved a German couple of Indian origin who wished to name their daughter Kiran, a name used in India for boys and girls alike. The fact that the name is 'neutral' with regard to gender, the court decided, does not jeopardise the bearer's welfare and it nevertheless gives her the possibility to identify with her gender. ${ }^{202}$

Regulations similar to the one above stand in sharp contrast to the Anglo-Saxon common-law tradition which freely allows androgynous names. Kaplan and Bernays (cf. 1999: 112) list names that once used to be exclusively male: Shawn/Sean, Robin, Chris, Toby, Tracy, Lee, Leslie, Billie, Bobbie, Jamie, Carey, even Michael, are nowadays given also to girls. Conversely, there exist traditionally feminine names

201 "Lässt ein Vorname Zweifel über das Geschlecht des Kindes aufkommen, so ist zu verlangen, dass dem Kinde ein weiterer, den Zweifel ausschließender Vorname beigelegt wird". DA a.F. 2012, § 262. http://www.vd-bw.de/spiderlink/211-2_01.b_inhalt\#, accessed Dec. 3, 2016.

202 Knud Bielefeld 2009. "Geschlechtsneutrale Vornamen ohne Zweitnamen erlaubt." Jan. 14. http://blog.beliebte-vornamen.de/2009/01 /geschlechtsneutrale-vornamen-ohne-zweitnamen-erlaubt/, accessed Dec. 3, 2016. 
that today are used for boys: Carol, Evelyn, Jocelyn, Vivian, Joyce, Kelly, Kerry, Lynn. There are also 'genderless' given names, e.g. Shannon, Courtney, Jody, Terry, Dana, Sam (Samantha or Samuel) and Pat (Patrick or Patricia) ${ }^{203}$.

What is more, even decidedly gender-specific given names are in some cultures used for the opposite sex. In Poland the name Maria as the holy name of God's mother can be bestowed on boys and girls alike, though in the case of boys it can only be a second name. This custom originated in $15^{\text {th }}$ century Italy ${ }^{204}$. In France a similar practice was connected with the names Anne and Marie, which historically could be bestowed on boys too, even as the first of the given names (e.g. Anne du Bourg ${ }^{205}$ or Marie-Pierre Konig ${ }^{206}$ ). Even today female given names are allowed as second or further given names for boys in France. At the beginning of the year 2012, 98 French males had among their given names the name Brigitte, 130 - Catherine, 144 - Anne and 218 - Julie. Conversely, the name Pierre was borne by 619 women and girls, Paul had 126 female bearers. Some names have comparable numbers of bearers of either sex: a case in point is Dominique (at the beginning of 2012 there were over 213

${ }^{203}$ Literature and film capitalize on androgynous names. Just One of the Guys, a 1985 American comedy directed by Lisa Gottlieb, makes use of the ambiguity of the name Terri (which could be a diminutive of both Teresa and Terence), the name of the heroine who disguises herself as a boy to land her dream job. In David Lodge's novel Nice Work the heroine's name Robyn - heard by the protagonist leads him to believe her to be a man (the pronunciation is the same as that of Robin, a male name borne e.g. by Robin Hood).

${ }^{204}$ Katarzyna Kłosińska Imię Maria odpowiednie dla mężczyzny?, audio material of July 31, 2015, available at http://www.polskieradio.pl/9/305 /Artykul/1483457,Imie-Maria-odpowiednie-dla-mezczyzny, accessed Dec. 3, 2016.

205 Auvergne-born $16^{\text {th }}$-century professor of law and martyr for the Protestant cause in France. He was sentenced to death and executed in Paris.

${ }^{206}$ French general, politician (1898-1970). He received posthumously the title of Marshal of France. 
thousand males and nearly 160 thousand females with that name in France) $)^{207}$.

\subsubsection{A given name should correspond to one's religion}

This is a long-standing conviction which is manifested in two ways: first, in the expectation that one should be able to tell the denomination on the basis of the name; second, that upon conversion one is expected to assume a new name, suited to the new religion. Examples of this attitude abound throughout history and can also be found nowadays. For instance, as Kulov (2007) wrote of the Pomak ${ }^{208}$ village of Slashten in Bulgaria, "many local Muslims would not come to the circumcision of a boy with a Christian-sounding name like Michael. They think it indecent to involve someone with such a name in a traditional Muslim ritual".

As an instance of the second assumption, in the $17^{\text {th }}$ century the ex-Paulicians ${ }^{209}$ of Bulgaria upon their conversion to Catholicism began to christen their children with Catholic names different from both the Orthodox and Muslim ones (cf. Selimski 1999: 198). In pre-war Poland Jews converting to Christianity were generally expected to change their names to Christian ones. The same applies to the given names of converts to Islam "if they contain wrong or bad meanings"

${ }^{207}$ Cf. http://www.meilleursprenoms.com/, accessed Nov. 24, 2016.

${ }^{208}$ Pomaks are Slavic Muslims living in Bulgaria, Greece, Macedonia, Turkey, Albania and Kosovo. In some of these states and regions they are called Torbeshi or Gorani. The total population amounts to about half a million.

${ }^{209}$ Paulicians were a sect active between the $7^{\text {th }} \mathrm{c}$. AD and the $12^{\text {th }} \mathrm{c}$. $\mathrm{AD}$, mostly in Asia Minor and Armenia. The last members of this group became Catholic in the $18^{\text {th }} \mathrm{c}$. They considered themselves Christians. Their beliefs, somewhat Manichaean in nature, included the rejection of the Old Testament and of Incarnation, by the conviction that Jesus was merely an angel, and by the faith in two acts of creation.

210 "New Convert: Is Changing Name Necessary?" Islam Online, Feb. 22, 2016. http://archive.islamonline.net/?p=1343, accessed Dec. 3, 2016. 
However, in a 1989 opinion poll in France, 25 per cent of French respondents believed that Muslim names should not be permitted on the birth certificates of Muslim children; Muslims, on the other hand, believed that name Frenchification was no way to promote integration, since the police, detaining Muslims, might now claim that their names "do not correspond to them" (cf. Jacob \& Horn 1998: 13-15).

\subsubsection{Civil law versus common law}

Under civil law (generally codified), a name change requires a good reason, time, money and paperwork; whether the change is granted at all is frequently left at the discretion of the officialdom. Names given to children are often found on special lists prepared by the state, or at least should look like given names. However, under common law (generally uncodified), almost any noun (including surnames and appellaties) can become a given name. The name is temporary and easily changeable for non-fraudulent purposes. As illustration, Rennick quotes an American court verdict:

A name assumed by the voluntary act of a young man at his outset into life, adopted by all who knew him, and by which he is constantly called, becomes, for all purposes which occur to my mind, as much and as effectively his as if he had an Act of Parliament to confer it upon him. (1984: 139, emphasis in the original)

The assumed stability of the name is a tenet that in some cultures and political systems is adhered to more than in others, to the extent that a name change may even be expressly forbidden. On the other end of the continuum, Holland (cf. 1995: 288) gave an example of a chain of personal name changes undergone by a Navajo tribe member. He began his life as Kiiyaa'aani ne7e7z biye 'son of the tall clansman', and afterwards was called by his parents merely 'ashkii 'boy'. Then, as a result of the Anglicisation of biye 'son of' he became 
Begay. His school name was Ben, in the next school it became Matthew. Next there followed the self-imposed middle name Hugh. After army service he became Herman ("...had a buddy by a certain name... liked it... wanted to change mine"). A ceremony taken when sick bestowed on him a secret name that he would not reveal to the researcher, and finally the birth of a son made him add Sr. (Senior) to his name, following AngloSaxon conventions. In his case, it appears that onto the nameinstability tradition typical of many native American naming patterns, the common-law system was superimposed. 
This page intentionally left blank 


\section{Given names}

\subsection{The laissez-faire approach - testing the limits}

The term "laissez-faire" implies that the government refrains from influencing the practices of language users, giving them a free hand. In terms of policies relating to all of the language, this non-interference, some researchers claim, is typical not only of the English-speaking countries but of European states in general, and what is more, amounts to a policy that favours stronger languages. In the words of Robert Phillipson, "when language policy issues are just left to evolve without any conscious, explicit language policy, this means that big languages are likely to expand at the expense of small languages [...] Laissez-faire in that sense is to some extent what governments do"211. However, it seems that this statement cannot be automatically applied to (given) name policies, which tend to be quite strict in some European states, in stark contrast to Anglo-Saxon countries (especially the USA but with the exception of New Zealand), where under common law there are virtually no restrictions. In the USA the naming practice is backed by a powerful name ideology rooted in the idea of personal freedom, as exemplified by a discussion on a forum devoted to government intervention in naming:

[Vic:] Democracy as administered by a committee of appointed bureaucrats? :) In the US, this kind of 'language protection' [as practiced in many European states, manifested in decisions forbidding parents to give their child a particular given name] would be considered nothing short of racism. Shall we force all the immigrant parents to give their children English names? Diego would be forbidden, but James would be okay? Juan would be bad, but John would be okay? Or (in the interests of European liberal socialism) should that be the other way

${ }^{211}$ Robert Phillipson [no date]. Laissez faire Language Policy. Video recording on the website "Language Policy Course." 2010. C Integration Research Institute, Estonia. http://www.integrationresearch.net/languagepolicy.html, accessed Dec. 2, 2013. 
around? Not to mention how apparently little authority a parent has to raise their own child!

[RabidMongoose:] This is a perfect example of why many Europeans and many Americans/Canadians will never understand each other. Europeans such as yourself apparently see immigrants and their descendants as invaders. [...] In the US or Canada, you can be American or Canadian while still retaining whatever name, identity, or culture you wish to keep. ${ }^{212}$

There seems to be very little or no state regulation regarding the choice of given names in the "laissez-faire countries", which include not only the USA or the UK, but also Venezuela, Honduras, Ecuador or Brazil ${ }^{213}$. If there is any limit there to what a human being can be named, it can only be seen when truly marginal cases test the limits of imagination and tolerance of the officialdom. Conflicts between individuals and the state are then resolved by courts on a case-by-case basis. The limits of tolerance seem to be very liberal. The name Hitler is in unchallenged use in Ecuador and Venezuela in the latter state with at least 60 bearers $^{214}$. When in 2008 the media discovered in New Jersey a three-year-old boy named Adolf Hitler Campbell, it suddenly turned out that the name was perfectly legal:

In selecting their children's peculiar names, the Campbells had exercised a right specifically recognized in New Jersey statutory

212 The thread was occasioned by the media news that Swedish authorities refused a request to register Superman as a child's name. https://forums.anandtech.com/threads/government-intervenes-with-namingof-child-wtf.1414339/page-2, thread "Government intervenes with naming of child...", Sept. 29, 2004, accessed Dec. 3, 2016.

${ }^{213}$ Cf. e.g.: Simon Romero 2007. "Venezuelan Parents Love a Famous Name." The New York Times, Jan. 7; Isabel Garcia 2006. "Nazywam się Czysta Wódka Zambrano" [on unusual given names in Ecuador]. Angora 52, Dec. 24, 80-81.

${ }^{214}$ Simon Romero 2007 “A Culture of Naming That Even a Law May Not Tame." Caracas Journal / The New York Times, Sept. 5. See also: "Hitler in Venezuela," April 23, 2012, http://venezuela-europa .blogspot.com/2012/04/hitler-in-venezuela.html, accessed Dec. 3, 2016. 
law, which states, "The designation of a child's name including the surname is the right of the child's parent(s)." Indeed, "the child may be given any chosen name(s) or surname." New Jersey recognizes only a few limited exceptions to this right [...] If the Campbells had named their son "R2D2," state authorities would have intervened. "Adolf Hitler Campbell," by contrast, presented no legal impediments (Larson 2011: 161).

Surprisingly, despite the apparent air of the laissez-faire approach, certain restrictions do exist in the USA; what is more, as Larson pointed out, particular states differ in that respect. Thus New Jersey statutory law prohibits names that contain an obscenity, numerals, symbols, or a name that is illegible. In the state of California, pictographs or ideograms are expressly not allowed as given names, and only the names using "26 alphabetical characters of the English language with appropriate punctuation if necessary" (ibid.: 169) are admissible, which effectively excludes the use of foreign diacritics, such as "é", "ñ" and "ç". Paradoxically, California's Hispanic population is thus effectively deprived of the right to register names like José or Lucía in correct Spanish orthography. Larson noted further:

In some states, there is a complete absence of any law on the subject. A Connecticut judge recently discovered, to his astonishment, that Connecticut did not require a name to be placed on a child's birth certificate [...] A wide range of issues were thus unaddressed, including "the use of a number in a name, such as CP30 [sic]; the selection of a name not matching the sex of a child;" or "the repetition of the same word three times as first, middle, and last name, such as Smith Smith Smith $^{215 "}$ (ibid.: 163).

${ }^{215}$ Incidentally, a similar dilemma - whether to allow the doubling of a given name of the same person - was considered by RJP in Poland at least twice, with the conclusion that providing the name itself is acceptable, there appear to exist no legal or linguistic obstacles to such naming, however unusual it might seem. The problem concerned the proposed male names Jan Jan and Pawet Pawet (cf. http://www.rjp.pan.pl/index.php?option=com 
Moreover, there are even cases where attempts to curb laissez-faire attitudes to given names fail spectacularly. Venezuela has long been (in)famous for its absolutely lenient approach to personal naming and for such feats of creativity as Yusmairobis, Nefertitis, Yaxilany, Riubalkis, Debraska, Nixon, Hitler, Darwin, Stalin, Mao Breznyer (after the Soviet Russian leader Brezhnev), Taj Mahal, Yesaidú (from 'yes, I do'), Yormery (probably from your Mary) or Jondre (from 'one hundred'). Therefore in 2007 a bill was proposed that would limit the parental choice to a list of 100 given names, with exemptions for Indians and foreigners. This bill aimed to "preserve the equilibrium and integral development of the child" by preventing parents from giving newborns names that expose them to ridicule or are "extravagant or hard to pronounce in the official language," i.e. Spanish. Also names that "generate doubts" about the bearer's gender were to be forbidden:

Limitación a la inscripción de nombres

Artículo 106.

Con el fin de preservar el equilibrio y desarrollo integral del niño, niña o adolescente, los registradores civiles no permitirán que los declarantes del nacimiento, sean éstos sus padres, representantes o responsables, les coloquen nombres que los expongan al ridículo; sean extravagantes $o$ de difícil pronunciación en el idioma oficial; contengan variantes familiares y coloquiales que denoten una identificación confusa o que generen confusión de sexo.

En estos casos, el registrador ofrecerá como referencia, un listado de los nombres y apellidos más comunes, emanado de la Oficina Nacional de Registro Civil. Este listado podrá ser utilizado para la identificación de los casos que lo requieran. Quedan exceptuados de esta disposición, los nombres de los niños, niñas o adolescentes de las etnias indígenas del país, así como los nombres de los hijos de los extranjeros, los cuales se ajustaran a sus respectivas culturas.

_content $\&$ view=article $\&$ id=1445:pawe-pawe $\&$ catid=76:opinie-o-imionach \&Itemid=58, accessed Dec. 3, 2016. 
Listado de nombres y apellidos

Artículo 107.

La Oficina Nacional de Registro Civil, se encargará de seleccionar de sus archivos, una cantidad no menor a cien (100) nombres y cien (100) apellidos, para la conformación de un Listado de Nombres y Apellidos. Anualmente, la Oficina Nacional de Registro Civil revisará dicha lista y, de ser necesario, la aumentará en un porcentaje proporcional a la población. Se tomará en consideración para la selección, aquellos nombres y apellidos que identifiquen el gentilicio venezolano. En las comunidades indígenas, se seleccionarán los nombres y apellidos más representativos de sus etnias ${ }^{216}$.

Nevertheless, the bill did not find favour with the National Assembly and was ultimately rejected. It is noteworthy that some of the given names of Venezuelan congressmen at the time were Jhonny Owee, Iroshima Bravo, Earle, Nagarith, Elvis and Berkis. ${ }^{217}$ A similarly motivated bill was not passed either in the Dominican Republic, where judge Jose Angel Aquinas in 2009 proposed to ban any names that could be confusing vulgar, composed of over three words, or those that do not indicate gender. Some given names actually registered in the Republic, which motivated the judge to act, included Datsun, Mazda Altagracia, Toshiba Fidelina, Querida Pina ('dear pineapple'), Tonton Ruiz ('Dummy Ruiz'), Rambo and Winston Churchill de la Cruz. ${ }^{218}$

216 Proyecto de Ley Organica del Registro Civil, Aug. 9, 2007. http://www.cne.gov.ve/web/documentos/registro_civil/2008/INFORME_JU RIDICO_LEY_8-8-2007_RC.pdf, accessed Dec. 3, 2016.

${ }^{217}$ Simon Romero 2007. "Venezuelan Parents Love a Famous Name." The New York Times, Jan. 7; Simon Romero 2007 "A Culture of Naming That Even a Law May Not Tame." Caracas Journal / The New York Times, Sept. 5.

218 "Dominican Republic to Consider Ban on Odd Names." April 22, 2009. http://www.foxnews.com/story/2009/04/22/dominican-republic-toconsider-ban-on-odd-names/, accessed Dec. 3, 2016. Cf. also: "Juez dominicano somete proyecto prohibe nombres raros," April 21, 2009. http://www.telemetro.com/insolito/Juez-dominicano-proyecto-prohibenombres_0_142785748.html, accessed Dec. 3, 2016. 


\subsubsection{One-letter names}

In September 2009 a Swedish couple from Åre ${ }^{219}$ were granted the right to name their son "Q". The boy's full name thus became $Q$ Anbjörn Jackrapat Rehnberg.

In a similar decision, the Supreme Administrative Court also overruled objections by the Swedish tax authorities in awarding a woman from Varberg in western Sweden named AnnChristine the right to change her legal name to A-C. According to the court, there is nothing to suggest that the name $\mathrm{A}-\mathrm{C}$ is offensive to anyone. "The choice of a first name is of such a personal nature that the individual must be given complete freedom," said the court. "The possibility that A-C could be interpreted as an abbreviation of another name doesn't mean in and of itself that it's obviously inappropriate. Nor is A-C obviously inappropriate as a first name for any other reason". 220

While marginal in Sweden, names composed of only one letter are relatively less unusual in the American naming culture. An example of such a naming was Malcolm Little, activist for the rights of black people, who symbolically changed his surname to $X$. As Malcolm himself explained in his autobiography:

For me, my "X" replaced the white slave master name of "Little" which some blue-eyed devil named Little had imposed upon my paternal forebears. The receipt of my " $\mathrm{X}$ " meant that forever after in the nation of Islam, I would be known as Malcolm X. ${ }^{221}$

${ }^{219}$ A ski resort in Jämtland County (central Sweden, not far from the border with Norway).

${ }^{220}$ Charlotte Webb 2009. "Swedish Parents Emerge Victorious in Bid to Name Son 'Q'." The Local. Sept. 30. http://www.thelocal.se/20090930 /22390, accessed Dec. 3, 2016.

${ }^{221}$ The Autobiography of Malcolm X as Told to Alex Haley. Ballantine Books 1992, e-book - no pagination. 
What may make such names more acceptable to an American ear is perhaps the long-standing tradition in the USA of the use of nicknames (also in the function of full names) which are homophonous with the names of letters or of their combinations, e.g. Deedee, Beejay, Jaydee, Kacey/Kacee/ Kaycee, Arjay, Jayvee, Jayar, Jacy/Jaicee/Jaycee, Kay, Kayvee, as well as the custom of addressing people in a familiar way, using the initials of their full name or of their given names: $L B J^{222}, J F K^{223}$. Sometimes people (including musicians, writers, performing artists, athletes) are publicly known only by their initials plus surname (with or without fullstops after initials): B.B. King, ${ }^{224}$ ZP Theart, ${ }^{225}$ K.C. Jones. ${ }^{226}$ As Ashley (cf. 1996: 1219) emphasised, also a middle initial in the USA may be exactly what its name implies: a letter that is not an abbreviation of any name. As an example he invokes the name of the president Harry $S$ Truman, written with no full stop ${ }^{227}$ after the letter $S$. That Truman's case of a "meaningless" initial was no exception is also indicated by the following citation from a biography of the president:

In a quandary over a middle name, Mattie and John [the president's parents] were undecided whether to honor her father or his. In the end they compromised with the letter S. It could be taken to stand for Solomon [maternal grandfather] or Shipp

${ }^{222}$ Lyndon Baines Johnson (1908-1973), American president in the years 1963-69.

${ }^{223}$ John Fitzgerald Kennedy (1917-1963), American president in the years 1961-63. JFK is also the colloquial name of a New York airport, named after him. B.King.

${ }^{224}$ Born 1925, American guitarist and blues musician, real name Riley

${ }^{225}$ Born 1975, heavy metal vocalist and a former member of the British band DragonForce.

226 Born 1932, former American basketball player.

${ }^{227}$ On the controversy around the use or non-use of the fullstop after Truman's middle initial, see http://www.trumanlibrary.org/speriod.htm (accessed July 16, 2012). 
[paternal grandfather], but actually stood for nothing, a practice not unknown among the Scotch-Irish, even for first names ${ }^{228}$ [emphasis added].

\subsubsection{Numbers, symbols and other unusual names}

In the 1970s a North Dakota resident, Michael Herbert Dengler, demanded court approval to change his name to 1069: "1069 expressed his individuality and personal philosophy, he explained, each of its four digits, respectively, standing for his relationship with nature, time and movement, the universe, and 'essence"' (Kaplan and Bernays, 1999: 191). After a four-year legal battle the request was denied:

Symbols, signs, figures," the court decided, "are simply not suited for use as names. If the Court indulges the present request $[\ldots]$, it could hardly deny use of other symbols to subsequent petitioners. A musician, for example, might seek an inimitable grouping of eighth notes as his name. A mathematician might want a particular equation, a financier the dollar sign, an astrologer the symbol for Sagittarius (Kaplan and Bernays 1999: 192).

Still, although numerals in the form of digits are inadmissible even in the USA, they would be accepted if spelt using letters (Larson 2011 gives a hypothetical example of a legally acceptable name Eight). Also a Roman numeral following the full name is permissible, e.g. in the state of Texas. As Larson (cf. 2011: 168) observed, a newborn registered in this state could be named John William Turner III, but not John William Turner 3 or John William 3 Turner.

In most countries numbers combined with letters are not acceptable. In 2007 the Registrar-General of Births, Deaths and Marriages in New Zealand told Mr and Mrs Wheaton they

${ }^{228}$ David McCullough 2003. Truman. New York: Simon \& Schuster, p. 26. 
could not name their newborn son "4Real" because a dictionary defines a name as "a sequence of characters" 229 .

According to a report on the language situation in China, released on Aug. 16, 2007 in Beijing, a couple in China attempted to name their newborn "@" maintaining that the name reflects their love for the child. When spelled as "at" with a drawn out "T", the name, the parents claimed, sounded similar to ai ta, or 'love him', to Putonghua speakers. The parents' request was denied. ${ }^{230}$

In 1993 the musician Prince Roger Nelson changed his stage name to a graphic symbol vaguely resembling a cross between a male $(\delta)$ and a female ( $(q)$ sign, which reportedly "entered his consciousness during meditation". The symbol being unpronounceable, "there was immediate confusion, not to mention considerable derision, as to how he would be referred to in the future, prompting Warner Bros. to send out computer floppy discs of the symbol so publications could use it in print" 231 .

In 1996 a Swedish couple, Elizabeth Hallin and Lasse Diding, decided to name their son Brfxxccxxmnpccclllmmnprxvclmnckssqlbb11116 (pronounced Albin, as they maintained) in protest against the strict Swedish name laws. When the court refused their request, they tried unsuccessfully to change the boy's name to $A$ (with the same pronunciation). Today their son's given name is Albin. ${ }^{232}$

${ }^{229}$ Eveline Harvey 2007. "It's 4Real: Parents Say They'll Call Their Son Superman." New Zealand Herald, Aug. 8. http://www.nzherald.co.nz /lifestyle/news/article.cfm?c_id=6\&objectid=10456528, accessed Nov. 25, 2016. Interestingly, the names Benson and Hedges for two brothers (after a cigarette brand) did not raise any objections from the New Zealand registry officials (cf. Felecan 2014: 139).

${ }^{230}$ Cf. "English Invades Chinese Language" 2007. People's Daily Online, Aug. 17. http://english.peopledaily.com.cn/90001/90781/90879/6241 904.html, accessed Dec. 3, 2016.


2016.

232 http://www.oddee.com/item_97196.aspx, accessed Dec. 3, 2016. 
Testing the tolerance of name registry was also the motivation for a family in the Philippines, who gave their children between twenty and forty given names each. As O. Felecan (2014: 137) explains,

the father of these children was upset by the fact that the government was too permissive towards the names that parents give to their children and he wanted to see whether he would be allowed to baptise his children by using a large number of names. It is amazing that no authority seemed to be bothered by this situation.

19-year old Jennifer Thornburg from the US state of Virginia changed her name to CutoutDissection.com in order to manifest her strong conviction that the practice of dissecting animals in the classroom should be abandoned. ${ }^{233}$

\subsection{Allowed given names and their lists}

Name lists constitute a convenient means of state control over the populace at large or, alternatively, over a selected (typically ethnic) group. One of the first such lists was one of 156 given names permitted to Jews by a 1787 decree of Joseph II of the Habsburg Empire (cf. Bering 1992: 35).

\subsubsection{Wartheland under Nazi German occupation}

Since October 8, 1939, western parts of Poland had been annexed by Nazi Germany and constituted the area which later came to be known as Reichsgau Wartheland (Wathegau). It comprised Wielkopolska (Greater Poland) as well as the area around the cities of Kalisz and Łódź (the latter renamed Litzmannstadt). On October 141940 Arthur Greiser, the administrator of Warthegau, issued a circular to civil registries regarding the naming of Polish children, which in view of the

${ }^{233}$ Bonnie Rochman 2008. "Hi, How Are You? My Name Is Cutout Dissection.com.” Time, Dec. 15. 
failure to comply was reiterated on Nov. 1, 1941 (with an accompanying name list issued on Dec. 9, 1941). According to the provisions of the circulars, Polish newborns were to be given only the names perceived by Nazis as typically Polish. In fact most of them were Slavic, sometimes distorted, and for the most part having fallen into disuse long before. As indicated above, the source for the list may have been the inaccurate calendar for the year 1828, compiled by Tadeusz (Władybóg) Wojewódzki. Therefore the names must have sounded extremely unusual to those who were forced to bestow them on their offspring. The list (354 male and 213 female names) contained almost no Christian names that had been commonly used throughout Europe (thus for instance Jan, Piotr, Pawet, Antoni, Maria, Elżbieta, Ewa, Katarzyna, i.e. the Polish equivalents of John, Peter, Paul, Anthony, Mary, Elisabeth, Eve, Catherine, were absent from the list), but probably owing to an overlooking - it did contain the names Jerzy, Jadwiga, Matgorzata. Apart from this, at the same time each child was obliged to get - as a means of ethnic identification - the name Kazimierz for boys, or its female equivalent Kazimiera for girls. Also the name Bogumita was recommended for girls. As Umińska-Tytoń noted, there may have been two reasons for the choice of Kazimierz. First, the name etymology implied 'destroying peace', which may have been a way of stigmatising the Polish people as responsible for provoking the war. Second, Kazimierz was the name of a Polish king who in the $14^{\text {th }}$ century allowed Jews to settle in Poland (cf. Umińska-Tytoń 1988: 127, Cygański 1965: 99).

In a similar manner, German children in Posen (Poznań) were to be given names from another, German-only list (205 male and 193 female names), which included such items as Detlef, Hildebrand, Reinhard, Genoveva. The children of Polish ethnicity, on the other hand, were to be given only the names from the "Polish" list, and - as one of the names - the name Kazimierz / Kazimiera. Jewish children were to be bestowed with one of the names from the 'Jewish' list. The 
restrictions led to a drastic depletion of the stock of given names. As estimated by Sarnowska-Giefing (cf. 2003: 108-9), at the end of the Second World War the five most common given names of Polish children in Poznań accounted for 77 per cent of girls and 61 per cent of boys.

\subsubsection{France}

In 1803 the Napoleon government decided that newborns in France were to be given only the names of Catholic saints or famous characters of ancient history:

Les noms en usage dans les différents calendriers, et ceux des personnages connus dans l'histoire ancienne pourront seuls être reçus, comme prénoms, sur les registres destinés à constater la naissance des enfants; et il est interdit aux officiers publics d'en admettre aucun autre dans leurs actes. ${ }^{234}$

That equalled an effective exclusion of minority names, which later led to controversies and even lawsuits. In the 1960s six children of Mireille and Jean-Jacques Manrot-le Goarnic - Adraboran, Brann, Diwezha, Gwendall, Maiwenn and Sklerijenn - were denied citizen status, since Breton names were not legally recognized ( $Q u^{\prime} y$ a-t-il dans un nom? $\left.1966^{235}\right)$. Over a century and a half later, the ministerial directive of 12 April 1966 approved also names from mythology (such as Achille, Diane, Hercule), regional given names - «Certains noms, propres à des idiomes locaux du territoire national (basques, bretons, provençaux, etc.)» - as well as certain foreign given names (exemplified in the directive by Ivan, Nadine, Manfred and James), certain former surnames (Gonzague, Régis, Xavier, Chantal), compound

${ }^{234}$ Art. 1 of Loi de 11 Germinal an XI of Apr. 1, 1803. Clément Benelbaz 2011. Le principe de laïcité en droit public français. Paris: L'Harmattan, p. 337.

${ }^{235}$ Cf. also: Witold Paweł Cienkowski 1967. Kalejdoskop językowy [essays in linguistics]. Warszawa: Nasza Księgarnia, p. 74. 
names (prénoms composés) consisting of no more than two elements, and some diminutives with their variants (e.g. Ginette, derived from Geneviève). ${ }^{236}$

A further step towards a relative relaxation of rules was made by a decree of the Cassation Court of June 10, 1981, whose basic line of argument was that "dans la mesure où il n'existe aucune liste officielle des prénoms autorisés, il n'y a pas lieu d'exiger que le calendrier invoqué émane d'une autorité officielle". ${ }^{237}$ The most up-to-date regulation (of January 8, 1993) is contained in Art. 57 of the Civil Code of 1993, which - contrary to most earlier regulations - refrains from specifying acceptable first names (i.e. there is no approved names list any more), only reserving for the state the right to interfere in the case of an unspecified violation of the interests of the child: "Lorsque ces prénoms [...] lui paraissent «contraires à l'intérêt de l'enfant $[. .]$.$» , l'officier de l'état civil$ en avise sans délai le procureur de la République." 238

It could be reasonably expected that such a regulation can only be used against the parents who endow their children with ridiculous, humiliating names, such as those who in 1993 insisted on naming their daughter Babar - the name met in Asia but hitherto unknown in France and reminiscent to the French only of an elephant from the well-known books for children $^{239}$. In fact, it is not only so. Also minority languages and names become the targets of legal action:

[t]his process figured in a well-known case of the late 1990s, 'L'Affaire Kawrantin'. Some Breton-speaking French citizens living in the French colony of New Caledonia attempted to

${ }^{236}$ Cf. Affaire Guillot C. France, European Court of Human Rights, Strasbourg, Oct. 24, 1996. http://hudoc.echr.coe.int/eng?i=001-62630\# \{\%22itemid\%22:[\%22001-62630\%22]\}, accessed Dec. 3, 2016.

237 Clément Benelbaz 2011. Le principe de laïcité en droit public français. Paris: L'Harmattan, p. 337.

238 Ibid., p. 338.

${ }^{239}$ A series of children's books written by a French author Jean de Brunhoff (1899-1937) and continued by his son Laurent. 
name their child Kawrantin, the Breton spelling of Saint Corentin. The civil registry contacted the prosecutor, who brought in the family court judge. The family showed the judge the book 'Prénoms en Bretagne', where the name is documented, and the judge accepted their argument. However, the prosecutor appealed the ruling, on the grounds that it was inappropriate to give a child a name 'aux consonnances barbares' ('with a barbaric sound'). A higher court ruled in favor of the parents, in May of 2000 (Liberman 2008). ${ }^{240}$

\subsubsection{Hungary}

More recent phenomena are lists of minority given names. Since 2004 separate lists of minority given names have also existed in Hungary (cf. Raátz 2008). It is the post-war history of allowed name lists in Hungary which provides a good illustration of how contingent name policies can be, and how they are by trial and error, with steps forward and back, adjusted to the needs of the public at large.

As Raátz (ibid.) noted, in 1948 a register ${ }^{241}$ appeared with about a thousand allowed and as many as several thousand unacceptable [!] given names, followed by their registrable forms. On the basis of this document, registry clerks made arbitrary decisions. However, the register contained no information as to the gender; as a consequence, some girls officially acquired male names. The next name list to appear (1965), by contrast, emphasized gender-specificity of names as well as explicitly prohibited double given names (Annamaria) and foreign ones if a Hungarian cognate existed. In 1971 a new name list was published ${ }^{242}$ which attempted to amend

240 On L'Affaire Kawrantin, see also: An Tour Tan. Archives de l'actualité bretonne. 1999. http://www.antourtan.com/actualite/19991213 .html, accessed Dec. 3, 2016.

241 Babó Szilárd "A hatályos anyakönyvi házassági és vallásügyi jogszabályok" [the current legislation concerning births, marriages and religious affairs].

${ }^{242}$ Ladó János "Magyar utónévkönyv" [Hungarian book of given names]. 
the shortcomings of the previous name lists. It included 896 female and 932 male names, as well as more detailed information (etymology, diminutive forms, name days) on each name. Until 1982 the list merely provided assistance in name choice, but in 1982 it became legally binding for parents of newborn babies. Even though in view of the practice the list with its 1827 names turned out to be "superabundant" (Raátz 2008: 5), in the 1970s and 1980s parents still insisted on extending it and 120-130 applications for new names were filed per year. Less than half of these applications were granted. After the fall of Communism (1989) the number of applications for new names to be approved rose to 500-600 annually, with most of the desired names (70\%) registered. Another register, of as many as 10 thousand names, was issued in 1993. This one in turn was criticised for too much tolerance and in 1997 yet another one appeared. The 1997 list comprised merely 2710 names, that is hardly over a quarter of the names included in its predecessor. Paradoxically, shortly afterwards the number of applications for new registrations dropped to 100-150 per year.

The post-war history of name lists in Hungary also raises some thought-provoking questions about the limits of naming freedom and about the criteria for deciding which needs of the policy recipients are real and which are too far-fetched, which demands are justified and which are superfluous. Raátz herself felt that Hungary's policy was too strict:

It is my personal question, bolstered also by most of my fellow researchers working in the field of onomastics, that we don't only regulate, but over-regulate in Hungary the process of choosing given names. Why do people have to wait 60-90 days for the results of their applications? If we are already following the rules and practice of the European Union then the question arises why we are not more permissive, why we not dare to adopt the already competent rules and practices of other European countries (2008: 10). 
It is noteworthy that the above-mentioned Hungarian 1993 list of 10 thousand registrable names (i.e. the longest one) was the product of simply compiling all the given names actually in use in Hungary in that year. Interestingly, the same organising principle (which might jokingly be epitomised by a citation from Alexander Pope: "Whatever is, is right") was proposed in Norway in the discussion conducted at the beginning of the $21^{\text {st }}$ century:

The committee appointed by the Department of Justice suggests that first names which are recorded in the national register may be allowed as first names, which is criticized by the onomastic group. This register contains about 40,000 forms of names (including variants of spelling), and many names have only one bearer (Brylla 2002: 366).

Whereas ten thousand names on the Hungarian list appears exaggerated, in some states the number of given names on contemporary name lists is incommensurable: the 2008 edition of Internationales Handbuch der Vornamen, standard reference for German registry offices, comprised 65 thousand given names, including Arabic, Albanian, Kurdish and Vietnamese ones.

\subsubsection{Poland}

In post-war Poland a name list at the disposal of registry offices constituted a tool of a powerful de facto policy. As Zaporowska \& Mazurkiewicz ${ }^{243}$ emphasised, the law required only that the name should not be indecent or subject its bearer to ridicule, that it should be gender-specific and that an individual should not have more than two names. Since 1986 there has also existed a prohibition of diminutive names. In practice, as the authors (both of them lawyers specialising in

243 Janina Zaporowska [\&] Jacek Mazurkiewicz 1995. “Arabella, Wolfgang Amadeusz, Solidariusz”. Rzeczpospolita, Sept. 6. 
family law) observed, for many years it was practically impossible for the members of the German minority in Poland to register German names for children (e.g. Klaus instead of Mikołaj), for Polish Muslems to register Islamic names, or for the members of the Sabbath Day Christian Church (Pol. Kościół Chrześcijan Dnia Sobotniego) to register Old Testament names. The source of the decisions of registries were these lists, which had no legal basis. Since 2015, in view of the liberalisation of the name-giving rules, the role of such lists diminished considerably. Interestingly, in 2008 a list of standardised Kashubian (minority) names was published (cf. Breza 2008).

\subsection{Forbidden names, by category and individually}

Forbidden names in a given state often share a common ethnic characteristic. For instance, in the Habsburg monarchy the 1787 decree by emperor Joseph II explicitly excluded "Jewish names or names otherwise unknown in the German language" (Bering 1992: 35). That particular regulation, the aim of which was to Germanise the given names of Jews, went hand in hand with the policy of making German the compulsory language of officialdom in the Habsburg Empire.

In the Third Reich, Old Testament names were off-limits for German children:

No German child can be called Lea or Sara; if an unworldly priest were one day to come up with the idea of registering such a name, the registrar would refuse to enter it and the priest's complaint would be dismissed from on high (Klemperer 2006: 72).

In modern times there still exist categories of forbidden given names, such as Kurdish names in Turkey, or - until recently - Amazigh (Berber) names in Morocco. As Morocco's Law on the Civil Registry stated, given names had to be "Moroccan in character". Until 2013, the way local administration interpreted this regulation amounted to the 
acceptance of Arabic-Islamic names only, to the exclusion of Berber ones, although Berbers are indigenous to Morocco. Paradoxically, given names taken from Turkish and Mexican soap operas broadcast in Morocco were accepted by registry offices. Those parents who insisted on Amazigh names faced a long court struggle and a temporary legal limbo for the unnamed child ${ }^{244}$. Moreover, Moroccan government used to send out to European countries lists of acceptable (i.e. ArabicIslamic) names to bestow on the children of Moroccan immigrants (many of whom retain double citizenship to ensure problem-free visits to their Moroccan families), thus enlisting their unwitting support. ${ }^{245}$ However, under the pressure exerted by human rights organisations, in 2013 it was released to the media that

Moroccan Interior Minister Mohand Laenser announced at the House of Representatives that the ministry has sent a memorandum instructing Moroccan civil registry services across the kingdom to start accepting applications for registration with Amazigh names. ${ }^{246}$

The same policy with regard to names of Turkish immigrants to European countries is still pursued by Turkey.

In January 2011 it was released to the media that Azerbaijan was to introduce a new name law. The law was to forbid "the names of persons who have committed aggression

${ }^{244}$ Cf. "Morocco: Lift Restrictions on Amazigh (Berber) Names" 2009. Human Rights Watch, Sept. 3. http://www.hrw.org/en/news/2009/09/03 /morocco-lift-restrictions-amazigh-berber-names, Dec. 3, 2016; Rabat (Hassan al-Ashraf) 2009. "Morocco bans Berber names on birth certificates". Al Arabija News, Jan. 12. http://www.alarabiya.net/articles /2009/01/12/64095.html, accessed Dec. 3, 2016.

${ }^{245}$ Paweł Szczerkowski 2007. „Holenderski imigrant walczy z muzułmańskimi imionami" [a Dutch immigrant fights Muslim names]. Gazeta Wyborcza, June 2, p.10.

${ }^{246}$ Larbi Arbaoui 2014. "Morocco Lifts a Ban on Amazigh Names." Morocco World News, March 21. https://www.moroccoworldnews.com/2014 /03/125938/morocco-lifts-the-ban-on-amazigh-names/, accessed Dec. 3, 2016. 
against the Azerbaijani people." Other unconditionally forbidden names are those with offensive meaning in Azerbaijani; those with negative meaning in other languages are subject to conditional ban (cf. Azerbaijan..., 2011).

By contrast, the reason to forbid a particular given name is frequently political, religious or cultural rather than ethnic/linguistic. For instance, a name might be associated with a criminal, an infamous person known from history, or a political opponent of those in authority. In October 2002 a law was passed in Jordan stating that names were not to "violate religious or social values, nor disturb public order". On the list of forbidden names which accompanied the law, there figured Usama bin Laden, Yitzak Rabin and Golda $M e i r^{247}$. The name Osama bin Laden, which a Turkish couple wanted to bestow on their son, was in 2002 rejected in Germany

da dieser eindeutig die Assoziation mit dem gleichnamigen Muslim-Extremisten hervorrufe und der Name auch in der Türkei nicht gebräuchlich oder zulässig sei. Nach deutschem Recht dürfen Eltern Kindern keine Namen geben, die die Würde des Kindes verletzen ${ }^{248}$.

O. Felecan (2014: 138) invokes an example of the ban on naming a child Nicolae Ceauşescu, issued in Romania in 1978, while the child's potential namesake was still in power as a dictator of Romania. As Felecan notes, the Communist party did not approve the request.

In November 2016 a boy in France was baptised with the name Mohamed Merah, the name of a terrorist who in 2012 killed seven people in and around the city of Toulouse.

${ }^{247}$ Cf. Alan George 2005. Jordan. Living in the Crossfire. London: Zed Books, p. 56.

248 "Namensfindung: Kölner Baby heißt nicht Osama Bin Laden." Spiegel Online Sept. 10, 2002. http://www.spiegel.de/panorama/namens findung-koelner-baby-heisst-nicht-osama-bin-laden-a-213292.html, accessed Dec. 3, 2016. 
The authorities intervened and a prosecutor announced an investigation into the parents' motives ${ }^{249}$.

The names Jesus Christ and Ned Kelly ${ }^{250}$ as given names were rejected in Australia on the grounds that bestowing them on children was "contrary to the public interest" as stated in the 1995 Registration Act ${ }^{251}$. Allah as a boy's name was in 2009 rejected in Sweden:

Skatteverket legal expert Lars Tegenfeldt told The Local that devout members of the public might take offense to certain names with highly religious connotations.

"God or Allah or the Devil is offensive to the public. Not me personally, but there are religious people who think so," he said. "Some religious names though, like Jesus, are normal," he $\operatorname{added}^{252}$.

Similarly Germany forbids Biblical names with negative connotations (e.g. Judas, Kain) and until 1998 it also banned the name Jesus. In 1998, however, the Higher Regional Court in Frankfurt accepted that name, so now it can be given to babies, though it is still not popular in Germany (in contrast with Spain or Portugal) ${ }^{253}$. The name Jesus Christ and similar names are differently treated in the USA. According to statistics, in 2012 over 800 US-born children were named Messiah, nearly 4,000 were named Jesus, and 29 baby boys

249 "France moves to stop parents naming baby after terrorist". The Local, Nov. 18, 2016. http://www.thelocal.fr/20161118/france-moves-tostop-baby-getting-terrorists-name, accessed Dec. 10, 2016.

$25019^{\text {th }}$ century Australian outlaw and gang member, treated by some as a folk hero and icon of culture symbolizing the defiance in resisting British rule.

${ }^{251}$ Nick Leys 2009. "Metallica's Fine, but Not Ned Kelly.” The Sunday Telegraph, Sept. 19.

${ }^{252}$ Charlotte West 2009. "Parents refused right to name son Allah." The Local, Dec. 23. http://www.thelocal.se/20091223/24024, accessed Dec. 3, 2016.

${ }^{253}$ Cf. Knud Bielefeld, no date. "Jesus." http://www.beliebte-vornamen .de/4615-jesus.htm, accessed Dec. 3, 2016. 
were named Christ ${ }^{254}$. In 2013 an attempt by court in the US town of Newport, Tennessee was made to enforce on parents a change of their baby's name from Messiah to Martin, but the ruling was soon overturned in a second instance court ${ }^{255}$.

The strongly marked name Hitler as a given name arouses equally strong official opposition in some countries, but not in others. The name Adolf Hitler, bestowed on a New Jersey boy by his parents (as well as the Nazi-inspired names of the boy's siblings, JoyceLynn Aryan Nation, Honzlynn Hinler Jeannie and Heinrich Hons), provoked no reaction of the state. It was only a supermarket that reacted: the order for a birthday cake with the boy's Nazi name written on it was refused by the shop manager. Interestingly, under New Jersey law the name is legal (cf. Larson 2011: 161). Rennick described a similar attempt at naming, made during the Second World War, which was similarly curbed not by the state but rather under the pressure of the public opinion: "In 1943 Joseph Mittel of Astoria, New York named his son Adolf Hitler. An outraged public, however, forced him to reconsider and he called the child Theodore Roosevelt instead" (1969: 205-6).

\subsection{Given names promoted by the state}

In certain cases, state authorities designed (or at least encouraged the creation of) new given names for children and then encouraged their use. Quite often such names were expressive of what was perceived as progressive ideas, revolutionary or religious zeal, and breaking with the rejected past.

For instance, the given names that became popular at the time of the Protestant Reformation comprised such unusual items as Accepted, Redeemed, Humility, Repentance, Sorry-

${ }^{254}$ Cf. Katy Steinmetz 2013. “Judge Resurrects 'Messiah' Name in Tennessee." Time Sept. 18. http://nation.time.com/2013/09/18/judgeresurrects-messiah-name-in-tennessee/, accessed Dec. 3, 2016.

255 Cf. ibid. 
for-sin, Praise-God, and even If-Christ-had-not-died-for-theethou-would-have-been-damned, effectively and paradoxically shortened to 'Damned' (cf. Smith 1970: 5). One can easily imagine how in the 'holier-than-thou' atmosphere of Protestant communities pressure could have influenced the flock, favouring such naming choices over the more usual options at the disposal of name-givers, such as the Old Testament names.

In a similar vein, after the French Revolution "many abandoned traditional Christian names and took advantage of article 7 of a decree of 20 September 1792, by which citizens could make a simple formal declaration before the registrar of their local municipality if they wished to select a new forename for themselves" ${ }^{256}$. New names included such revolutionary ones as Fleur d'Orange Républicaine, Droit de I'Homme Tricolor, Simon la Liberté ou la Mort, Lucius PlebEgal, Raison, Floréal or Themidor (the latter two being names of months in the revolutionary calendar). There were also others, revolutionary not by their semantic content but rather by the very fact of ostentatiously parting with prerevolutionary naming tradition grounded in Christianity. Thus novel names like Pomme, Fraise, Rhubarbe or Seigle became popular $^{257}$. By a paradoxical twist of fate, such new formations were expressly forbidden only a few years later, i.e. in 1803 , by the Loi de 11 Germinal an XI.

Policies that were also symbolically breaking the link with the rejected past, and attempted to shape a new man were later implemented in the USSR and other countries behind the Iron Curtain. The new, state-accepted (and even state-promoted) ways of naming in Azerbaijan, which will be described here, are typical in that respect of a far wider-spread phenomenon.

In post-revolutionary Azerbaijan, there emerged such new names as Traktor, Kombayn, Narkom (from Russian 'Narodniy'

${ }^{256}$ Roderick Munday 1985. "The Girl They Named Manhattan. The Law of Forenames in France and England." Legal Studies, 5/3, 331-344, p. 332. Available online at: http://onlinelibrary.wiley.com/doi/10.1111/j.1748-121X. 1985.tb00331.x/pdf, accessed Dec. 3, 2016.

${ }^{257}$ Cf. ibid. 
Komitet - People's Committee), Raykom (from Azerbaijani or Rus. 'Rayon Komitesi' 258 - Regional [Communist Party] Committee), Tashkilat ('propaganda'), Malumat ('information'), Oktyabr (Rus. 'October') ${ }^{259}$, Mayis (after the $1^{\text {st }}$ of May), and names based on the name of V(ladimir) I(lyich) Lenin: Vilen, Vladlen, or Ninel ('Lenin' spelled backwards). Many of them were borrowings from Russian or calques from this language. Other names inspired by the Communist system included Azad for boys / Azade for girls ('freedom'), as well as masculine names Bakhtiyar ('fortune'), Saadat ('happiness'), Ingilab ('revolution'), Mubariz ('struggle'), Mubarak and Tabrik (both meaning 'congratulations') and Vugar ('pride'). Among female names, there were Irada ('will' or 'determination'), Matanat ('strength', 'steadiness', 'tolerance'), and Rafiga ('friend', 'companion' - suggesting comradeship with men in building the new society) (cf. Garibova and Blair 1996). The same trend existed in the early years of the Soviet Union in Russia, yielding such names as Lenera (Lenin's era) or Revdit (short for 'revolutionary child'), which in the years 1924-1930 were even included in Russian calendars (cf. Superanskaja 1995).

It is not surprising that analogous tendencies were present in other communist countries too. In Bulgaria this trend was manifested by the use of such items in the function of given names as Lenin, Vladilen (Vladimir + Ilič + Lenin), Stalineta, Vildiras (Lenin's initials $\mathrm{V}+\mathrm{I}+\mathrm{L}$ with di+ra+s $=$ 'dictature of workers and peasants') or Molot - after W.M. Molotov ${ }^{260}$ (cf. Selimski 1998: 106-107). "[Sometimes] a family, Selimski

${ }^{258}$ Rus. районный комитет (райком for short).

259 After the Russian Revolution of 1917, which, according to the Julian calendar in use in Russia at the time, took place in October (corresponding to November in the Gregorian calendar).

260 Vyacheslav Mikhailovich Molotov (1890-1986, Rus. Вячеслав Михайлович Молотов) - Soviet politician of the highest rank (in the years 1930-41 Chairman of the Council of People's Commissars of the Soviet Union), Foreign Minister and diplomat. Molotov was a pseudonym (from Rus. molot 'hammer'). His real surname was Skryabin. In a 2009 posthumous lawsuit found guilty of the 1930s famine in Ukraine (Holodomor). 
wrote, taking into account only the political circumstances, decides to bestow on a child a name that would manifest loyalty to the regime and that would set one on the career path" (1998: 106).

Names favoured by the state may express (sometimes transient) political preferences:

When USSR supported African nations in their struggle against colonialism, boys by the name Kokos 'coconut' or Afrikan were born. And in Russia names last not one, but two generations. I know a thirty-something-year-old man by the name Nikita and the patronymic Kokosovich.

It also happens that names may be harmful.

The cosmonaut Titov was born in 1935, when Stalin was friends with Nazi Germany. Then German names were often bestowed on children.

Thus Titov got the given name German. At the age of 26 he stood a good chance of becoming the first cosmonaut, but Nikita Khrushchev ${ }^{261}$ did not even want to consider the possibility that a country that had just defeated Nazi Germany should have a German as the first man in space. So Titov had to yield priority to the pure Slavic Yuri ${ }^{262}$.

261 Nikita Khrushchev (1894-1971, Rus. Никита Хрущёв), Soviet Communist party leader, First Secretary of the Communist Party of the Soviet Union in the years 1853-64. German Stepanovich Titov (1935-2000, Rus. Герман Степанович Титов) - a Soviet cosmonaut, the fourth man ever in space and the second man to orbit the Earth. Yuri Alekseyevich Gagarin (1934-1968, Rus. Юрий Алексеевич Гагарин) - Soviet cosmonaut, the first man ever in space.

${ }^{262}$ Wacław Radziwinowicz 2007. „, Olimpiada Kokosowna, wnuczka Dazdrawpiermy" [on unusual politically-inspired names in the USSR]. Gazeta Wyborcza, July 25. It is not certain to what extent the above account is true in the part regarding the motivation behind the choice of Gagarin over Titov. Many sources give as the motivation for Titov's given name the name of a hero from Pushkin's short story The Queen of Spades (Rus. Пиковая дама), first published in 1834. Incidentally, the hero of the story, Hermann (Rus. Германн), is described by Pushkin as German by descent. A similar anecdote can also be found on the official website of a Russian state television channel: "In one of the many myths surrounding the selection of the astronaut number one, head of the party and the country Khrushchev said 
A very unusual instance of a "promoted" given name comes from interwar Poland. By a 1926 decree of the then Polish president Ignacy Mościcki, every seventh son of a Polish family, baptised Ignacy (as a first or second given name), could become the President's godson. Before the honour was conferred, the boy's family members had been vetted for impeccable moral record and for purely Polish roots to the fourth generation backwards; the parish priest's opinion was also solicited. These children, of whom in the years 19261939 there were about 900, were dubbed 'born with a silver spoon': they were entitled to free medical care, free schooling and university studies in Poland and abroad, a scholarship, free public transport and discount transport for siblings, as well as a christening gift of approximately half a prewar teacher's salary on a savings account. In 2008 there were still almost 300 living godsons ${ }^{263}$.

It must be admitted that the category of favoured names is on the margin of language policy and close to the domain of individual naming choices. It is argued, however, that there is a definite difference between names chosen for the expected profits (however vague those profits might be), and - on the other hand - names chosen because they are in vogue, such as those of celebrities, famous athletes, soap opera characters, and so on. The former, I believe, constitute a legitimate domain of language policy, while the latter do not.

\subsection{Discouraged given names}

This category comprises both individual names and their whole sets, with various motivation - often national/ethnic or religious. A case in point might be the name policy of the

that a Soviet cosmonaut could not have a non-Russian name. Stepan Titov, a village teacher, gave his son the name in honor of Pushkin's hero The Queen of Spades - Hermann." ("Gherman Titov. First after Gagarin”, Pervyy kanal. http://www.1tv.ru/documentary/print/fi=6746, accessed Jan. 28, 2014)

263 Józef Matusz 2008. „Chrześniacy prezydenta Mościckiego” [President Mościcki's godsons]. Rzeczpospolita 263, Nov. 10-11. 
Third Reich. A scholar and at the same time eyewitness to the Nazi times in pre-war Germany recounted:

Am I really exaggerating so terribly when I talk of standardization? Perhaps not if one considers that a string of established forenames either fell into disrepute or were as good as banned. Christian names are particularly unwelcome; their owners are all too easily suspected of belonging to the opposition (Klemperer 2006: 70-1).

The above-mentioned policy affected a relatively clearly defined group of given names: Christian names. The reason for such a treatment of Christian names was the fact that most of them were derived from the Old Testament, routinely equated by Nazis with Judaism. The motivation may also be strictly ethnic/national, without the religious component, as the following extract illustrates. This time the undesirable given names were the names of German origin, associated with the Nazi occupation of Poland as well as with the German past of Silesia:

Wilhelm Szewczyk, a well-known journalist in Katowice ${ }^{264}$ and in his writing the Communist party line toer, confessed as late as September $1989^{265}$ regarding the attempts to have him change his given name: General A. Zawadzki suggested that I should change my given name to $\mathrm{Wiesław}^{266}$, promising that [if I did] he would have my statement about why I changed my German name to a Polish one, printed in thousands of copies, scattered from a plane all over Silesian towns. I resisted, putting forward the argument that I was using this name when I debuted as a writer before the war, that I was using this name in a Nazi prison or while working as head literary critic for a radio station; finally, I deployed the strongest argument:

${ }^{264}$ One of the biggest cities in Upper Silesia.

265 Shortly after the fall of the Communist system in Poland.

266 Pseudonym of Władysław Gomułka (1905-1982), Polish Communist leader, the First Secretary of the Communist Party in the years 1956-70. 
'My superior in Warsaw is called Wilhelm Billig...'

The general retorted:

'Well, but he's supposed to, he's a Jew.' (Pollok [c. 1998]: 58-9)

Pollok went on to describe the kind of routine that used to be followed in the case of such encouraged changing of discouraged given names ${ }^{267}$ :

Shortly after the positively vetted Silesians ${ }^{268}$ were granted citizenship, the campaign of changing foreign-sounding personal names and placenames started. "Citizens" used to be summoned to the seat of rada narodowa ${ }^{269}$ and there a clerk would say to them more or less the following words:

'You see, Schmidt, there are no such given names as Zygfryd in Poland. How about we change it to something more suitable, eh? Would you rather have Zygmunt or Zbigniew? Also regarding the surname, it would be a good idea to return to the old, ancestors' name - Kowal ${ }^{270}$. I'd personally advise Kowalski, though - will go down better. Kids will have it easier at school and work.'

'But that's the name I was given at baptism, and the surname I inherited from my father.'

'Mister Schmidt, you declared yourself Polish, so be consistent now. In Poland there are Polish given names, one mustn't use the German ones.' (Ibid.)

\subsection{Obligatory given names}

This category is not richly exemplified, yet all the more interesting for its rarity. As discussed in more detail above, in Nazi-occupied Warthegau newborn children of Polish and

${ }^{267}$ Pollok cited an extract from the article "Obrona Ślązaków" [in defense of Silesians] by Alojzy Bułą, Opole 1990, No 1, 6-8, 17-18.

268 Those inhabitants of Silesia who declared themselves Polish after WW2.

${ }^{269}$ An organ of local-level government in Communist Poland (19521989).

${ }^{270}$ Pol. kowal 'smith' corresponds to the German Schmied, from which the surname Schmidt is derived. 
Jewish ancestry were onomastically marked for their ethnicity by the officialdom, the practice that had its roots in prewar Germany ${ }^{271}$.

\subsection{Hyphenation and number of given names}

Some European states officially set limit on the number of given names that may be given to a baby. In Germany hyphenation in given names is allowed (e.g. Hans-Joachim, Georg-Berndt, Anna-Maria) and the limit of five given names is more of administrative practice than codified law, but there is another restriction resulting from the size of the ID card: given names, including spaces between them, must not exceed 28 characters $^{272}$. The Finnish law sets the limit of given names at three and hyphenated given names are admissible ${ }^{273}$. Estonian law admits three separately written names or two names connected with a hyphen.

Few states explicitly allow hyphenation in given names. Among those that do, there is France. Hyphenated given names are a tradition there and their emergence is attributed to the limitations of the Napoleonic law of April 1, 1803 (Loi de 11 Germinal an XI). By force of that regulation, only given names of Christian saints and famous personages of ancient history were allowed, which provision diminished the available pool of names. Therefore hyphenated given names such as Jean-Claude or Marie-Claire - became a way to enlarge that pool and they are in use even today, although the

${ }^{271}$ Cf. paragraphs $440-443$ of the German civil code - Bürgerliches Gesetzbuch - of 1938.

${ }^{272}$ Cf. Knud Bielefeld "Nur 28 Zeichen für die Vornamen." Oct. 14, 2010. http://blog.beliebte-vornamen.de/2010/10/nur-28-zeichen/, accessed Dec. 3, 2016.

${ }^{273}$ For the current Finnish language version of the Finnish name law see http://www.finlex.fi/fi/laki/alkup/1991/19910253?search\%5Btype\%5D $=$ pika\&search\%5Bpika\%5D=nimilaki\#highlight2, accessed Dec. 3, 2016. Unofficial English translation of Nimilaki [names act] 694/1985, with amendments up to 253/1991, has been provided by the Ministry of Justice, Finland (e-mail communication of June 18, 2010). 
restrictions of 1803 have been lifted. Other European states in which hyphenated given names are acceptable are Spain, Austria and Estonia. In Finland they are tolerated, though not encouraged.

An example of a European state that does not allow such names is Poland, where they are perceived as artificial coinages contrary to the Polish language tradition 274 (regardless of the fact whether they are spelt with a hyphen, Anna-Maria, or as one word, Annamaria). However, the refusal of such a name is a decision on the level of a particular registry office, since the law refers explicitly only to the condition that a child be given no more than two names. Regarding this name, RJP observed:

[I]n my opinion Poles perceive the names Anna and Maria as two separate, independent names, which require declension, so they must be written as separate words. The argument that these names may be written as one word in English or German, and used as one name, is irrelevant, since Polish - in contrast with both these languages, and especially with English - is an inflectional language. In German we write Ich liebe Annemarie or Ich liebe Anne Marie, in English we write I love Annamaria or I love Anna Maria, but in Polish our language intuition would have us say and write Kocham Annę Marię (not Annamarię). ${ }^{275}$

Still, Rymut (cf. 1995: 29) noted that 69 women and girls in Poland bore the name Annamaria in mid-1990s (however, there were none with the hyphenated version of the name).

${ }^{274} \mathrm{Cf}$. the negative opinions of RJP on the proposed names EdwardWładysław, Monika-Helena, Jakub-Izrael http://www.rjp.pan.pl/index.php ?option=com_content $\&$ view=category $\&$ id=76\%3Aopinie-o-imionach $\&$ Ite mid=58\&layout=default, accessed Dec. 3, 2016). For the legal point of view, see also http://e-prawnik.pl/domowy/prawo-administracyjne-1/zmiananazwiska/odpowiedzi/podwojne-imie-dziecka.html, accessed Dec. 3, 2016.

275 http://www.rjp.pan.pl/index.php?option=com_content\&view=article \&id=1056: annamaria\&catid=76\&Itemid=146, accessed Dec. 3, 2016. 
For different reasons, in the Third Reich hyphenated given names of Germanic origin were popular "owing to their rich sonority and two-fold profession of faith, i.e. their rhetorical character (and thus also their rightful place within the LTI): Bernd-Dietmar, Bernd-Walter, Dietmar-Gerhard..." (Klemperer 2006: 70).

\subsection{Models of relationship between majority and minority given names}

In this section five logically possible models of the relationship between majority and minority names will be proposed and then each of them will be discussed in more detail. In fact each of these models finds its reflection in reality, although some $(\# 1, \# 2, \# 5)$ are more commonly found than others. Before providing exemplification, it must be stressed that these five models relate only to official naming as approved by the state. Thus no mention is made of the fact that stricter language policies on names frequently make those who are the targets of those policies circumvent them by developing a parallel system of alternative, unofficial naming.

1. Strong assimilation, where members of a minority may only register and use officially the names characteristic of the linguistic / cultural majority. This type is typical for example of Lusatia in Germany before 2007. As mentioned above, this does not preclude the unofficial or semi-official use of minority names. For instance, until 2007 the Sorbian minority in Lusatia could use Sorbian names only in regional periodicals and books, in membership cards of regional organisations and in Sorbian schools, as well as privately - but not officially (cf. Rzetelska-Feleszko et al. 2002: 272). Similarly in Turkey only Turkish names can be legally given to Kurds or Assyrians (also only the Turkish alphabet is admissible in names, the fact which excludes the letters $W, Q$, $X$, present in many Kurdish names). Until 1993 (art. 57 of the 
French Civil Code), this model was also followed in France, where Breton and other minority names used to be forbidden (cf. Liberman 2008).

2. Weak assimilation. In this model a minority has two options available: minority names or majority names. However, for the majority only the option of majority names (often in the form of an officially accepted list) is open. This type is exemplified, among others, by the name policy in Slovenia. According to Article 3 of the 1987 Law on Personal Names (Official Gazette of the Republic of Slovenia, No. 2/87), "personal names of members of the Italian or Hungarian national minorities shall be recorded in the Italian or Hungarian script and form, unless otherwise decided by the members of these national minorities" ${ }^{276}$. It must be noted that this law also includes surnames.

This model is applicable to the situation in Slovakia too. "According to Law No. 300 of 1993 on first names and family names, minority names can be officially registered, for example, the Hungarian (Károly) or German (Karl) equivalents of Charles can be registered, as can the Slovak equivalent (Karol)"277. However, parents of Slovak nationality are obliged to choose names from the official Slovak list at the disposal of registry offices. Just as in the case of Slovenia, also in Slovakia the pattern comprises not only given names but also surnames (specifically, minorities do not have to add the Slovak feminine suffix -ová absent in German or Hungarian).

Model 2 remains in force in Poland too, even though the practice in Poland, just like in many other states that follow this model, does not necessarily reflect the theoretical guidelines and postulates set by the language regulators (in Poland - RJP).

276 Local Self-Government, Territorial Integrity, and Protection of Minorities. 1996. Strasbourg: Council of Europe Publishing, p. 159.

277 Gizella Szabómihály Gramma 2006. "Language Policy and Language Rights in Slovakia”, p. 19. http://81.184.1.14/mercator/pdf/wp23 eng.pdf, accessed Dec. 3, 2016. 
3. Weak dissimilation: this is not a common option in today's Europe. On the contrary, nation-states quite frequently follow the policy of assimilation, so the majority version of names is given a priority. However, there are exceptions. Until recently, Dutch Moroccans could only choose Moroccan names (whose list was provided by the state of Morocco), though ethnic Dutch were and still are free to choose any name they like - so in theory also Moroccan names.

4. Strong dissimilation. It is not frequently met either and the context for its application is mostly racial and segregationist. Thus during the Second World War in Nazioccupied Wartheland (western Poland of today) Jews were obliged to have only Jewish names, Poles - Polish ones, and Germans - German ones. This was seen as one of the measures to prevent the mixing of races and to separate the "Übermenschen" from the "lower races".

5. The laissez-faire model is typical of the Anglophone countries, which have a tradition of the common law. The state does not interfere into the personal naming of citizens, with the possible exception of the omission of non-English diacritics. Even gender-specific surname suffixes of Slavic languages tend to be accepted upon request ${ }^{278}$. Nevertheless, it is usually not possible to register a name in a script other than the Latin script.

The following graph shows into what relationships given names may enter:

${ }^{278}$ Helen Chocieszynska, personal communication. 




1. Strong assimilation



3. Weak dissimilation

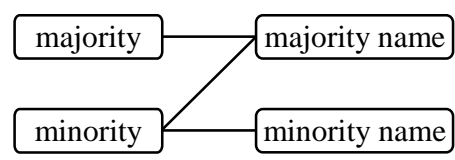

2. Weak assimilation

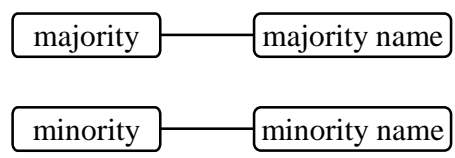

4. Strong dissimilation



5. The laissez-faire model

Similar models can be applied not only to given names but also to naming patterns as such, where under the term naming patterns will be understood the possible officially ${ }^{279}$ acceptable combinations of given name/s (and surname/s) that together form an individual's official full name. In most states of the Western cultural circle the possible naming patterns are the following ${ }^{280}$ :

1) $\mathrm{GN}(+\mathrm{GN})+$ FN: Albert Einstein, Juan Antonio Samaranch

2) $\mathrm{GN}(+\mathrm{GN})+\mathrm{FN}+\mathrm{FN}$ (two family names, optionally linked by a hyphen or a conjunction): Frances Hodgson Burnett, Montague Francis Ashley-Montagu, Miguel de Cervantes y Saavedra

${ }^{279}$ As opposed to unofficial naming, which will here be termed naming practices.

${ }^{280}$ Note that, of the so-called "Western" cultures, the Hungarian convention reverses the GN/FN order. 
3) GN-GN (two given names linked by a hyphen and treated as a unit) (+ GN) + FN: Jean-Paul Belmondo, JeanBaptiste Camille Corot

4) $\mathrm{GN}+\mathrm{MN}+\mathrm{FN}$ : John Fitzgerald Kennedy

5) GN + P/M: Björk Guðmundsdóttir, Heiðar Helguson

6) GN + P + FN: Лев Никола́евич Tолсто́ú (Lev Nikolaevich Tolstoy)

Nevertheless in the case of naming patterns basically two models are possible: the most common strong assimilation model - e.g. Russian names in Lithuania are deprived of their patronymic part, foreign names in Iceland until recently were remodeled so that the family name was discarded and replaced with a patronymic; and the relatively rare laissez-faire model, such as that of Indonesia, where mononyms are officially accepted alongside various Western patterns. 


\section{Surnames \\ 4.1. Compulsory adoption of surnames}

At some point in their history, mostly in the $18^{\text {th }}-19^{\text {th }}$ centuries, European countries made surnames obligatory for all their citizens. When this "project in official legibility" (Scott 1998: 65) was being carried out, customary surnames for at least certain classes of people had already been known in Europe for many centuries. In China their history was even more impressive, going back to the $4^{\text {th }}$ c. B.C ${ }^{281}$. The assumption of surnames in many countries of Europe coincided to a degree with the gradual introduction of individual rather than group responsibility, accountability and registration (censuses switched from registering households to registering individuals, though at first only males).

Thus, for example, in 1771, by force of the king of Denmark's decree, all inhabitants of the Duchy of Schleswig were to assume fixed surnames - all children were from that moment to be bestowed at baptism with a surname alongside the given name. It was at the discretion of the parents to choose the surname. Many used the hitherto used bynames, others adapted patronyms, which often led to the addition of a real patronym before the new surname in further generations. A similar law in Denmark was introduced only in 1828, even though the first law on names in Denmark, making it compulsory (for the gentry only) to bear fixed family names, dates back to the year 1526 (cf. Holmberg 2005: 1316-7). In the France-annexed Netherlands, by Napoleon's decree of 18 August 1811 (No. 7178), all citizens who at the time had no surname were obliged to take one. The widespread belief that the Dutch people did not treat this law seriously and, resisting

281 "By roughly the fourth century B. C. (although the exact timing and comprehensiveness are in dispute), the Qin dynasty had apparently begun imposing surnames on much of its population and enumerating them for the purposes of taxes, forced labor, and conscription" (Scott 1998: 65). As mentioned above, in China the so-called Eastern order of personal names is followed, with the surname preceding the given name. 
Napoleonic rule, invented ridiculous names in the conviction that the surnames were to be only temporary is probably largely a myth (cf. Joor 2009), though many contemporary Dutch surnames are indeed unusual: Zeldenthuis ('seldom at home'), Zondervan ('without a surname'), Naaktgeboren ('born naked'), or Suikerbuik ('sugar belly').

Among some ethnic groups of the Habsburg Empire such as Hungarians, Croatians, Poles, Slovaks and Germans surnames evolved over time and came into use in a natural way. Other groups, however, began using fixed surnames only as a consequence of the $18^{\text {th }}-19^{\text {th }}$ century decrees (as for instance Gypsies in 1783), and the Greek Orthodox (mostly Serbian) minority by force of the decree by Franz I in 1817 (cf. Bering 1992; Farkas 2007, 2009, Farkas and Maitz 2008). And obviously a sizeable group comprised the Austrian Jews, of whom more is to follow.

In the following part of this section three different surname-bestowing policies on three groups of hitherto unsurnamed citizens will be presented and compared: Ashkenazi Jews in Central and Eastern Europe $\left(18^{\text {th }}-19^{\text {th }}\right.$ century), Filipinos in the years 1849-50, and the Sioux at the beginning of the $20^{\text {th }}$ century. Each of these three groups had different characteristics, represented different cultures and religions, and responded differently to the enforced state policies. Nevertheless, there were common denominators as well. First and foremost, the chief motivation behind the name policy in each case was what might be provisionally termed "enlightened pragmatism": modernising societies needed subjects who could be made to pay taxes, who could be conscripted and who could easily be controlled. For this reason surnames were needed. What is more, those surnames had to be "legible" to those in power (cf. Scott 1998: 65). Therefore Jews in Austria had to assume German surnames, while in Russia - Russian ones, complete with the traditional Russian patronymics. In the Spain-governed Philippines the indigenous population was given Spanish-language names, 
easily recognisable as such by the officialdom. In the USA the names of the Sioux were given the English veneer. What name illegibility meant for those in power was shown by Scott et al. on the example of a couple of Indian names, which, even if literally translated into English, were hardly any more comprehensible to non-native Americans:

[T]he recorded names were only one of many possible phonetic renderings $[\ldots]$ Had there been standard rules for transliteration and had the recorders of names followed these rules rigorously, the results would have still been mystifying and unpronounceable to white officials.

There were two further problems from the point of view of government agents. First, even translated names that could be understood came in an incompatible format. Take, for example, the names "Barkley-on-the-other-side," "Alice shoots-as-shegoes," "Irvie comes out of fog" [...] The given name is clear, perhaps, but what should be taken as the surname: the whole phrase, the last word...?

Secondly, and more seriously, the indigenous naming system only rarely gave any indication of sex and family relationship [...] As we shall see, such illegible naming practices were unsuited to the twin normative legal requirements of civilized life: property ownership and marriage by law (2002: 19-20).

Jews in the Austrian (since 1867 Austro-Hungarian) Empire were to receive their obligatory surnames by force of a decree of July 23, 1787, issued by Emperor Joseph II, which also made it effectively obligatory for Jews to assume German - i.e. not Hebrew or Yiddish - given names).

The law that required Jews in Russia to assume surnames appeared in 1804, though the process was gradual and extended in time throughout the $19^{\text {th }}$ century. Evidently not everybody complied if the law had to be repeated thirty years later (Zax 2008: 3). Once adopted, the surname could not be changed. A prominent Russian poet and - in the years 18021803 - Minister of Justice wrote: 
[A]ll Jews need to add to their name and patronymic ${ }^{282}$ a Russian surname. For example, Nota Khaimovich Zamyslavatyi, Leiba Itskovich Promyshlennyi, Khatskil Mordukhovich Dikii, Leizar Movshovich Derevenskii, etc. - announcing the abovementioned to everyone, in order for each Jew to remember and be called by a surname. ${ }^{283}$ (Quoted and translated from Russian by Avrutin 2005: 161)

The first law in France that made surnames mandatory appeared in 1792 and concerned all citizens alike, not only those of Jewish extraction (ibid.). By Napoleon's decree of July 20, 1808, all Jews in France were required to assume fixed surnames (and fixed given names as well) and to make a declaration to that effect to the registrar of the municipality where they were residing:

Art. 1er. Ceux des sujets de notre Empire qui suivent le culte hébraïque ${ }^{284}$ et, jusqu'à présent, n'ont pas reçu de nom de famille et de prénoms fixes, seront tenus d'en adopter dans les trois mois de la publication de notre présent décret, et d'en faire la déclaration devant l'officier d'état civil de la commune où ils sont domiciliés. ${ }^{285}$

After Napoleon's defeat, many Jews from countries captured by Napoleon (Prussia and Russia) reportedly returned to patronymics ending with - sohn ${ }^{286}$.

282 The Jewish patronymic coincided with the traditional Russian отчество.

283 Gavrila Romanovich Derzhavin 1872. "O sochinenii novoi evreiskoi pogolovoi perepisi”. Sochineniia Derzhavina, vol. 7, St. Petersburg: ed. Imperatorskoi Akademii Nauk, p. 273.

284 The wording of the law referred to the religion rather than to ethnicity.

${ }^{285}$ Décret de Bayonne, Bulletin des Lois de l'Empire français, 4e série, tome 9, Paris août 1809, pp. 27-28, décret $n^{\circ} 3589$. http://www.genami.org /culture/fr_decret-bayonne.php, accessed Dec. 4, 2016.

286 Cf. "Jewish Family Names" 2012 (updated). New South Wales Board of Jewish Education. http://bje.org.au/course/jewish-self/family/familynames/, accessed Dec. 4, 2016. 
In Prussia the first obligatory surnames were introduced as early as the last decade of the $18^{\text {th }}$ century in Silesia, with the rest of Prussia gradually following suit in the next century - e.g. in Posen (Poznań) under Prussian rule in 1833. Other German states of the time also introduced similar regulations: Frankfurt am Main ${ }^{287}$ in 1807 , in Rhineland and Westphalia (Rheinland-Westfalen) under the French rule in 1808, in Baden in 1809, in Bavaria (Bayern) in 1813, and in Saxony (Sachsen) in 1834 (Farkas and Maitz 2008: 22). Just as in the case of the newly acquired surnames in the Netherlands, also in Prussia the unusual semantic meaning of some of the surnames newly bestowed on Prussian Jews led to the popular lore about the circumstances of their origin. E. T. A. Hoffmann ${ }^{288}$, among others, is believed to have whimsically and thoughtlessly coined many of them. The following account, however, is merely literary fiction:

Mr. Hoffmann does not receive clients every day, since he is usually occupied with his writing, and when he does condescend to see them, he is in such a hurry that one is not allowed to ask him anything. Before dinner, on an empty stomach, he issues serious or melancholy surnames, after dinner more amusing ones.

In the office, Hoffmann sits with his back to the window looking fiendish [...] He glares at the client in deathly silence, and then shouts out the first word which comes to mind. This word, which the clerk enters into the Register, becomes the client's official surname [...]

Today being Friday, we learned that Mrs Hoffmann, who is a Polish Catholic, had served him pike in parsley sauce for dinner, so he has been handing out nothing but the names of fishes... Last Sunday, he was given a bouquet of roses after

${ }^{287}$ Part of the Principality of Aschaffenburg (Fürstentum Aschaffenburg) since 1806.

${ }^{288}$ German Romantic writer and composer (1776-1822). In the years 1804-1806 he worked in Warsaw (which at the time belonged to Prussia) as a Prussian administration clerk responsible for registering (and according to some sources maybe also inventing) surnames for Jews. 
conducting the local choir, so all day Monday he handed out the names of roses. Everyone was reasonably satisfied, except for the merchant who is now called Mr. Rozenmedchen. On another occasion having visited the district of Warsaw where cage-birds are sold, he came back to the office and created a mass of Vogels. Once, when Hoffmann had been playing the organ in church, he issued a string of surnames with a religious flavour, such as Helfgot, Himmelblau, Kadzidło (Incense), Paniebożedopomóż (Help-Us-Good-Lord), Bożakrówka (Ladybird, or literally 'God's Cow'), and so on.

Or again, one night Mr. Hoffmann went drinking with a Prussian Colonel. In the morning he ordered cold water to be poured over his head, arrived in the office in a fine humour, and started issuing military surnames such as Festung, Fojer, Pistolet, Szyspulver, Trommel, Trompeter, Harmata. That's as far as he got, because the rest of his clients fled (Davies 2001, no pagination).

The cited passage appeared in English translation in the study Heart of Europe by Norman Davies. The Polish title of the source he cited translates into English as Filipek's Memoirs $^{289}$, and perhaps this is why Davies seems to have treated it as a historical source. In fact the said Filipek is a fictitious character and the author of the book - Władysław Zambrzycki - mystifies the reader claiming he is merely publishing a manuscript written by an anonymous, bright guttersnipe whose only revealed identity is his given name Filipek ${ }^{290}$. Zambrzycki's facetious literary account of the surname bestowals by Hoffmann started its own apocryphal life, especially after its translation by Davies made it accessible to Anglophone readers. Thus completely fictitious

289 Władysław Zambrzycki 1956. Pamiętnik Filipka. Warszawa: Czytelnik, pp. 116-8.

${ }^{290}$ Cf. Jan Styczeń 1956. "Nowe książki o Warszawie" [reviews of new books about Warsaw, including the review of Zambrzycki's book]. Stolica 44. http://www.zambrzycki.eu/smedia/ftp/o_ksiazkach/filipek/styczen_nowe _ksiazki.pdf, accessed Dec. 4, 2016. 
surnames apparently invented by Zambrzycki are cited in all earnestness to this day as historical fact ${ }^{291}$.

A similarly apocryphal and probably invented story about a Galician $^{292}$ Jew is cited by Zax (2008):

The Jew Eliuser, son of Naphtali, a Levite, was called up. He is 50 years old. Nicknamed Der Lahme (the lame). Has a wife Rebekche and daughter Gitel. Lives in his own little house near the water (the Sered ${ }^{293}$ River). Earns a living as a teacher of the Talmud and biblical writing. He was asked what he wanted to be called. Gave no answer. Was asked again. Cried (weinet) and groaned (stöhnet). Gave no answer. The name Weinstein was given to him and all his descendants; recorded.

The above does not mean that all the circumstances described by Zambrzycki were pure fiction. In fact, there were surname-giving commissions in Austria, Prussia and other German states before the unification of Germany (1871), and there are reasons to believe that in order to make the procedure easier and more efficient, most surnames (Zax 2008 sets their proportion in some parts of Galicia at over eighty per cent) were artificial, composed of two morphemes: Gold-, Silber-, Fein-, Rose-, Blum-, Sonne- were combined with -au, -bach, -berg, -garten, -haus, -zweig. Thus the resulting surnames had the semantic meaning of, for instance, 'silver branch', 'golden garden', 'rose meadow', etc., making the newly acquired surnames of Ashkenazi Jews so formulaic and recognisable until today. This circumstance in turn led to the stigmatisation of Jews in Germany and other European states (cf. Bering 1992: passim).

${ }^{291}$ It is only symbolic that in the years 1947-59 Zambrzycki was a columnist of a sensational Warsaw daily Express Wieczorny and his column originally bore the heading "Let him believe, whoever wants to."

292 The name Galicia (derived from Halych, Ukr. Галич, the name of a town in Ukraine) refers here to a historical region, comprising what is today partly south-eastern Poland, partly western Ukraine.

${ }^{293}$ A rare spelling variant of the river name Seret (today in Ukraine). 
Outside Europe, an interesting insight into the European name policies targeted at the subjugated populations of colonies overseas is offered by the story of Filipino surnames, discussed here on the basis of Scott (cf. 1998: 69-71), Zorc (1995) and Santos (1995-1998). A two-name system existed in the Philippines even before the arrival of Spaniards, which consisted of a given name accompanied by a surname in the form of a (non-inheritable) byname alluding to a physical feature, or a teknonym which defined an individual by referring to one of his/her children. Remarkably, some of these pre-Hispanic bynames (in Tagalog called banság) are still in use today as nicknames ${ }^{294}$, testifying to the resistance of the indigenous population against the imposition of Spanish culture.

The Spanish colonisation of the islands began as early as the $16^{\text {th }}$ century; the surnaming project, however, started only in the middle of the $19^{\text {th }}$ century with the decree of November 21, 1849, by Governor Narciso Claveria y Zaldua. The rationale behind the top-to-bottom imposition of surnames was to facilitate tax collection. To this end, Spanish subjects in the Philippines had to be precisely identified. It is ironic that the previous policy of Christianisation was only too successful in the islands - consequently, too many Filipinos adopted as their new surnames the names of saints promoted by missionaries, thus creating a multitude of unrelated people with the same surname, such as Santos or San Antonio. Apart from grouping people by families (which was not possible within the old system of bynames or teknonyms), the new scheme was to combat such isonymy too.

To this end, Claveria decided to use a catalogo, i.e. an alphabetical list of not only personal names but also names of plants, animals, minerals, geographical names, words to do with art, etc. Pages of the catalogo were then distributed among the local clerks so each locality obtained pages

${ }^{294}$ Cf. Mellie Leandicho Lopez 2006. A Handbook of Philippine Folklore. Quezon City: The University of the Philippines Press, p. 111. 
beginning with different letters of the alphabet in the following fashion:

Beginning with $\mathrm{A}$ at the provincial capital, the letters $\mathrm{B}$ and $\mathrm{C}$ mark the towns along the coast beyond Tabaco to Tiwi. We return and trace along the coast of Sorsogon the letters $\mathrm{E}$ to L; then starting down the Iraya Valley at Daraga with M, we stop with $\mathrm{S}$ to Polangui and Libon, and finish the alphabet with a quick tour around the island of Catanduanes (Scott 1998: 69).

To ensure the observance of the new naming system, it was forbidden to use any other names in schools. The teachers were made responsible for that and even punished for not complying. All documents that used surnames different from the newly bestowed ones or that did not mention those surnames were declared null and void. Paradoxically, the success of the enforced policy led to the situation where it soon became impossible for the state to trace pre-reform property ownership and tax collection - due to the old names being so quickly and so successfully forgotten. Also, given relatively low spatial mobility in the Philippines, the initial letters of Filipino surnames of Spanish origin can even today provide reliable information on the hometown or native village of the surname's bearer.

A different course of action was adopted in the first decade of the $20^{\text {th }}$ century to bestow on each member of the Sioux population in the United States a permanent surname. Each surname was "selected for its euphony and appropriateness from among the various cognomens in use among them [the Sioux], of course suppressing mistranslations and grotesque or coarse nicknames calculated to embarrass the educated Indian" (Eastman 1915). Charles Eastman (Ohiyesa, Ohíye S'a), the person who wrote these words, was a native American commissioned by president Theodore Roosevelt to assist the Sioux with the process of acquiring legal surnames in order to prevent them from being cheated out of their land. Indian names had to be made compatible with the American 
standard of naming; also the problem of Indians traditionally changing their names during lifetime to make them correspond to the different stages in life needed to be addressed and some name stability had to be achieved. The project was conducted in the years 1903-1909. Eastman recollected:

My instructions were that the original native name was to be given the preference, if it were short enough and easily pronounced by Americans. If not, a translation or abbreviation might be used, while retaining as much as possible of the distinctive racial flavor. No English surname might be arbitrarily given, but such as were already well established might be retained if the owner so desired. Many such had been unwisely given to children by teachers and missionaries, and in one family I found a George Washington, a Daniel Webster, and a Patrick Henry ${ }^{295}$ ! (Eastman 1915).

The example of the Sioux names ${ }^{296}$ show what types of problems Eastman must have encountered in his work. First, some names were simply too long and too difficult to pronounce to be admitted as American surnames: thus the Indian female name Tateyohnakewastewin (meaning 'she-whohas-a-beautiful-house') got "shortened" to Goodhouse. Second, many Indian names were composed of more than one word: High Eagle, for example was changed to Higheagle and Bob-tailed ${ }^{297}$ Coyote became Robert T. Wolf. Third, there were derisive names, such as Rotten Pumpkin, and these needed to be made more acceptable to their bearers - the abovementioned one was altered to sound Robert Pumpian. Fourth,

295 Daniel Webster (1782-1852) was a conservative politician, Congressman, senator and Secretary of State. Patrick Henry (1736-1799) was an American politician and one of the Founding Fathers, fighting for American independence.

296 Raymond Wilson 1999. Ohiyesa: Charles Eastman, Santee Sioux. Champaign: University of Illinois Press, p. 127.

297 A play on words: Bob-tailed - 'with a tail cut short', Bob diminutive for Robert; the middle initial T. looks like the abbreviation of the word tailed; coyote and wolf might be associated on the basis of similarity. 
there were native Indian names that had none of the above drawbacks, and these were preserved as surnames, a case in point being the name Mateska 'White Bear', turned into a surname.

The project covered about 25 thousand surnames. Though by today's LHR standards perhaps it was somewhat controversial, overall, it is positively evaluated today:

Although the renaming project can be viewed as part of the overall assimilation programs of the late nineteenth and early twentieth centuries, it was more than just a blatant assault on Indian naming practices, especially in regards to Eastman's participation. Of course, some beautiful Indian names were drastically altered, but, in most cases, Eastman tried to preserve the initial meaning of the original names. Those Indians possessing absurd or derogatory names benefited as well by receiving proper names. ${ }^{298}$

The explicit preference for the original native American name, as well as express respect for the Indian culture make the project stand in sharp contrast to many similar European initiatives targeted at Native Americans, where policymakers were not as considerate. For comparison, the practice followed with the Apaches might be considered, as illustrated by the story of the life of an Apache named Chevato:

Chevato's daughter, Mineha, had been forced to attend the agency school from about the age of seven, where she was renamed Carrie Heath [...][T] he English names bestowed prior to 1889 at least bore some relation to the translation of a person's Indian name, and the naming policy was only applied to about one-third of the population. When Cowart ${ }^{299}$ took over as agent, however, he decided that everybody must have an English name, and most of the names he chose bore no relation whatsoever to

298 Ibid., p. 128.

${ }^{299}$ Fletcher J. Cowart was in 1880s an Indian agent, i.e. a person whose responsibility was to interact with Indians on behalf of the US government and to help assimilate them. 
any translation from an older, Indian name. When Chevato was informed in 1889 that his name was now to be Jasper Antrim, he absolutely refused to be recorded in this way on the agency rolls. Prior to 1889 Chevato's name had simply been translated from Spanish to English, and he was recorded as William Goat or Billy Goat. After his refusal to be known as Jasper Antrim, he did acquiesce to the name of William Heath $[\ldots]^{300}$

In 1920s obligatory surnames for all citizens were introduced in Norway. Many former patronymics or farm names were used in this function.

On June 21, 1934 the Surname Law in Turkey made it obligatory for all citizens to acquire surnames (at the same time making illegal the use of titles, such as effendi or pasha). Until then, Muslims in Turkey typically did not use surnames, unlike the Turkish Jews or Christians (Armenians, Greeks) ${ }^{301}$. In its Art. 3 the law stated that 'the names of tribes, foreign races and foreign nations' were forbidden as surnames (cf. Casier and Jongerden 2010: 73). The law went hand in hand with other attempts to modernize Turkey, which included, among others, the abandonment of the Arabic script and adoption of the Roman alphabet for Turkish (1928), the 1925 introduction of the solar (Julian) calendar, the abolition of the fez (the 'Hat Law' of 25 November 1925), the introduction of the European civil, penal and commercial codes, and a ban on polygamy (cf. Türköz 2007). Interestingly, old habits die hard: it was not until 1950s that telephone directories in Turkey started sorting entries alphabetically according to the surname and not - as previously - by the given name (cf. Scott et al. 2002: 40).

300 William Chebahtah [\&] Nancy McGown Minor 2007. Chevato: The Story of the Apache Warrior who Captured Herman Lehmann. Lincoln, NE: University of Nebraska Press, p. 147.

301 In theory, these groups did not need new surnames. In practice, many changed their already existing surnames to new, Turkish ones. 


\subsubsection{Previous names as surnames with new given names}

The above examples show that surnames, wherever they did not evolve naturally over centuries, were bestowed on the population basically to complement the already existing given names. Sometimes, however, the opposite took place in the European cultural circle, including the regions outside Europe colonised by Europeans: the hitherto existing names were shifted into the domain of surnames, while new given names (usually Christian) were bestowed on the population. Consequently, from the point of view of the official/state /majority language (these three categories may, but do not have to, refer to the same language), given names became readily recognizable as such. For instance, as noted by Senn (1945: 128), the Grand Duchy of Lithuania's official recognition of Roman Catholicism (1386-1387) resulted in massive baptisms, which entailed the adoption of Christian given names. On that occasion, the previously borne name tended to become a hereditary surname, following the Western European model. Wenzel recounted a similar story of surnames in Lower Lusatia:

Mit der Christianisierung und der fortschreitenden Germanisierung begann ein ständig anschwellender Strom christlicher und deutscher Rufnamen, das alte Rufnameninventar zurückzudrängen. Ein entscheidender Umbruch trat mit dem Übergang von der Einnamigkeit zur Zweinamigkeit ein. Dieser Prozess begann in der Niederlausitz im 14. Jahrhundert, kam aber erst im 18. Jahrhundert mit der offiziellen Verwendung von Vor- und Familiennamen in allen Bevölkerungsschichten zum Abschluss. Bei der schriftlichen Fixierung der Hofbesitzer zwecks Einbringung der Feudalrente griff man auf die bisher gebrauchten sorbischen Rufnamen zurück, die damit aus der anthroponymischen Subklasse der Rufnamen in die Subklasse der Hofbesitzernamen, kurz Hofnamen, und später der Familiennamen überwechselten. Das war der entscheidende Grund dafür, dass sich viele slawische 
Rufnamen überhaupt erhielten. Die im Zweinamensystem entstandene Stelle der Vornamen besetzten fast ausschließlich deutsche und christliche Rufnamen (2008: 245).

That this phenomenon was not limited to Europe can be seen from the example of the names of the Inuit. Since the beginning of the $20^{\text {th }}$ century, the Inuit in Canada had been baptised by missionaries with Christian names - John, Mary, Abel, Noah, Solomon, etc. - which they used officially. Privately they nevertheless adhered to their traditional names such as Yugayugausiq, Arnaguatsaaq, Maatu, Makivik - of which each person could have several. Thus Ann Hanson, christened Annie, was at home called Lutaaq, Pilitaq, Palluq, or Inusiq (cf. Hanson n.d.). Similarly the Inuit of Greenland used their traditional names alongside the missionarybestowed biblical, or Danish, names (cf. Alia 2009: 46). However, the Inuit pronunciation of their baptismal names distorted these names beyond recognition, thwarting attempts at uniform recording: John would become Joanasie, Mary Miali, Abel - Ipeelie, Solomon - Salomonie (cf. Hanson n.d.). In Canada, Dr. MacKinnon, Medical Officer, complained in the 1930s:

It does not seem to ease our troubles [...] that [the Inuit] have in recent years taken their names from the Bible. A good example of this is in the rather common name of Ruth. The native cannot get his sounding mechanism around the letter $\mathrm{R}$ at the first of the word. As a result different persons would write down the following when the native gave the child's name, Vrootee, Olootee, Alootah with other alterations along the same line. (Quoted in Alia 2009: 50)

Consequently, to ease identification for official purposes, in the 1940s the Inuit in Canada were given special identity tags in the shape of leather discs on a piece of string, which they were obliged to wear at all times and which contained their personal identity numbers. Many Inuit took this scheme as typical of the ways of the white man and even had no 
awareness of the fact that other Canadians possessed surnames. The disc system was finally abolished around the year 1970 [!], where Project Surname was being introduced. It is this project, aimed at the Inuit acquiring permanent family names, that in its effects parallels the Lusatian solution. Each Inuit family was to choose a permanent surname; in many cases the (traditional) given name of a relative was chosen. Consequently, the end result was, despite all the differences, exactly the same as in the above mentioned case of Lower Lusatia: a two-name system with a Christian given name and a surname based on a native given name (cf. Hanson n.d., Alia 2009).

In the 1950s the USSR introduced the so-called internal passports' (ID cards for use inside the USSR), which meant for the Chukchi - a group that until then used merely given names - the need to assume fixed surnames. To this end, their traditional given names were officially changed into fixed and inheritable family names then, while the function of given names was taken over by Russian names ${ }^{302}$ :

Maksim was raised by his grandfather and his uncle. The grandfather, Ottoch, assumed the Russian name Nikolai, and of his Chukchi given name made the surname that Maksim bears today ${ }^{303}$.

A similar policy was pursued in the Arctic in North America. Boeri (1985: 51) mentioned two Alaska Natives of Sivuqaq (renamed Gambell) on St. Lawrence Island: "At birth, Irrigoo and Oovi had one name apiece. But the missionaries named them Samuel and Lloyd and made their Eskimo names surnames."

302 Cf. Jacek Hugo-Bader 2011. „Obcy ósmy pasażer Pelikena” [account of travel to Chukotka, autonomous region (okrug) in the north-east of Russia]. Gazeta Wyborcza-Duzy Format, Mar. 6.

303 Wojciech Lipiński 2011. Ludzie tundry. Tożsamość $i$ granice etniczne na pótnocy Syberii [the people of the tundra: identity and ethnic borders in the north of Siberia]. Warszawa: Wydawnictwo DiG, p. 199. 
While Iirgu's (Samuel Irrigo's) parents were called merely Waamseghaan and Amenaanga, as they did not possess surnames, in the next generation his oldest brother Awergen became Ira Iworrigan, and another brother, Aghtuqaayak Richard Okhtokiyuk. Iirgu's sister Suunaaghruk was 'renamed' Edna Soonharook ${ }^{304}$.

The very same pattern can be traced in the recent history of name-changing by John Abraham Godson, a Nigerian immigrant to Poland who became the first-ever black Polish MP:

I was born Godson Onyekwere. In 1993 I came from Nigeria to Poland. In 2006 I changed my given name into a family name, because people kept making mistakes anyway. I chose the names of biblical figures that I admire: John - Jezus' beloved disciple. Abraham - the father of nations $[\ldots]^{305}$

The common denominator in all such changes is the underlying assumption that permeates many naming cultures the assumption about how given names are perceived as opposed to surnames. While surnames may be unusual, highly irregular morphologically and not easily construed as surnames, given names are more likely to constitute a (semi-)closed set with elements that are readily recognisable as given names. This fact is understandable if one takes into account how names enter the life of an individual: surnames are inherited whereas given names are bestowed. Owing to this fact, policymakers can exert a far stronger influence on those affected by their policies in the case of given name bestowals, since for reasons of "citizen legibility" - in the sense Scott (cf. 1998: 65) used the concept - surnames should

${ }^{304}$ Cf. From the Elders: Documentary Educational Resources. No date. www.der.org/resources/study-guides/from-the-elders.pdf, accessed Mar. 14, 2011.

305 Czerwiński, Adam 2012. „Czy mogę dotknąć twoich włosów” [interview with John Abraham Godson]. Gazeta Wyborcza - Duży Format, June 17. 
not be altered without a good reason to do so, lest intergenerational confusion ensues.

\subsection{Forbidden categories of surnames}

Forbidden surnames may appear in combination with given names. However, there are also cases of only a particular category of surnames (and not of given names) which is banned, mostly on account of the ethnicity or religion it implies. Jewish surnames may serve as a case in point. As early as $\mathbf{1 7 8 7}$, by decree of Joseph II, surnames formed from place names and "in the Jewish language" 306 were forbidden in the Habsburg Empire (Bering 1992: 35).

France followed suit when, on July 20, 1808, Napoleon issued a decree prohibiting Jews from assuming Old Testament names or town names as surnames (though both could be used as given names and also exception could be made for those surnames that had always been used by their bearers in a consistent fashion):

Art.3. Ne seront point admis comme nom de famille, aucun nom tiré de l'Ancien-Testament, ni aucun nom de ville. Pourront être pris comme prénoms, ceux autorisés par la loi du 11 Germinal an XI.

Art.5. Seront exceptés des dispositions de notre présent décret, les Juifs de nos Etats, ou les Juifs étrangers qui viendraient s'y établir, lorsqu'ils auront des noms et prénoms connus et qu'ils

${ }^{306}$ It is not clear which language was meant in the decree as "the Jewish language." The 'Jewish' languages of the Jews in the Habsburg Empire were Yiddish (in Polish lands annexed in partitions to Austria) and Hebrew (for religious purposes). Joseph II's "Systematic Regulation of the Jewish Nation," issued in 1783 for the Austrian Empire, allowed both languages only in prayer (and not e.g. for business transactions or for printing texts of non-religious nature). Many Jewish names in the Habsburg Empire before the decree of 1787 were based on Hebrew, but some were derived from Yiddish too. According to Abramowicz 2002, Jews often gave their children two names: a Hebrew name for use in synagogue and its translation into Yiddish for secular use. 
ont constamment portés, encore que lesdits noms et prénoms soient tirés de l'Ancien-Testament ou des villes qu'ils ont habitées. ${ }^{307}$

\subsection{Forbidden individual surnames}

The situation where only particular surnames are officially forbidden is rather uncommon, yet possible. Thus in the year 1569 , a law was passed in Britain that prohibited the use of the surname $O^{\prime}$ Neyle $\left(O^{\prime}\right.$ Neill $)$ "on the grounds that Ulstermen had deferred more to the sovereignty of the O'Neills than to the English monarch" (Rennick 1984: 139-40). In 1600 Ruthven, the name of a Scottish clan, was forbidden by Parliament as a result of the so-called Gowrie conspiracy ${ }^{308}$, considered to be treason. In April 1603 the names of MacGregor and Gregor were forbidden in Scotland by an edict of king James VI of Scotland. Also in this case the reason was the acts of treason committed against the Crown (cf. Smith 1970: 201, Rennick 1984: 140).

In Vietnam, a similar prohibition was extended onto the names of the ruler's family members as well and its infringement was punished by imprisonment (cf. Nguyễn 1995: 895). Generally speaking, such isolated and rare instances tend to be either politically motivated (as in the case of Britain) or to constitute a legalised taboo.

\subsection{Discouraged surnames}

While not explicitly forbidden, these are names which are associated with such official or societal stigma (or the former hand in hand with the latter) that a lot of pressure is exerted on their users to change the offending name. Rennick (1969: 203)

${ }^{307}$ Décret de Bayonne, Bulletin des Lois de l'Empire français, 4e série, tome 9, Paris août 1809, pp. 27-28, décret $n^{\circ} 3589$. http://www.genami.org /culture/fr_decret-bayonne.php, accessed Dec. 4, 2016.

308 An alleged attempt to kidnap King James VI by one of the clan members (August 1600). 
reported: "In March, 1936, a Rumanian rabbinical candidate, Israel Hitler, was informed that, although he had passed his examination, his chances of receiving his degree would be immensely increased by a change-of-name."

\subsection{Protected surnames}

Surnames may be protected against use by people who decide to change their surname for various reasons. Most importantly, this concerns the surnames of famous people and of noble families. A case in point was the Swedish Personal Names Law of 1982, which placed restrictions on the change of surnames if the new surname would imply unjustified claim to nobility ${ }^{309}$. In Italy, "surnames of historical importance or belonging to families particularly known in the place where the birth certificate is made" 310 cannot be given to children whose parents are not known. A similar prohibition existed since 1919 in Poland (cf. Banach 1946: 15): wherever an objection was raised by those who already bore a given surname, it could not be assumed by the person changing his or her name. While the 1945 decree (cf. ibid.) lifted that ban, the idea of the protection of existing surname resurfaced after the end of Stalinism in Poland, i. e. after 1956. According to the Polish law of November 15, 1956 on the change of given names and surnames, "[a]pplication for surname change will not be considered if the applicant would like a historic surname, famous in culture and academic research, political, public or military activity."

However, they may exist a different motivation for the limitations of surname change. For example, in Finland the

${ }^{309}$ Cf. Carol J. Williams 2001. "Fleeing the Monotony of 'Son of." Los Angeles Times, Jan. 1. http://articles.latimes.com/2001/jan/01/news/mn-7163, accessed Dec. 4, 2016.

${ }^{310}$ D.P.R. 3 novembre 2000, n. 396 (1). Regolamento per la revisione e la semplificazione dell'ordinamento dello stato civile, a norma dell'articolo 2, comma 12, della L. 15 maggio 1997, n. 127. http://www.esteri.it/MAE/doc /DPR396_2000.pdf, accessed Dec. 4, 2016. 
Names Act of $1985^{311}$ states: "A surname that has been entered into the Finnish Population Register or a name that is commonly known to have been established as the name of a given Finnish or foreign family cannot be approved as a new surname, unless there is a special reason for the approval". In Estonia, the 1934 Surnames Act specified in $\S 11$ that "a requested new surname may not be a surname of a wellknown figure or of a generally known family or a surname which has been entered into the protection register of surnames" (Judgement 2001). It must be noted, though, that the Finnish Population Register comprises the surnames of all Finnish citizens, whereas Estonia's register - only the stateprotected ones. This means in practice that a Finnish citizen seeking surname change must invent a new, hitherto unknown surname. The same principle is operative in Sweden: surnames in current use may be assumed only if the name-hanging person can prove family relationship with their bearers.

Yet a different approach to the problem of surname change has been adopted by Denmark, where law stipulates that surnames borne by 2,000 individuals or less are protected and cannot be assumed at surname change ${ }^{312}$. It other words, the Danish authorities, protecting rare surnames, encourage the adoption of popular ones. The same applies to Norway, except for the fact that there protected are the surnames born by less than 200 bearers. By contrast, under the Dutch legislation a surname may be changed if it has become too common ${ }^{313}$.

\subsection{The number and hyphenation of surnames}

Many countries legally limit the permitted number of surnames that an individual can bear. Germany may be a case

$311 \S 12$, http://www.finlex.fi/fi/laki/alkup/1985/19850694 accessed Dec. 4, 2016.

312 Fornavne, mellemnavne og efternavne. https://ast.dk/born-familie /navne/fornavne-mellemnavne-og-efternavne, accessed Dec. 4, 2016.

313 https://www.justis.nl/producten/naamswijziging/achternaam-wijzigen /index.aspx, accessed Dec. 4, 2016. 
in point. On May 5, 2009, the Federal Constitutional Court of Germany decided that limiting the number of surnames to two is constitutional, thereby upholding the verdict of a lower court in the case of Frieda Rosemarie Thalheim of Munich. She had wished to marry a man with a double-barrelled surname and combine her surname with his, thus creating a triple surname but was not allowed to do $\mathrm{so}^{314}$. However, the German law does not apply to German aristocracy, whose members are exempt from it; a case in point may be a German politician and Minister of Defence, Karl-Theodor zu Guttenberg, whose full name is Karl Theodor Maria Nikolaus Johann Jacob Philipp Franz Joseph Sylvester Freiherr von und zu Guttenberg ${ }^{315}$. This means that his surname is composed of five words, in addition to his ten given names.

Polish law allows no more than two surnames, which must be joined by a hyphen. Thus if a person with a doublebarrelled surname marries, she (or he) must choose if to retain the birth name, assume the spouse's one, or hyphenate the spouse's surname with only one part of the double-barrelled one. Nevertheless, a multi-part surname may be the result of a marriage to a foreigner. When Róża Maria Woźniakowska, a politician and NGO activist, married in 1981 an Austrian aristocrat Franz Graf von Thun und Hohenstein (and then lived with him for 10 years in Germany), she became Róża Maria Gräfin von Thun und Hohenstein. The aristocratic background visible in her five-part surname was believed by some to be a handicap when in 2009 she decided to become a parliamentary candidate and by a court verdict her full name

314 Kate Connolly 2009. "German woman loses triple-barrelled surname battle". The Guardian, 5 May.

315 Aristocratic titles are legal in documents in Germany, despite the 1919 constitution of the Weimar Republic and the 1949 Bonn constitution, which formally ended the recognition of nobility. By contrast, Austria abolished the official use of aristocratic titles in 1919 (to the effect that von and similar nobiliary particles disappeared from the front of surnames) and nowadays official documents such as IDs do not include titles. In Poland, titles were abolished by the March Constitution of 1921 . 
had to appear on the voting lists ${ }^{316}$. What is more, in election documents she was listed alphabetically under "G" (for "Gräfin") and not under "T" (for Thun). Nevertheless, in her public activities in Poland she uses the shortened version of her name (Róża Thun).

Of European surnaming traditions, the Portuguese one seems to be the most liberal with respect to the number of names, allowing an individual to posses as many as four surnames - one after each of the four grandparents. The usual Spanish usage is that of two surnames: the paternal one and the maternal one, traditionally (though nowadays not obligatorily) in that order. In fact, an individual in Spain is routinely expected to be using two surnames. This fact had rather amusing consequences at the time of the Spanish presidency of the European Union (1 January - 30 June 2010), when journalists applying for accreditation in Brussels had problems logging on the presidency website. " "Error. Field missing. Please fill in: Surname 2," the website announced curtly each time a non-Hispanic journalist tried to enter his or her details on the site without the crucial second name" ${ }^{317}$.

In both Spain and Portugal multiple surnames are traditionally written as separate words, though name users may decide to hyphenate them for practical reasons: "to avoid confusion in computerized systems that automatically take the last word in the name field to be the last name, a lot of $[\mathrm{H}]$ ispanics hyphenate their apellidos" ${ }^{\prime 318}$.

316 „Róża Thun pod pełnym nazwiskiem” [Róża Thun by the full surname]. Rzeczpospolita, Apr. 27, 2009. http://www.rp.pl/artykul/297174 .html, accessed Dec. 4, 2016.

${ }^{317}$ Ben Nimmo 2010. "What's in a Surname? In Europe, Quite a Lot." M\&C News, Aug. 19. http://www.monstersandcritics.com/news/europe/features /article_1578641.php/What-s-in-a-surname-In-Europe-quite-a-lot, accessed Sept. 20, 2012.

318 Manuel A. Pérez-Quiñones 1996. Hispanic Last Names: Why Two of Them? Last updated Aug. 26. http://web.archive.org/web/1999 0429161253/http://exodo.upr.clu.edu/ mperez/apellidos.html, accessed Dec. 4, 2016. 
Other European states, if they do allow more than one surname, typically set the limit at two, and these two surnames are sometimes spelled as two separate words, but more often linked by a hyphen. Occasionally exceptional spellings are allowed if they are historical spellings; it also happens that provisions are made to distinguish between such historical spellings of surnames and the orthography of the newly coined double-barrelled surnames which result from marriage. Thus in December 2004 a decree was introduced in France that required all new double-barrelled surnames to be spelled with two [!] hyphens, e.g. Dupont- -Dupond. By contrast, the 'old', historic double-barrelled surnames were to remain singlehyphenated or written as two separate words (e.g. Sarkozy de Nagy-Bocsa or Giscard d'Estaing). The new decree, the authorities claimed, was meant to help distinguish between the "new" single-generation double-barrelled names from the traditional ones. In the case of the single-generation, i. e. noninheritable surnames (in which situation only one surname of the two was to be passed on to offspring), the second hyphen could be dropped in everyday life. Before it was lifted by the Conseil d'Etat in 2010, the regulation included 175000 children born in the years 2005-2010. Now their parents can delete one of the hyphens or let the unusual double hyphen remain $^{319}$.

\subsection{Patronyms}

In most of Europe the direction of the development has been from patronyms, to the extent they were used, to hereditary family names. In fact, many fixed surnames developed from frozen patronyms (or, decidedly less frequently, metronyms ${ }^{320}$ ). Some systems, notably in Russia

319 John Lichfield 2010. "Double-Hyphen Surname Law Gets Both Barrels." The Independent, Jan. 8.

320 Metronyms (also called matronyms, metronymics) are names derived from the name of the mother. 
and in some of the states which are former Soviet republics, still preserve the intermediate stage, with both a patronymic and a surname, which results in a three-name system: Lev Nikolayevich Tolstoy.

At some point in their history Nordic countries underwent a transition from patronyms to fixed family names, starting in 1828 in Denmark and in 1832 the Faroe Islands, with Sweden (family name regulation act, Säktnamnsförordningen, of 1901) and Finland (1920) following suit, and ending with Norway 1923 (cf. Willson 2002, Wylie 1987: 127). The process of the adoption of fixed family names was in some cases gradual. For instance in Sweden the law of 1901 did not force the population at large to adopt compulsory surnames. On the contrary, the transition from patronymics in Sweden in fact lasted until 1966, when those who had not selected for themselves a family name by then were to take the hitherto used patronymic as a hereditary surname. Except for Iceland, fixed hereditary family names are used uniformly in Scandinavia now, just like in the rest of Europe. However, recently the Faroe Islands have seen a partial reversal of this trend. "A law of 1991 regulating personal names," Barnes (2005: 1583) noted, "allows for both patro- and metronymics and a few individuals have adopted one or the other, sometimes in addition to their surnames." Also Sweden (1982), Norway (2002) and Denmark (2006) reintroduced the use of patronymics as a possible (not obligatory) alternative to hereditary surnames.

At the beginning of the $20^{\text {th }}$ century discussions were held in Iceland about whether surnames should be adopted at all, or, conversely, if the patronymics in use should be preserved. The name law of 1913 allowed the adoption of a fixed surname provided a government permission to do so was obtained and a fee paid. The intention of the lawmakers was curbing the practice, widespread at the time, of using foreign surnames and given names. Only surnames already in use before January 1, 1901, were legally recognized, and in the case of those, no 
permission needed to be sought. A few years later, however, the trend was reversed. The name law of 1925 (in force until 1991) forbade the adoption of new surnames, though those already in use by that time could be kept (cf. Willson 2002, Tomasson 1980). Estimates of the percentage of Icelanders with fixed family names range from 7 per cent (cf. Willson 2009) to 15 per cent (cf. Willson 2002, Tomasson 1980).

As in the case of other cross-cultural differences between particular anthroponymic systems, also the clash between a patronymic and a non-patronymic system may give rise to tensions. The Soviet rule in Lithuania (1940-1991) resulted in the imposing on Lithuanians of Russian-style patronyms as the obligatory middle element of the personal name:

Russification was not consistent throughout the soviet period. For some time Lithuanian patronymics were written in the genitive case of Lithuanian, which is the main form of the semantics of possession in Lithuanian. This way of writing did not contradict the rules of Lithuanian grammar. But in the last decades of the Soviet period Russification was very intensive and Lithuanian patronymics in identity documents were written in a different way - with Russian patronymic suffixes, which were not characteristic of Lithuanian, for example masculine -ovič, feminine -ovna. In the spoken mode these forms were not commonly used, but sometimes Russians addressed Lithuanians by their given name and patronymic formed according to the rules of Russian grammar. In this way certain patterns of naming, which were alien to Lithuanian, were used (Ramoniene 2007: 430).

Following the dissolution of the Soviet Union, Lithuania, as well as some other post-Soviet states, renounced the patronymics that had been imposed by the Soviet authorities.

\subsection{Feminine forms of surnames}

Some European languages - such as Czech, Slovak, Polish, Russian, Sorbian, Latvian or Lithuanian - traditionally 
have had different feminine forms of surnames, formed from masculine surnames by using special suffixes which additionally may, though do not have to, indicate the marital status (single versus married) of the woman. The conflict potential - and, consequently, the occasion for state regulation to intervene - of such a system is of two types:

1) Language-internally, an increasing number of women nowadays would not prefer their surnames to convey the marital status information, which is not revealed by male surnames.

2) Language-externally, the existence of feminine suffixes, which make the surnames of women different from those of the male members of their family, may result in problems with the recognition of identity or family relationship in language contact that involves a 'non-feminine-suffix' language. Where a 'feminine-suffix' language dominates, pressure may be exerted on a foreigner/minority member to add such a suffix to their surname.

In fact, language-external problems with feminine suffixes exist cross-linguistically and it is only relatively recently that some of them found their - albeit partial - solution. A case in point may be Slovakia, which made it possible for some groups of the population (notably the Hungarian minority) to renounce the feminine suffixes on surnames by force of the Law on Names and Surnames of 1993. The change is not automatic but must be applied for and motivated by Hungarian ethnicity. The law does not apply to foreign names since their bearers have not been born in Slovakia; thus Sophia Loren remains Sophia Lorenová (cf. Puskás 2009: 166).

In the Czech Republic it was only in 2004 that it became legally possible for Czech women living abroad or marrying foreigners to discard the feminine suffix -ova in surnames. Before 2004, it was only allowed in the case of women of nonHungarian ethnicity, such as foreigners or those from the national minorities officially recognised by the Czech 
Republic ${ }^{321}$ (Bulgarian, Croatian, German, Greek, Hungarian, Polish, Romany, Russian, Ruthenian, Slovak, or Ukrainian).

The situation in Lithuania is somewhat different than in Slovakia or the Czech Republic because a traditional Lithuanian feminine surname, apart from identifying its bearer as a girl/woman, also reveals her marital status. For this reason, and perhaps also because Lithuania's most numerous majorities (Polish and Russian) speak languages that also have feminine surnames, the most pressure towards change was observed in connection with the marital-status issue. In June 2003 VLKK passed a resolution ${ }^{322}$ that made it possible for women to opt for the third, status-neutral form ending with $-\dot{e}$, for example masculine surnames Jurgutis, Butkus, Adamkus, now yield the following three (rather than two) types of feminine surnames: Jurgutyte, Butkute, Adamkute (unmarried); Jurgutienè, Butkienè, Adamkienè (married); or Jurgutė, Butke், Adamke (neutral). Nevertheless, the status-neutral feminine surnames, although admissible, have not yet gained wide popularity in Lithuania - the traditional suffixes still prevail ${ }^{323}$.

Feminine surnames indicative of marital status were required by law in inter-war Poland; they were formed by adding special suffixes to the masculine base form (sometimes with its modification), e.g. masculine surnames Nowak, Zajac, Zaręba, Skarga yielded the forms Nowakówna, Zajacówna, Zarębianka, Skarżanka (for unmarried women), and Nowakowa, Zajacowa, Zarębina, Skarżyna - for married ones. However, this concerned only some part of the surnames - the so-called nominal-type. The remainder, i.e. the adjectival type, made it only possible to discern the gender, but without the information about the marital status of the woman (e.g.

${ }^{321}$ Act No. 301/2000 Coll. on registers, names and first names, and the amendment of certain laws.

${ }^{322} \mathrm{Cf}$. http://www.vlkk.lt/vlkk-nutarimai/nutarimai/del-moteru-pavardziu -darymo, accessed Dec. 4, 2016.

${ }^{323}$ Cf. "Naujoviškos pavardès tradicinių neišstūmè", Veidas March 3, 2008. http://archive.is/TAxB6, accessed Dec. 4, 2016. See also Ramonienè (2007: 431). 
masculine surnames Kowalski, Babicki, Rudzki, Konieczny, Zawodny corresponded to the feminine forms Kowalska, Babicka, Rudzka, Konieczna, Zawodna. Post-war Poland has inherited the nominal vs. adjectival surname type distinction, and only in the latter type is it now possible to recognise the gender at all, with the disclaimer that women with adjectival surnames that do not end with -ski or -cki (-dzki) may opt for the masculine version of their surnames ${ }^{324}$.

A different type of surname for married women is found in Hungary, where let us say Anna Nagy, the wife of Dániel Molnár, is traditionally (but also officially) referred to as Molnár Dánielné. This pattern grew in popularity historically, until in the $19^{\text {th }}$ century it became dominant and remained so until the next century, with almost two thirds of women in Hungary using this form even today (cf. Fercsik 2012). What is so interesting about such a pattern is the fact that the married woman's birth name is effectively obliterated, as Fercsik aptly shows:

In official papers, women who use the Kis Jánosné name form [the husband's given name is János and his surname is Kis], have to write Jánosné into the column that stands for first name. This form does not function as a personal name as it does not distinguish, nor does it identify. The -né suffix [...] does not actually join the male first name, but rather the whole, two-part name, or simply the family name. This way, the Jánosné name form is not adequate, especially not as a first name. Addressing women by the Kis Jánosné name form is also not easy, as the actual first name of the person is not revealed (2012: 60-61).

Even though the most common, this pattern is nevertheless not the only one legally acceptable - other options are presented below in the chapter "Names and the law", section devoted to Hungary.

${ }^{324}$ For a detailed and more nuanced description of the situation in prewar and post-war Poland, cf. Walkowiak 2012. 


\subsection{Objectives of surname policies 4.9.1. Reducing isonymy - enhancing surname diversity}

Surnames developed basically for administrative purposes:

The development of the personal surname [...] went hand in hand with the development of written, official documents, such as tithe records, manorial dues rolls, marriage registers, censuses, tax records, and land records. They were necessary to the successful conduct of any administrative exercise involving large numbers of people who had to be individually identified and who were not known personally by the authorities (Scott 1998: 67).

However, once acquired, they also provided the additional benefit of helping to identify an individual more accurately on a private plane as well, similarly to nicknames. In fact, some surnames are known to have developed from nicknames.

Hypothetically, the need for identification afforded by two or more elements of a name should be especially urgent where the pool of available given names was for some reason limited. In fact, the opposite was more often the problem, i.e. the pool of surnames was limited due to the history of their development. In Sweden, for instance, most surnames developed from petrified (frozen) patronymics. There were not as many given names in circulation at the time. Consequently, among the twenty most frequent Swedish surnames in 2009, nineteen are frozen patronymics ending with -son: Johansson, Andersson, Karlsson, Nilsson, Eriksson, Larsson, Olsson, Persson, Svensson, Gustafsson, Pettersson, Jonsson, Jansson, Hansson, Bengtsson, Jönsson, Jakobsson, Magnusson, Olofsson $^{325}$ and together their bearers make over 22 per cent of the population. In 2000, there were 288496 Swedish citizens by the surname of Johansson, which tops the list and

${ }^{325}$ Namnstatistik [Swedish given name statistics]. No date. http://www .scb.se/namnstatistik/, accessed Dec. 4, 2016. 
constitutes over 3 per cent of the entire population. For comparison, Nowak, the most common surname in Poland, in the year 2000 had over two hundred thousand bearers (cf. Zawadzki 2002: 184), which accounts for only about 0.5 per cent of the total population; the bearers of top twenty Polish surnames taken together make roughly 5 per cent of the population of Poland.

Wishing to remedy the problem of too few surnames and the resulting ambiguity in personal identification, the Swedish government at the end of the $20^{\text {th }}$ century adopted special measures: citizens are encouraged to invent new surnames for themselves and the procedure of name change has been simplified. As long as the invented surname sounds Swedish and is not claimed by anyone, it can be chosen and legally assumed. A repository of 40000 new surnames has thus been created. Each year about five thousand Swedes change their surnames and only one in ten applications is rejected.

Still, neither the problem nor the solution is new. Encouraged by the authorities, Swedes have been changing their frozen patronymics into other types of surnames ever since the middle of the $19^{\text {th }}$ century. In 1901 a law on surnamechanging was passed that suggested inventing surnames containing geographic features such as sjoe lake', dahl 'valley', or berg 'mountain' ${ }^{\text {'226. }}$

A parallel situation, only on a decidedly larger scale, arose in China. The Chinese name is typically composed of a onesyllable FN followed by a two-syllable (or, in under twenty per cent of cases, only one-syllable) GN. While given names are relatively diverse and there is no fixed list of them, it is not so in the case of surnames. The most common surname Wang, for instance, is borne by 93 million people (about 7 per cent of the total population), and about 85 per cent of the population have one of the 100 most common surnames. A 2007

${ }^{326}$ Cf. Carol J. Williams 2001. "Fleeing the Monotony of 'Son of." Los Angeles Times, Jan. 1. http://articles.latimes.com/2001/jan/01/news/mn-7163, accessed Dec. 4, 2016. 
regulation in China, however, drafted by the Ministry of Public Security, allowed a baby to have the combined surname of the mother and the father. For instance, "if a father's family name is Zhou, and the mother, Zhu, the baby could have four options for the surname: Zhou, Zhu, Zhouzhu or Zhuzhou." 327 According to the Chinese press reports, ethnic minorities letters or characters are allowed in the name, while any foreign letters, self-made characters, Chinese pinyin, Arabic numerals or the original complex form of simplified Chinese characters are not permitted. The new law is expected to lead to the creation of 1.28 million new surnames.

An alternative solution, suggested by Wang Dayou, might be the addition of the revived traditional Chinese names zi (表) 字 (the so-called style name) and hào 號 (pseudonym), abandoned at the time of the cultural revolution as a vestige of the feudal past. ${ }^{328}$

The policies targeted at diminishing isonymy described above might be termed comprehensive: they apply basically to all citizens. A selective policy of this kind was adopted in the 1990s in Canada. Sikh immigrants to this country, who typically have the surname Kaur (women) or Singh (men), were forced to change their surnames for more variety. According to the authorities, given that in 2001 there were almost 300 thousand Sikhs in Canada, the repeatability of the surname would contribute to great confusion in documents. The surname-change regulation was lifted in $2007 .{ }^{329}$

${ }^{327}$ Zhu Zhe 2007. "What's in a Surname? A Combination of Mother's and Father's." China Daily. Updated June 12. http://www.chinadaily.com.cn /cndy/2007-06/12/content_891917.htm, accessed Dec. 4, 2016.

328 "Scholar Makes Bid to Revive Traditional Names." China Daily, Dec. 1, 2004. http://www.chinadaily.com.cn/english/doc/2004-12/01/content _396156.htm, accessed Dec. 4, 2016.

329 "Canada Drops Policy of Sikh Surname Change." Indian Express, July 26, 2007. 


\subsubsection{Limiting the number of bearers of popular surnames}

Similarly to the previous policies, also this one is intended to reduce name ambiguity and increase "citizen legibility" (Scott 1998) to the state administration. Its means is the law by which surnames must not be changed to common ones. For instance, in Poland the law of 1929 prohibited taking common surnames, which were defined in the 1930 regulation to the 1929 law as those that are "neither historical nor popular, yet so commonly used that problems with identifying particular persons or families arise" (Rajkowski 1955: 78). Also $\S 8$ of the Norwegian law on surname change of Feb. 9, 1923, forbade taking commonly used names (cf. ibid.). Contemporary Finnish law (Section 10.1) allows surname commonness as a permissible reason for surname change, stating as follows: "A surname can be changed if the applicant establishes that the use of his/her present surname causes inconvenience due to its [...] frequency or for some other reason." 330

\subsubsection{Assimilationist versus segregationist surname policies}

Some surname policies are targeted at assimilating minorities or immigrants, whereas others have the opposite objective. The following policies may serve as exemplification.

The 1905 name law in Sweden allowed as new surnames only those whose morphology, spelling and pronunciation were Swedish. To ensure this, books were published with suggested new surnames.

Until 1934 Turks, in accordance with the Muslim tradition, usually had only one name, possibly accompanied later in life by an additional optional one for easier everyday

$330 \S 12$, http://www.finlex.fi/fi/laki/alkup/1985/19850694 accessed Dec. 4, 2016. 
life identification. On June 21, 1934, however, the Surname Law was introduced in Turkey which made it compulsory for all citizens to assume and officially register surnames. "The change fit other important national purposes as well. Requiring that the names be authentically Turkish - names derived from Arabic or Persian roots were not permitted - the state reinforced the national and even ethnic identity of the community as opposed to its religious identity" (Howard 2001: 105-106). In spirit this policy corresponds closely to a very typical and common policy of surname change (sometimes also accompanied by given name change) in order to assume more native-sounding names. That kind of surname change will be discussed at length in the section devoted to name changes.

The opposite policy was attempted in 1939 in Poland. Since October 24, 1919, a legal option had been opened for those interested in changing their surnames, as long as they were Polish citizens, paid a high fee, applied in writing to the Minister of the Interior giving reasons for the change, and as long as no bearers of the requested surname raised objections. This law occasioned many protests and quarrels over the issue continued for twenty years, until on February 20, 1939, a bill was submitted by a group of MPs which was to make such changes impossible. "The change of surnames of Jewish people, conducted on a mass scale [...]", the authors of the bill wrote, arguing their case, "is meant to mislead the Polish society as to the Polish origin of those people, and its objective is only material, especially facilitating the establishing of business and social relationships as well as obtaining various positions." 331

331 Michał Kitala 2011. “'Nazwiskowe ustawodawstwo' Drugiej Rzeczypospolitej" [legislation concerning surnames in the Second Polish Republic]. Nov. 16. http://por.genealodzy.czestochowa.pl/zasoby/biblioteka /func-startdown/115/, accessed Dec. 4, 2016. 
This page intentionally left blank 


\section{Name changes}

\subsection{Voluntary name changes \\ 5.1.1. Immigrant name change}

In the USA, in the absence of any official, top-to-bottom, codified de jure name policy, there is a powerful bottom-totop pressure on immigrants to change their names in order to assimilate, to avoid the nuisance of having their names mispronounced or misspelled, and possibly also to enhance their career prospects. The agents of such a de facto policy are the people whom the immigrant encounters routinely at work, at school or in other everyday situations. A 1913 Syrian immigrant to the USA tells a very typical story:

I arrived in Beatrice, Nebraska, on the first day of July and was met at the depot by a group of Syrian men who also worked for Mr. Tewell [the author's employer]. One of these men was the brother of Mr. Tewell. [...] That evening while I was with these men and after we had become fairly well acquainted, one of them suggested I should take for myself a new American name, as the name Mohammed would seem odd to the American people.

'What are the most common American names?' I asked, and they began suggesting 'George,' 'Mack,' 'Joe,' and 'John.' Then one of them said 'Ed,' and I liked this immediately, for it was short and sounded like the last part of my real name [Mohammed], so right then and there I decided I was Ed Aryain. ${ }^{332}$

The immigrants to the US feel just how much of an asset an Anglo-Saxon name is. As a result, of the 50 surnames that were the most popular in the USA around the year 1970, almost all were English, Irish, Scottish or Welsh (cf. Smith 1970: 96).

${ }^{332}$ Ed Aryain [\&] J'Nell L. Pate 2006. From Syria to Seminole: Memoir of a High Plains Merchant. Lubbock, Texas: Texas Tech University Press, p. 49. 
Those few immigrants or their descendants who nevertheless decide to retain their original foreign-sounding names occasionally face an uphill struggle. An interesting illustration of this fact comes from the realm of politics. In November 2010 Lisa Murkowski, who owes her surname to her Polish great-grandfather, ran for re-election to the US Senate as an Alaskan write-in candidate. Since it is legally forbidden in Alaska to attach preprinted stickers to the write-in ballots, her supporters had to learn the correct spelling of her name. To this end, she distributed wristbands with her name, T-shirts, even temporary tattoos. Over eight thousand ballots were challenged by Murkowski's rival. These included such spellings of her name as Marcouski, Murkrowsky, Mirkowsky, Marcovsky, or Markovsky ${ }^{333}$. In the end Lisa Murkowski won, and as a blogger commented, "It worked. All those commercials created a spelling movement. Maybe it would have been a handicap for her to have been named Smith." 334

In his book On Becoming American, Ted Morgan ${ }^{335}$ (quoted in Kaplan and Bernays 1999: 193) wrote: "Namechanging is as American as a basketball hoop over a garage door, as green money, as sliced bread, as competitive overeating". Indeed, common law freely allows a change of name as long as it is not made for fraudulent purposes (cf. Rennick 1984).

It is noteworthy that occasionally the opposite situation takes place: after their name change, immigrants would return to their original foreign name and would petition the American court to that effect. In one such case an Italian immigrant, who had changed his name at the 1840 naturalisation, was reportedly

${ }^{333}$ Mariusz Zawadzki 2010. „Ortografia - klucz na Alasce” [spelling the key factor in Alaska]. Gazeta Wyborcza, Nov. 13-14.

334 Sheila Lennon, Nov. 17, 2010. http://blogs.providencejournal.com /arts-entertainment/subterranean/2010/11/lisa-murkowskis-spelling-lesso.html, accessed July 21, 2013.

${ }^{335}$ Born Comte St. Charles Armand Gabriel de Gramont, naturalised American writer and historian of French origin. 'Ted Morgan' is an anagram of his French last name. 
promised to obtain money from his father in Italy if he reverted to the Italian family name. Such reversions were often motivated by the fact that at arrival the immigrants' insufficient knowledge of English provided them from resisting the pressure of their new environment. Also the 'commonness' of the Americanised name (e.g. Smith) induces the applicants to revert to their original foreign-sounding surnames (cf. Scherr 1986).

\subsubsection{Symbolic name change}

Sometimes a name change is something more that merely a matter of convenience or the need to melt into the new milieu. In such cases changing one's name equals what Shohamy (2006: 16) terms "languaging" (which she defines as "the multiple ways of representation that are not limited to words but rather include additional ways of expression such as languaging through music, clothes, gesture, visuals, food, tears and laughter") - on this occasion languaging with names. To put it differently, the choice of name becomes a medium through which to communicate something. Thus the name goes far beyond denotation. In fact, its connotative function is of far more importance than the fact that the name denotes. In fact, mass-scale name-changing campaigns, described in more detail in the following section, relied heavily on such connotations. However, what is meant here by symbolic name change is changes effected by individuals. Often these individuals were prominent people of high social visibility.

Thus in 1910 the throne of the British Empire was inherited by king George V from the House of Saxe-Coburg and Gotha - a German dynasty. With the outbreak of the First World War these German connotations of the ruler's name became embarrassing. How can we win the war, the press asked, if even our king is German? Under the pressure of the common anti-German sentiment, the king decided to Anglicise his name, thus starting a hitherto unknown dynasty of 
Windsor. Belgian monarchs, related by blood to their British cousins, changed the name of their line from Saxen-CoburgGotha to de Belgiquelvan België in $1920^{336}$. A similar fate befell the name of prince Frederick Charles of $\mathrm{Hesse}^{337}$ : when in 1918 he was elected king of Finland, he Finnicised his name to Kaarle I and then to Väinö I. Also the last Tsars of Russia were of German origin (the House of Schleswig-HolsteinGottorp) and in 1762 assumed the name Romanov - which by that time had formally died out in the male line - to emphasise their Russian identity.

That such symbolic individual name changes need not be the prerogative of the royalty is evidenced by the case of Jakub Krauthofer $^{338}$, who in 1848 changed his German-language surname to the Polish-language Krotowski to manifest his national sentiments (cf. Litwin 1930: 10-1).

Józef Kirschrot (1842-1906), a Polish lawyer, journalist and social activist of Jewish descent, who was an ardent advocate of the assimilation of Jews in Poland, suggested in 1882 in Kurier Warszawski that Polish Jews should attach Polish surnames to their German-sounding surnames in order to blend into the society more effectively. He set the example and in 1882 assumed the name Kirszrot-Prawnicki. ${ }^{339}$

\subsubsection{Pseudonyms assumed as surnames}

A marginal, yet interesting phenomenon of the official legal recognition of military pseudonyms (noms de guerre) could be observed in inter-war Poland, as outlined in Litwin (1930). These pseudonyms, which later either replaced the

336 Lars Ulwencreutz 2013. Ulwencreutz's The Royal Families in Europe V. [no place of publication] Ulwencreutz Media, p. 298.

337 His full German name and title was: Friedrich Karl Ludwig Konstantin Prinz und Landgraf von Hessen-Kassel.

338 A Poznań (Posen) lawyer. Polish patriot and political activist (18061852). He fought against Prussians in the Grand Duchy of Posen during the unsuccessful uprising of Poles against Prussia at the time of the so-called "Spring of nations" of 1848.

${ }^{339}$ Cf. Kurier Warszawski 1906, No 211, p. 7. 
surnames of their bearers or were incorporated into them (with the pseudonym following the birth surname, hyphenated ${ }^{340}$ ), are qualitatively distinct from the so-called "soldier names" in Sweden, discussed in Chapter Two. Even though Swedish names bestowed on soldiers in most cases eventually became their legal surnames, the backdrop for their bestowal was essentially different from the situation in which noms de guerre were assumed by Polish officers. In the case of Sweden, the "military" naming was a top-to-bottom initiative of the soldiers' superiors, whose aim was efficiency (for instance, soldier names within a given military unit were not to be repeated). Other objectives behind this name policy were in all likelihood fostering comradeship (esprit de corps), boosting the morale and self-confidence of the drafted (it is no coincidence that so many Swedish soldier names evoke belligerent connotations), as well as making a symbolic break with the civilian past.

Polish military pseudonyms, by contrast, were selfimposed and meant as a means of disguise, or identity protection. Their bearers were typically volunteer fighters for the Polish cause shortly before and during the First World War. For some of this time Poland was still formally under partitions, allegiances shifted ${ }^{341}$, but in many cases participation in such formations ${ }^{342}$ might pose a threat for the family of those involved. The soldiers who bore such

${ }^{340}$ A case in point may be Edward Śmigły-Rydz (1886-1941), army commander, since 1936 Marshal of Poland. His birth surname was $R y d z$ ('saffron milk-cap'), and Śmighy ('slender; swift') was one of his several noms de guerre. In the 1920s he used the surname Rydz-Śmighy, and at the end of the 1930s - Śmighy-Rydz.

341 As embodied e.g. by the so-called Oath crisis (Pol. Kryzys przysiegowy) of 1917, which consisted in the refusal of Polish soldiers to swear allegiance to the German Emperor Wilhelm II.

${ }^{342}$ Examples of these formations during the First World War included the Polish Legions, formed in the years 1914-15 in Galicia, as well as formations in France (e.g. in the town of Bayonne in the Pyrénées), Italy, Finland, Odessa (city on the Black Sea in today's Ukraine) and the Caucasus region. Cf. Litwin (1930: 35). 
pseudonyms - and this included not only officers but also the rank and file - often wished to keep them after the end of the First World War (which simultaneously brought Poland independence from the partitioning powers of Russia, Germany and Austro-Hungary). It was formally possible ${ }^{343}$ to change surname under the provisions of a law of October 24, 1919. However, only the law of May 11, 1920, made such an option available to a larger group of people. Examples of pseudonyms accepted as surnames include: Olszyna, Prot, Ziemiański, Raczyński, Graba-Lęcki.

The motive behind the 1920 bill being introduced to the Parliament was relatively clear: it was the desire to reward soldiers for their sacrifice and bravery. Many soldiers, it was claimed, distinguished themselves under assumed names while rendering service to their homeland; it was only just to let them keep these names now that Poland was independent. The time bracket within which the assumption of the pseudonym was to have taken place was defined as between August 6, 1914 (when the first Polish formations were created) and May 28, 1920 (which was two days after the new law took effect). After May 28, 1920, pseudonyms had either to have become surnames (or parts of them), or else disappear from public life. In practice, they were nevertheless tolerated until March 22, 1921 (cf. Litwin ibid.: 49).

The reasons for the wish to keep one's nom de guerre appear to have been varied. First, some soldiers took the opportunity to change their foreign-sounding names to Polish ones. On the basis of the data comprising 87 surnames given by Litwin (ibid: $305-7$ ) it may be calculated that about $23 \%$ of all changes consisted in replacing a German-sounding surname (including Jewish names) with a Polish-sounding one, mostly ending with $-s k i^{344}$. Surname change that consisted in replacing

${ }^{343}$ Under the 1919 law, the name-changing procedure was troublesome and costly, and its outcome - uncertain.

344 This suffix has traditionally - even if not quite accurately - been associated in Poland with nobility. 
a Polish-sounding appellative-type surname (often linked with the rural population) with a -ski-ending one (or by affixing the suffix -ski to the existing appellative surname) accounted for a further $17 \%$. By contrast, there was only one name change where a Polish name was replaced with a German one.

What seems the most interesting about this policy is the readiness of the authorities to create an exception to the rule of surname stability in times in which such stability had long been achieved. Paradoxically, in the same year 1920 (August 8) a regulation was issued by the Ministry of the Interior which insisted that citizens should appear in documents "under the names that they are by law (according to birth records) entitled to, and not under the names that they only use in everyday life" (Litwin ibid.: 52).

\subsection{Encouraged change of name and name-changing campaigns \\ 5.2.1. Hungary}

This country witnessed a surge of encouraged Magyarisation of surnames in the $19^{\text {th }}$ century ${ }^{345}$ and the name ideology behind the massive movement can well serve as a point of departure for the discussion of analogous movements elsewhere. For all those who wanted to manifest their patriotic feelings, name change constituted what Simon Telkes, an ardent advocate of surname Magyarisation and the founder of the Central Society for Name-Magyarization (Központi Névmagyarosító Társaság), called 'national baptism' - an affirmative act of willful assimilation and a manifestation of one's identity:

345 "During the reign of Franz Joseph between 1848 and 1916, ethnic minorities were integrated into the monarchy - some more willingly than others $[\ldots]$ In the Hungarian part of the monarchy, non-Hungarian ethnic people were encouraged to adopt Hungarian surnames and to learn the Hungarian language in addition to the several others they were already speaking" (Stefania Ruzsits Jha 2002. Reconsidering Michael Polanyi's Philosophy, Pittsburgh: University of Pittsburgh Press, p. 7). 
Comparable to the religious ceremony of baptism by which a man becomes Christian and a member of the Christian community, the Magyarisation of surnames with all the character of a national baptism, definitely admits the Magyar bearer of a foreign name into Magyar society, including him among the true children of the nation. [...] The Magyarisation of the name is an oath of fidelity, a patriotic vow. [...] Some eminent name in our literature, in our science, in our art, is frequently considered as a non-Magyar when he bears a foreignsounding name, and in cases like that, our culture loses a good deal of its prestige on the other side of the frontiers. [...] [T]he Magyarisation of names will create a homogeneous, unitary Magyar society, that will stand in the stead of the motley society we have today (Telkes 1898/1977: 47-49).

Telkes listed concrete guidelines for name change. Too common names, such as Fekete ('black'), Nagy ('great') or Kovács ('smith') were best avoided; so were historic names of revered Hungarian heroes or dignitaries, e.g. Rákóczi, Hunyadi, Bánfi. A new name, Telkes suggested, might be created for instance by adding the suffix -i to one's birthplace, by translating the present foreign name into Hungarian if possible, by choosing the name of a profession or trade (Mészáros 'butcher', Halász 'fisherman', Katona 'soldier', Tanitó 'teacher'), or by referring to one's former nationality (Bajor 'Bavarian', Görög 'Greek'). Yet another possibility was taking a suitable common noun as a surname: Farkas 'wolf', Sas 'vulture', Szerda 'Wednesday', or a proper name: Balaton. As a last resort, Telkes recommended turning for inspiration to the works of great Hungarian poets and novelists. He warned, however, against hybrid formations such as Mayerfi (German Mayer with the Hungarian patronymic suffix $-f i^{346}$ ) as neither German nor Hungarian, or against literal translations of each part of foreign two-component surnames since the resulting formations would betray the foreign origin of names.

${ }^{346}$ Cf. Farkas 2009: 370. 
As the name-changing campaign gained momentum, the administrative fee was lowered from 5 forints (the Hungarian name for Austro-Hungarian guldens), to 50 Kreuzers ${ }^{347}$ (1 forint equalled 100 Kreuzers) to encourage more interest. In fact the number of surname changes between the middle of the $19^{\text {th }}$ century and the middle of the $20^{\text {th }}$ century, which for the most part meant their Magyarisation, is estimated at 300,000. Nevertheless, even today only approximately 60-70 per cent of Hungary's surname inventory is of native stock (Farkas 2009: 367f).

The campaign resulted in unexpected careers of some surnames, such as Kárpáthy. Farkas (2009: 372) noted:

This surname is the most successful proof of the Hungarianization of surnames in Hungary. It is completely missing from the historic surname stock, but for different reasons (including its appearance as a surname of a Hungarian literary hero), it became very popular among people changing names and fitted into the Hungarian surname stock quite well. It is estimated to be the $170^{\text {th }}$ most frequent surname in Hungary nowadays, and the most frequent of its type, i.e., of artificial surnames as a result of name Hungarianization.

\subsubsection{Finland}

In the years 1906-1907 a surname-changing campaign was announced on the initiative of writer Johannes Linnankoski on the $100^{\text {th }}$ anniversary (which was on May 12, 1906) of the birth of Johan Vilhelm Snellman, a philosopher and an ardent advocate of Fennicization:

In connection with the Snellman celebrations, an appeal went out to the people to 'Fennicize' their names. Thousands complied. In many cases, Finnish appellations long ago discarded for more 'favorable' Swedish names were revived, Snelmanns returning to Virkkunens, Branders to Paloheimos.

${ }^{347}$ In $19^{\text {th }}$-century Hungarian krajczár (modern spelling krajcár). 
Blomstedts became Jalases; Eliel Aspelin became AspelinHaapkylä. Around the same time Gallén exchanged the accent in his surname for a hyphen and added 'Kallela' after it, thereby covering both Finnish and Swedish bases. ${ }^{348}$

The campaign led to the Finnicization in the very year 1906 of about 100 thousand surnames ${ }^{349}$, which meant specifically changing their form from Swedish to Finnish. Also given names were Fennicized: Johannes > Juhani, Axel > Akseli, Carl > Kaarlo, Georg > Yrjö.

\subsubsection{Estonia}

Estonians generally acquired their surnames in the years 1816-1835. Before that time, there existed names in that function (usually patronymics or names derived from the name of the farmstead of the bearer), but they were unstable. In 1920, when for the first time in its history the country became independent, many Estonian surnames were of foreign origin. About three quarters of foreign surnames of Estonians were German-based. Others were of Swedish, Russian, Polish, Latvian, Finnish, even Dutch origin. A law on name change was adopted in 1919 (published officially in 1920 in "Riigi Teataja"350) and in 1921 the book "Eestlasele essti nimi!" ('An Estonian Surname for an Estonian') was published. Its contributors were folklorists Oskar Kallas (who probably was the initiator of the idea) and Mattias Johan Eisen, literary scholar Gustav Suits, poet Karl Eduard Sööt, as well as linguists Johannes Aavik, Oskar Loorits, Villem Ernits, Lauri

348 Glenda Dawn Goss 2009. Sibelius: A Composer's Life and the Awakening of Finland. Chicago - London: University of Chicago Press, p. 327.

${ }^{349}$ Cf. Petra Broomans [\&] Marta Ronne 2010. In the Vanguard of Cultural Transfer: Cultural Transmitters and Authors in Peripheral Literary Fields. Groningen: Barkhuis, p. 130.

${ }^{350}$ An official gazette in Estonia. 
Kettunen. The book was meant to help people choose new Estonian surnames for themselves.

Until 1928 the response was lukewarm: only 160 foreign surnames were actually changed, and in many of those cases the chief motivation was the wish to be rid of an embarrassing name rather than patriotic feelings. However, in the year 1934 the Law on the Regulation of Surnames (Lagen om reglering av släktnamn), which simplified the name-changing procedure and made it free of charge, was introduced. The introduction of the law was accompanied by a carefully orchestrated campaign, conducted among others in the media, with the participation of famous personages and with official propaganda. The choice of the surname was left to the person concerned and legal protection of the name was possible. This time the response to the idea was enthusiastic and perhaps surprised even its initiators: almost 200 thousand people changed their surnames until 1939. Some of them wished to make their surnames sound Estonian and not foreign, others intended to get rid of ridiculous surnames, such as Lombak 'lame,' Zolk (solk 'swill, garbage), Madrats 'mattress', Monstrum (Mundström) 'monster', Karafin 'decanter'. Also non-standard and obsolete surname forms were corrected. Among the well-known Estonian citizens who Estonicised their names in 1935 there were politician and journalist KarlAugust Einbund (he changed his name to Kaarel Eenpalu), the painter Hans Laipman (since 1935 Aants Laikmaa) and the wrestler Kristjan Trossmann (since 1935 Kristjan Palusalu).

Surname changes comprised not only the semantic but also the phonetic aspect: the stops $b, d, g$, alien to the Estonian language system and hitherto present chiefly in foreign loans, were replaced with their voiceless equivalents $p, t, k$. On the morphological level, foreign morphemes were either replaced with similar-sounding ones of different meaning (e.g. German -berg 'mountain' > Estonian -pere 'family, household, swarm of bees') or translated (-berg > -mäe). What is interesting, given names were also changed to make them Estonian: 
Georg > Jüri; Gustav > Kustas; Karl > Karla, Kaarel; Reinhold > Rein; Rudolf > Ruudi; Vassili > Valev; Mihhail > Mihkel; Hans > Ants (Raag 1999: 176-184). The linguists' efforts to promote Estonian name type surnames ending in -ste or -la were not successful since few people actually heeded this advice - notable exceptions being linguists Saareste, Ariste, Mägiste, Laugaste. ${ }^{351}$

At the beginning of the 1920s a large percentage of the Seto minority population in Estonia for historical reasons did not possess surnames at all. Therefore a regulation was issued in June 1921 that made it obligatory for all the Setos to assume surnames of their choice. For instance, names of farmsteads could be taken as family names. However, it was not allowed to choose Russian surnames, even though many Setos would want them. Lists of recommended surnames were to be prepared (Raag 1999: 184).

It is noteworthy that a similar campaign - this time meant chiefly to assimilate Russian ${ }^{352}$ names - was proposed in Estonia at the beginning of the $21^{\text {st }}$ century. As the minister of regional affairs reported, 890 people responded to the policy in 2007. Of them 739 changed their surnames, the rest changed their given names or both given names and patronymics. Estonian Minister of Regional Affairs Siim Kiisler was reported by the media in 2008 to be preparing amendments to the Names law, in order to facilitate surname change for non-

${ }^{351}$ Cf. Hillar Palamets "Eestlasele eesti nimi!". http://tartuekspress .ee/index.php?page $=1 \& i d=1830 \&$ print $=1$, accessed Dec. 4, 2016. Andrus Saareste (1892-1864) - Estonian linguist and dialectologist, born Albert Helmut Gustav Saaberk (Saaberg), changed his surname in 1921 and his given name in 1935. Paul Ariste (1905-1990) - Estonian linguist, born Paul Berg, changed his surname in 1927. Julius Mägiste (1900-1978) - Estonian linguist, born Julius Mälson, changed his surname in 1922. Eduard Laugaste (1909-1994) - folklorist, born Edward Treu.

352 Russians constitute about one fifth of the population of Estonia. Estonia's most frequent surname is Ivanov, with Russian surnames Smirnov and Vasilyev also high on the ranking list. http://self.gutenberg.org/articles /list_of_the_most_common_surnames_in_europe\#Estonia, accessed Dec. 4, 2016. 
native residents - especially "if a person wishes to have an Estonian-like surname for the purpose of integrating into Estonian society" 353 . The project provoked criticism on the part of the Russian newspaper Pravda, which accused Estonia of forcing those wishing to become integrated into the Estonian society to change their names. The previous namechanging campaign, Pravda emphasised, while changing primarily German-sounding names, "did not stop many Estonians from becoming staunch allies of Nazi Germany several years later" 354 .

\subsubsection{Italy}

In the times of the rise of Fascism in pre-war Italy a massive campaign meant to Italianize personal names was launched. The non-Italian surnames - chiefly Slavic (Croatian and Slovene), German and Jewish - were modified or translated so they would be 'converted' to their allegedly original Italian or Latin shape; French and other Latinate or Western names were not affected. De-Slavicization of a surname frequently entailed the removal of the Slavic suffixes such as -ich, -cich, -vich, e.g. Bassich > Bassi, Paulovich > Paoli. Consequently, the process was dubbed surname restoration or correction. Originally (as of January $10,1926)$ the surname decree to that effect applied only to the locality of Trent (cf. Pizzi 2001 :127). As soon as Apr. 1927, however, the legislation was extended to comprise all the territories "annexed to the Kingdom by the laws of September

353 "Estonianization Is Opposed by Some in Estonian Government" 2008. Bonjour l'Estonie, Dec. 10. http://shaan.typepad.com/shaanou /2008/12/estonianization-is-opposed-by-some-in-estonian-government.html, accessed Dec. 4, 2016.

354 Vadim Trukhachev 2008. "Estonia to Launch Nationalist Campaign to Humiliate Russian-Speaking Population." Pravda.ru, Dec. 18. http://english.pravda.ru/world/ussr/18-12-2008/106844-estonia-0/, accessed Dec. 4, 2016. 
26 and December 19, 1920" 355 (Hametz 2012: 44). In May 1927 a commission composed of teachers and university professors was appointed by the prefect of Trieste to prepare scholarly background for surname change in the form of guidelines as well as to draw a list of surnames to be restored to their 'original' Italian/Latin form. The head of the commission became Aldo Pizzagalli, a linguist, writer, civil servant and ardent Fascist from Trieste. The commission drew a set of specific guidelines on how exactly to Italianize surnames, complete with sound and letter correspondences (cf. ibid.: 88). After almost two years of work, the list included over two thousand surnames deemed fit for Italianization.

The authorities went to great lengths to give the campaign the appearance of a voluntary action. In fact, some participants actually did want a surname change:

Those seeking surname corrections ranged across the spectrum of nationalist fervor. Some were ecstatic at the prospect and obsessively sought Italianized surnames to demonstrate 'enthusiastic adherence to the surname convention' or to rid themselves of names 'barbarously distorted over the centuries.' Others claimed to want to rectify the spelling of names to make them easier to pronounce. Many sought corrections out of a sense of pragmatism, hoping that the patriotic act would enhance their economic, social, or political position (ibid.: 90).

Nevertheless, in many cases the surname change was effected by coercion or pressure, such as the threat of losing a job in the state service. Nevertheless, to keep up the appearances of a voluntary act, some well-known personages, such as the government minister Fulvio Suvich, were allowed to keep their non-Italian surnames. About 300 surnames were changed in Trieste alone. In 1936 a book entitled Il lavacro dei cognomi (The cleansing of surnames) was published in South Tyrol by Ettore Tolomei, Italian nationalist and 1923 senator.

${ }^{355}$ Bolzano; Istria, Trieste, and Gorizia and Gradisca within Venezia Giulia; Zara (Zadar); Trento (Trent) with its region of Trentino. 
The aim of the book was to prove the Italian or Latin origin of the German surnames used in South Tyrol. All in all, in the years 1927-1943 almost a hundred thousand people (a quarter of the population of the areas that became part of Italy after the First World War) were affected by the surname change. The side effect of the policy was the breaking of the family connection as marked by the unity of the surname. A case in point may be the Cociancich family: its various members, after the surname change was finally granted by the authorities, became Canciani, Canziani, Coceani, Cociani, Cosciani, and Cossiani (ibid.: 85).

Also given names were subject to the governmentinspired and state-supported change. In 1928 an old and obscure Austrian (Habsburg) law was renewed by a royal decree: by its force, from that time on it was forbidden to give newborns 'ridiculous, immoral, or offensive to religious and national sentiment' names. Also surnames in the function of given names were not allowed. With time the law affected not only naming the newborns but also justified the enforced change of given name already bestowed, especially with regard to people aged six to twenty, whose names had been entered in school and army registers. Names of the heroes of Risorgimento $^{356}$, such as Garibaldo, Azeglio, Oberdan were admitted, whereas such names evocative of leftist tendencies as Anarchio, Libera, Liberto, Comunardo, Ribelle, Robespierre were inadmissible. The selective ideology behind the law in question is visible in the story of a woman who changed her name from Anita Repubblica Trieste to Anita Maria Trieste. The name Anita, commonly associated with Garibaldi's wife, was acceptable, while Repubblica, reminiscent of unwelcome democratic tendencies, got replaced with a name typically and safely associated with Conservatism, religion and tradition. In contrast with the surname law, the law on given names applied to all of Italy, and not only to the territories acquired after the First World

${ }^{356}$ I.e. the unification of Italy that for the most part ended in 1870. 
War. Specifically the given names of Croat, Slovene and German saints were prohibited (cf. Hametz 2005, 2012).

It is interesting to note that although foreigners were easily granted permission to Italianize their names, this option was not open to everybody. "Political enemies [of the Fascist regime] or those with criminal records were denied permission as 'Slavs' or simply 'foreigners', implying that they were inevitably and irrevocably enemies of the Italian state" (Hametz 2005: 127).

\subsubsection{Poland}

In the aftermath of the Second World War Poland lost its eastern territories to the USSR, in 'compensation' receiving from defeated Germany the lands to the west of pre-war Poland, called by the Communist authorities 'the Recovered Territories' (Pol. Ziemie Odzyskane). These territories include, among others, Silesia, whose pre-war population of German extraction was largely forced to leave for Germany and those people who stayed were vetted before they were granted Polish citizenship. The integral component of the vetting procedure consisted in renamings that were disguised as (semi-)voluntary though in fact a lot of pressure was exerted on the segment of the overall population which met the predefined criteria. ${ }^{357}$

As Linek (cf. 1997: 50-58, 71-72, 80-90, 104-118, 122124) pointed out, the main legal basis for renamings of both placenames and personal names (including the removals of the latter from signboards, notices, letterheads and even

357 The Scheffler family from the town of Cieszyn (near the PolishCzech border) after WW2, in the 1940s, were requested by the local authorities to change their surname from a German to a Polish-sounding one, as well as to change their daughter's name Gertruda. When they refused, a few days later they learned that from that time they would be called Szewscy, and their daughter instead of Gertruda Anna would be just Anna. Monika Nowak "Ukradzione nazwiska", 16.06.2012, http://www.fronda.pl/a /ukradzione-nazwiska,20447.html, accessed Nov. 27, 2016. 
tombstones) was the decree of Nov. 11, 1945 on Changing and Determining Given Names and Surnames ${ }^{358}$ in Art. 3 (5) gave as one of the permissible reasons for surname change the situation when the surname is of non-Polish sounding. This stood in sharp contrast to the 1919 (Oct. 24) law that mentioned such a situation as a reason for not being able to change the surname (cf. Banach 1946: 10-11). The original aim of the decree was in fact bringing more order to the registration of population after a period of chaos during the Nazi occupation of Poland, when many people - especially those active in the resistance movement - assumed pseudonyms or false names for reasons of safety and then continued to use them after the end of the war. Nevertheless its article 3 item 2 point 5 and article 10 item 2 point 1 allowed name changes "due to the non-Polish sounding of the name", which provided the authorities with a rationale for renamings.

Pollok (cf. [c. 1998]: 8, 52-62, 141) provided anecdotal information on the renamings but his work is best treated as a source based on personal experience rather than a detached scholarly analysis. More factual information can be found in Linek 1997 and Hejger 2008 - especially the former constitutes an invaluable source of information on renamings, backed by thorough and in-depth archival research - and these two works will provide the factual basis for the description of this policy, whose motivation is described also in Rospond 1947.

The motto of the so-called re-Polonisation policy was: "Polish citizens, Polish children bear Polish given names and surnames." Its agents were state clerks, but also managers in factories and parish priests, who were pressurised into giving children Polish names at baptism. Schoolteachers were required to persuade the parents of their pupils at PTA meetings to Polonise their names: those parents who resisted were to be threatened with the risk of depriving them of the

${ }^{358}$ Dekret z dnia 10 listopada 1945 r. o zmianie i ustalaniu imion i nazwisk. Dz.U. 1945 nr 56 poz. 311. http://isap.sejm.gov.pl/DetailsServlet ?id=WDU19450560310, accessed Dec. 4, 2016. 
custody of their children (Linek 1997: 90). At the beginning the procedure of name change was relatively expensive, especially considering that the person interested had to bear not only the administrative costs but also finance a statement in a newspaper. Therefore, as an incentive, on March 15, 1947, Deputy Minister for the Recovered Territories ${ }^{359}$ decided to lift this duty. However, the Ministry of Public Administration ${ }^{360}-$ the Ministry for the Recovered Territories' successor since Jan. 21, 1949 - reintroduced the duty to publish in the press the information about renamings.

The policy was pursued the most energetically in the latter half of 1947 and in 1948. Since Sept. 2, 1947, the role of name-changers was effectively reduced to giving to the administration clerk their personal data, to deciding which name will be used instead and to signing the form - the red tape on this occasion was reduced to an absolute minimum. As a means of exerting pressure on potential name-changers, lists of those who did not comply (even though they qualified) were obligatorily compiled in workplaces, especially in organs of state administration, whose employees were expected to set a good example. Official circulars provided the ideology behind the policy:

Bearing German names by Polish citizens is a sign of Germanness, or at least shows some sort of positive feelings towards things German. This external symptom smites sacred Polish feelings and may disparage many a citizen in the eyes of the Polish society [...]

By Polonising German names all ties of Poles, even if only apparent, with the hated invader, who in the course of history committed so much harm to the Polish Nation, should and must be severed [...] By Polonising their given name or surname Polish citizens are to prove, not only to the Polish Nation but to all the world, that they feel with all their might a part of their Nation [...] not only for themselves, but also for their offspring

${ }^{359}$ Pol. Ministerstwo Ziem Odzyskanych.

${ }^{360}$ Pol. Ministerstwo Administracji Publicznej. 
and for future generations, because a Polish surname will from then on be forever transmitted from generation to generation. (Both citations after Linek 1997: 106, 111.)

An important role in the policy was played by Instytut Śląski in Katowice as a language regulator. Within its structure a special department was created whose task was to give linguistic advise to name-changers as well as provide the cachet of science to the campaign.

The results of the policy were impressive by contemporary democratic standards, yet insufficient in the eyes of the authorities. In the Silesian voivodeship alone about 265 thousand people changed their surnames until the end of the campaign in the middle of 1948. In the region of Opole (Oppelner Schlesien in German), where the name-changing lasted longer, it included about 63 thousand people until 1954.

\subsubsection{South Korea}

As Park (1989) noted, ever since the birth of a democratic Korea in 1948, language policy in this country had been strongly marked by linguistic purism whose aim was ridding the language of Chinese characters and Sino-Korean words. Instead, Hangul, the Korean alphabet that goes back to the $15^{\text {th }}$ century, has been energetically promoted and increasingly introduced. In its many aspects the policy has affected various spheres of life, including among others education (textbooks and curricula), linguistic landscape (signboards and billboards), the language of religion, the press and other media. Of interest for the present discussion, however, will be especially personal names and the "name campaigns" associated with them, held annually at some Korean universities "with a view to popularizing pure Korean first names. These pageants of pure Korean names are usually sponsored by activist student groups calling themselves 'the Students for the Korean Language"' (Park 1989: 133). 


\subsubsection{The patterns and directionality of surname changes}

In the case of voluntary surname changes, certain patterns recur. For example, there is a tendency to preserve the initial letter or letters of the original surname (adding suffixes or cutting off the final part of the original surname): Ettlinger, Murátin > Hungarian Etlényi, Muráti; Metropolitanski > French Metreu. If the target language does not include a particular letter or if its pronunciation differs, then its possibly close substitute may be chosen: German Wurm, Quintz, Singer > Hungarian Vajda, Koltai, Szabados respectively (cf. Farkas 2009, Jacob \& Horn 1998).

Regarding the direction of changes, in the case of encouraged surname changes, the relevant state legislation typically makes it possible to acquire surnames only in the majority/national language form. The Estonian Surnames Act of Oct. 22, $1934^{361}$, may serve as a good example of this unidirectionality:

A requested new surname may not be [...] a surname, which has derogatory or vulgar meaning, is ill-sounding or which is in too wide use, nor a non-Estonian surname, if the person requesting change of surname is of Estonian origin or has an Estonian name. (§ 11, emphasis added; Judgement 2001).

It is interesting that while the legislation of some countries freely allows change of personal names on the occasion of immigrant naturalisation, not everybody is prepared to do it. Statistics quoted by Jacob and Horn (cf. 1998: 14) indicate that in France less than 20 per cent of immigrants actually use that possibility.

${ }^{361}$ Riigi Teataja [official gazette] 1934, 91, 735. 


\subsection{Enforced change of name}

That kind of change has been in history and still is quite a frequent method of forcible cultural assimilation. Since personal names are so closely linked with identity, their change can be seen as severing a symbolic tie with the old cultural values and political loyalties, as an attempt at creating the new man or the new society, or as connected with renouncing or eradicating the old religious beliefs. It is no coincidence that certain rites of passage are marked with name changes. The method of forcible renaming has been employed in history by numerous totalitarian regimes, as well as by Europeans in colonies outside Europe. As an example one may take the fate of the indigenous population of Guanches on the Canary Islands after the arrival of Spaniards. From the $15^{\text {th }}$ century onwards the Guanches were forcibly baptised and on this occasion new Spanish names of Christian saints were bestowed on them. The renaming process was later completed by adding the surnames of their Spanish godfathers, thus resulting in a total destruction of the indigenous naming system and an accompanying loss of identity. Popular Christian names used when baptising Guanches were those of royalty: Isabel, Catalina, Fernando, or Juan ${ }^{362}$. However, numerous instances of less sweeping changes in the history of Europe can be invoked as well, even in recent times.

\subsubsection{Lorraine}

Under the Nazi occupation of the Lorraine during the Second World War, a plan to Germanize given and family names was prepared, on the basis of the document "Ordinance on German Name Giving in Lorraine" of 29 August 1942. The

${ }^{362}$ Cf. Sarah Andrews, Josephine Quintero [\&] Sally O'Brien 2007. Canary Islands. Footscray, Victoria: Lonely Planet, p. 29. John Mercer 1980. The Canary Islanders: Their Prehistory, Conquest, and Survival. London: Collings, p. 229. 
previous year a group of scholars - onomasticians, Germanists, genealogists - as well as officials and local NSDAP representatives had met in the village of St Johann, Rhineland-Palatinate, with the aim of developing guidelines for Germanizing French names. The outcome of the conference, whose moving spirit was the scholar and NSDAP member Fritz Braun, was a 43-page "Index of First Names with Devices for Their Germanization" and a 330-page list of surnames in their French and the new German version (cf. Haar and Fahlbusch 2006: 164-5).

\subsubsection{Luxembourg}

A similar policy was implemented in Luxembourg under the occupation by Nazi Germany. By a decree of Jan. 31, 1941, all Luxembourgers with French-sounding names were required to request to have their name Germanized. Since most people failed to comply, names were imposed on the populace by the administration in a rather uncoordinated fashion. For instance, three Delvaux brothers got a different surname each: Dellmann, Delff, and Därental. Opposing the law, many people chose the given names Charlotte, Jean or Mary reminiscent of the Grand Duchess ${ }^{363}$, the heir apparent ${ }^{364}$ or Virgin Mary respectively ${ }^{365}$.

363 Charlotte vu Lëtzebuerg (1896-1985), reigning as the Grand Duchess of Luxembourg in the years 1919-1964.

364 Jean vu Lëtzebuerg (born 1921), reigning as the Grand Duke of Luxembourg in the years 1964-2000. At the time of the Second World War he was heir apparent (le Grand-Duc héritier) to the grand ducal throne of Luxembourg.

365 Paul Dostert 2003. "Le Luxembourg sous l'occupation Allemande 1940-1945: collaboration et resistance." In: Annexion et nazification en Europe. Actes du colloque de Metz 7-8 Nov. 2003, pp. 47-53. Université de Metz. http://www.memorial-alsace-moselle.com/f/fiches/colloque_metz/ME MORIAL_COLLOQUE_basse_reso.pdf, accessed Dec. 4, 2016, p. 50. 


\subsubsection{Dalmatia}

Following its annexation by Italy, since 1941 intensive Italianization of the area took place, with the goal of assimilating the native Croat and Serb inhabitants as soon as possible. By force of the royal decree of May 18, 1941, the annexed Dalmatian territories became an integral part of Italy. In his speech in Rome on June 10, 1941, Mussolini declared 'the dalmatian question' to have finally been solved. Italian became the official language of administration and there followed Italianization of Croatian given names and surnames, which were given Italian etymology. At the same time new identity documents were issued. ${ }^{366}$

\subsubsection{Macedonia}

For many years it has been an object of two conflicting forces: Hellenisation and (re-)Slavicisation:

[t]he Hellenizing of the Macedonian Christian and surnames was formalized by a legislative edict printed in the Greek government gazette in February 1927. Macedonian surnames [, which] commonly end in -ov/-ova, -ev/-eva and -ski/-ska, were changed to reflect a Greek character - "-os", "-es", "opoulos", "-as", "-iou", etc. ${ }^{367}$

Conversely, in 1944, a plan prepared by the Yugoslav Communist Party assumed making all Macedonian surnames carry the suffix -ski (-ska for women). Thus minority (Greek, Serbian) surnames would not be so readily recognisable, and the state would appear ethnically homogeneous.

${ }^{366}$ Cf. Zdrawko Dizdar 2005. "Italian Policies Toward Croatians in Occupied Territories During the Second World War." Review of Croatian History 1, 179-210, p. 188.

367 "Macedonian Ethnicity Denied." Macedonia Forum. Jan. 22, 2008. http://www.topix.com/forum/world/macedonia/T561CAOROQUGI7SUR, accessed Dec. 4, 2016. 


\subsubsection{Bulgaria}

This state has been testing ground for name-changing projects a number of times. Organised attempts at renaming large portions of the population took place in the years 19121913, 1941-1943, 1956, 1960, 1972, and 1984-87. The ethnic groups affected by the name changes are sometimes referred to as Bulgarian Muslims or Pomaks, sometimes (e.g. in the Helsinki Watch Report) as Turks. A quotation will suffice as an illustration of the inconsistency in terminology:

With the start of what has been referred to as "the revival process" against the Turks in Bulgaria in 1984-1985, the policy of the regime with respect to the names of the Bulgarian Moslems came to a kind of 'culmination' (Krăsteva-Blagoeva 2006: 70, emphasis added).

As Klejn (cf. 2004: 5) has noted, Turks constitute approximately 10 per cent of the inhabitants of Bulgaria, whereas the number of Pomaks is estimated at 2-3 per cent.

The first of the massive renamings of Bulgarian Muslims took place in the times of the First Balkan War, 1912-1913, and was connected with massive forcible conversions of Muslims to Christianity. The number of those converted and renamed at the time is estimated at about 200,000. There was typically no connection between the original Muslim and the new Christian name (e.g. Ahmed > Kiril) since the latter was often owed to the Christian godparent, though sometimes the initial letter was preserved. Also the Orthodox priests had a say in the name choice, hence a large proportion of the names of the most popular and considered 'powerful' saints and holy personages: George, Nicholas, Michael, Maria.

The second wave of renamings in the early forties was related to the activity of the Rodina organization, which had "the aim of helping the Bulgarian Moslems become aware of their Bulgarian origins" (Krăsteva-Blagoeva 2006: 65). This time the motivation was nationalistic rather than religious, thus 
the names were to be symbolic of the Bulgarian nationality rather than typically Christian. To this end, a list of Bulgarian folk names was prepared by Rodina members. A circular of Apr. 30, 1943, obliged all muftis to register babies only by Bulgarian names from the list. The names on the list were taken from old Bulgarian folk songs, fairy tales and legends, and there were also names with traditional Slavic elements Brat-, Drag-, Dobr-, Rad-, Stan-; in the case of female names also the names of flowers and plants were used. Generally these names were perceived as rare and had an archaic ring to them.

The renamings of 1956 and 1960 were characterised, in the words of Krăsteva-Blagoeva, by "uncertainty and insecurity in the status of the Bulgarian Moslem population" (ibid.: 68), which showed in the fact that name changes from Muslim to non-Muslim names happened simultaneously with changes in the opposite direction, i.e. reverting to roots. Some changes were "voluntary", as it were in anticipation of a new wave of repressions.

The changes in the 1970 s were characterised by the attempts of the parents to give their children intentionally ambiguous ('duck-rabbit', see below) names that could pass for both Muslim and Christian/Bulgarian ones: Aldin, Veli (Velizar or Velin), Elin, Sabin, Sevdalin, Sevd. Also the first letter of the official and of the unofficial name was often the same. Another characteristic of the 1970s name changes was the inclusion, generally for the first time, of the surnames as well.

The enforced name changes in the 1980s concerned not only Muslims but also Gypsies. Muslim names were changed to Bulgarian, often Christian ones, and new identity documents were issued accordingly. The official stance of the authorities was that there were no Turks in Bulgaria, only "ethnic Bulgarians who have reestablished the culture and traditions that had been suppressed during five centuries of Turkish rule“ (Laber 1987: 12). There was typically some superficial phonetic similarity between the original and the 
new name, manifested in the preservation of word-initial elements: Yuksel > Yulian, Mehmet > Milet, Ramadan > Radon, Hasan > Hristo. In some cases the given name change 'corrected' the names acquired in the 1970s as still 'insufficiently Bulgarian': an example given by KrăstevaBlagoeva (cf. 2006: 70) is Osman, in 1972 renamed to Vekil, and then in the 1980s to Veselin. Unless the person in question was bearing a Bulgarian name, no birth certificate could be issued and no marriage registered. Similarly no money could be drawn from a bank and no salary or old-age pension paid unless the recipient could produce an identity document with a Bulgarian name. A special book of national Bulgarian names was compiled by the authorities (cf. Laber 1987: 21) and it was forbidden to bestow on a child a name that was not included in it (Muslim names were not included). Between December 1984 and January 1985, about 850,000 Muslim Bulgarians had their names compulsorily changed.

Name changes were merely one aspect of Bulgaria's policy towards minorities which, according to Laber (cf. 1987: passim), included also:

- a ban on speaking Turkish and singing Turkish folk songs;

- fines for those who continue to address one another by Turkish names;

- prohibition of circumcision;

- military control of villages inhabited by Turks;

- discontinuation of Turkish-language media;

- removal of the Turkish language as a subject from school curricula;

- $\quad$ the closing of some mosques;

- a ban on Islamic burials and the obliteration of some Muslim cemeteries;

- finally, sending people to prison camps (e.g. on the island of Belene on the Danube) and forced expulsion of Turks from Bulgaria.

In the aftermath, there were several waves of migration to Turkey in the 1980s. Paradoxically, in the summer of 1989, 
after the immigrants to Turkey were ceremoniously greeted with flowers, their surnames were changed again, this time by the activists of the Motherland Party (Avatan). Dimitrova (1998) listed some of those new surnames: Vatansever ('patriot'), Tekulus ('single nation'), Yozturk ('pure-blooded, genuine Turk'), Savas ('battle'), Kilic ('sword'), Kahraman ('hero'), Zafer ('victory, triumph'), Basaran ('successful'), Mutlu ('happy, lucky, blessed'), Neseli ('glad'), Yilmaz ('fearless').

The 1980s events in Bulgaria resulted in the death of several hundred Muslims, occasioned a Helsinki Watch report (1986), and even became the subject matter of a 2005 film $^{368}$. Following Todor Zhivkov's resignation in November 1989, the Turkish-Arabic names of Bulgarian Muslims were restored (by force of the resolution of the plenum of the Central Committee of the Bulgarian Communist Party - December 29, 1989) and the policy of Bulgarization was abandoned (cf. Laber 1987; Neuburger 2004; Klejn 2004; Eberhardt 2005; KrăstevaBlagoeva 2006; Angelov and Marshall 2006).

\subsection{Voluntary vs. enforced changes}

Voluntary name changes are often manifestations of the need to belong and show attachment to a particular culture and unity with it. As has been shown, when they appear on a mass scale, they frequently accompany 'national revivals', 'national awakenings', in other words the process of creation or recreation of an imagined community in Andersonian sense (cf. Anderson 2006), whose members, regardless of their original ethnicity, manifest the will to become loyal citizens. Nevertheless, given similar motivation, such changes may occur on an individual basis as well. For instance, Mountbatten and Windsor, the surnames of the British royalty, were assumed in connection with the First World War to manifest patriotic feelings and unity with the nation, and

368 “Откраднати очи” [Otkradnati ochi, 'stolen eyes'], a Bulgarian production directed by Radoslav Spasov. 
especially as a means of obliterating the German origins of the dynasty by translating the name Battenberg as Mountbatten. It is noteworthy that certain moments in history seem to have provoked spontaneous and voluntary individual acts of assimilative name changes, e.g. in France following the end of the Second World War and of the Algerian War (Jacob and Horn 1998: 13).

Enforced name-changing campaigns, on the contrary, are motivated by a common name ideology. This ideology is well epitomized by Konstantinov, who referred specifically to the Pomaks, yet his remarks had a universal appeal and the attitude of Bulgarian authorities can be recognized in the policies in other European nation states:

The nation-state had to 'explain' to the Bulgarian Muslims who they really were and help them regain their 'true' identity. The underlying proposition is that the Bulgarian Muslims have 'forgotten' about the true facts, or have been 'misled'. In official discourse they are presented as people whose 'national consciousness has to be cleared up'. The Bulgarian Muslims are seen as living in some sort of communal oblivion and ignorance and they need to be helped to get out of this state. ${ }^{369}$

Nevertheless, the above ideology does not apply to compulsory name changes to which immigrants are occasionally subjected. Iceland may serve as a case in point. In the years 1952-1995 foreigners applying for citizenship in Iceland had to assume Icelandic names (Willson 2009).

It must be emphasised that often the line between enforced and voluntary name changes is very fine indeed. The incentives used to encourage citizens to comply with namechanging campaigns range from subtle to quite

${ }^{369}$ Yulian Konstantinov 1997. Three Pomak Stories. Sofia: Bulgarian Society for Regional Cultural Studies. Quoted after Shane Jacobs 2001. "A History of Oppression. The Plight of the Bulgarian Pomaks." Central Europe Review, Vol. 3, No. 19, May 28. http://www.ce-review.org/01/19 /jacobs19.html\#bk1, accessed Dec. 4, 2016. 
straightforward. For instance Alicja Michałowska née Szczemirska, a Polish woman who before WW2 used to live in Koltyniany $^{370}$, recollected:

Soon after the entry of [Lithuanian] troops into the Vilnius Region on 28 of October 1939 my parents were dismissed from work because they did not consent to having the spelling of their surname changed by adding the ending -as. They would be called Szczemirskas then. Besides, my parents did not want to assume Lithuanian citizenship. For the refusal they were threatened with being arrested ${ }^{371}$.

The Italianization of Slavic and German surnames serves as another example. Theoretically voluntary, when scrutinised more closely, the surname-changing campaign appears de facto at least partly enforced. This is how the Trieste province was made "more Italian" in the aftermath of the First World War by force of the Treaty of Rapallo (1920), whereby Austria lost the province to Italy:

In March 1928 the provincial education office urged teachers to help the schools to be among the 'first in this manifestation of Italianness'. Prefectural records indicate that many complied. The power of the authorities to dismiss teachers, or revoke their credentials, combined with psychological pressure upon them. Civil servants too risked censure. Many employees of the customs authority, the Central Warehouse Authority and large shipping firms dependent on state contracts, were among early petitioners for alteration of foreign names. Edoardo Weiss, a noted psychoanalyst, claimed that he was asked to resign his post at the provincial psychiatric hospital because he refused to change his German-Jewish surname (Hametz 2005: 127).

${ }^{370}$ Lith. Kaltanenai, a town in the east of Lithuania, before WW2 within the borders of Poland.

371 Alicja Michałowska “Gdzie Żejmiana, gdzie Odra”. Kurier Wileński, Jan. 13, 1998, p. 6. 


\subsection{Forbidden name change}

In the $19^{\text {th }}$ and $20^{\text {th }}$ centuries, in many newly emergent nation-states whose separate existence resulted from the collapse of a larger multi-ethnic entities, surname change was encouraged as a means of unifying and consolidating the (titular) nations. If any minorities were still left inside the new state, attempts were made to assimilate them in this way, as well as in other ways. It was so in the case of Estonia, Hungary and other states. However, the reverse phenomenon even though definitely less frequent - occasionally took place as well: an express prohibition of surname change.

The motivation for such a prohibition was connected with the attempt on the part of the authorities to provide a means of distinguishing between Christians and Jews. It was felt that Christian names should not be bestowed on Jewish children (the only excuse for such an action being conversion to Christianity). Thus in the Habsburg Empire, the 1787 imperial decree that introduced compulsory surnames for Jews, at the same time forbade name-change (of given names and surnames), the ban lifted in 1814 by emperor Franz I (cf. Farkas and Maitz 2008). Similar bans were introduced in various German states. In Prussia, for instance, in 1828 name change from 'Josel Salomon' to 'Joseph Salomon Wolters' was requested by a Jewish merchant. Granting the change, king Friedrich Wilhelm nevertheless expressed irritation at the scale of the name changes and he expressed it in his note to the Minister of Interior Friedrich von Schuckmann: "I remark on this occasion that the Jews are still changing their names at will, particularly their first names [...] and I therefore instruct you strictly to ensure through the police authorities that this disorder does not occur in future" (Bering 1992: 50).

A 1915 law in the USA forbade enemy aliens to change their names. According to the 1919 Aliens Restriction Act, aliens in the USA were forbidden to change the names they had borne on August 4, 1914 (cf. Rennick 1984). Since the 
motivation behind such a ban is typically the ease of identification, the ban may include, alongside surnames, also given names. 
This page intentionally left blank 


\section{Names and the law \\ 6.1. Domestic legislation in selected European states}

When names are objects of de jure NP, they become subjected to the relevant laws and thus may be considered from the legal point of view:

Names are [...] undoubtedly linked to family law. Names mainly result from the change of a civil status which is family related, such as marriage or divorce. The private international law aspects of names may, nonetheless, operate independently of such rules regarding civil status. The law applicable to the marital status of a person may therefore not always be the law applicable to the name derived thereof ${ }^{372}$.

Examples of special name laws from many countries of Europe include:

- the Czech Republic - Zákon o matrikách, jménu a príjmení a o změně některých souvisejicich zákonů [law on registry, given name and surname, amending certain related acts] 301/2000;

- Croatia - Zakon o osobnom imenu [law on personal name] of 2012;

- Denmark - Navnelov [law on names] of 2006;

- Estonia - Nimeseadus [names act] of 2004, with later amendments;

- Finland - Nimilaki [name law] of 1985, with amendments;

- Hungary - Törvényerejü rendelet az anyakönyvekröl, a házasságkötési eljárásról és a névviselésröl [the decree on registers, the marriage procedure and names] of 1982;

- Iceland - Lög um mannanöfn [personal names act] of 1996;

${ }^{372}$ Linnea Håkansson 2012. "Your Europe - your name? An analysis of the compatibility of Swedish private international law with European Union law in name matters". Uppsala: Uppsala Universitet, p. 21. https://www .uppsalajuristernasalumnistiftelse.se/wp-content/uploads/2014/11/Linnea-H \%C3\%A5kansson.pdf, accessed Dec. 4, 2016. 
- Latvia - Regulations on Spelling and Identification of Names and Family Names, 2000, and Law on Changing the Registered Name, Surname or Ethnicity, 1994;

- Lithuania - Lietuvos Respublikos Aukščiausiosios Tarybos Nutarimas "Dèl vardu ir pavardžiu rašymo Lietuvos Respublikos piliečio pase" [resolution of the Supreme Council "on name and surname spelling in the passport of the citizen of the Republic of Lithuania"] of 1991;

- Macedonia - Закон за личното име [law on personal names] of 1995;

- Norway - Lov om personnavn (navneloven) [law on personal names] of 2006;

- Slovakia - Zákon Národnej Rady Slovenskej Republiky o mene a priezvisku [law on the given name and surname] of 2006;

- Slovenia - Zakon o osebnem imenu [personal name act] of 2006;

- Sweden - Namnlag [name act] of 1982, with amendments.

In January 2011 media reported that Azerbaijan was to introduce a law on names too (Azerbaijan... 2011). Where there are no special name laws, personal names may be found interspersed among various laws, including the civil or family codes, laws on citizenship and/or civil registry, or laws on the rights of national minorities. Thus in Germany, for instance, the regulations on names are contained in the Civil Code (Bürgerliches Gesetzbuch - BGB), while name changing is dealt with in Allgemeine Verwaltungsvorschrift zum Gesetz über die Änderung von Familiennamen und Vornamen (NamÄndVwV) of 1980/1986 and the Act on Changes of Surnames and First Names of 5 January 1938, amended by the Act of 16 December 1997.

Austria, in turn, regulates names by means of such laws as Personenstandgesetz ${ }^{373}$, Volksgruppengesetz ${ }^{374}$, and

373 http://www.ris.bka.gv.at/GeltendeFassung.wxe?Abfrage=Bundesnorm en\&Gesetzesnummer=10005556\#header, accessed Aug. 10, 2012.

$374 \mathrm{http}: / / w w w . r i s . b k a . g v . a t / G e l t e n d e F a s s u n g . w x e ? A b f r a g e=B u n d e s n o r$ men\&Gesetzesnummer=10000602, accessed Aug. 10, 2012. 
Namensänderungsgesetz ${ }^{375}$.

In what follows, legislation concerning personal names in selected European states ${ }^{376}$ will be discussed taking into account, as far as possible, the following criteria:

1. the allowed number of given names and their hyphenation (if permitted)

2. admissible given names and an official list (if there is one)

3. if there is obligatory gender-specificity of given names

4. forbidden / inadmissible names

5. change of given name

6. the allowed number of surnames and their hyphenation (if permitted)

7. change of surname (admissible reasons)

The descriptions of the laws in particular states, which follow, differ considerably in length. The reason is that some countries regulate personal naming in great detail, while in others there are few provisions concerning explicitly names, and restrictions, if imposed, are the result of other mechanisms (e.g. there are no rules about admissible names but courts object to some names proposed by parents on a case-by-case basis on the grounds that these names are detrimental to the well-being of the child in question).

\subsubsection{English-speaking countries}

The United Kingdom. Similarly to other common-law countries, there are practically no formal restrictions on the choice of the given name(s) bestowed on a child.

Name change is possible and best done by making a deed poll. The detailed procedure is different for Scotland and for the rest of the $\mathrm{UK}^{377}$. One of the scenarios for given name

375 www.transx.at/Dokumente/NaeG_95.pdf, accessed Aug. 10, 2012.

${ }^{376}$ In the case of some countries updates after 2014 may not have been taken into account.

${ }^{377}$ https://www.gov.uk/register-birth/print, accessed Dec. 9, 2016. 
and/or surname change in Scotland is "where the registered name(s) is a non-English name(s), (for instance a Gaelic name) and the alternative name(s) is the English equivalent $[\ldots]$ the alternative name(s) so recorded will be shown on any birth certificate alongside the name(s) as originally registered, for example: Domhnall (Donald)"378.

Ireland. There are generally no formal restrictions on the bestowal of given names (there may be more than one) for newborn babies.

The newborn's surname may legally be either that of the mother, or that of the father (if entered on the birth certificate), or a hyphenated surname that combines, in either order, the surnames of both parents ${ }^{379}$. A person's surname can be changed either by common usage (under common law), or by an official procedure called the deed poll, which involves a formal written declaration that one is abandoning one's old name and shall use the new one at all times.

\subsubsection{German-speaking countries}

Germany $^{380}$. The limit on the number of given names per individual is five (one of these - not necessarily the first one is by custom designated as Rufname, i.e. the name to be actually used in everyday life), with a double hyphenated given name counting as one. In case of doubt the book Internationales Handbuch der Vornamen is consulted; as the name implies, it contains not only German, but also Arabic,

${ }^{378}$ https://www.nrscotland.gov.uk/files/registration/rcn1-leaflet.pdf, updated Dec. 2016, accessed Dec. 9, 2016.

379 http://www.citizensinformation.ie/en/birth_family_relationships /after_your_baby_is_born/registering_birth_your_baby.html, updated Jan. 25, 2016, accessed Dec. 9, 2016.

380 Jennifer Willms 2011. 10000 Vornamen: So soll unser Kind heißen! Augsburg: Weltbild. See also https://www.muenchen.de/rathaus /Stadtverwaltung/Kreisverwaltungsreferat/Standesamt-und-Urkunden/Geburt /Namensgebung.html, accessed Dec. 9, 2016. 
Albanian, Kurdish, Vietnamese and other names (the 2008 edition comprised about 65 thousand names). A foreign given name may be recorded with foreign diacritics ${ }^{381}$. A given name must be gender-specific - if it is androgynous, then it must be accompanied by another, gender-specific one ${ }^{382}$. Traditionally a boy may be given the name Maria as a second name. The given names of siblings must differ. Given names must not expose their bearers to ridicule or be malicious ${ }^{383}$, and they must not be overly eccentric. The given name must be recognisable as such, which means that no company name, noble title or surname can be assumed as a given name ${ }^{384}$. In theory no place-name can become a given name either, though in practice there are exceptions. Thus in 1995 Chelsea was approved as a girl's name and in 2003 a boy's name San Diego was accepted on the grounds that it is composed of two acceptable names. Nevertheless, Borussia as a female name was rejected in 1996.

German surnames are composed of two elements (and then obligatorily hyphenated) only in two cases. One is the traditional aristocratic Doppelnamen. The other case of a double-barrelled surname is when one of the marriage partners (most often the wife) decides to combine, in either order, his/her pre-marriage surname with the surname of the spouse. The other spouse, however, retains his/her premarriage surname, and this single surname, not the doublebarrelled one, is passed onto the children. No chains of more than two surnames ("Bandwurmnamen", "Namensketten") are allowed $^{385}$.

${ }^{381}$ http://www.babycenter.de/a9996/namensrecht-welchen-vornamendarf-ich-meinem-kind-geben, accessed Dec. 9, 2016.

${ }^{382}$ Past approvals based on this principle were e.g. Tjorven, November, Ogün, Jona.

383 This principle led to the rejection by German registry offices of such name proposals as Heydrich, Judas and Kain.

${ }^{384}$ Names rejected for this reason in the past were e.g. Hemingway, Porsche, Schröder. However, Persil was accepted.

${ }^{385} \mathrm{Cf}$. http://www.focus.de/finanzen/recht/nachnamen-drei-sind-einer- 
Austria. Regulations are generally rather similar to those in Germany, though not identical. For instance, the first (not: one) of given names must be gender-specific. Names that are unusual or could negatively affect the child's wellbeing are forbidden. However, there is no formal limit on the number of given names ${ }^{386}$.

\subsubsection{Nordic countries}

Sweden $^{387}$. An individual may have one or more given names (förnamn), which must not "cause offence or be supposed to cause discomfort for the one using it"; also forbidden are "names which for some obvious reason are not suitable as a first name" 388 . There is no official list. At given names change, at least one of the names must be kept. Surnames must not be used as given names.

The middle name (mellannamn), which is more similar in idea to the American-style middle name as a type of surname than to a second given name, may be a way for married women to keep their maiden surname, but it may not be transmitted to children (cf. Dacey-Fondelius 2007). In more general terms, only one of the spouses (traditionally the woman, but by law any of them) can have a hyphenated name consisting of own premarriage surname and the spouse's surname, while the other retains own pre-marriage (single) surname and it is the latter, single surname (called "the common surname", gemensam efternamn) which is given to children.

zu-viel_aid_396106.html, accessed Dec. 9, 2016.

${ }^{386} \mathrm{http}: / / w w w . b a b y c e n t e r . d e / a 9996 /$ namensrecht-welchen-vornamendarf-ich-meinem-kind-geben, updated 2016, accessed Dec. 9, 2016. https://www.schwanger.at/namensrecht-in-oesterreich.html, accessed Dec. 9, 2016.

${ }^{387}$ http://www.notisum.se/rnp/sls/lag/19820670.htm, accessed Dec. 9, 2016.

388 This regulation is rather vague: accepted given names in Sweden include Google (as a middle name) and Lego; rejected ones - Metallica, Ikea. 
Surnames may be changed through marriage or by applying for a name change to the Swedish Patent and Registration Office (Patent- och registreringsverket, $\mathrm{PRV}^{389}$ ). The change may be to an existing or to a new surname. In the former case, the applicant has to be a linear descendant of persons who have carried this name for at least two generations within the last 100 years $^{390}$. Otherwise a surname currently in use, or one that has died out, must not be assumed. If one wants to change the surname to a newly-created one, to be approved by PRV it must be suitable as a surname in Sweden in form, pronunciation and spelling, it must not be a double surname or in use as a given name, nor a name of a railway station, post office etc., or otherwise likely to deceive the public. It must not be offensive or likely to lead to discomfort for the person bearing it. Widely known foreign or artists' surnames, names of foundations, non-profit organizations or any similar institutions, legally protected trademarks and distinctive titles of literary works ${ }^{391}$ must not be adopted as surnames, whether newly created or not.

${ }^{389}$ On its website (https://www.prv.se/en/our-services/personal-names/, accessed Dec. 9, 2016) the Office provides advice to potential namechangers.

390 After the Swedish language version of the film The Hobbit appeared, Swedish citizen Yvonne Ekenskjöld revealed she intended to take legal action for making Ekenskölde (Oakenshield in English) the name of a dwarf in the film. "It's not a noble family name anymore though; that family died out 200 years ago. We're not really sure what she's talking about - she's claiming that her name is special and it's only her family that can use it," commented the spokesman for the Swedish Film Institute. As The Local wrote, "Swedish law affords a high level of protection to unusual surnames. Companies can be prevented from using aristocratic names as trademarks, for instance. The law is also frequently used to prevent ordinary Swedes from acquiring status by adopting noble surnames, unless the noble family has died out." [Quoted after: Oliver Gee "'Noble' Swede: Hobbit dwarf stole my name." The Local. Dec. 18, 2012, http://www.thelocal.se/20121218 /45144, accessed Dec. 9, 2016.

${ }^{391}$ On these grounds the name Asterix has been rejected. 
Norway ${ }^{392}$. A person may have a first name (fornavn) and a middle name (mellomnavn). A name which figures in the Central Population Register as a surname or middle name must not be taken as a first name, but can be taken as a middle name. In that respect middle names have more affinity to surnames than to given names.

A surname (etternavn ${ }^{393}$ ) may be single or double (then typically hyphenated). Surnames borne by $200^{394}$ or fewer people are protected and may not be taken at name-change without the consent of all their bearers; this principle does not apply if the desired surname is the surname borne by one's family members specified in the regulations, such as parents or grandparents. Nor can people who change their surname take a surname similar to a protected one, or one that is identical with or similar to a widely known business name, trademark, a generally known name of a foundation, association, institution, etc. or a generally known artist name, where it must be assumed that the legitimate interests of the abovementioned would suffer. However, names that are not registered in the Central Population Register as surnames in use in Norway can be taken as surnames. Given names must not be used as surnames (unless a particular given name has a tradition of such use in Norway or abroad).

Denmark $^{395}$. Every child must have at least one given name. A given name may not denote the opposite gender in relation to the individual who will bear it. There are two official lists published by the Minister for Social Affairs and

392 http://www.lovdata.no/all/hl-20020607-019.html, accessed Dec. 9, 2016.

${ }^{393}$ By a 2002 law (in force since 1.01.2003), this term replaced the older term slektsnavn (cf. Brylla 2002: 364).

${ }^{394}$ Before the adoption of the 2002 law, this limit used to be 500 bearers.

395 https://www.retsinformation.dk/Forms/R0710.aspx?id=176627, accessed Dec. 10, 2016. 
the Interior - one for boys and one for girls ${ }^{396}$. In December 2016 there were 19,516 girls' names and 15,929 boys' names on the list. There is also the third list of unisex names (as of December 2016, including 871 given names), such as Aiden, Angel, Charlot, Elvin, Frankie, Kim, Nikki, Sasha. However, names not included on the lists may also be approved ${ }^{397}$ as long as (i) they are proper first names, (ii) they are not unsuitable for use as a first name in Denmark, (iii) they are not inappropriate and will not cause offence. Conversely, given names which do not fulfill one of these three conditions may be legally changed.

Middle names (mellemnavne) also exist in Denmark. They are similar to surnames in character and a person may have more than one middle name. A possible middle name is:

(i) any name admissible as first name (regardless of the gender denoted by the name) or as surname;

(ii) a name which has previously been the applicant's middle name;

(iii) a name which the individual concerned is entitled to adopt as a last name;

(iv) a name which is/has been borne as a middle name by the applicant's parents, grandparents, great-grandparents, great-greatgrandparents, or of the applicant's parent's current or former spouse, or of the applicant's current or former foster parent (unless it is a patronymic);

(v) a name borne as a middle name or last name by the spouse (unless it is a patronymic).

396 https://ast.dk/born-familie/navne/navnelister, accessed Dec. 10, 2016.

397 "But those wishing to deviate from the official list must seek permission at their local parish church, where all newborns' names are registered. A request for an unapproved name triggers a review at Copenhagen University's Names Investigation Department and at the Ministry of Ecclesiastical Affairs, which has the ultimate authority. The law applies only if one of the parents is Danish [...] About 1,100 names are reviewed every year, and 15 percent to 20 percent are rejected, mostly for odd spellings" (Lizette Alvarez "Picked baby's name? Not so fast, in Denmark." The New York Times, Oct. 9, 2004) 
Surnames (in the English-language version of Danish laws often referred to as 'last names', which helps prevent confusing them with middle names) can be single or double if double, they must be hyphenated. A surname borne by 2,000 or fewer individuals is by law protected (beskyttet efternavn) and cannot be freely taken by people not related to its bearers (however, the surnames that were once unprotected cannot become protected even if the number of their bearers drops below the 2,000 limit). As a last name can be taken for example a name that is, or has been, borne as a last name by one of the applicant's parents, grandparents, greatgrandparents, great-great-grandparents, by a parent's spouse, by a current or former foster parent, by a spouse or - under certain conditions - by a co-habiting person; this concerns also the protected surnames ${ }^{398}$. A protected surname can also be taken if one gets the permission of every person bearing it.

A novelty introduced by the law that came into force on April 1, 2006 was the readmission of patronymics and matronymics, in line with the traditional Scandinavian naming system. These are formed from the given name of a parent, with the use of the suffixes -søn ('son') or -datter ('daughter'), or of any other prefix/suffix to denote kinship, if the name is rooted in a culture which permits this. If the name is rooted in a culture which does not distinguish between first and last names, the first name of either parent, a grandparent or spouse may be taken as last name. Finally, Danish law allows for the creation of artificial surnames as long as they are not easily confused with protected surnames. The new creations must

${ }^{398}$ As Kay Xander Mellish, an American blogger who has lived and worked in Denmark since 2000, noted, "[t]hese names are prized family heirlooms, which only specific descendants are allowed to bear: one of my friends was given the right to use the family name by his grandmother on her deathbed. They are also the sometimes the subject of lawsuits about which branch of the family has the right to the treasured name." ("Danish names: Why it's bad to be Brian", http://howtoliveindenmark.com/stories-about-lifein-denmark/danish-names-why-its-bad-to-be-brian/, April 13, 2013, accessed Dec. 10, 2016) 
then be officially approved. Given names, registered company names, registered names of performers (i.e. artists) and those of foreign or historical persons (or confusingly similar ones) cannot be taken as surnames.

Finland $^{399}$. The maximum number of given names is three. There is no official given names list. Nevertheless, a given name that is improper or may otherwise cause an obvious disadvantage cannot be approved. Also forbidden is any given name ${ }^{400}$ which

(1) in its form or spelling is contrary to the Finnish naming practices;

(2) is a woman's name for a boy or a man's name for a girl;

(3) is a surname, unless it is constructed from the given name of the father or the mother, ends in -poika ('-son') or -tytär ('-daughter') and is used after another given name (in other words, if a patronymic/ metronymic is used, it must not be the first of the given names);

(4) already belongs to a sibling or stepsibling, unless used with another given name.

At marriage each spouse may retain their own surname or they may both adopt the surname of one of them as a common marital surname. Also, since the change of law in 1985, one of the marriage partners has been able to decide to combine his/her pre-marriage surname with the surname of the spouse. Then the other spouse retains his/her pre-marriage surname. As Paikkala (2002) observed, the holders of such hyphenated marital double names represented a mere $0.3 \%$ of the Finnish population in the 1985 statistics, after half a year of the functioning of the new law. Within the subsequent decade the

${ }^{399}$ For the Finnish language version of the Finnish name law see http://www.finlex.fi/fi/laki/ajantasa/1985/19850694, accessed Dec. 10, 2016. Unofficial English translation of Nimilaki [names act] 694/1985, with amendments up to $253 / 1991$ has been provided by the Ministry of Justice, Finland (e-mail communication of June 18, 2010).

400 There may be exceptions to this rule due to religious or national / ethnic considerations. 
number of such hyphenated surnames in Finland doubled (from 15 thousand to over 30 thousand). However, as Paikkala emphasised, the invoked statistical data exclude a marginal number of surnames built according to the Spanish or Norwegian model (e.g., Garcia Nuutinen, Jensen Strang), where there are no hyphens. Change of surname is allowed as long as no surname already in use in Finland (and thus listed in the Finnish Population Register) is chosen as the new surname, unless there is a special reason to do so, such as the fact that the surname in question was used in the past by the person's ancestors, if this can be proved. Anyone who believes that such a surname change might infringe his/her rights is entitled to objection. Besides, a name cannot be approved as a new surname if it may be misapprehended in connection with, or confused with,

(i) the name of a foundation, association or other organisation;

(ii) a registered trade name or trademark or other protected symbol used in trade;

(iii) a generally known pseudonym ${ }^{401}$.

Iceland. ${ }^{402}$ By law the full Icelandic name consists of a given name (or names - but no more than three of them), a middle name ${ }^{403}$ (only one, where it exists), and one's surname. At the same time the total number of a person's given names, plus the middle name, may not exceed three. If a given or middle name is not on the Personal Names Register

${ }^{401}$ This regulation concerns the stage names of artists and similar personal names.

${ }^{402} \mathrm{Lög}$ um mannanöfn [personal names act], http://www.althingi.is /lagasofn/nuna/1996045.html, accessed Dec. 10, 2016. English language version: http://eng.innanrikisraduneyti.is/laws-and-regulations/english/perso nal-names/, accessed Dec. 10, 2016.

${ }^{403}$ In Icelandic millinafn. The official English translation on the Iceland's Ministry of the Interior website refers to them as "family names" (http://eng.innanrikisraduneyti.is/laws-and-regulations/english/personal-names/, accessed Dec. 10, 2016); given the nomenclature adopted here, it seemed more appropriate and less misleading to call them middle names. 
(Mannanafnaskrá), it cannot be approved, provisionally registered or given to the child, but the matter must be referred to the Personal Names Committee (Mannanafnanefnd). Given names must be capable of having Icelandic genitive endings or must be established by tradition in the Icelandic language; they may not conflict with the linguistic structure of Icelandic; they must be written in accordance with Icelandic orthography 404 (unless another orthography is established by tradition); they must not be embarrassing and they must indicate gender. A child whose either parent is or was a foreign national is exempt from these rules, but one of the child's given names must be in accordance with these rules.

Middle names (millinöfn), introduced by a 1996 law, must have Icelandic language roots or be established in the Icelandic language by tradition. They may not have genitive endings. Names established by tradition solely as men's given names or women's given names may not be middle names. The name of one of the child's parents, in the genitive case, may, however, be given as a middle name. Middle names formed in the same way as patronymics or metronymics are not permitted. These requirements do not apply if the middle name in question is or was borne as a given or middle name by one of the person's full siblings, parents or grandparents. Middle names must not be embarrassing.

Surnames are of two types: patronymics / metronymics and family surnames. The latter are surnames in the usual European sense. However, most Icelanders use patro- or metronymics ${ }^{405}$, which are formed using the suffix -son (for men) or -dóttir (for women). Consequently, telephone directories and other publications list Icelanders by their given

404 Thus the names Cara, Carolina, Cesil and Christa have all been rejected since there is no letter $\mathrm{C}$ in the Icelandic alphabet. Anna Andersen "Icelandic girl fights for right to her own name." Yahoo! News Jan. 3, 2013. http://news.yahoo.com/icelandic-girl-fights-her-own-name-074758814.html, accessed Dec. 10, 2016.

405 In the 1970 s only $15 \%$ of the population bore inherited fixed surnames (Willson 2002: 135). 
names. In 1970s this practice was even adopted by the US Library of Congress in cataloguing Icelandic authors (Tomasson 1980: 165). A person may bear simultaneously a patro- and a metronymic, and a person entitled to a family surname may bear it alongside a patro- or a metronymic.

The use of family surnames in Iceland is discouraged and limited by law in many ways. For instance, to bear a family surname, a person must have the right (which generally comes from the tradition of such use in the family) and choose to do so. No new family surnames may be adopted. Icelandic citizens may not adopt their spouses' family surnames. After divorce a person may demand that the Minister of Justice issue a ruling that a former spouse is no longer permitted to bear his / her family surname after the spouse remarries. Finally, any person may discontinue the use of a family surname, or adopt it as a middle name.

In contrast with the previous regulations and practice, foreigners (and their children) acquiring Icelandic nationality may now retain their full name without any changes, although they may adopt an Icelandic-style name. Persons who had to Icelandicise their names in the past may re-adopt their previous names.

\subsubsection{The Baltic states}

Lithuania $^{406}$. One or two given names are admissible. There is no official given name list, though in case of doubt registry offices consult Lithuanian and international name dictionaries.

Double (hyphenated) surnames are allowed. Lithuanian surnames are gender-specific and feminine surnames in their suffixes traditionally indicate marital status as well (e.g.

406 Lietuvos Respublikos Teisingumo Ministro įsakymas dèl civilinès metrikacijos taisyklių patvirtinimo $2006 \mathrm{~m}$. gegužès 19 d. Nr. 1R-160 http://www3.lrs.lt/pls/inter3/dokpaieska.showdoc_1?p_id=277920, accessed Nov. 5, 2013. 
Kazlauskaite - unmarried, Kazlauskiene - married). Since 2003, a feminine surname form which does not reveal marital status (e.g. Kazlauské) may also be assumed ${ }^{407}$. Surname change is allowed if the present surname is degrading or inconvenient to use, if the applicant wishes to return to the previously held name or wishes to assume the name of the parents, grandparents, great-grandparents or other ancestors, or when the applicant has changed his/her surname in a foreign country ${ }^{408}$.

Given names and surnames of persons of nationality other than Lithuanian are written in official documents according to their pronunciation and, depending on the request of the name bearer, either with Lithuanian suffixes (sugramatinta forma, "grammaticalised") or without them (nesugramatinta forma, "non-grammaticalised") 409 . A more detailed account of the theory and practice of personal name Lithuanisation is described and analysed in this book in the section devoted to the case study of personal name Lithuanisation policy.

Latvia $^{410}$. Up to two given names are admissible. Double (hyphenated) surnames are allowed. Change of given name or surname is possible if the name is hard to pronounce, does not

${ }^{407}$ Rekomendacija dèl šeiminès padèties nerodančių moterų pavardžių su galūne -è kirčiavimo (Patvirtinta Valstybinès lietuvių kalbos komisijos $2009 \mathrm{~m}$. lapkričio $26 \mathrm{~d}$. protokoliniu nutarimu Nr. PN-4 (K-18)). http://www.vlkk.lt/lit/nutarimai/tartis-kirciavimas/pavardziu-moteru.html, accessed Nov. 5, 2013.

408 Lietuvos Respublikos Teisingumo Ministro ịsakymas dèl Teisingumo Ministro $2001 \mathrm{~m}$. birželio 20 d. İsakymo nr. 111 „Dèl asmens vardo, pavardès, tautybès pakeitimo taisyklių patvirtinimo“ pakeitimo 2008 m. spalio 29 d. Nr. 1R-415. http://www3.1rs.lt/pls/inter3/dokpaieska .showdoc_l?p_id=329828, accessed Nov. 5, 2013.

${ }^{409}$ Lietuvos Respublikos Aukščiausiosios Tarybos nutarimas dèl vardų ir pavardžių rašymo Lietuvos Respublikos piliečio pase (AT nut. Nr. I-766, 1990.11.08; Nr. I-767, 1990.11.08.) http://www3.lrs.lt/pls/inter3/oldsearch .preps2?Condition $1=652 \&$ Condition2=, accessed Nov. 5, 2013.

410 "Dzimšanas fakta reǵistrācija" http://www.tm.gov.lv/lv/nozarespolitika/pakalpojumi/nozares-pakalpojumi/dzimsanas-faktu-registracija /dzimsanas-fakta-registracija, accessed Nov. 5, 2013. 
match ethnicity, but also when the applicant wishes to acquire his or her historic family name in the direct ascending line ${ }^{411}$.

The most prominent part of the present Latvian name policy, however, is the Latvianisation of personal names ${ }^{412}$. Foreign names, regardless of their origin (hence also those originally written in the Latin alphabet), are spelled in the Latvian language according to their pronunciation. They also acquire masculine or feminine endings that correspond to the Latvian language grammatical system, according to the person's gender (except for common gender family forms with the feminine endings for persons of both genders). Names of foreign origin ending with $-a,-e,-i,-i,-o,-u,-u$ are indeclinable in Latvian. At the request of the person concerned, the original form or the transliterated (replaced letter by letter from other alphabets' spelling) form in Latin alphabet writing can be added in documents. This domesticating policy has been a controversial issue (cf. Brands-Kehris and Pūce 2005a: 26, Brands-Kehris and Pūce 2005b: 55) and has led to several lawsuits since Latvia's regaining independence after the dissolution of the Soviet Union.

411 "On the Change of a Given Name, Surname and Ethnicity Record." (adopted by the Saeima on 15 June 2006) www.vvc.gov.lv/export /sites/default/docs/LRTA/Likumi/Change_of_a_Given_Namex_Surname_an d_Ethnicity_Record.doc, accessed Dec. 10, 2016. There have been amendments to this law in the part pertaining to changing the nationality record (cf. http://www.baltictimes.com/non-ethnic_latvians_no_longer _allowed_to_change_their_nationality_record_to_latvian_/, 15 Sept., 2016, accessed Dec. 10, 2016)

412 The detailed language rules of Latvianisation are contained in the document "Noteikumi par personvārdu rakstību un lietošanu latviešu valodā, kā arī to identifikāciju" (Regulation on Writing and Use of Person's Names in Latvian Language, issued under the provisions of the 3rd part of Art. 19 and 3rd part of Art. 23 of the State Language Law. Regulation 114, adopted on 02.03.2004, in force since 06.03.2004). http://likumi.lv/doc.php?id =85209, accessed Dec. 10, 2016. 
Estonia $^{413}$. A given name may consist of not more than three names written as separate words or two names linked by a hyphen. A non-Estonian given name must be in use in another state as a given name. The following are forbidden as a given name: a name which contains numbers or nonalphabetical signs; one which separately or together with the surname is in conflict with good morals; an unconventional given name not suitable to be used as a given name due to its complex spelling or pronunciation, or spelling or pronunciation which does not comply with the general (i.e. Estonian) language use, or due to its meaning. A name which does not correspond to the gender of the bearer, or a wellknown name used as a personal name, a shortened version of the name, a name of a well-known author or a service name cannot in principle be admitted. However, exceptions can be made if, due to their citizenship, family relations, nationality or other circumstances, a child or its parents have personal connection to the foreign-language name tradition and the name applied for complies with this tradition.

A surname may be single or double (if double, then it must be hyphenated); upon application, it may consist of several names (if, due to his or her citizenship, family relations, national identity or religion, a person has personal connection to the foreign-language name tradition and the name applied for complies with this tradition). A child receives the surname of the parents (if they have a joint surname) or of one of them (if different), but not a surname consisting of two names assigned to a parent upon marriage. If the surname of both parents consists of two names assigned upon marriage, the surname of one of the parents is assigned to the child upon

413 https://www.eesti.ee/eng/teemad/perekond/rasedus_ja_lapse_sund /sunni_registreerimine_ja_nime_valik, accessed Dec. 10, 2016. https://www.google.pl/url?sa=t\&rct=j\&q=\&esrc=s\&source=web\&cd=1\&cad =rja\&uact=8\&ved=0ahUKEwjv9MLbkurQAhUI3SwKHW96CxkQFggoM AA\&url=https $\% 3 \mathrm{~A} \% 2 \mathrm{~F} \% 2 \mathrm{Fwww}$.riigiteataja.ee $\% 2 \mathrm{Fen} \% 2 \mathrm{Ftolge} \% 2 \mathrm{Fpdf} \% 2$ F508112013004\&usg=AFQjCNHusEtQeTpGBvF83YBv0tFdFxPyrQ, accessed Dec. 10, 2016. 
agreement between the parents. A surname may not contain numbers or non-alphabetical signs or be separately or together with the given name contrary to good morals.

Certain regulations regarding personal names in Estonia result from the state's ethno-demographic situation. In particular, as a consequence of the solutions adopted in independent Estonia after the dissolution of the USSR, about 16 per cent of Estonia's residents are persons of undetermined citizenship or citizens of other countries ${ }^{414}$. In practical terms, these are mostly Russians. Therefore "an Estonian administrative authority or court may assign a personal name to a citizen of a foreign state or to an alien temporarily staying in Estonia who is not a citizen of any state" It is further stated that "a personal name shall be applied [...] by the transcription of the non-Latin name entered in the source document with Estonian-Latin letters, which shall be done according to the transcription rules for non-Estonian personal names"415 Names given or received abroad are recognised by Estonian name law if they are written in Latin script; if not, they are transcribed, with the information on the original form of the name also kept in the register ${ }^{416}$. Patronyms (this regulation concerns chiefly Russians in Estonia) may in practice be registered as

${ }^{414}$ Cf. "Distribution of the Estonian population by citizenship, as of 1 December 2016" (Source: Ministry of the Interior, Population Register), http://estonia.eu/about-estonia/society/citizenship.html, accessed Dec. 10, 2016.

415 https://www.google.pl/url?sa=t\&rct=j\&q=\&esrc=s\&source=web\& $\mathrm{cd}=1 \& \mathrm{cad}=\mathrm{rja} \&$ uact $=8 \&$ ved $=0$ ahUKEwjv9MLbkurQAhUI3SwKHW96Cxk QFggoMAA\&url=https $\% 3 \mathrm{~A} \% 2 \mathrm{~F} \% 2 \mathrm{Fwww}$.riigiteataja.ee $\% 2 \mathrm{Fen} \% 2 \mathrm{Ftolge} \%$ 2Fpdf\%2F508112013004\&usg=AFQjCNHusEtQeTpGBvF83YBv0tFdFxPy rQ, accessed Dec. 10, 2016. The term "non-Latin name" refers first of all to the names of Russians.

${ }^{416}$ Estonia's position on the European Commission's Green Paper 'Less bureaucracy for citizens: promoting free movement of public documents and recognition of the effects of civil status records' (COM(2010)747), Dec. 8, 2011, http://ec.europa.eu/justice/newsroom/civil /opinion/files/110510/public_authorities/bureaucracy_estonia_en.pdf, accessed Dec. 10, 2016. 
second given names, though this solution does not appear satisfactory to minorities in which patronyms are usual ${ }^{417}$.

\subsubsection{Romance-language countries}

France. ${ }^{418}$ There is no limit to the number of given names for a newborn; however, the parent registering the birth should indicate if among the given names to be bestowed on a child there is a composed name and if so, whether this name shall be spelt with a hyphen or separately. Since 1993, there has been no official list ${ }^{419}$ but the state reserves the right to override parents' choice in the interest of the child. Parents may choose not only from French name books but also from foreign ones; thus it is legally possible to choose names known as foreign, as well as certain diminutives. Given names may cross gender, but the first of them must agree with the gender of the bearer (e.g. Marie-George for a girl, Jean-Marie for a boy). There exist unisex names (Dominique). A given name is forbidden if it might harm the interests of the child (ridiculous names, etc.) or when it might infringe the right of a third party (for instance, if as a given name a surname is taken whose use would constitute a usurpation). Also the surname of the parent who has not passed it onto the child must not be bestowed on this child as a given name ${ }^{420}$. A given name may be changed if

417 Advisory Committee on the Framework Convention for the Protection of National Minorities. Second Opinion on Estonia, adopted on 24 February 2005, p. 25-26. https://rm.coe.int/CoERMPublicCommonSearch Services/DisplayDCTMContent?documentId=090000168008c175, accessed Dec. 10, 2016.

${ }^{418} \mathrm{http}: / /$ vosdroits.service-public.fr/particuliers/F882.xhtml (accessed Dec. 10, 2016).

419 "Thanks, mum. Governments find reason to regulate the names of children." The Economist, Jan. 14, 2012.

${ }^{420}$ The reason for such a regulation is that the French law distinguishes between nom de famille, which is found on the acts of civil status and is legally transmissible to offspring, and nom d'usage, which can be used (without official name-change procedure) on administrative forms, especially that these usually have separate fields for nom de famille and for 
the present one exposes its bearer to ridicule (alone or in combination with the surname $)^{421}$, or if the bearer wishes to Frenchify their name (in this case the petition for name change must be accompanied by application for citizenship, or within one year from this application). Only letters of the French alphabet may be used in names ${ }^{422}$.

Surnames in France may be single or composed. Composed surnames formed since 2005 are treated as one unit and are transmitted accordingly. There are several admissible reasons for surname change. The change is granted if the present surname is ridiculous or pejorative ${ }^{423}$; if it sounds

nom d'usage. By force of a 1985 law, everyone is entitled to add to their nom de famille the surname of the parent whose surname they are not bearing and thus to create a composed nom d'usage. If the same name as the one forming part of nom d'usage were also used as a given name (e.g. Girard LefevreGirard, or Martin Petit-Martin), this would lead to confusion. Cf. also questions.assemblee-nationale.fr/q13/13-10201QE.htm (accessed Nov. 2, 2013), https://www.service-public.fr/particuliers/vosdroits/F882 (accessed Nov. 25, 2016).

421 The name Daemon, chosen by the parents after a character in the TV series The Vampire Diaries (with the addition of the letter 'e' to make it look more Frenchified), was rejected by a French court on these grounds in 2011. Interestingly, the priest whom the parents contacted saw no reason for not baptising their baby under that name, while the prosecution found the name to have "satanic connotations." Ultimately the name was admitted. (Christine Ducros [\&] Fabrice Amedeo "Daemon, un prénom diabolique devant la justice". Le Figaro, Dec. 2, 2011. http://www.lefigaro.fr/actualitefrance/2011/12/02/01016-20111202ARTFIG00341-1-enfer-d-une-famillepour-appeler-son-fils-daemon.php, accessed Dec. 10, 2016. Jessica Samakow "Daemon, Baby Named After 'The Vampire Diaries,' Allowed To Keep Name." The Huffington Post Jan. 13, 2012. http://www.huffingtonpost .com/2012/01/13/daemon-baby-named_n_1205469.html, accessed Dec. 10, 2016.

422 https://www.service-public.fr/particuliers/vosdroits/F882, accessed Nov. 25, 2016.

423 "In 1967 the French Council of State set out some guidelines intended to help Frenchmen decide if they had a nom ridicule - a ridiculous, insulting or otherwise unappealing surname - that they could legally change. In the field of animals, from which a number of French surnames are taken, a Monsieur Duck, Cow, Camel, Ass or Snipe would be allowed to change his name, but a Monsieur Ox, Bull, Goat, Nightingale or Leopard would not. 
foreign; or if it is "strikingly visible nationwide" (survivance d'un nom illustré de manière éclatante sur le plan national) e.g. similar to the name of a notorious criminal. It is also possible to change one's surname to one which is extinct or in danger of extinction, or when the change would be merely a formality since the present one is not used anyway. The intended surname change must be officially announced so that anyone who feels their interests are threatened has the opportunity to object.

Italy ${ }^{424}$. The given name must correspond to gender and be composed of no more than three separate elements. A surname cannot be used as a given name. Shameful or ridiculous names are also banned. However, other restrictions (e.g. that a given name must not be the name of a country or continent) are no longer in force, so parents enjoy great liberty in naming their baby. It is forbidden for the child to have the same name as the living father, brother or sister. If a foreign name is given to an Italian baby, the name must be written using the letters of the Italian alphabet, extended by the letters $J, K, X, Y, W$ and, as far as possible, the diacritics typical of the language from which the name stems.

In the case of children whose parents are not known, the surnames imposed on them must not reflect a child's origins ${ }^{425}$;

Nouns such as tripe, cheese, cemetery and cuckold, and adjectives like hideous and ugly were frowned on as surnames; but unaccountably, villain and pimp were acceptable. The council also suggested that people with Jewish-sounding names, even if they were not Jews, should be encouraged to change them, the better to avoid 'a repetition of the events of the last war." ("France: the surname game", Time, Sept. 11, 1972). In 1972 a court in Melun southeast of Paris decided that a couple by the surname Trognon ('stump', 'butt end') could not bestow their name on their three-year-old foster son.

${ }^{424}$ D.P.R. 3 novembre 2000, n. 396 (1). Regolamento per la revisione e la semplificazione dell'ordinamento dello stato civile, a norma dell'articolo 2, comma 12, della L. 15 maggio 1997, n. 127. http://www.esteri.it/MAE/doc /DPR396_2000.pdf, accessed Dec. 10, 2016. http://www.nomix.it/articolo _leggi_6.php, accessed Dec. 10, 2016.

${ }^{425}$ Such as Esposito ('exposed, placed outside'), a surname allegedly 
nor must they be the surnames of historic personages or of the people particularly known locally.

Spain $^{426}$. Only one compound nombre, or given name (hyphenated, with both elements capitalised) or alternatively two simple (i.e. one-element, not compound) names may be bestowed on a child. Foreign names are permitted if they are translatable into any of the languages of Spain. Prohibited names include those considered harmful for the bearer and those that make identification difficult or that might be misleading about the gender of the bearer. At the request of the person concerned or his/her legal representative, the registrar shall replace the given name with its equivalent in any of the languages of Spain.

A typical Spaniard has two surnames, written as separate words linked by the conjunction y. Official forms have two fields for surnames, marked primer apellido (or apellido 1) and segundo apellido (apellido 2) ${ }^{427}$. The traditional surname order with the paternal surname first was replaced in law with the principle that the spouses will make that decision with regard to the surname order of their children; if they do not agree, the registry official shall decide ${ }^{428}$. The order of

once bestowed on foundlings.

${ }^{426}$ http://www.webjuridico.net/rc/rc09.htm, accessed Nov. 10, 2013.

${ }^{427}$ Sometimes followed by the note: opcional para extranjeros. On the intricacies of the Spanish naming patterns, see Manuel A. Pérez-Quiñones 1996, updated 2002. "Hispanic Last Names: Why Two of Them?" http://perez.cs.vt.edu/twolastnames, accessed Dec. 10, 2016.

${ }^{428}$ In 1999 Ley 40/1999, de 5 de noviembre, sobre nombre y apellidos y orden de los mismos [law of Nov. 5 on names and surnames and their order] introduced the principle that parents jointly decide on the order of paternal and maternal surname for their children - if they can not reach agreement, "the provisions of law shall be applied", which ensured the default paternal surname first, http://www.boe.es/buscar/doc.php?id=BOEA-1999-21569, accessed Dec. 10, 2016. However, a new regulation which made registrars decide in case of parental disagreement, took effect in 2013, cf. http://noticias.juridicas.com/base_datos/Vacatio/120-2011.t6.html\#c1, accessed Dec. 10, 2016. On the controversies about the new law, see also: Rob Lunn 2014. "What's in a name? Spain's great faith in public servants." 
surnames registered by parents for the eldest child is binding for their subsequent children. Surnames of foreign origin, if in the country of origin they have separate masculine and feminine forms, are registered according to the gender of the bearer. A person of unknown parents obtains a given name and surnames commonly used in Spain; however, the surname must not be Expósito ('foundling') or any similarly revealing name. Surname change may be granted, including the case when the aim is to prevent the disappearance of a Spanish surname.

Portugal $^{429}$. The maximum allowed number of given names is two. There are lists of approved given names and of banned ones (the list updated Dec. 7, 2016 contained 5439 names, with each name marked yes or no, sometimes with a comment that it is admissible as a second name only or only for one specified gender ${ }^{430}$ ). The given name should correspond to the gender - however, this requirement concerns only the first of the given names, so a girl's second given name might be masculine and vice versa. The name Maria, in particular, can be given to boys as the second given name. It is also expressly forbidden for siblings to be given the same first name, unless one of them is dead.

The maximum legal number of surnames is four (connecting particles, partículas de ligação - such as $e$ 'and' and $d e, d a, d a s, d o$, dos 'of (the)' - are not counted). However, both a surname and a given name may be compound ${ }^{431}$ and

Legally Yours from Spain, posted August 29. http://legalspaintrans.com /legal-spain/whats-in-a-name-spains-great-faith-in-public-servants/, accessed Dec. 10, 2016.

429 http://www.irn.mj.pt/IRN/sections/irn/a_registral/registo-civil/docsdo-civil/dar-o-nome/, accessed Dec. 10, 2016.

430 http://www.irn.mj.pt/IRN/sections/irn/a_registral/registos-centrais /docs-da-nacionalidade/vocabulos-admitidos-e/, accessed Dec. 10, 2016.

431 They may (though do not have to) contain connecting particles: $d e$, $d a$, das, do, dos. Examples from the allowed names list of such a compound given name (Port. conjunto onomástico) are: Alfonso Henriques, Maria do Alívio, João Baptista, Beatriz da Conceição, Maria de São José. 
thus consisting of two or more words, but with an own meaning which is not related to the meanings of the constituent parts ${ }^{432}$, which effectively increases the overall number of elements in a full name. Apart from the above, married women may, semilegally, attach two more surnames of their husband as the final constituent parts of their full name, which custom is tolerated. The surnames are freely chosen (within the limit of four), in any order (the traditional Portuguese order, with the surname of the mother's family preceding that of the father's family, is not obligatory), from among the surnames of parents (or the surnames to which parents are entitled) and of their ancestors. If the surnames of parents' ancestors are chosen, one must prove that he/she is entitled to these surnames.

Personal names must be Portuguese or adapted in its written and phonetic form to this language.

Romania $^{433}$. The name is composed of a given name and a surname. Given names must not be indecent or ridiculous, and they must not affect the public order or the interests of the child. Change of given name and surname or of only one of these is permissible.

\subsubsection{Slavic countries}

Poland. The legal basis for name-giving is the Law of Civil Registry Acts of Nov. 28, 2014, which states that no more than two given names may be bestowed on a child, that the name must not expose its bearer to ridicule, be indecent or in the diminutive. The name may also be a foreign one

432 Examples of such surname compounds with their own meaning independent of the meanings of their constituent parts are: Castelo Branco (a placename), Espírito Santo (a religious reference).

${ }^{433}$ Noul Cod civil al Romaniei (in vigoare de la 1 octombrie 2011, actualizat prin legea 71/2011) [the new Civil Code of Romania, in force since Oct. 1, 2011], art. 83, 84, 85. http://www.euroavocatura.ro/articole/1127 /Numele_Art_82_-_85_-_Noul_Cod_Civil, accessed Dec. 10, 2016. 
(a novelty in contrast to the previous law of $1986^{434}$ ), and it does not have to be gender-specific, as long as it is commonly used for one gender only. ${ }^{435}$ Before the 2014 law, more detailed instructions were to be found in the "Guidelines for registry offices regarding giving names to children of persons of Polish citizenship and nationality" (cf. Zalecenia 1996). These guidelines were advisory rather than legally binding, even if registry offices tended to follow their advice. As an exception, the feminine name Maria may be bestowed on boys as the second name - this custom is more of a de facto rule than codified law.

A Polish surname may generally be simple or composed (e.g. as a result of marriage) - in the latter case, the two component elements must be linked with a hyphen. Marriage may not lead to hyphenating more than two elements of a surname. Surname change is possible, for instance when the surname exposes its bearer to ridicule or is "incompatible with human dignity;" if a different name is used in practice or borne according to the laws of another state, whose citizenship the bearer also possesses; or if it had been changed unlawfully. When changing one's name, it is not allowed to take a historic surname, famous in culture and academic research, political, public or military activity, unless one possesses family members by that surname ${ }^{436}$.

Croatia $^{437}$. A person's full name (osobno ime) may consist of no more than two given names (ime) and no more than two

${ }^{434}$ Art. 50 ustawy Prawo o aktach stanu cywilnego [Law on civil status]. Dz.U. 1986 nr 36 poz. 180.

${ }^{435}$ Art. 59 ustawy Prawo o aktach stanu cywilnego [Law on civil status]. Dz.U. 2014 poz. 1741, http://isap.sejm.gov.pl/DetailsServlet?id=W DU20140001741, accessed Dec. 10, 2016.

${ }^{436}$ Ustawa z dn. 17.10.2008 r. o zmianie imienia i nazwiska [the law on changing given name and surname] (Dz. U. $2008 \mathrm{nr} 220$, poz. 1414). http://isap.sejm.gov.pl/DetailsServlet?id=WDU20082201414, accessed Dec. $10,2016$.

437 http://www.zakon.hr/z/43/Zakon-o-osobnom-imenu, accessed Dec. $10,2016$. 
surnames (prezime). A child may bear the surname of one or both parents. Change of name is possible unless the proposed name is insulting or detrimental to the rights and freedoms of others, violates public order or public morals, or is not a personal name in the sense of the law.

The Czech Republic ${ }^{438}$. Two given names are allowed. Names must clearly indicate the gender. They must not be common nouns, proper names other than personal ones, the names of fairytale characters, garbled, familiar or in the diminutive (there are exceptions, e.g. Jaro - short for Jaroslav - accepted as an independent name on the grounds that such a name exists in Dutch and German ${ }^{439}$ ). Siblings cannot bear the same name. To be accepted without further procedures, given names should be found in Knappová 2010. A name is more likely to be approved if it is actually used in another country. Examples of recently accepted such names are Coco for a girl (inspired by Coco Chanel), Merlin for a boy (after the wizard of Arthurian legends), and Nerys for a girl (after a character from the TV series Star Trek) ${ }^{440}$. Paradoxically, sometimes foreign names are easier to register than diminutives of Czech names, such as Kát'a (short for Kateřina) or Miša (Michal). The inventory of permissible names is continuously enlarged due to the acceptance of hypocoristics, to the restoration of names used in the past, to the creation of feminine forms on the basis of masculine names, and to

438 Zákon o matrikách, jménu a příjmení a o změně některých souvisejících zákonů [law on registry, given name and surname and on amending certain related acts] 301/2000, https://www.zakonyprolidi.cz/cs /2000-301/zneni-20160101\#cast1, accessed Dec. 10, 2016; http://www .babyweb.cz/jmena, accessed Nov. 8, 2013.

439 Bohdana Jarošová 2009. "Stát poroučí, jak se máme jmenovat. Možná to změní zákon" [the state commands what we are to be called. Perhaps a law will change that] http://zpravy.idnes.cz/stat-porouci-jak-semame-jmenovat-mozna-to-zmeni-zakon-ppn-/domaci.aspx?c=A090305_224 054_domaci_anv, accessed Nov. 8, 2013.

${ }^{440}$ Cf. Bára Procházková "Bude to Coco". Respekt, Feb. 20, 2011. http://respekt.ihned.cz/c1-50449330-bude-to-coco, accessed Feb. 3, 2014. 
borrowings from other languages (cf. Harvalík 2013: 45). In case of doubt, an opinion is given by the Department of Onomastics of the Institute of the Czech Language of the Academy of Sciences of the Czech Republic, as well as by M. Knappová.

The surnames have two forms: the masculine one (e.g. Knapp, Novotny) and the feminine one with the suffix -ová on the nominal-type surnames (e.g. Knappová) or -á on the adjectival-type surnames (e.g. Novotná). Few surnames have the same form for both genders (e.g. Kočí, Jankü, Filipi (though the forms Kočová, Filipiová for women are also possible). Since the year 2000 women of nationality other than Czech have been allowed to omit the feminine suffix ${ }^{441}$. Since 2004, also women of Czech nationality married to foreigners and those living permanently abroad have been allowed to discard the feminine suffix ${ }^{442}$. This applies also to the surnames of newborn girls, which additionally may be recorded in the non-suffixed form at the request of parents, if one of them is a foreigner. In the case of women who wish to combine their maiden surname with that of the husband, the order must be with the married name first ${ }^{443}$. The resulting double surname is non-hyphenated ${ }^{444}$. The issue of how to treat surnames of foreigners in the media and books (e.g. whether to write Angela Merkel or Merkelová, the latter form being called in Czech prechýlenè) is still open to discussion.

441 This included foreigners and members of the officially recognised minorities: Bulgarian, Croatian, Hungarian, Polish, German, Romany, Russian, Greek, Slovak, Ukrainian, Ruthenian.

${ }^{442}$ Lenka Ponikelska 2004. "Law Would Mean Surname Options." The Prague Post, Mar. 4. http://www.praguepost.com/archivescontent/38777-law -would-mean-surname-options.html, accessed Oct. 30, 2009.

443 Elizabeth Haas 2013. "What's in a Name?" Expats.cz. July 8. http://www.expats.cz/prague/article/for-moms/whats-in-a-name/, accessed Nov. 8, 2013.

444 This change in the law was not consulted with linguists, who recommend returning to the traditional hyphenation (Milan Harvalík, e-mail communication of May 20, 2014). 
Slovakia. A child may obtain up to three given names (including foreign ones), which must follow linguistic norms. Surnames, geographical names or new coinages are not admissible as given names. Appellatives (such as names of the days of the week or names of objects), names of living siblings, derogatory names, or male names for female babies (and conversely) are not permitted - these restrictions, however, do not apply to a foreign name if it is common knowledge that such use is in accordance with the tradition of the country where this name is commonly used. If the name proposed by parents is not found in calendars ${ }^{445}$, they must apply to the registry office for a special permission. Especially foreign names may be problematic since they do not figure in (Slovak) calendars ${ }^{446}$. A special permission to change name is not necessary when a foreign language given name is changed to its Slovak equivalent and vice versa.

Regarding the surname, the official Slovak feminine suffix -ová $\hat{a}^{447}$ may be omitted, at the request of the person concerned, in the following cases:

- if one of the spouses is not a citizen of Slovakia,

- if both spouses are citizens of Slovakia, but the wife is of a non-Slovak nationality,

- if a citizen of Slovakia, whose surname is concerned, is also a citizen of another country.

In case of ommission, it is necessary to register the surname without the written Slovak suffix also for female children.

${ }^{445}$ A book by Milan Majtán and Matej Považaj, entitled Vyberte si meno pre svoje diet'a [choose a name for your baby], is used in registry offices and is mandatory for parents of Slovak nationality. The 1998 edition contained over 1800 names.

446 http://najmama.aktuality.sk/kalendar-mien/vznik-a-zapis-mien/, accessed Dec. 10, 2016; Zákon Národnej Rady Slovenskej Republiky o mene a priezvisku 445/2006, http://www.zbierka.sk/sk/predpisy/445-2006z-z.p-9530.pdf, accessed Dec. 10, 2016.

${ }^{447}$ In some surnames the feminine suffix $a ́$ is used instead - e.g. Suchý - Suchá. 
Also, since July 1, 2002, it has been possible at marriage to choose one of the surnames of spouses as a common name (spoločné priezvisko). Thus one of the spouses does not change his/her pre-marriage surname, while the other spouse obtains a double surname, no hyphenation, with the common name first and his/her own pre-marriage surname second. If the bearer of the double surname in such a situation is the woman, then she should have both surnames in the same form, i.e. both with -ová suffix or both without it (the latter option only if she is allowed to drop the suffix at all $)^{448}$. A special permission to change surname is not necessary when the change consists in the registration of a female name of other than Slovak nationality without the Slovak female suffix, or in the registration of a surname according to the Slovak spelling rules.

The issue of suffixation of feminine surnames in Slovakia is still subject to heated debates. In January 2013 the Ministry of the Interior supported the view that at the written request any woman should be allowed to use her surname without the feminine suffix. However, many linguists in Slovakia consider the feminine forms of surnames an indispensable element of the Slovak language (cf. e.g. Valentová 2016). The Ministry of Culture expressed the opinion that such a solution violates $\S 2.3$ of the Law on the State Language and that feminine forms of surnames entered in the registry must respect the laws of the Slovak language ${ }^{449}$.

Bulgaria $^{450}$. The name entered into documents is composed of the given name (лично име, собствено име), patronymic (бамино име) and surname (фамилно име).

${ }^{448} \mathrm{http}$ ://www.slovak-republic.org/marriage/, accessed Dec. 10, 2016.

449 “Kaliňák chce dat' ženám možnost' nepoužívat' -ová, Mad’arič je proti." Nedel'a Jan. 20, 2013.

450 Закон за гражданската регистрация [law on civil registration], http://www.lex.bg/bg/laws/ldoc/2134673409, accessed Dec. 11, 2016. See also http://www.newbalkanslawoffice.com/publications/determining-a-childs -name-a-brief-review-of-possible-issues-in-bulgaria, accessed Dec. 11, 2016. 
A given name must not be dishonouring, socially unacceptable or, in the wording of the Bulgarian law on civil registration, "incompatible with the national honour of the Bulgarian people".

Patronymics are formed with the suffix $-о в$ or $-е в$ (-ов $a$ or -ева for women), unless the father's given name does not allow these suffixes or when a patronymic would contradict the family, ethnic or religious traditions of the person's parents.

The surname of each person is the surname or middle name (i.e. patronymic) of the person's father with the suffix ов or -ев for men, -ова or -ева for women, unless family, ethnic or religious traditions of the person's parents dictate otherwise. Children of the same parents are registered with the same surname. If a child has only the mother, the child obtains a metronymic (from the child's mother's given name or its root), and the child's surname is then that of the mother or one formed from his maternal grandfather's given name. Alternatively, the child of a single mother may receive the patronymic formed from his maternal grandfather's given name - in such a case the child's surname will be that of the mother.

Any part of the name may be changed if it is dishonoring or socially unacceptable or if there are other important reasons. However, two types of name change deserve a special mention. One may accompany the acquisition or restoration of Bulgarian citizenship - then one's given name may be Bulgarised, whereas one's patronymic and surname may acquire the $-о в /-е в \quad(-о в a /-e в a)$ suffix. The other concerns Bulgarian citizens whose names were forcibly changed in the past $^{451}$ : at the written request their (and their children's, if applicable) former names may be restored.

451 They are typically members of the Muslim minority in Bulgaria. 
Slovenia $^{452}$. Every citizen is obliged by law to bear a name. The name to be used in legal records is composed of the given name (osebno ime) of a maximum of two words and the surname (priimek) of a maximum of two words. The given name must be a word, not a single letter or a number. Citizens have the right to choose their names, a right which can be limited only if necessary for the protection of public security, morality and freedoms of others. Name change is not granted only in the case of prosecution or conviction for a criminal offence.

At marriage each spouse may keep his/her birth surname, hyphenate one's surname with that of the spouse (but the resulting surname must be composed of no more than two elements), or one of their surnames may be designated as the common family surname.

Names of members of the Italian or Hungarian minority are registered respectively in the Italian or Hungarian script and form, unless the person concerned wishes otherwise.

Macedonia $^{453}$. A person's name is composed of a name and surname, each of which may be composed of several words. Only one of these, either the given name or the surname, may be changed. The name may not be contrary to the public morals.

The Law on Identity Cards (Official Gazette of the Republic of Macedonia No. 8/95) and the Law on Registration of Birth, Deaths and Marriages (Official Gazette of the Republic of Macedonia No. 44/95) allow names of persons from minorities to be entered in the language and alphabet of their respective minority group ${ }^{454}$.

452 http://www.uradni-list.si/1/objava.jsp?urlid=200620\&stevilka=746, accessed Dec. 11, 2016.

${ }^{453} \mathrm{http} / / /$ www.ecoi.net/file_upload/1504_1217230192_law-on-personal -name.pdf, accessed Dec. 11, 2016.

454 https://www.ecoi.net/file_upload/1504_1217230683_law-on-identitycard.pdf, accessed Dec. 11, 2016. http://eudo-citizenship.eu/NationalDB /docs/MAC\%20Law_Registers_Birth_eng.pdf, accessed Dec. 11, 2016. 
The Russian Federation ${ }^{455}$. The existence in the Russian naming culture of the traditional three-element naming system - a given name (собственно имя), a patronymic (отчество) and a surname (фамилия) - is also reflected in the federal legislation. Although there is no explicit prohibition of a multiple given name in the Russian Civil Code or the Family Code, the given name in these codes is always referred to in the singular, and it appears that in practice double name (such as Анна-Мария, Арнольд-Рудоль $ф)$ are discouraged, unless one parent is a citizen of a foreign state ${ }^{456}$. If double, the name is best hyphenated. The given name must not be dissonant, hard to pronounce, pretentious or diminutive; this is even more important considering that an inappropriate given name may be transmitted in the form of a patronymic onto the next generation ${ }^{457}$. In many registry offices there are name lists as aid, yet the parents' choice need not be limited to the names included on those lists.

The surname of the child must not be created by hyphenating the respective surnames of the father or the mother. However, if one of the parents already bears a hyphenated surname, it can be passed onto offspring. At the

${ }^{455}$ Семейный кодекс Российской Федерации [Family Code of the Russian Federation], art. 58, http://imja.name/imyaipravo/imya-v-rossijskom -prave.shtml, accessed Dec. 11, 2016; Гражданский кодекс Российской Федерации [Civil Code of the Russian Federation], art. 19, http://www .zakonrf.info/gk/19/, accessed Dec. 11, 2016.

${ }^{456} \mathrm{Cf}$. e.g. the rules for name registration as explained on the official website of the administration of Artyom urban settlement (Артёмовский городской округ) in the Primorsky Krai, Russia: http://www.artemokrug.ru /administration/otdel/detailsinfo.php?ELEMENT_ID=617, accessed Dec. 11, 2016, and on the official website of the administration of Kurgan Oblast (Курганская область) http://zags.kurganobl.ru/dvojnye_imena.html, accessed Dec. 11, 2016. Incidentally, at the Orthodox baptism multiple names are discouraged.

${ }^{457}$ Generally, it is emphasised that registry employees have no right to interfere with the parents' naming choices. However, on the website of Artyom urban settlement an example is given of a father who insisted on calling his newborn daughter Забава ('fun') and a lot of effort was needed to persuade him not to bestow such an unusual name on the child. 
motivated request one's surname, given name and/or patronymic may be changed. If different from the federal legislation, the legislation of the subjects of the Federation (закон субъекта Российской Федерации) shall prevail. For example, in 2012 a law was passed that enabled Yakut (Sakha) children to have their personal names registered according to the traditional Yakut system (e.g. coining a patronymic by adding to father's name the suffix уола for boys and кblbl' $a$ for girls $)^{458}$.

Ukraine $^{459}$. The name legislation in this state reflects the traditional tripartite naming system: a given name (особове ім'я), a patronymic (патронім, ім'я по батькові) and a surname (прізвище). A child may be given no more than two given names, unless otherwise provided by the customs of the minority to which the mother and/or father belong, and there are practically no restrictions on the choice of given name (for instance, hyphenated given names are acceptable). It is allowed to create the surname of the child by hyphenating the respective surnames of the father or the mother. Ukrainian citizens in whose national tradition patronymics are not used have the right to write in the passport only their given name and surname, and on the birth certificate - the name of their father and mother ${ }^{460}$.

458 "Принят закон, который позволит присваивать ребенку фамилию и имя в соответствии с якутскими национальными обычаями” [a law has been adopted that will allow to bestow on a child a surname and given name in accordance with national Yakut traditions]. April 26, 2012. http://news.ykt.ru/article/3216, accessed Dec. 11, 2016.

459 Сімейний кодекс України [Family Code of Ukraine], стаття 145-146, http://zakon0.rada.gov.ua/laws/show/2947-14/page3, accessed Dec. 11, 2016.

460 Закон України про національні меншини в Україні [Ukrainian law on national minorities in Ukraine] of July 25, 1992 (with later amendments), стаття 12. http://search.ligazakon.ua/1_doc2.nsf/link1/T2494 00.html, accessed Dec. 11, 2016. 


\subsubsection{Other countries}

The Netherlands ${ }^{461}$. Any type and number of given names is admissible, providing they are not offensive, or the same as existing surnames (unless already in use as given names). Parents decide if their first child receives the surname of the mother or the father (combining the two is forbidden) and this decision is binding for the subsequent offspring. In absence of the parents' agreement, the child will automatically be given the father's surname if the parents are married, or the mother's in the opposite case. Spouses / partners retain their pre-marriage surnames in documents, but in everyday life each may also legally use their spouse's surname, alone or hyphenated (in any order) with their own pre-marriage one. Surname change is effected by Royal Decree (Koninklijk Besluit). It is allowed if the surname is indecent or ridiculous (also in combination with one's job, as an ophthalmologist whose surname is Blind), misspelled, non-Dutch or too common (examples of such common surnames are De Jong, Jansen, Bakker or De Vries) ${ }^{462}$. The new surname should be as similar as possible to the old one, or - failing that - the surname of the other parent. If this is not possible either, then a completely new, Dutch-sounding surname should be invented (different from any surnames already in existence in the Netherlands). A surname spelled the official Dutch way may also be written in Frisian orthography (e.g. Zuidem instead of Sudem).

Greece. A full name consists of the given name, the patronymic in the genitive, and the surname, which is different in form for men and for women (for women it is also in the

461 http://wetten.overheid.n1/BWBR0002656/2015-01-01\#Boek1_Titel2, accessed Nov. 24, 2016.

462 Naamswijziging 2015. Den Haag: Ministerie van Veiligheid en Justitie. https://www.justis.nl/binaries/brochure-naamswijziging-(december2015)_tcm34-85236.pdf, accessed Nov. 24, 2016. 
genitive). Regarding given names, there are basically no state restrictions ${ }^{463}$ beyond the requirement that a name is not to offend against morality (as e.g. a boy's name for a girls).

Since 1983 women have been required by law to keep their birth surnames after marriage. At the same time it was allowed for each spouse to use, only in social relations, the other spouse's surname; a 2008 amendment allowed each spouse to add the other spouse's surname to his/her own ${ }^{464}$. The surname of a child may be either the surname of one of the parents or a combination of the parents' surnames (the resulting surname is to be composed of no more than two elements); if parents can not reach the decision, the default surname is the father's ${ }^{465}$. Repatriating ethnic Greeks who are found to have Greek nationality may request the Hellenisation of their given name and surname, if these had been changed in the country from which the person originates ${ }^{466}$.

${ }^{463}$ Over $90 \%$ of the population are of Greek Orthodox religion, which requires at least one name of a saint (albeit not necessarily the same as the one registered in civil registry) for the newborn as a precondition for baptism.

${ }^{464}$ Greek Civil Code 2000, art. 1388, http://www.ministryofjustice.gr /site/kodikes/\%CE\%95\%CF\%85\%CF\%81\%CE\%B5\%CF\%84\%CE\%AE\%C F\%81\%CE\%B9\%CE\%BF/\%CE\%91\%CE\%A3\%CE\%A4\%CE\%99\%СE\%9 А\%СЕ\%9F\%СЕ\%А3\%СЕ\%9А\%СЕ\%А9\%СЕ\%94\%СЕ\%99\%СЕ\%9А\%С E\%91\%CE\%A3/tabid/225/language/el-GR/Default.aspx, accessed Dec. 11, 2016. Cf. also: Heather Long 2013. "Should women change their names after marriage? Consider the Greek way." The Guardian, Oct. 6; Eleni Zervogianni "The Changing Concept of "Family" and Challenges for Family Law in Greece". https:/www.google.pl/url?sa=t\&rct=j\&q=\&esrc=s\&source =web\&cd=10\&ved=0ahUKEwib88S39uzQAhXLFiwKHRQcDekQFghgM Ak\&url=https $\% 3 \mathrm{~A} \% 2 \mathrm{~F} \% 2 \mathrm{Fwww}$.eap.gr\%2Fimages $\% 2 \mathrm{Fstories} \% 2 \mathrm{Fdoc} \% 2 \mathrm{~F}$ 2013_deo10_dp_series_11.doc\&usg=AFQjCNEc4CYpi9UfHCmiQnoGFGD i21078w, accessed Dec. 11, 2016.

${ }^{465}$ Greek Civil Code 2000, art. 1505, http://www.ministryofjustice.gr /site/kodikes/\%CE\%95\%CF\%85\%CF\%81\%CE\%B5\%CF\%84\%CE\%AE\%C F\%81\%CE\%B $\%$ CE\%BF/\%CE\%91\%CE\%A3\%CE\%A4\%CE\%99\%CE\%9

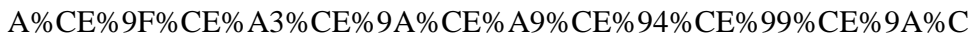
E\%91\%CE\%A3/tabid/225/language/el-GR/Default.aspx, accessed Dec. 11, 2016.

466 Code of Greek Nationality 2004, art. 18a, http://www.legislation line.org/documents/id/5394, accessed Dec. 11, 2016. 
Hungary ${ }^{467}$. A child may be given no more than two names corresponding to the child's gender. Two name lists one of nearly 1.8 thousand names for boys ${ }^{468}$ and one of about 2.4 thousand names for girls ${ }^{469}$ - are the disposal of parents; nevertheless, if a name is not on the list, parents may apply to the Ministry of Public Administration and Justice, which usually bases its decision on the opinion of the Research Institute for Linguistics of the Hungarian Academy of Sciences ${ }^{470}$. Names from outside the lists are acceptable if they do not jeopardize the interests of the child, but they also should fit the system of the Hungarian given names in terms of semantics, structure and spelling. For instance, fantasy names (such as Felhö 'cloud' or Zápor 'heavy rain', Csibécske 'little chick') have been rejected (cf. Raátz 2012: 27). Given names should not be overly diminutive ${ }^{471}$. Geographical names ${ }^{472}$, brand names and names of artists are not recommended as given names. A literary name from foreign-language literature may be accepted if it is already in use as a given name abroad. However, foreign given names must be spelled on the basis of their pronunciation according to the spelling rules of the Hungarian language. In general, foreign-language cognates are best avoided if their Hungarian counterparts exist (e.g.

467 http://www.nytud.hu/oszt/nyelvmuvelo/utonevek/alapelvek.html, accessed Dec. 11, 2016.

468 http://www.nytud.hu/oszt/nyelvmuvelo/utonevek/osszesffi.pdf, accessed Dec. 11, 2016.

469 http://www.nytud.hu/oszt/nyelvmuvelo/utonevek/osszesnoi.pdf, accessed Dec. 11, 2016.

${ }^{470}$ Andrea Bölcskei, e-mail communication of May 20, 2014.

${ }^{471}$ In the case of male names, the name is acceptable if it can be proved that the diminutive form was used as a personal name in the Middle Ages. E.g. Gergö, a diminutive form of Gergely, is quite a popular name today. (Andrea Bölcskei, e-mail communication of May 20, 2014.)

472 In Hungarian, numerous settlement names developed in the Middle Ages from "bare" personal names (i.e. no suffixes or compound elements were added to the personal name to form a settlement name). It is possible today to back-form given names from such geographical names, as has been the case with the recently accepted male name Apaj. (Andrea Bölcskei, email communication of May 20, 2014.) 
Gáspár, not Casper, and Katalin, not Catharina, are best bestowed on children). All these guidelines and regulations are binding for citizens of Hungarian nationality and do not concern minorities or children whose one or both parents are foreigners. Since 2004 minority members may choose names in harmony with their ethnicity and have the right to change their own given name to an ethnic one; they are also allowed to register both the given name and the surname according to the spelling of their ethnic language (cf. Raátz 2008).

Surnames (which in Hungarian precede given names) can be single or double. In the latter case, since the 2004 amendment of the 1952 law, they may also be hyphenated and may be passed on to children provided that each parent kept their birth name as at least part of the new (married) name. Surname change is admissible, but historical surnames are protected and may not be taken unless one is able to prove family relationship ${ }^{473}$. The names of married women may follow a number of patterns (more than before 2004). Thus a woman by the name of Kovács Anna, marrying Szabó András, may retain her maiden (birth) name, or can be called one of the following: Szabó Andrásné, Szabó Andrásné Kovács Anna I Szabóné Kovács Anna, Szabó-Kovács Anna / Kovács-Szabó Anna, Szabó Anna, Szabóné Szabó Anna. Her husband since 2004 may be not only Szabó András, but also Kovács András, Szabó-Kovács András / Kovács-Szabó András ${ }^{474}$.

\subsection{The international level: European legislation}

Personal names used officially are the subject not only of domestic but also of international laws. Some of them are concerned with recording names in international contact, other focus on the rights of minorities. Regarding the former, it is necessary to mention the International Commission on Civil

473 Adrian Phillips [\&] Jo Scotchmer 2010. Hungary. Chalfont St Peter: Bradt Travel Guides, p. 27.

474 http://www.mfa.gov.hu/kulkepviselet/BR/hu/Konzuliinfo/konz_nev viselesi_szabalyok.htm, accessed Dec. 11, 2016. 
Status,${ }^{475}$ which is an intergovernmental organisation, founded in the years 1948-49, concerned with international cooperation in matters of recording civil status. Its members are currently (as of February 2013) fifteen European states: Belgium, Croatia, France, Germany, Greece, Italy, Luxembourg, Mexico, the Netherlands, Poland, Portugal, Spain, Switzerland, Turkey and the UK, with eight more states that have observer status (Cyprus, the Holy See, Lithuania, Moldova, Romania, the Russian Federation, Slovenia and Sweden). The activities of ICCS include, among others, the adoption of conventions and the issuance of recommendations. Among the conventions, of particular interest is the Convention on the Recording of Surnames and Forenames in Civil Status Registers, signed at Bern on September 13, 1973. As Satkauskas (2008: 119) noted, it is the most farreaching and the most favourable to minorities (and at the same time, in the wording of the explanatory report, "essentially technical in nature." Unfortunately, the Convention has been signed only by six ICCS members: Germany (ratified 1977), Greece (1977), Italy (1981), Luxembourg (1982), the Netherlands (1977) and Turkey (1976) ${ }^{476}$. In addition, Austria signed the Convention (ratification 1980) but withdrew from ICCS membership in 2008. The articles of the convention relevant to the present discussion are the following:

Article 2. Where a record is to be made in a civil status register by an authority of a Contracting State and there is produced for that purpose a copy of or extract from a civil status record or some other document that shows the surnames and forenames in the same characters as those used in the language in which the record is to be made, those surnames and forenames shall be reproduced literally without alteration or translation.

475 ICCS, Fr. La Commission Internationale de l'État Civil.

${ }^{476} \mathrm{http} / / / \mathrm{ciec} 1 . \mathrm{org} / \mathrm{WD} 210 \mathrm{AWP} / \mathrm{WD} 210 \mathrm{Awp} . \mathrm{exe} / \mathrm{CONNECT/SiteCIE}$ C?_WWREFERER_=http $\% 3 \mathrm{~A} \% 2 \mathrm{~F} \% 2 \mathrm{Fciec} 1$. org $\% 2 \mathrm{~F} \&$ _WWNATION_=5, accessed Dec. 5, 2016. 
Any diacritic marks forming part of such surnames and forenames shall also be reproduced, even if such marks do not exist in the language in which the record is to be made.

Article 3. Where a record is to be made in a civil status register by an authority of a Contracting State and there is produced for that purpose a copy of or extract from a civil status record or some other document that shows the surnames and forenames in characters other than those used in the language in which the record is to be made, those surnames and forenames shall be reproduced as far as possible by transliteration, without being translated. If there are standards recommended by the International Organisation for Standardisation (ISO), they shall be applied.

Article 4. In the event of a discrepancy in the spelling of surnames or forenames between two or more of the documents produced, the person concerned shall be designated according to the civil status records or documents establishing his or her identity that were drawn up in the State of which he or she was a national at the time when they were drawn up.

For the purposes of this provision, the term "national" includes not only persons who hold the nationality of a given State but also refugees and stateless persons whose personal status is governed by the law of that State.

Article 5. Unless domestic law otherwise provides, persons who have no surname or whose surname is unknown shall be designated, in any record made in a civil status register by an authority of a Contracting State, by their forenames only. If they have no forenames or if these too are unknown, they shall be designated in the record by the name by which they are commonly known. ${ }^{477}$

As visible from the above provisions, the Convention aims at protecting, as far as possible, the form of personal names characteristic of the individual's state of origin. This includes, among others, the prohibition of translation of personal names, as well as the preservation of diacritics.

${ }^{477}$ http://ciec1.org/Conventions/Conv14Angl.pdf, accessed Feb. 7, 2014. 
The European Charter for Regional or Minority Languages (ECRML) was adopted under the auspices of the Council of Europe on November 5, 1992. Between 1992 and 2010 it was ratified by the following nation-states: Norway 1993, Finland 1994, Hungary 1995, the Netherlands 1996, Liechtenstein, Croatia and Switzerland 1997, Germany 1998, Slovenia, Sweden and Denmark 2000, Austria, Slovakia, Spain and the UK 2001, Armenia and Cyprus 2002, Ukraine and Luxembourg 2005, Montenegro, Serbia and the Czech Republic 2006, Romania 2007, Poland 2009, Bosnia and Herzegovina 2010. France, Italy, Iceland, Moldova, Macedonia and Russia signed it without ratifying. As of 2010, the Charter was not signed (nor ratified, naturally) by Greece, Ireland, Portugal, Bulgaria, Belgium, Albania, Turkey, Georgia and all the three Baltic states.

The Charter's only explicit reference to personal names is article $10, \S 5$, which states in very general terms that "[t]he Parties undertake to allow the use or adoption of family names in the regional or minority languages, at the request of those concerned."

Signatories of the Charter have to specify the languages to which they agree to this part being applied, and then they have to select at least thirty-five (out of the total of sixty-eight) undertakings in respect of each language. Naturally, of interest in the present discussion are only those states which chose part III, article $10, \S 5$ - they are presented in the table that follows. It is noteworthy that frequently a signatory state defined more languages as minority languages, yet declares that the provision expressed by article $10, \S 5$ of ECRML shall apply only to some of them. As a case in point, Romania defined 10 minority languages used on its territory as those to which provisions of the Charter shall apply - yet art. 10, 55 shall only apply to half of them, as presented in the table below. As another example one might take Ukraine, which declared that the Charter shall apply to 13 languages (Belarusian, Bulgarian, Gagauz, Greek, Jewish, Crimean Tatar, Moldavian, German, 
Polish, Russian, Romanian, Slovak and Hungarian). Nevertheless, art. 10, $\$ 5$ of part III is not to apply to any of them, therefore Ukraine is not listed in the table.

\begin{tabular}{|c|c|}
\hline State & $\begin{array}{l}\text { Languages to which the Charter is to apply } \\
\text { regarding part III, art.10, } \$ 5\end{array}$ \\
\hline Armenia & Assyrian, Yezidi, Greek, Russian and Kurdish \\
\hline Austria & $\begin{array}{l}\text { Burgenlandcroatian in the Burgenlandcroatian } \\
\text { language area in the Land Burgenland; } \\
\text { Slovenian in the Slovenian language area in the } \\
\text { Land Carinthia; } \\
\text { Hungarian in the Hungarian language area in the } \\
\text { Land Burgenland }\end{array}$ \\
\hline $\begin{array}{l}\text { Bosnia and } \\
\text { Herzegovina }\end{array}$ & $\begin{array}{l}\text { Albanian, Montenegrin, Czech, Italian, Hungarian, } \\
\text { Macedonian, German, Polish, Romanian, Rysin, } \\
\text { Slovak, Slovene, Turkish, Ukrainian, Jewish } \\
\text { (Yiddish and Ladino) and Romani }\end{array}$ \\
\hline Croatia & $\begin{array}{l}\text { Italian, Serbian, Hungarian, Czech, Slovak, } \\
\text { Ruthenian and Ukrainian }\end{array}$ \\
\hline $\begin{array}{l}\text { The Czech } \\
\text { Republic }\end{array}$ & $\begin{array}{l}\text { Polish in the Moravian-Silesian Region, in the } \\
\text { territory of the districts of Frydek-Místek and } \\
\text { Karviná; } \\
\text { Slovak - all the territory of the Czech Republic }\end{array}$ \\
\hline Denmark & German in Southern Jutland \\
\hline Finland & Sami, Swedish \\
\hline Germany & $\begin{array}{l}\text { Danish in the Danish language area in Land } \\
\text { Schleswig-Holstein; } \\
\text { Upper Sorbian in the Upper Sorbian language area } \\
\text { in the Free State of Saxony; } \\
\text { Lower Sorbian in the Lower Sorbian language area } \\
\text { in Land Brandenburg; } \\
\text { North Frisian in the North Frisian language area in } \\
\text { Land Schleswig-Holstein; } \\
\text { Sater Frisian in the Sater Frisian language area in } \\
\text { Land Lower Saxony; } \\
\text { Romany - all the territory of Germany }\end{array}$ \\
\hline
\end{tabular}




\begin{tabular}{|l|l|}
\hline \multicolumn{1}{|c|}{ State } & \multicolumn{1}{|c|}{$\begin{array}{c}\text { Languages to which the Charter is to apply } \\
\text { regarding part III, art.10, §5 }\end{array}$} \\
\hline Hungary & $\begin{array}{l}\text { Croatian, German, Romanian, Serbian, Slovak and } \\
\text { Slovene }\end{array}$ \\
\hline Montenegro & Albanian and Romany \\
\hline Netherlands & Frisian in the province of Friesland \\
\hline Norway & Sami \\
\hline Poland & $\begin{array}{l}\text { Belarusian, Czech, Hebrew, Yiddish, Karaim, } \\
\text { Kashub, Lithuanian, Lemko, German, Armenian, } \\
\text { Romani, Russian, Slovak, Tatar and Ukrainian }\end{array}$ \\
\hline Romania & $\begin{array}{l}\text { Bulgarian, Czech, Croatian, German, Hungarian, } \\
\text { Russian, Serbian, Slovak, Turkish, Ukrainian }\end{array}$ \\
\hline Serbia & $\begin{array}{l}\text { Albanian, Bosnian, Bulgarian, Hungarian, Romany, } \\
\text { Romanian, Ruthenian, Slovakian, Ukrainian and } \\
\text { Croatian }\end{array}$ \\
\hline Slovakia & $\begin{array}{l}\text { Bulgarian, Croatian, Czech, German, Hungarian, } \\
\text { Polish, Roma, Ruthenian and Ukrainian }\end{array}$ \\
\hline Slovenia & Italian and Hungarian \\
\hline Spain & $\begin{array}{l}\text { The languages recognised as official languagues in } \\
\text { the Statutes of Autonomy of the Autonomous } \\
\text { Communities of the Basque Country, Catalonia, } \\
\text { Balearic Islands, Galicia, Valencia and Navarra, as } \\
\text { well as the languages protected by the Statutes of } \\
\text { Autonomy in the territories where they are } \\
\text { traditionally spoken. }\end{array}$ \\
\hline Sweden & Sami, Finnish and Meänkieli \\
\hline Switzerland & Romansh and Italian \\
\hline The United \\
Kingdom & \begin{tabular}{l} 
Welsh, Scottish-Gaelic and Irish \\
\hline
\end{tabular} \\
\hline
\end{tabular}

The Framework Convention for the Protection of National Minorities (FCNM) was adopted by the Committee of Ministers of the Council of Europe on 10 November 1994. On February 1, 1995, it was opened for signature by the $\mathrm{CoE}$ member States. Regarding personal names, it stipulates that 
[t]he Parties undertake to recognise that every person belonging to a national minority has the right to use his or her surname (patronym) and first names in the minority language and the right to official recognition of them, according to modalities provided for in their legal system (Article 11, p.1).

The Explanatory Report clarifies further the issue of the shape of minority names, stating that the signatories may

apply [the Convention] in the light of their own particular circumstances. For example, Parties may use the alphabet of their official language to write the name(s) of a person belonging to a national minority in its phonetic form. Persons who have been forced to give up their original name(s), or whose name(s) has (have) been changed by force, should be entitled to revert to it (them).

The signatories of the FCNM undergo regular monitoring by the Advisory Committee (AC) as to the implementation of the Convention; as a result, opinions are formulated on particular signatory states, although in the case of certain states (Belgium, Greece, Iceland, Luxembourg) no opinions are available because these states have signed the FCNM but never ratified it. In the case of many states complaints concern the insistence on the part of the state on registering the official-language rather than minority version of the surname. It is or used to be so in the case of:

- $\quad$ the Montenegrin minority in Albania;

- minority names in Azerbaijan;

- Czech, German, Lithuanian and Slovak names in Poland (occasionally, as emphasised in the opinion);

- minority names in the Russian Federation;

- minority names in Serbia;

- minority names in Ukraine.

Another area of controversy was language contact where one of the languages has feminine suffixes in surnames, while 
the other does not or has different feminine suffixes. Such prolems were reported in:

- the Czech Republic - especially regarding the Czech suffixes on names of the Polish and German minority;

- Germany - regarding the state's refusal to recognise such suffixes in Sorbian;

- Serbia - regarding Macedonian, Slovak, Bulgarian and Ruthenian minority names;

- the Slovak Republic.

Where in one of the languages there are patronyms, they could be rejected in official registers (if the language with patronyms is a minority language) or conversely, imposed on minorities (if the patronyms are in the state, majority language). This problem was mentioned in relation to Estonia, which refuses to officially recognise minority patronyms or register them as anything other than at best a second forename (AC opinion does no specify the minority in question, but obviously the Russian minority is meant).

Difficulties with registering a minority given name for a new-born child were reported in Austria as well as in the the case of Roma children in the Russian Federation. Conversely, FCNM monitoring revealed with approval that Hungary adopted lists of admissible minority given names drawn up by 12 out of 13 self-governments.

Another issue commented upon was the lack of minoritylanguage diacritics in registered names (assuming that both the state language and the minority language in question are based on the Latin script). This problem was reported in the follwing signatory states:

- Austria - with regard to Slavic names;

- Finland - regarding Sami names;

- $\quad$ Italy - regarding Slovene names;

- Turkish and Bosniac names in Kosovo (however, in the case of the Cyryllic script for the Bosnian language, there is also a difference in the scripts); 
- $\quad$ Montenegro - in Albanian names;

- Poland - in Czech, German, Lithuanian and Slovak names.

In the case of two states - Latvia and Lithuania - the situation is not only exceptional but also complex. In both states minorities file complaints regarding the spelling of their names. Even though in the case of numerically significant minorities other than Russians there is no difference in the script used (i. e. both the state, 'titular' language - Latvian and Lithuanian respectively - and minority languages use the Latin script), minority language names are spelled as transcribed into the titular language on the basis of pronunciation, even if all the letters of the original exist in Lithuanian / Latvian respectively. As far as Lithuanian and Latvian is concerned, the case study that follows explains the situation in more detail.

Wherever the script of the official language differs from that of the minority language (e.g. Latin vs. Armenian, Latin vs. Cyryllic), other problems arise. For example, in the case of the Ukrainian, Belarusian and Russian minorities in Armenia, transcription of documents does not take into account the grammatical rules of these languages and does not allow the addition of the suffix "-ovich", "-ovna", "-yievich", “-yievna" or "-yich", "-yivna" to patronymics, which are written instead following the grammatical rules of Armenian, i.e. with the suffix "-i". There were also complaints in Macedonia (FYROM) about the transcription of Turkish and Albanian minority names.

Finally, criticism of the implementation of FCNM was connected with unsatisfactory (e.g. because too slow, too difficult, too costly) re-adoption of minority names that had been changed in the past. Such criticism was expressed with regard to:

- Bulgaria;

- Turkish names in Macedonia (FYROM);

- minority (i.e. non-Albanian) names in Kosovo; 
- Albanian names in Montenegro;

- minority (e.g. Kven and Finnish) names in Norway;

- minority names in Ukraine.

Quite exceptional was the situation in Denmark (apart from Southern Jutland), where registering births is a prerogative of the Danish National Church, which might raise issues of conscience, especially for non-believers, but might also entail limits to the free choice of names.

The Universal Declaration of Linguistic Rights (1996) lists, among others, the right to the use of one's own name (Art. 3). With regard to personal names, it is also further stated that

All language communities have the right to preserve and use their own system of proper names in all spheres and on all occasions. (Art. 31)

Everyone has the right to the use of his/her own name in his/her own language in all spheres, as well as the right, only when necessary, to the most accurate possible phonetic transcription of his/her name in another writing system. (Art. 34)

\section{The Oslo Recommendations Regarding the Linguistic Rights of National Minorities (February 1998):}

1. Persons belonging to national minorities have the right to use their personal names in their own language according to their own traditions and linguistic systems. These shall be given official recognition and be used by the public authorities.

The Explanatory Report that accompanies the Recommendations goes no further than the FCNM, i.e. allows for the using of the script of the official state language(s) to record minority personal names in their phonetic form. 


\section{Case study: Lithuanisation of the personal names of Poles in Lithuania \\ 7.1. The identity problem: language - name - self- identification}

Every Polish child learns at school the opening verses of the Polish epic poem Pan Tadeusz: "Lithuania, my country! You are as good health..." ${ }^{478}$ The author of these memorable verses, signing himself Adam Mickiewicz, in spite of having spent only two weeks in his entire life in what today is known as Poland ${ }^{479}$ could not speak a word of Lithuanian. As Stanisław Cat Mackiewicz used to say, if Mickiewicz had been asked in Paris if he were a Pole, he would have answered: it's obvious, since I'm a Lithuanian! (Quoted after Kiełpiński et al. 2010: 24). Nevertheless, Lithuanians consider him to have been a prominent Lithuanian writer and he is known in Lithuania by the name of Adomas Mickevičius, despite the fact that he never signed his name that way. Furthermore, he was born in what is now Belarus, hence yet another contemporary nation-state can claim the great artist as its son. As Tomas Venclova pointed out (cf. ibid.: 56), Mickiewicz actually meant the Slavic-speaking area that today is Belarus rather than Lithuania. ${ }^{480}$ As Davies observed, it is a paradox that "Poland's national bard did not come from Poland. It is as if William Shakespeare had lived in Dublin." 481

478 Translated by Marcel Weyland. Adam Mickiewicz 2004. Pan Tadeusz or The Last Foray in Lithuania: a tale of the gentry during 18111812. Blackheath: Verand Press.

${ }^{479}$ More accurately, in the area called in Polish Korona 'the Crown', i.e. the Polish part of the Polish-Lithuanian Commonwealth, partitioned at the end of the $18^{\text {th }}$ century by Russia, Prussia and Austria.

${ }^{480}$ It must be remembered that "the territory of the Grand Duchy [of Lithuania] from 1569 and until the Partitions of Poland in the $18^{\text {th }}$ century roughly coincided with today's Belarus, Lithuania and the western provinces of Russia” (Andrew Savchenko 2009. Belarus - A Perpetual Borderland. Leiden: Brill, p. 29).

${ }^{481}$ Norman Davies 2010. Vanished Kingdoms. The Rise and Fall of States and Nations. London: Penguin, p. 296. 
In fact, such ethnic-cum-linguistic complexity was no exception in $19^{\text {th }}$-century former Polish-Lithuanian Commonwealth, partitioned among its neighbours, and with Lithuanians striving hard for emancipation from the Polish cultural, linguistic and political domination. Among Polish officers of the time, Józef Dowbor-Muśnicki spoke poor Polish, Lucjan Żeligowski spoke Byelorussian rather than literary Polish, while Józef Poniatowski's, Jan Henryk Dąbrowski's and Karol Kniaziewicz's mother tongue was German $^{482}$. Jonas Basanavičius, an activist of the Lithuanian national revival and one of the signatories of the Act of Independence, corresponded with a Lithuanian entrepreneur and philantropist Petras Vileišis in Polish, including the signature. "We, Lithuanians, will never deny our ethnicity, although we speak and write in Polish," Stefania Wojniłowiczowa declared (Daniłowicz 2010: 51). A possible solution to this seemingly unsurmountable problem might be declaring oneself gente Lithuani natione Poloni ${ }^{483}$ - of Lithuanian race and Polish nationality - which was for instance the choice of the bishop and Romantic poet writing in Polish and Lithuanian and signing himself as Antoni Baranowski or - in Latin-language church documents Antonius Baranowski (1832-1902), now going by the Lithuanian name of Antanas Baranauskas. As early as 1885, an oral researcher noted the following dialogue between himself and a shoemaker from the Kaunas area:

${ }^{482}$ Cf. Robert Daniłowicz 2006. „,Trudne czasy dla flisaków” [hard times for raftsmen]. Rzeczpospolita (Plus-Minus), June 10-11, p. 13. Józef Dowbor-Muśnicki (1867-1937), Lucjan Żeligowski (1865-1947), Józef Poniatowski (1763-1813), Jan Henryk Dąbrowski (1755-1818) and Karol Kniaziewicz (1762-1842) were Polish generals.

483 This expression referred to the well-known identity statement: gente Rutheni natione Poloni - of Ruthenian race (ethnicity) and Polish nationality (statehood), espoused by many Polonised members of the Ukrainian nobility and intelligentsia at the time of the Commonwealth but also in the $19^{\text {th }}$ century under the partitions. 
'What tribe do you belong to?'

'I am a Catholic.'

'That's not what I mean. I'm asking you whether you are a Pole or a Lithuanian.'

'I am a Pole, and a Lithuanian as well.'

'That is impossible. You have to be either one or the other.'

'I speak Polish, the shoemaker said, and I also speak Lithuanian' (Davies 2005: 52).

How unclear ethnicity issues in Lithuania were has already been shown above on the example of the 'three Smiths' in the times of the First World War. In the words of Liulevicius,

Everywhere were people whose surnames were messes of ethnicity (or living testimony to the accretion of history and identity, depending on one's view) [...] "Elective ethnicity" ruled. Families splintered along many planes of fracture, different branches ending with different permutations of names and allegiances. [...] There are "Lithuanians" who speak no word of Lithuanian, and vice versa there are committed "Poles," in a religious or other tradition, who speak only Lithuanian (2000: 34).

Indeed, ethnic and nationality division lines frequently ran across families. Stanislovas Narutavičius was a Lithuanian politician and one of the signatories of the Act of Independence of Lithuania in 1918; his brother Gabriel Narutowicz was President of Poland in 1922. Buchowski (2006) lists the surnames of families divided in this way: Birżyszko (Lith. Biržiška), Dowgird (Daugirdas), Putwiński (Putvinskis), Chodakowski (Chodakauskas), Bacewicz (Bacevičius), Sylwestrowicz (Silvestravičius), Pietkiewicz (Petkevičius), Hryncewicz (Grincevičius), Plechowicz (Plechavičius), Rondomański (Rondomanskis), Malinowski (Malinauskas), Zawisza (Zaviša), Landsberg (Landsbergis), Szyling (Šilingas), Tyszkiewicz (Tiškevičius). Povilas 
Plechavičius ${ }^{484}$ was remembered to speak excellent Polish and to have claimed to be a Pole ${ }^{485}$ (cf. Daniłowicz 2010: 53). An ardent Polish-born Lithuanian activist, Andrzej Rondomański, shortly before the Second World War even changed his name to Andrius Randamonis to emphasize his Lithuanian identity. His pro-Lithuanian and anti-Polish radio programmes in Polish, which he had been hosting since 1928, so enraged his settled in Poland brother that after one such programme he sent a letter to the media in which he wrote: "I, Mr Andrzej Rondomański's brother, deeply hurt in my patriotic feelings, publicly condemn his incalculable media activity and I am hereby severing all family ties with him" (ibid.: 52).

As a further example of intra-family ethnic divisions as manifested by surnames, Petras Klimas, a Lithuanian historian and one of the signatories of the 1918 Act of Independence of Lithuania, recollected in his memoirs that at baptism he was registered under [what he perceives as] the Polish version of his surname - Klimaševskis, as the only of his brothers, all of whom got the Lithuanian surname (cf. Janužyte 2005: 121-2). Stanisław Piasecki ${ }^{486}$, quoted by Buchowski (cf. 2006: 201-2), mentioned a conversation with a member of the Lithuanian Nationalist Union ${ }^{487}$ who claimed that a certain Polish activist must in fact be Lithuanian since he had a Lithuanian surname. The paradox was that in fact Piasecki's interlocutor himself

484 1890-1973, Lithuanian general and the creator, under German auspices, of Vietine rinktine (the Lithuanian Territorial Defense Force) that fought against the Soviet Red Army and the Polish Armia Krajowa (Home Army, main underground resistance force against Nazi Germany in the Second World War).

485 Grzegorz Górny 2004. „Awantura o generała” [controversy surrounding the life of general Plechavicius]. Przewodnik Katolicki 10.

486 Polish journalist and national activist (1900-1941).

${ }^{487}$ In Lithuanian Lietuviu tautininku sajunga, a nationalist political party founded in 1924 and ruling Lithuania from 1926 until the Russian occupation of 1940. It was reactivated after Lithuania's regaining independence in 1990. 
bore a typically Polish surname, embellished with the Lithuanian suffix $-a s^{488}$.

Equally inaccurate as the tacit assumption that sworn Lithuanians will all know and speak Lithuanian is the traditionally held conviction that at the end of the $19^{\text {th }}$ century Polish was the language of the upper classes, whereas Lithuanian was the language of the peasants. As Daniłowicz (cf. 2010: 51) has pointed out, this is largely an oversimplification. A case in point may be Mikalojus Konstantinas Čiurlionis, considered to be the greatest Lithuanian painter and composer, who as a child spoke only Polish at home, yet he was of peasant ancestry and he learned Lithuanian only as an adult (cf. Snyder 2006). There were many similar cases.

The complicated history of the Polish-Lithuanian relations is reflected, among others, in numerous surnames of Lithuanian origin still in use in Poland (such as Narwid, Żemajtis, Giedrojć, Dowgird from Narvidas, Žemaitis, Giedraitis, Daugirdas respectively, cf. Rymut 2005: passim and Rymut 1999: 1xxii), as well as in surnames of Polish origin currently used in Lithuania (Malinauskas, Gribauskaite, Navickas, Baranauskas from Malinowski, Grzybowska, Nowicki, Baranowski respectively). Such a state of affairs is obviously a carryover from the past of the Polish-Lithuanian relations.

An interesting illustration of the complex name situation in the inter-war period is provided by the story of the surnames of Steponas Darius and Stasys Girènas, two Lithuanian pilots who in 1933 made an attempt to fly non-stop from New York to Kaunas and crashed near the then German town of Soldin $^{489}, 650 \mathrm{~km}$ from Kaunas. Darius came from the family by the surname of Jucewicz-Dorosz, which is attested to have been living in Lithuania in 1585. Steponas Darius' father, married to a Lithuanian woman and himself Lihuanian, Lithuanised his surname to Jucius, and this was also the

${ }^{488}$ Nominative singular masculine grammatical marker.

489 Today Myślibórz in Poland. 
surname of Darius' brother Boleslovas. Steponas, however, decided to use as a surname the Lithuanised form of "Dorosz" - Darius. Thus his full Lithuanised surname would be Jučevicius-Darašius. The shortened version of the latter part of the surname is Darius, and by this name he ultimately went down in history as a Lithuanian national hero. The other pilot, Girenas, came from the Girski family, which is known to have lived in Lithuania as early as 1667. Originally he used the Lithuanised surname Girčius, then (as an émigré to the USA) Girch. One of his brothers used the surname Girskis, another one - Girènas ${ }^{490}$.

Another example of a name change from Polish to Lithuanian is the name of the above-mentioned Jonas Basanavičius, the publisher of the first Lithuanian national newspaper Aušra ('Dawn'). He was born in 1851 as Jan Basanowicz and still used his Polish name in the early 1880 s (Kamusella 2009: 185, 973) ${ }^{491}$.

One of the tenets of the Lithuanian movement was that Lithuanian surnames were a definite proof of pure Lithuanian ethnicity, whereas Polish surnames were no proof of Polish descent at all, since the inhabitants of Lithuania with Polish surnames were treated not as Poles, but as Polonised Lithuanians. Any situation wherein a person had a Lithuanian surname but professed Polish affiliation would provoke disbelief and utter contempt. Such fate in inter-war times befell Czesław Mikołajunas, a student activist from Kaunas: a Lithuanian journalist from the periodical Mūsų Vilnius ('Our Vilnius') wondered how it was at all possible for somebody with a Lithuanian surname to be on the board of a Polish organization (cf. Buchowski 1999: 39, 2006: 201). (An alternative point of view, presented in 1920 by Henryk Wierciński, was that through intermarriages, generation by

490 Andrzej Kostrzewski 1991. „,Darius i Girènas”. http://www .lenczewski.com.pl/darius.html, accessed Dec. 12, 2010.

${ }^{491}$ In the first, 1883, issue of Aušra the surname of the publisher was spelt Bassanawiczius. 
generation Lithuanian blood got more and more diluted until their descendants were no longer Lithuanians but in fact Poles, with only the Lithuanian surname left behind - cf. Buchowski 2006: 50, 35).

The long-held conviction, regarding personal names in Lithuania, that many of them were originally Lithuanian, but with time they got Polonised by being translated from Lithuanian to Polish, was expressed by Zinkevičius:

The use of this foreign language [i.e. Polish] in official establishments resulted in the distortion of Lithuanian personal names and toponyms. The formation of surnames was being finalized in the $18^{\text {th }} \mathrm{c}$. They were recorded in documents mostly without Lithuanian endings, Lithuanian sounds were replaced with Polish ones, foreign suffixes were affixed to them and the surname was often simply translated into Polish (1998: 256-257).

Zinkevičius gave the examples of Ožélis (from Lithuanian ožys 'billy-goat') changed into Koziet/Kozłowski, and of Vābalas ('beetle') changed into Żukowski /Żuk. Claims about surname translations, often exemplified by these two surnames, recur in works by Lithuanian authors ${ }^{492}$. In fact, the conviction that many Polish-sounding (or Slavic-sounding) names are actually Lithuanian surnames which had been (without the bearers' consent or at least knowledge?) translated into Lithuanian appears to constitute one of the founding myths of independent Lithuania, along with the claim that the Polish/Slavic minority is in fact composed of ethnic Lithuanians, living within their titular areas, who had been forcibly Polonised in the past to the extent that they do not realize now that they are in fact Lithuanians (and must be

${ }^{492} \mathrm{Cf}$. for example the review of the $2^{\text {nd }}$ vol. of Lietuviu pavardžiu žodynas in Lituanus 36/3 (1990): “There are many such cases where the original Lithuanian family names were translated - by local organists, priests, registrars - into some form of Slavic forms, mainly into Polish." http://www.lituanus.org/1990_3/90_3_09.htm, accessed Dec. 5, 2016. 
aided to do so). This myth may be said to have become a language ideology in the sense attributed to the term by Spolsky and Shohamy (cf. 1999: 31-32).

Both language policy and name policy are deeply rooted in language ideology, and the latter - in national ideology. Lithuanians often perceived themselves as culturally endangered and likely to disappear as a nation. Hence the tendency to treat ethnicity in biological terms rather than cultural and/or linguistic terms (allowing people to determine for themselves their own ethnic/national affinity) has been the hallmark of Lithuanian thinking about their national identity for many years. An interesting example of this way of thinking was the idea of a Lithuanian geographer Kazys Pakštas, who long before the Second World War in all earnestness suggested buying uninhabited land outside Europe and sending selected young Lithuanians there so Lithuanian genes as well as the language and culture could survive intact. He considered such places as Madagascar, Angola, Argentina and many others ${ }^{493}$.

\subsection{Lithuania and Poland: history and beyond}

The events in Lithuanian history of relevance to the present discussion start with the personal union of Kreva ${ }^{494}$ of August 1385, which established Lithuanian Grand Duke Jogaila as King of Poland and led to the Christianisation of Lithuania (1387, with Samogitia following suit in 1413). There followed a succession of Polish-Lithuanian unions (1401, 1413, 1432-34, 1499, 1501), culminating in the Union of Lublin of $1569^{495}$, whereby the Commonwealth of the Two

$493 \mathrm{http}: / /$ pasauliolietuvis.lt/kazys-pakstas-fantaziju-profesorius-ar-gen ialus-geopolitikos-strategas-2/, accessed Dec. 5, 2016.

494 A union between Poland and Lithuania, by force of which Lithuania's Grand Duke Jogaila (1351-1434, reigned 1386-1434) was to convert to Christianity, to marry Jadwiga, queen of Poland (1373/4-1399, reigned 1384-1399), and to be crowned Polish king.

495 A union between Poland and Lithuania, by force of which the union of Kreva was replaced with a real union, elective monarchy was to be 
Nations (i.e. Poland and Lithuania) was created. Today's evaluation of this union depends largely on the nationality of a historian. For Lithuanian scholars it was beyond doubt a national disaster:

Exploiting Lithuania's difficult situation, Poles sought not the union of both countries, but rather the annexation of Lithuania to Poland. That is exactly what happened in 1569 in Lublin. The Union Act which was signed dealt a great blow to Lithuania's statehood (Zinkevičius 1998: 244).

For (at least some) Polish historians it was a diplomatic achievement leading to a powerful state, though - from the point of view of Polish interests - not necessarily a step in the right direction:

The Polish-Lithuanian union changed Poland into a large, multinational, multilingual, and multidenominational state in the east of Europe [...] Did this change constitute the stage upon which the great days of the country were played out as Poland shaped a unique and vigorous culture, of diverse origins, into a powerful and attractive national culture, or did this constitute a misdirection of Poland's historic vector bringing into it alien territories far from vital interests farther west?Did Poland lose its way and become dissolved in a sea of foreign influences and traditions and thus condemn itself to disunity, weakness, and eventual destruction? These fundamental questions of the Polish national experience have never been answered decisively (Biskupski 2000: 10-11).

In 1697 Polish became the official language of the Grand Duchy of Lithuania. In 1772, 1793 and 1795 successively, the Commonwealth was partitioned among Austria-Hungary (except for the second partition), Russia and Prussia. The partitions gave Russia vast territories of the Grand Duchy of Lithuania. In the third partition also some area as far north as

introduced, and the Polish-Lithuanian Commonwealth was created. 
the Nemunas ${ }^{496}$ river was given to Prussia; following the Congress of Vienna this area, known as the Trans-Nemunas, became Russian.

A period of somewhat voluntary Polonisation continued, followed after the Russian crushing of the Polish-Lithuanian January Uprising 497 (1864) with intensified enforced Russification and partly also (in Lithuania Minor ${ }^{498}$ ) Germanisation, which lasted in varying degrees until the First World War. Simultaneously, the second half of the $19^{\text {th }}$ century was the period of Lithuanian national revival, similarly to analogical movements at the time in other parts of Europe. Many Poles believed this revival to be Tsarist-inspired and meant to pit peasant Lithuanians against the Polish gentry, which conviction led, among others, to coining for the Lithuanian activists the derogatory term litwomani ('Lithuanomaniacs'). The Polish gentry in Lithuania, as well as the public opinion in "the Crown," found it difficult to understand Lithuanian aspirations to being liberated from the Polish influence. A literary proof of this are the words put in 1832 by Adam Mickiewicz in the mouth of one of his characters: 499 "About Lithuania, by God! I know less than about China." Seven decades later Bolesław Prus, a prominent Warsaw prose writer, expressed the opinion that "any Pole of at least some education needs not go to Lithuania in order to

${ }^{496}$ Belarusian: Нёман, Nioman, [' ${ }^{j}{ }^{j}$ oman]; German: Memel; Latvian: Nemuna; Estonian: Neemen; Polish: Niemen; Russian: Неман, Neman; Ukrainian: Німан.

497 Called in Lithuania the 1863-1864 uprising (1863-1864 m. sukilimas).

${ }^{498}$ Lithuanian Mažoji Lietuva, German Kleinlitauen, Polish Litwa Mniejsza / Pruska, Russian Малая Литва. Historical region on the Baltic, called East Prussia. Comprised of the Klaipeda Region (Lithuanian Klaipedos kraštas, German Memelland) in today's Lithuania and of the area now in Kaliningrad Oblast (Russian Калинингра́дская о́бласть, Kaliningradskaya oblast).

${ }^{499}$ In the drama Dziady part III (1832), these were the words of Kamerjunkier (gentleman of the chamber), a member of the high society frequenting a fashionable Warsaw parlour of the time. 
know it [...] No less known and equally close to us is the folk there" 500 . Probably both statements were equally true: Poles from "the Crown" knew little about Lithuania and yet were convinced there was in fact not much to know.

Surprisingly to Lithuanian Poles, ethnic Lithuanians of the last decades of the $19^{\text {th }}$ century did not want their country to be either unified or identified with ethnic Poland any more. Earning for themselves the nickname Nowolitwini (NeoLithuanians), they strove to preserve Lithuanian heritage, to make Lithuanian the language of the church and of school instruction, finally to be rid of Poles whom they saw as oppressors. This movement is clearly visible in Dzwonnik (The Bell-Ringer), a 1907 short story by Henryk Sienkiewicz. In the story, an old bell-ringer from Lithuania, who for many years has been living in Poland under an assumed name (for fear of being identified as a participant in the January Uprising), is visited by a young relative from Lithuania. The visitor tells his uncle about the changes that took place there:

He began to tell me how the Lithuanian nation awoke, how Lithuanians don't want to be Poles even in some areas populated by the gentry, how the Lithuanian language develops, how books and newspapers are printed in this language, how some priests drive away Polish services from churches - and he kept talking almost until dinner time, and the day being hot, he was all hot and bothered trying to convince and convert me, while I just listened [...] We quarrelled and we have quarrelled for good. He told me when leaving: Uncle, don't come to see us, for you won't feel good among us. ${ }^{501}$

As an influential New York City urban planner Robert Moses once wrote: majorities, of course, start with minorities. Thus ethnic Lithuanians (as opposed, for instance, to contemporary Belarusians - the term "Lithuanian" over

500 Bolesław Prus "Wszyscy za jednego" [all for one]. Tygodnik Ilustrowany 4/1907, p. 81.

${ }^{501}$ Henryk Sienkiewicz "Dzwonnik", idem, p. 77. 
centuries had various meanings), who for many years felt minoritized in their own homeland, in the aftermath of the First World War overnight found themselves a majority within their own nation-state. Lithuania's declaration of independence took place on February 16, 1918. Soon there followed Żeligowski's Mutiny ${ }^{502}$ of 1920, resulting in the creation of the Republic of Central Lithuania around Vilnius and leading ultimately to the annexation of the area by Poland. Kaunas became the capital of the inter-war Republic of Lithuania. As the subsequent Lithuanian constitutions of 1928 (art. 5) and 1938 (art. 6) stated, Lithuania's capital was Vilnius, "only temporarily [the capital] has been moved elsewhere." 503

Between the final collapse of the Polish-Lithuanian Commonwealth in 1795 (when Lithuania became part of Russia as the so-called Northwestern Territory, Северозападный край) and the First World War, there occurred a radical change of perspective. The multi-ethnic state by the name of the Grand Duchy of Lithuania, extending as far to the south-east as the Black Sea, became Lithuania the nation-state within its titular ethnic boundaries, distinct from the rest of what once was its territories and what now constituted part of Belarus (soon to become part of the USSR) and Ukraine. The feeling of national identity in Belarus, especially in its rural areas, crystallized much later that in Lithuania and is not so well-formed even today (cf. Straczuk 1999).

Throughout the inter-war period Poland was effectively in a state of undeclared war with Lithuania. The movement of citizens across the border was practically non-existent -

${ }^{502}$ Military operation led by General Lucjan Żeligowski in secret agreement with Poland's Chief of State Józef Piłsudski, which led to the creation of the Republic of Central Lithuania, in 1922 annexed to Poland.

${ }^{503}$ Cf. 1938 m. Lietuvos Konstitucija [Lithuania's constitution of 1938] http://lt.wikisource.org/wiki/1938_m._Lietuvos_Konstitucija, and Lietuvos Valstybès Konstitucija (1928 m. gegužès 15 d.) [Lithuania's constitution of May 15, 1928]. http://lt.wikisource.org/wiki/Lietuvos_Valstyb\%C4\%97s Konstitucija_\%281928_m._gegu\%C5\%BE\%C4\%97s_15_d.\%29, both accessed Dec. 5, 2016. 
Czesław Miłosz (quoted in Łossowski 1985a: 203-204) recollected crossing it illegally with his mother a number of times to get from Vilnius to his family home in Lithuania which was accompanied by a Lithuanian ban on correspondence from Poland and on importing Polish newspapers, books and films. In the Lithuanian press Poles were caricatured as lice sucking the blood of neighbouring peoples ('Poland - the louse of Europe', a cartoon caption in the monthly Ragutis said), and in Polish periodicals Lithuanians were depicted as drooling and obnoxious midgets (cf. Kiełpiński et al. 2010: 27-9). ${ }^{504}$

In the middle of June 1940 the Soviet Army entered Lithuania. In August 1940 Lithuania was already annexed by the Soviet Union. There followed two further periods of Russian occupation of Lithuania (1940-1941 and 1944-1990), between which there was the German occupation in the years 1941-1944. In 1944 Lithuania became one of the republics of the Soviet Union.

On March 11, 1990 the Supreme Soviet of the Lithuanian SSR declared the sovereignty of the Lithuanian state, which was followed by a referendum on February 9, 1991, showing overwhelming support for independence. Diplomatic relations with Poland were resumed on Sept. 5, 1991. Today the Polish minority in Lithuania numbers about 235 thousand (2001 census; Polish activists speak of even 300 thousand ${ }^{505}$ ), whereas the Lithuanian minority in Poland, according to the 2002 census, is 5.6 thousand people (Lithuanian activists' estimation is 10-12 thousand, cf. Kiełpiński et al. 2010: 45).

${ }^{504}$ Many examples of such caricatures can be found in: Krzysztof Buchowski 2004. Panowie i żmogusy. Stosunki polsko-litewskie w międzywojennych karykaturach [Polish-Lithuanian relationships in inter-war caricatures]. Białystok: Instytut Historii Uniwersytetu.

${ }^{505}$ Monika Żmijewska [\&] Emilia Romaniuk 2008. „W Wilnie pierwsze Karty rozdane" [first Cards given out in Vilnius]. Gazeta Wyborcza, June 17. 


\subsection{The emergence of contemporary Lithuanian spelling}

Lithuanian is classified as an Eastern Baltic language, related to Latvian (with Latgalian, traditionally classified as its dialect, more recently as an independent language) and to the now extinct Curonian, Selonian and Semigallian; there also once existed the Western Baltic group, whose languages (old Prussian and Sudovian) are extinct today. Baltic languages together with Slavic languages form the Balto-Slavic group of the Indo-European languages (cf. Majewicz 1989: 36). In the Middle Ages Lithuanian was basically a spoken language. The earliest (hand-)written text in Lithuanian dates back to the beginning of the $16^{\text {th }}$ century, whereas the first printed book in Lithuanian, The Simple Words of Catechism by Martynas Mažvydas, was published in 1547. Originally Lithuanian employed the Latin script and its spelling was basically that of Polish of the time; such spelling was still in use in the first half of the $19^{\text {th }}$ century. Following the crushing by Russia of the 1863-1864 uprising in Lithuania ${ }^{506}$, the printing of books and periodicals in Latin script was forbidden - only the Cyrillic script could be used. This prohibition came to be known as the Lithuanian press ban (spaudos draudimas). Directly afterwards attempts to adapt Cyrillic script for Lithuanian were made by Jonas Juška, Stanisław Mikucki, Jonas Krečinskis ${ }^{507}$ and others (cf. Subačius 2005, Kielpiński et al. 2010: 56).

Soon the only source of books printed in Lithuanian using the Latin alphabet were the printing shops of Lithuania Minor in East Prussia, from which the literature in Lithuanian was smuggled by the so-called knygnešiai (book smugglers) across

506 Called in Pol. Powstanie styczniowe (the January Uprising).

507 Jonas Juška (1815-1886), Lithuanian schoolteacher, linguist, copublisher of a dictionary of Lithuanian and of Lithuanian folk songs. Stanisław Mikucki (1814-1890), Polish linguist, studied Lithuanian dialects. Jonas Krečinskis (ab. 1820-1884), Lithuanian schoolteacher in Kaunas. 
the border; until 1896, over three million books were smuggled into Lithuania, most of them religious literature, calendars and alphabet books (cf. Bojtár 1999: 200). The personage active in the movement was bishop Motiejus Valančius. The ban was introduced in 1864 - the year when Russian also became the language of education in Lithuania - and remained in force until 1904. Since the law referred specifically to 'Latin-Polish spelling', some of those opposing the ban argued that the alphabet in question is in fact Latin-Czech or Latin-Lithuanian and not Latin-Polish (cf. ibid.: 198).

In the second half of the $19^{\text {th }}$ and the beginning of the $20^{\text {th }}$ century, as the Lithuanian revival was gaining momentum, the Polish $c z, s z$ and $\dot{z}$ were being slowly replaced by the so-called "New Lithuanians $508 "$ with $\check{c}$, $\check{s}$ and $\check{z}$ respectively. In the wording of Norman Davies, "Lithuanian orthography, to spite the Poles, was based on the Czech alphabet" (2005: 52). The process of replacement was gradual and after the printers in Lithuania Minor introduces changes, American communities in the USA followed suit. Subačius (2004) provides a brief account of the process of spelling change. As he stresses, it is not easy to establish when exactly the letters $c$ and $s$ with caron (inverted circumflex) first appeared in Lithuanian writings. The dates 1860, 1861, 1876 and 1883 are given by various researchers, and among the names of those who presumably first introduced the new spelling, there are the publishers of the students' newspaper Kol saula uztekes, rasa ir akis išes, as well as Jonas Juška, Stanislovas Raila, Jonas Basanavičius, and Kazimieras Daukša ${ }^{509}$. Apart from being gradual, the transition

508 Those inhabitants of Lithuania in the latter half of the $19^{\text {th }}$ century who understood being Lithuanian in its strictly ethnic sense (as opposed to 'Old Lithuanians' who saw Lithuania as part of the large multicutural and multidenominational Polish-Lithuanian Commonwealth with Poland as the dominant actor). New Lithuanians strived for cultural and political emancipation from the traditions of the Grand Duchy of Lithuania. In the eyes of many Belorusians today, they also appropriated the historic legacy of the GDL, to the detriment of Belarus.

${ }^{509}$ Stanislovas Raila (1844-1918), Lithuanian lawyer, contributor to 
also had its dead ends. Thus Jurgis Pabrèža ${ }^{510}$, for instance, at some point used the spelling with $\check{s} z \check{z}, \check{c} z$ (Subačius 1997). What is an established fact is that in 1899, in its first issue, the periodical Varpas ('The Bell') urged all newspapers to use the letters with caron, which was dubbed the "invention of the epoch" (Subačius 2004: 189-190). Finally, 1901 saw the publication of Lietuviškos kalbos gramatika, the normative grammar of Lithuanian, by Jonas Jablonskis.

It is also interesting to look at the treatment of the letters to be gradually replaced in another periodical of key importance for the development of Lithuanian, Aušra ('The Dawn'). It was published in the years 1883-1886. The first issue, published in 1883, still used $s z, c z, w$ (including $s z$ in the title of the newspaper). In $1884 w$ was replaced with $v$. The calendar for the year 1886, published in 1885 under the auspices of Auszra, still employed $s z, c z$, but there was already $\check{z}$ in the place of $z$. The 1886 issues retained the Polish diagraphs $s z, c z$. It must be noted that contrary to some sources (cf. e.g. Łossowski cited in Kamusella 2009: 973), the name of the periodical was not changed in the first period of its publication, i.e. 1883-1886, and remained so until (and including) the issue number 5 in the year $1886^{511}$ The spelling $A u s ̌ r a$, however, is frequently used in contemporary sources ${ }^{512}$.

Apart from the emergence of letters with carons, $v$ came to be used instead of $w$, as well as $l$ in the place of $t$. This is, for example, what Jonas Juška was trying to do in his writings

Aušra and other Lithuanian newspapers of the time. Kazimieras Kristupas Daukša (1795-1865), Lithuanian linguist, scholteacher. Author of a grammar of Lithuanian and of a dictionary of Lithuanian. Part of the manuscript of the latter (about 8 thousand entries), written in the years 1836-1844, was found in the Poznań University Library.

510 Jurgis Ambrozijus Pabrèža (1771-1849), Lithuanian priest, Franciscan monk, botanist and physician, author of medical treatises, of a geography coursebook in North Samogitian dialect, and a collector of Lithuania's ethnographic and historical material.

${ }^{511}$ Cf. http://www.epaveldas.lt/, accessed Dec. 5, 2016.

512 Cf. e.g. Saulius Suziedelis 2011. Historical Dictionary of Lithuania. Lanham: Scarecrow Press, passim. 
(cf. Zinkevičius 1998: 269). The 1904 proclamation after lifting the press ban already bore all the features of the changed spelling: in the place of digraphs, there were letters with carons and there was no $w$ or $t$.

Shortly before the Second World War, a special commission established by the Ministry of Education, which had been working since mid-thirties, was ready to introduce the new 'final' version of Lithuanian orthography, whose tenets included the reduction of diacritics. However, the outbreak of war cut short all these plans and after the war, when Lithuania became one of the republics of the USSR, the pre-war spelling was mostly used. The only change introduced by the Soviet authorities was discarding the letter $\bar{o}$, still used in the publications of the Lithuanian diaspora but not reintroduced in Lithuania after 1991. In the 1970s the Institute of Lithuanian Language and Literature of the Lithuanian Academy of Sciences initiated some spelling changes, such as the reintroduction of the letter $j$ in bjaurus 'hideous', pjauti 'to cut', spjauti 'to spit', as well as vowel regularization in certain future forms, or the spelling of compound words. Nevertheless, what was still left undecided was the orthography of foreign proper names, such as exonyms and personal names of foreigners. Therefore, conforming to the long-established tradition, forms such as Meje (Meillet), Niksonas (Nixon), Šmitas (Schmidt), Baironas (Byron) or Lydsas (Leeds), characterised not only by Lithuanian orthography but also morphology, remain in Lithuanian (cf. Klimas 1983, Kamusella 2009: 189).

\subsection{The surname-spelling conflict, its historical background and chronology}

The roots of Lithuanising the surnames of Poles are to be found in the times of the Lithuanian national revival in the second half of the $19^{\text {th }}$ century. As Górski ${ }^{513}$ noted,

${ }^{513}$ Konrad Górski (1895-1990), who since 1934 worked as university professor in Vilnius and later, after the war, in Torun, specialised in the 
As early as in the first issue of Aušra there appeared articles emphasising what shame it is for a Lithuanian to change his purely Lithuanian surname into a Polish one [...] Thus there started the 'regaining' of such falsely Lithuanian surnames as Kondratowicz (Kundraitis), Odyniec (Adinčius), Chodźko (Katkis), Chodkiewicz (Katkevičius), Wasilewski (Vasylius), Bogdanowicz (Bagdonas), Pawłowski (Povilajtis), etc. [...] Little wonder that a simple Lithuanian peasant, hearing a surname like Grabowski or Borkowski, would pronounce it his own way, Grabauskas or Borkauskas, but educated people used to respect the form that the name owner wished it to be (1995: 338-339).

After regaining independence after the First World War, the spelling of personal names in Lithuania was regulated by the 1920 law Isakymas dèl žmoniu vardu, pavardžiu ir pravardžiu, taip pat ir vietu vardų rašymo [law on the spelling of given names, surnames and nicknames, as well as place names]. In $\$ 2$ it was stated that non-Lithuanian given names and surnames are written in documents with the addition to the unchanged root of Lithuanian endings. ${ }^{514}$

Two years later, by force of the Constitution, Lithuanian became the state language. Alongside the efforts to standardise the language, also personal names were a matter of concern. The issuance of new identity documents occasioned further name changes. This is how the procedure was remembered by a Polish Lithuanian - Stefania Römer:

history of Polish literature and not in the history of Polish-Lithuanian relations. Nevertheless his book Divide et impera, written during the Second World War, is based on both scholarly research and personal, first-hand experience. Citing the book, Kosman described it as "hervorragend dokumentierte, obwohl vom Subjektivismus nicht ganz freie" (Marceli Kosman 1997. "Litauen - Legenden einer großen Vergangenheit und Realitäten der Gegenwart”. WeltTrends 16, p.119).

514 "Ne lietuvių vardai ir pavardès rašomos nekeičiant jų šaknies, tik prikergiant lietuviškas galūnès”. Vyriausybès žinios, Feb. 6 1920, p. 5. 
When in the newly arisen Lithuanian state identity cards were given out, Polish surnames would at best get Lithuanian endings. Say, Romeris, but considering that the surname had originally been spelled Römer, they would write Riomeris, Remeris or Reimeris - this is how various Romers came into existence. But Jankowski had it even worse, for he would become Jankauskas. A peasant once told me that his grandfather had his surname recorded in the ID as Zając, his father - as Zając-Kiszkis, and he is only Kiszkis ${ }^{515}$. Reportedly Lithuanian officials filling ID cards had been instructed to record under the heading 'nationality' - 'Lithuanian', because they did this without asking. I know that from Uncle Jaś. Uncle received a new Lithuanian identity card, he brought it home and as his family looked at it, it turned out that in the section 'nationality' it had been recorded 'Lithuanian'. And neither this Lithuanian nor his grandparents or parents could speak Lithuanian. So uncle took the ID card back to the police station and demanded to have it exchanged - they had to give him a new ID. But that was Uncle Jaś, an energetic young man, while many peasants accepted it saying 'Well, what difference does it make?' As it turned out later on, whoever had been recorded as Lithuanian could not send children to Polish schools. And there were many such people. [The account comes from Stefania Römer's unpublished memoirs; quoted after Zielińska 2002: 35.]

A law dated January 17, 1922 - Pavardžiu keitimo istatymas [a law on surname change]- allowed for surnames to be Lithuanised "for important reasons" 516 . It was not specified what these important reasons were. Requests for change of surname were to be addressed to the Minister of the Interior.

In 1933 an editorial in the Vilnius Polish-language daily Stowo, signed "m."517 quoted the Lithuanian weekly Trimitas:

515 Polish zając, Lithuanian kiškis - 'hare'.

516 "Esant svarbioms priežastims, pavardès gali būti keičiamos." Vyriausybès žinios, Feb. 10, 1922, p. 1.

517 The author of the editorial was, in all likelihood, Józef Mackiewicz. Cf. Maciej Wojtacki 2009. "Słowo” Stanisława Cata-Mackiewicza, dziennik konserwatystów wileńskich $w$ latach 1922-1939. Monografia pisma [monograph of the conservative daily "Słowo", published in Vilnius in the 
As historical documents indicate, until the $17^{\text {th }} \mathrm{c}$. Lithuanian surnames were almost without exception without the Slavic suffixes [such as]: auskas, auskis, ickas, ickis, awiczius, ewiczius, eckas, that nowadays abound in Lithuanian surnames. Lithuanian surnames were usually Slavicized without the consent of their owners. On the other hand, occasionally their very owners added Slavic suffixes for material or other reasons. All this greatly harmed the Lithuanian Nation.

Slavic suffixes on Lithuanian surnames create quite the wrong impression abroad, confirming, as it were, the false rumours spread by the enemies of Lithuania that in Lithuania there are no Lithuanians.

Getting rid of the Slavic surnames would amount to getting rid of yet another disgraceful Slavic vestige and to restoring the original pure shape of the Lithuanian Nation. ${ }^{518}$ [Capitalisation of the original.]

The same editorial cited the Lithuanian daily Lietuvos aidas:

Contrary to what some might think, the de-Slavicizing of surnames is neither a trivial nor a personal matter. Slavicized Lithuanian surnames testify to the national weakness of Lithuanians in former days and of the process of decay that had begun within the Lithuanian society. Today the Lithuanian society is recovering. It needs to be aided in this by an operation [!] and by renouncing the internal dependence on foreign influences. De-Slavicising must be dynamic, revolutionary, compulsory in nature. De-Slavicizing is needed not by individuals but by the whole Nation. Individuals should consent to it. ${ }^{519}$

According to the official communiqué published in Lietuvos aidas ${ }^{520}$, on November 2, 1933 Lithuania's Minister

years 1922-1939]. Toruń: Wydawnictwo WSKSiM, p. 255.

518 „Hańbiąca Litwę ustawa” [a law that dishonours Lithuania] 1933.

Stowo, Wilno, Dec. 21.

519 Ibid.

520 "Pavardžių atlietuvinime komisija pas Vid. Reikalų Ministerį". 
of Internal Affairs, [Steponas] Rusteika, met with a committee entrusted with the task of Lithuanizing of surnames, which consisted of Prof. J[uozas] Balčikonis [of Kaunas University], Ignas J. Šeinius [the editor of "Lietuvos aidas"], as well as Dr. A[ntanas] Salys [of Kaunas University]. The committee was to review, county by county, the lists of about 300,000 surnames that had been sent from all Lithuania's counties; those sent from the Alytus and Marijampole counties had already, reportedly, been reviewed. The project of name Lithuanisation became part of the general Lithuania's policy targeted at Poles and gained more momentum following the German-Polish Non-Aggression Pact of January 26, 1934 (cf. Darski 2008, Ramonienè 2007: 429).

On December 6, 1938, a new surname law (Pavardžiu istatymos) was introduced in Lithuania ${ }^{521}$. According to $\$ 14$ of the law, surnames were "restored to their Lithuanian shape" if they had Slavic suffixes, if they had been translated into other languages, or if they had been distorted under the influence of other languages ${ }^{522}$. According to $\$ 15$ of the said law, two further types of Lithuanian surnames were to undergo "correction" (Lith. taisymas): those of dialectal origin and those that violated the general principles of the Lithuanian language ${ }^{523}$. In $\$ 17$ and $\$ 23$ there was reference to the surname dictionary which was to be consulted in surname change. As provisioned by $\$ 20$, the old surname, at the request of the person concerned, might be entered in documents alongside the new surname.

Lietuvos aidas, Nov. 3, 1933, p. 6.

521 Vyriausybès žinios, Dec. 23, 1938, pp. 593-4. Detailed rules governing the implementation of the law (Pavardžiu istatymui vykdyti taisyklès) were published in Vyriausybès žinios, Jan. 28, 1939, pp. 21-2.

522 "Šiai kategorijai priklausè lietuvių pavardès: 1) turinčios slaviškas priesagas, 2) verstos ị kitas kalbas ir 3) iškreiptos svetimų kalbų ịtakos.” Ibid. See also Górski 1995: 339.

523 "Ištaisomos šios lietuviškos pavardès: 1) tarminès ir 2) nukrypusios nuo bendrinès kalbos dèsnių." Vyriausybès žinios, Dec. 23, 1938, p. 594. 
In December 1939 Lithuanian authorities introduced what came to be known as Passport Law: given names and surnames in passports were Lithuanised and at the same time three quarters of the approximately 200,000 inhabitants of Vilnius were classified as foreigners. Thus "a man born outside the confines of the Lithuanian republic as envisaged by the Moscow treaty, say in Smorgonie ${ }^{524}$, as a politically troublesome alien would possess in Vilnius fewer rights than, say, a Frenchman born in Paris and residing in Lithuania as a regular foreigner" (Mackiewicz 1947). The new law conferred citizenship on the inhabitants of Vilnius only on a number of conditions, the most important of which was documented Vilnius residence on particular, specified the days - they were in fact the days when the population of the Vilnius area was at its lowest due to war, evacuation and the army draft $^{525}$. Many inhabitants of the city whose ancestors had lived there for generations were not able to meet so defined criteria. The issuing of passports was used by the Lithuanian government as an opportunity for Lithuanisation. There were numerous cases of exerting pressure on applicants to have their ethnicity recorded in passports as Lithuanian, as well as instances of Lithuanising surnames. Representatives of the Institute of Lithuanian Studies sat on passport committees to make sure that the recorded surnames met the requirements of the forthcoming dictionary of surnames. Since the printing of the dictionary was falling behind schedule, there were delays in the issuance of passports as well (cf. Łossowski 1985b: 115117). As Zinkevičius (1998: 308-309) wrote,

Surnames were the most problematic. They had been reworked and distorted in various ways under the influence of enforced denationalization. Often in a given family group some would have a Lithuanian, others a Polonized or Slavicized surname

${ }^{524}$ A town in today's Belarus, close to border with Lithuania. Belarusian Смаргонь, Lithuanian Smurgainys.

${ }^{525}$ All the conditions that had to be met simultaneously in order to obtain Lithuanian citizenship under the new law are listed in Górski (1995: 408). 
[...].There was a desire to restore the original forms of these altered Lithuanian surnames. To this end [the linguists] accurately recorded the surnames as used by the people and created an index (about 260,000 entries) for them. Preparations were made to publish a dictionary of original Lithuanian surnames, but time ran out. The onset of World War II and the occupation of Lithuania interrupted the work.

Bronisław Krzyżanowski, a Lithuanian-born Polish lawyer and inter-war Member of Parliament of the Republic of Central Lithuania ${ }^{526}$, explained in his memoirs what meeting the requirements of the surname dictionary meant in practice:

Demanding the intactness in passport of a surname such as Krzyżanowski seemed to the authorities impudent. As the authorities would have it, this surname should sound Križanauskas or at least Kšižanovskis. The most difficult task was to retain the letter $\mathrm{w}$, which does not figure in the Lithuanian alphabet, and to get rid of the final s. (Quoted after Łossowski 1985b: 117.)

Krzyżanowski went on to give instances of translating surnames from Polish into Lithuanian, so that Wróblewski or Zajączkowski became Žvirblis ('sparrow') or Kiškis ('hare') respectively. Until the end of June 1940, it is estimated, 60-70 thousand passports were issued, while the population of Vilnius at the time, including refugees from outside the city, was probably about 300 thousand (cf. Lossowski 1985b: 117).

An analysis of a sample of nearly two hundred personal names of the inhabitants of Vilnius (over 130 of whom declared Polish nationality) as they were recorded in writing on 1942 census forms, collected by the German-Lithuanian authorities during the German occupation of Vilnius ${ }^{527}$, reveals

${ }^{526}$ A political entity that came into existence following Żeligowski's Mutiny in 1920 and lasted until the annexation by Poland in 1922, comprising the region around Vilnius, inhabited mostly by Poles and Jews.

${ }^{527}$ On the documents called Wohnungs-Haushaltungsliste (Pol. Lista gospodarcza mieszkania, Lith. Buto-ūkio lapas). The following streets have 
to what extent contemporary inconsistencies in the spelling of surnames in Lithuania have their roots in the past. The census forms were seldom signed personally by residents: most lists bear signatures of building administrators or of official census takers. Therefore in only a small percentage of cases has it been possible to establish with certainty the Polish shape of the surnames. However, even in those cases where only the Lithuanian version of a name is available, it was visible that not only had the names been Lithuanised but there were often two different Lithuanian name versions in two different places of the census form. Sometimes a third version figured on a summarised list of all the residents of a particular building.

Under the Soviet rule in the years 1944-1991 identity documents used to be bilingual: Russian and Lithuanian. A Lithuanian name would be recorded in its Lithuanian form alongside the Russified (Cyrillic-script) form. Thus a Polish minority member by the Polish name of Maciej Szczepański would in documents be recorded as Матвей Щепанский in Russian and Matvejus Ščepanskis in Lithuanian, which amounted to the Lithuanization not of the Polish but of the Russian form of the name. A Pole by the given name of Jan or Józef, for instance, would in the Russian version become Иван or Йосиф respectively (cf. Ramonienè 2007: 429-430, Mażul 2005, Mikulewicz 2011, Bobryk 2006: 461). However, shortly before the final collapse of the Soviet Russian rule in Lithuania, on January 25, 1989, the Decree on the SSR Official Language Usage posited Lithuanian as "the official language of the Republic" and further stated as follows:

In order to ensure the development and the use of the Lithuanian language in state and social life without abridging the constitutional right of those whose native language is not

been selected: ul. Krupnicza (Lith. Kruopu g.), Turgielska (Lith. Turgelių g.) and Zaułek Bernardyński (Lith. Bernardinu g.). The completed census forms are in the possession of Lithuanian Central State Archive (Lith. Lietuvos centrinis valstybès archyvas), Fond FR 743, Ap. 1. 
Lithuanian to use their native language, the Presidium of the Supreme Soviet of the Lithuanian SSR decrees: [...]

9. That state government bodies of the Lithuanian SSR shall enhance the prestige of the Lithuanian language, preserve Lithuanian personal names and place names, as well as provide general assistance to scholarly institutions devoted to the Lithuanian language, and create the material basis necessary for the development, research, and expansion of the Lithuanian language. At the same time, conditions shall be provided for the development of other languages used in the Republic.

The bilingual (i.e. Russian and Lithuanian) name system was brought to an end with the restoration of independence of Lithuania in 1991. The first declaration of independence was made by the Supreme Council, formerly the Supreme Soviet, on March 11, 1990, only to be suspended three months later. Finally, Vytautas Landsbergis announced the end of the suspension in January 1991. In the early 1990s, Russian identity cards were replaced with passports issued by the independent Lithuanian state. A considerable part of Poles in Lithuania got their surnames Lithuanised then - sometimes without their consent, sometimes encouraged by clerks. At approximately the same time, on January 31, 1991 the Decree of the Supreme Council of the Republic of Lithuania Del vardu ir pavardžiu rašymo Lietuvos Respublikos piliečio pase [on the writing of names and surnames in the passports of citizens of the Republic of Lithuania] ${ }^{528}$ was issued. It stipulated, among others, that

1. Names and surnames in passports of citizens of the republic of Lithuania shall be written by using Lithuanian spelling and letters in accordance with the Lithuanian part of existing passports or other identification documents which serve as the basis for the issuance of a passport.

2. Names and last names of individuals of non-Lithuanian nationality in a passport issued to a citizen of the republic of

${ }^{528}$ Cf. https://www.e-tar.lt/portal/lt/legalAct/TAR.A0DD1190CAE9, accessed Dec. 5, 2016. 
Lithuania shall be written by using Lithuanian spelling and letters. In accordance with a citizen's written request the names and last name shall be written:

(a) in accordance with the pronunciation and without grammatical transformation (without Lithuanian suffixes), or

(b) in accordance with the pronunciation and grammatically transformed (by adding Lithuanian suffixes)

3. Names and surnames of individuals who possess a citizenship of another state may be written in a passport issued to a citizen of the Republic of Lithuania in accordance with a passport or equivalent document of their previous state of citizenship... [English translation after Morava 2003: 479-480]

In connection with the above law on names, in 2001 a case was brought first to the European Court of Human Rights and then to the Human Rights Committee by a Lithuanian citizen, Tadeusz Kleczkowski from Vilnius (Klečkovski v. Lithuania) who had been fighting for the original version of his surname since 1989. In his complaint to the HRC it was stressed that

in Eastern Europe the populace has a strong ethnic consciousness and is particularly sensitive to the ethnic symbols of identity. Generally speaking, Eastern European citizens perceive a personal name, including the way it is spelled, to be much more than a mechanical means of personal identification. Names are commonly perceived as carrying historic and cultural value, and as such, a name is a source of self-respect and pride (Morava 2003: 481).

In 2003, before any verdict was given, Tadeusz Kleczkowski died. For Kleczkowski the issue was all the more important since the surname, he established, had been conferred in the $15^{\text {th }}$ century on one of his ancestors by no less than king Władysław Jagiełło himself (Mażul 2005). The Kleczkowski family come from the village of Kleczkowo in Mazovia, a region in central-eastern Poland ${ }^{529}$. Kleczkowski's

${ }^{529}$ Michał Kleczkowski, personal communication of Oct. 21, 2013. 
nephew, Michał, who in many documents figures as Michalas Klečkovskis, continues the struggle ${ }^{530}$. One of his arguments is that he is discriminated against in comparison to naturalized Lithuanians, who can retain the spelling used in their previous state of nationality. It is indeed so: according to the resolution of the Lithuanian Supreme Court of January 31, 1991, "the names and surnames of persons who had previously had citizenship of any other State may be written according to the passport of the citizen of that particular State or a document corresponding thereto," whereas in the case of citizens who have always been Lithuanian residents, names are to be written according to their pronunciation and with/without Lithuanian endings (the choice is left to the person concerned).

The Declaration on Friendly Relations and Good Neighbourly Cooperation, signed on January 13, 1992 by Lithuanian Foreign Minister Algirdas Saudargas and his Polish counterpart Krzysztof Skubiszewski, briefly referred to the issue of personal names of Poles in Lithuania:

The Republic of Poland and the Republic of Lithuania guarantee persons belonging to national minorities to use the mother tongue versions and spelling of their forenames and surnames in accordance with documents adopted by the Conference on Security and Co-operation in Europe.

The next chronologically of the documents relating to the spelling of personal names was the Constitution of the Republic of Lithuania, approved in a referendum on October 25, 1992 and initialled by the Lithuanian president on November 6 of the same year, states in Article 14 that "Lithuanian shall be the State language".

530 Cf. "Klečkovski v. Lithuania", Communication No 1285/2004, Report of the Human Rights Committee, 498-504. www.ccprcentre.org/doc /ICCPR/AR/A_62_40_vol.II_E.pdf, accessed Dec. 5, 2016. Jacek J. Komar 2005. "Polak z Wilna walczy o polską pisownię swego nazwiska" [a Pole from Vilnius fights for the Polish spelling of his surname]. Gazeta Wyborcza, July 25 . 
On April 26, 1994, the Treaty on Friendly Relations and Good Neighborly Cooperation of the Republic of Lithuania and Republic of Poland was signed in Vilnius by President Algirdas Brazauskas and President Lech Wałęsa. It came into force on November 26 of the same year ${ }^{531}$. In Article 14 of the treaty the given names and surnames were mentioned. It is instructive to compare the translation into English done by the Lithuanian side with that done by the Polish one. The treaty translated into English by the Lithuanian party employs the following wording:

The Contracting Parties declare that the persons, named in Article 13 paragraph 2, also have the right:

[...] - to use their names and surnames according to the sound of the national minority language. Specific norms on writing surnames will be established in a separate treaty. ${ }^{532}$

The English translation made by the Polish party is somewhat different:

The Contracting Parties declare that the persons referred to in Article 13, paragraph 2 have in particular the right to:

[...] - use their names and surnames in the version used in the language of the national minority. Specific regulations concerning the spelling of names and surnames will be laid down in a separate agreement. ${ }^{533}$

The Polish-language text of the treaty contains the phrase $w$ brzmieniu, which in Polish is ambiguous. According to a Polish-English dictionary, the Polish verb brzmiec has the following meanings:

${ }^{531}$ A detailed account of the negotiations preceding the 1994 treaty is offered by Antanas Valionis, Evaldas Ignatavičius [\&] Izolda Bričkovskienè 1998. "From Solidarity to Partnership: Lithuanian-Polish Relations 19881998." Lithuanian Foreign Policy Review, 2.

${ }^{532}$ Lithuanian Foreign Policy Review 1998/2. Emphasis added.

${ }^{533}$ Zbiór Dokumentów 1994/L, X-XII. Warszawa: Polski Instytut Spraw Międzynarodowych, p. 29. Emphasis added. 
- $\quad$ (of voice, music = to be heard) to sound; (of a bell) to ring, to sound; (of footsteps, echo) to resound: the music sounded in the distance; his words were still ringing in my ears;

- $\quad$ (of a musical instrument $=$ to produce sounds) to sound: the violin produces a piercing sound; clear/loud sounding;

- $\quad$ (of a sentence, text = to express content) to read, to run: the sentence should read as follows; the order was: 'don't shoot'; that sounds banal / wonderful / bad; the answer is $n o !^{534}$

From the above, it is obvious that the phrase $w$ brzmieniu might refer - especially in legal parlance - to the wording of a legal act (the way a legal act reads) as well as to the actual sound of the personal names invoked in the treaty ${ }^{535}$. The Lithuanian-language version of the passage reads: "[...] vartoti savo vardus ir pavardes pagal tautinès mažumos kalbos skambesi. “536

Until 2016, no separate treaty with the norms for writing surnames has been signed.

The Law on the State Language (Valstybinès Kalbos Istatymas) of January 31, 1995 (last amended on June 13, 2002), seems to have effectively eliminated the choice between using or not using the Lithuanian declension endings on names. As mentioned above, this choice had been introduced by the Decree of the Supreme Council of January 31, 1991. As the 1995 law in its Article 15 stipulates: "Genders, which are prescribed by laws, of personal names of the citizens of the Republic of Lithuania shall be used in the

${ }^{534}$ Wielki słownik polsko-angielski PWN - Oxford 2004. Warszawa: Wydawnictwo Naukowe PWN, p. 71.

535 The problem of the meaning of the Pol. phrase w brzmieniu in legal documents is extensively discussed by Andrzej Gulczyński in his article "Zmiana nazwiska w polskim prawie administracyjnym" [surname change under Polish law]. Czasopismo Prawno-Historyczne 2003, z. 1, 99-148, pp. 131-3.

${ }^{536}$ Lietuvos Respublikos Seimas, http://www3.lrs.lt/pls/inter2/dokpaieska .showdoc_1?p_id=11154\&p_query=\&p_tr2=, accessed Dec. 5, 2016. Emphasis added. 
Republic of Lithuania. Personal names shall be changed and corrected in the manner prescribed by laws," which is tantamount to making Lithuanian endings of names obligatory.

On February 1, 1995, the Framework Convention for the Protection of National Minorities was signed by Lithuania. It was ratified over five years later, on Mar. 23, 2000, and entered into force on July 1 the same year.

In May 1996 talks between Lithuania and Poland regarding the spelling of Polish names started in Vilnius and were continued in Warsaw in September of the same year. During his visit to Warsaw on January 7, 1997, Lithuanian Foreign Minister Algirdas Saudargas declared that negotiations would start in February that year and would lead to the prompt signing of the agreement. However, on February 12, 1997, a draft law on the spelling of given names and surnames in identity documents was submitted for discussion to the Seimas ${ }^{537}$. The draft law stipulated that no diacritics of the type used in Polish to mark palatalisation or nasality would be used in IDs. The intervention of president Algirdas Brazauskas eased the situation and in June 1997 another round of talks was held. Yet no agreement was signed then, either (cf. Mażul 2005).

On March 26, 1999, the Minister of Justice of the Republic of Lithuania decreed (No. 65) that foreign names may be reproduced according to their spelling (i.e. transliterated) and diacritics should be omitted only if they cannot be reproduced technically. This referred only to the Roman alphabet (Satkauskas 2008: 119-120). Yet merely seven months later, on October 21, 1999, the Lithuanian Constitutional Court ruled that the names of Lithuanian citizens were to be written in Lithuanian as the national language. In other words, the Court upheld the constitutionality of the 1991 Resolution of the Supreme Council (stating, in particular, that the Resolution does not contradict Articles 18, 22, 29 and 37 of the Constitution).

537 Seimas of the Lithuanian Republic (Lith. Lietuvos Respublikos Seimas) is the Lithuanian Parliament. 
On October 31, 2001, Lithuania submitted a state report on the implementation of the Council of Europe Framework Convention for the Protection of National Minorities. With regard to personal names, it presented the regulations of the resolution (decree) of January 31, 1991, stressing its conformity with paragraph 1 , art.1 of the Convention and invoking the subsequent 1999 ruling of the Constitutional Court of Lithuania, which confirmed the constitutionality of the 1991 law. The Lithuanian state report further referred to the 1994 bilateral treaty between Poland and Lithuania, especially stressing the numerous attempts to draft an agreement between the two states on the detailed norms of writing surnames. As explained in the report,

Lithuania suggests writing the names and surnames according to the sounding of the language of the national minority in Latin characters. However, Poland has rejected this proposal and holds to its proposal that the names and surnames of persons belonging [to] the Polish national minority in the Republic of Lithuania be written with diacritics that are characteristics to the Polish language. ${ }^{538}$

The report in its part relating to the name issue concluded with listing the cases in which Lithuanian citizens and Lithuania's stateless residents may change their names:

1) When the choice of a new name or surname instead of the existing ones is determined by the fact that the existing name or surname sounds bad or is difficult to pronounce;

2) When a person wants to have the surname of the spouse or to have back the surname existing before the marriage, provided that the fact has not been notified in dissolution of the marriage; 3) When a person wants to change a double name or surname into one of them, or vice versa;

4) When a person wants to have his or her name or surname written according to the pronunciation and without adhering to

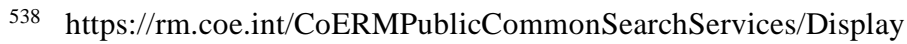
DCTMContent?documentId=090000168008b0f3, accessed Dec. 5, 2016. 
the grammatical norms of the language (without Lithuanian endings) or according to the pronunciation and adhering to the grammatical norms of the language (with Lithuanian endings);

5) Upon changing the surname with a view to preserving the surname of the ancestors;

6) When a person participates in the programme for the protection of witnesses. ${ }^{539}$

On February 21, 2003, as a result of the $1^{\text {st }}$ monitoring cycle, the Advisory Committee on the Framework Convention for the Protection of National Minorities at its $16^{\text {th }}$ meeting adopted the opinion on the implementation of the Convention in Lithuania. Regarding Article 11, the Committee expressed its regret that "no commonly approved solution has yet been found on the modalities of transcribing the surnames and first names of persons belonging to national minorities (in particular the Poles) in passports."

In its comments to the 2003 opinion, Lithuania did not refer to the problem of personal names of minorities at all. In the second cycle of monitoring (28 February 2008) the Advisory Committee "welcomes the positive developments [...] concerning the exercise of the right of all persons belonging to national minorities to use their surname (patronym) and first name in the minority language" and mentions as such a development the draft law of 2005 by the Ministry of Justice. According to the draft law,

personal surnames and first names, when not originally written in Latin characters, will be phonetically transcribed using the Latin script, without the addition of Lithuanian characters. According to the State Report, more detailed technical specifications should be provided in the 'Rules on the writing of surnames and first names in documents', which was being prepared by the State Commission on the Lithuanian language.

539 Ibid. 
As media reported in $2005^{540}$, in September 2005 the conflict was thus nearly resolved. Had the bill become law, it should have taken effect in 2007. During his visit to Poland in June 2007, Lithuanian Prime Minister Gediminas Kirkilas assured his Polish counterpart Jarosław Kaczyński that "his Government had approved a draft Act on Name and Surname Spelling, allowing for the names of Poles living in Lithuania to be spelt in Polish" ${ }^{541}$. This bill envisaged the spelling of nonLithuanian names in the original version, taking into account also non-Lithuanian letters, such as $q, w, x$. Whether such Polish letters with diacritics as $\dot{c}, \dot{n}, \dot{s}, \dot{z}, \dot{z}$ would be allowed was to be decided by suitable government instructions which were to follow.

However, article 6 part 2 of the proposed bill foresaw only Lithuanian given names as permissible for children whose family names were of Lithuanian origin or had been Lithuanised. The Legal Department of the Office of Lithuania's Seimas rejected both the 2005 and the 2007 government bills as unconstitutional, invoking the 1999 verdict of the Lithuanian Constitutional Court (cf. Radczenko 2007, Radczenko 2009).

In July 2009, on behalf of a married couple - Małgorzata Runiewicz-Wardyn, a Lithuanian citizen from Vilnius, belonging to the Polish minority, and her Polish husband Łukasz Wardyn - legal action was brought against Lithuania to the Court of Justice of the European Union. In Lithuanian documents, the wife's name was Malgožata Runevič-Vardyn and on the marriage certificate her husband was referred to as Lukasz Pawel Wardyn. This frequently led to problems in personal and professional life of the spouses. However, even

540 „Litwa zezwoli na pisownię polskich nazwisk po polsku” [Lithuania to allow Polish spelling of Polish surnames] 2005. Gazeta Wyborcza, Sept. 22.

541 "Prime ministers of Poland and Lithuania about energy security and improving situation of Poles in Lithuania and Lithuanians in Poland". The Chancellery of the Prime Minister, Republic of Poland, June 1, 2007. http://www.poprzedniastrona.premier.gov.pl/archiwum/english/070601-1.htm, accessed Nov. 29, 2013. 
though in the past similar complaints about incorrect spelling of names, lodged by citizens of Spain, Greece and Germany, resulted in verdicts favourable to those citizens ${ }^{542}$, the verdict of the Court of Justice of May 12, 2011, was unfavourable to the applicants:

[A] refusal to amend the marriage certificate of a citizen of the Union who is a national of another Member State in such a way that the forenames of that citizen are entered on that certificate with diacritical marks as entered on the certificates of civil status issued by his Member State of origin and in a form which complies with the rules governing the spelling of the official national language of that latter State does not constitute a restriction of the freedoms which the Treaty confers on every citizen of the Union. ${ }^{543}$

In the meantime, parallel signals in the domain of name planning were sent by Lithuanian authorities - namely, in September 2009 Lithuania's Minister of Justice, Remigijus Šimašius, announced forthcoming changes in legislation that would enable Lithuanian citizens to change their surnames easily so as to make them more Lithuanian. The Slavic elements in them, such as for example the suffixes -avicius or auskas, would be dropped with the minimum of formalities: it would suffice to express in a registry office one's desire to do so. Thus Jankiewicz, Lithuanised as Jankevičius, would ultimately become Jankunas. Similarly Jaunkauskas would be changed to Jaunkus, and Stankevičius to Stankus. According to Lithuanian linguists, such a comprehensive and compulsory action was seriously considered in the inter-war period and never actually implemented. This time, however, it was to be encouraged but not enforced ${ }^{544}$. Such a procedure, it was

${ }^{542}$ Ewa Łosińska 2010. „Prawo UE uratuje polskie nazwiska?” [will the EU law save Polish surnames?] Rzeczpospolita, April 28.

$543 \mathrm{http} / / /$ europa.eu/rapid/press-release_CJE-11-45_en.htm?locale=en, accessed Nov. 26, 2016.

544 Tomasz Kowalski 2009. ,, Litewskie nazwiska będą jeszcze bardziej litewskie" [Lithuanian surnames to become even more Lithuanian]. Gazeta 
claimed in the Lithuanian press, would help the people who wish to restore the original shorter surname of their ancestors but possess no documents that would prove the existence of such a surname.

On November 6, 2009, the Lithuanian Constitutional Court decided that the non-Lithuanian versions of minority names in identity documents could be only auxiliary to the Lithuanian version and could be printed on other than the first page of the passport, which is to contain the Lithuanianlanguage version of the name. On the other hand, the Court stressed the fact that the Lithuanian alphabet is part of the Latin alphabet and thus it is at the sole discretion of the Seimas to decide which Latin letters may be treated as Lithuanian and which may not.

Before the verdict of the Constitutional Court, Andrius Kubilius, Lithuania's Prime Minister, had promised that should the Court's verdict be unfavourable to Poles in Lithuania, his government would prepare a bill that would take into account their expectations. Surnames would then be granted the status somewhat similar to that of registered trademarks; this would make them exempt from the national language law, which forbids he use of non-Lithuanian letters.

In fact, Kubilius's government did prepare a bill that allowed in passports the original version of a non-Lithuanian name, written in any language whose spelling is based on the Latin script. Nevertheless, on Apr. 8, 2010, the Lithuanian Parliament rejected the bill. Of the 104 deputies present, 30 supported the bill and 38 were against it, with 36 abstaining ${ }^{545}$. The government bill received the most support from the Liberal Movement (Liberalu sajüdis). Against the bill were most of the parliamentary fractions, including the conservative Christian Party (Krikščioniu Partija), the Labour Party (Darbo Partija), largely "Order and Justice" (Tvarka ir teisingumas),

\footnotetext{
Wyborcza, Sept. 30.

545 These data are given after http://www3.lrs.lt/pls/inter/w5_sale.bals? p_bals_id=-7969, accessed Dec. 5, 2016.
} 
but most notably - and paradoxically - the Homeland Union Christian Democrats of Lithuania (Tèvynès Sajunga - Lietuvos Krikščionys Demokratai, TS-LKD), which is Premier Kubilius's own party.

In the case of the rivalling bill, prepared by Gintaras Songaila and Rytis Kupčinskas of TS-LKD, out of the 88 deputies present at the voting, 75 were in favour of it, with 3 against (all of them of the Electoral Action of Poles in Lithuania $^{546}$ ) and 10 abstaining. Thus the Songaila-Kupčinskas bill was accepted in the first reading. The victorious bill permits for non-Lithuanian names to be spelt in the original version but only on additional pages of the passport as 'other annotations' (kiti ịrašai); such an entry would have no legal consequences and, moreover, will incur an extra fee for those who would wish to apply for it. ${ }^{547}$

On the occasion of state visits Lithuanian politicians stress the will to find a solution to the long-standing problem that would satisfy the demands of the Polish minority in Lithuania. For instance, Prime Minister Kubilius reiterated his conviction that if foreign companies active on the Lithuanian market used in their names non-Lithuanian letters, then the same right should also be enjoyed by individuals in their names ${ }^{548}$. Despite such promises, the situation has been the same for years. Moreover, the validity of the Law on Ethnic Minorities (Lith. Lietuvos tarybų socialistinès respublikos tautinių mažumų istatymas ${ }^{549}$ ) of 1989 (amended) terminated in January 2010 and no law was passed in its place ${ }^{550}$.

${ }^{546}$ In Polish Akcja Wyborcza Polaków na Litwie - a centre-right political party in Lithuania, representing the Polish minority, founded in 1994.

${ }^{547}$ Stanisław Tarasiewicz 2010. „Litewski Sejm postanowit: Nie będzie polskich nazwisk" [Lithuanian parliament decides: no Polish surnames]. Kurier Wileński, April 9, pp. 4-5.

548 Agnieszka Filipiak 2010. „Polskie nazwiska po litewsku” [Polish surnames in Lithuanian]. Gazeta Wyborcza, Dec. 17.

549 http://www.minelres.lv/NationalLegislation/Lithuania/Lithuania_Mino rities_Lithuanian.htm, accessed Dec. 9, 2016.

${ }^{550}$ For an analysis of the minority-related legislation in Lithuania, see Vasilevich 2013; the texts of relevant laws in English and Lithuanian can be 
It is noteworthy that some signals sent by Lithuanian linguists indicate that they do not necessarily object to writing the surnames of Poles in Lithuania in Polish. For instance, even though Jüratè Palionyte ${ }^{551}$ in 2005 objected strongly to a provision about the right of Lithuania's national minorities to spell their names in their minority languages ${ }^{552}$, four years later she nevertheless admitted that non-Lithuanian surnames are not part of the Lithuanian language, hence the acceptance of Polish surnames in their original form does not mean extending the Lithuanian alphabet by new letters (cf. Radczenko 2009). She also emphasised in a 2013 interview that from the linguistic point of view the personal names of Poles in Lithuania might be written in identity documents in their original, i.e. non-Lithuanian, version. "This is how surnames are written in some EU states", she added ${ }^{553}$. As Antanas Smetona ${ }^{554}$ stressed, both Polish and Lithuanian use the same Latin alphabet, known to both nations, so there should arise no problems for the users of either language, regardless of which version of the surname - Polish or Lithuanian - is used (cf. Radczenko 2009). A similarly positive attitude to diacritics in minority names, though for the sake of human rights rather than for linguistic reasons, was taken by Satkauskas (2008) in Lithuanian Foreign Policy Review, which, notably, is a journal published by the Foreign Policy Research Center in cooperation with the Institute of International Relations and Political Science (Vilnius

found at http://www.minelres.lv/NationalLegislation/Lithuania/lithuania.htm, accessed Dec. 9, 2016.

${ }^{551}$ Deputy head of VLKK, a Lithuanist.

552 Cf. Tadeusz Andrzejewski 2005. „Dwie ustawy, dwa problemy” [unresolved problems with passing the law of citizenship and the law of minorities in Lithuania]. Tygodnik Wileńszczyzny Nov. 24-30, online edition No. 272.

$553 \mathrm{http}: / / z w . l t / s a l o n-p o l i t y c z n y / j u r a t e-p a l i o n y t e-z-j e z y k o w e g o-p u n k t u-$ widzenia-jest-mozliwosc-zapisywania-imion-i-nazwisk-w-oryginale/, accessed Dec. 5, 2016.

${ }^{554}$ A Lithuanian professor of Vilnius University, specialising in the Lithuanian language. 
University) and the Ministry of Foreign Affairs of the Republic of Lithuania. "What are the reasons," Satkauskas asked, "to deprive the members of national minorities [of] the right to use letters not appearing in the script of the official language, when such a right is guaranteed to foreigners?" (2008: 120) This opinion coincides with the argument put forward by Michał Kleczkowski, who claimed that as a member of a national minority he was discriminated against in comparison with naturalised Lithuanians ${ }^{555}$.

To complicate matters further, Lithuanian top politicians sometimes appear to be sending confusing and unclear signals. For instance, in a 2010 interview (cf. Kiełpiński et al. 2010: 150), referring to the surname spelling conflict, Dalia Grybauskaite ${ }^{556}$ explained that in the Lithuanian alphabet there are practically all Latin letters, including " $w$ " and the combination [diagraph] "cz", as well as others. She went on to mention a law of 1938 which allowed the use of these letters. While she was probably referring to the project that never actually became law, it is not so easy to account for her statement about the presence of the letter $\mathrm{w}$ in the Lithuanian alphabet or the acceptability of the cz digraph in it. More statements in a similar vein could be invoked. For instance, in May 2011, immediately after the verdict of the European Court of Justice, Remigijus Šimašius, Lithuania's Minister of Justice of the time, expressed the opinion that the right to the original spelling of one's surname is a human right and should be exercised as long as the exercise of this right is not contrary to public order and does not incur serious costs. At the same time Prime Minister Kubilius announced changes in Lithuanian laws so as to make provisions for Lithuanian women who marry foreigners ${ }^{557}$.

${ }^{555}$ Decision of the Human Rights Committee, Ninetieth Session, 9-27 July 2007, Communication No. 1285/2004. http://www.ccprcentre.org/wpcontent/uploads/2012/12/1285_2004-Lithuania.pdf, accessed Dec. 5, 2016. 2009.

${ }^{556}$ Lithuanian politician, born 1956. Elected President of Lithuania in

557 "Człowiek ma prawo do swego nazwiska" [a man has the right to 
While such changes were not introduced, in July 2015 a court in Vilnius nevertheless passed a verdict in favour of the applicant - a Lithuanian woman who married a Belgian by the surname of Pauwels, but in the marriage certificate her new married name, against her wish, was spelled Pauvels instead. The court ruled that the inviolability of an individual's private and family life should have a priority over the right of the state to protect its cultural identity, especially considering the fact that Lithuania is a member of the European Union ${ }^{558}$.

On April 12, 2016 a court in Vilnius obliged the Civil Registry Office in Vilnius to change into 'Wardyn' the surname of Michal Leon Vardyn, the son of Malgorzata RuniewiczWardyn and Lukasz Pawel Wardyn, born in Belgium, and to issue a new birth certificate ${ }^{559}$.

\subsection{The ideology}

Language policy, Schiffman contends, "is ultimately grounded in linguistic culture, that is the set of behaviours, assumptions, cultural forms, prejudices, folk belief systems, attitudes, stereotypes, ways of thinking about language, and religio-historical circumstances associated with a particular language" (1996: 5). All these are directly related to language ideology. By analogy, when referring to names, one might make use of the notion of name ideology, which would mean all the above assumptions in relation to names.

The chief argument given when explaining the stance of the Lithuanian party regarding the spelling of surnames is the specificity of the Lithuanian language. Being a highly

their surname] 2011. Onet/PAP, author: PN, May 13. http://wiadomosci .onet.pl/swiat/czlowiek-ma-prawo-do-swego-nazwiska,1,4303725, wiadomosc .html, accessed Dec. 5, 2016.

558 http://en.efhr.eu/download/2015\%20m.\%20liepos $\% 2030 \% 20$ d. $\% 20$ Vilniaus\%20m.\%20apylinkes\%20teismo\%20nutarimas.pdf, accessed Nov. 25, 2016.

559 http://en.efhr.eu/download/2016_m._balandzio_12_d._sprendimasEN.pdf, accessed Nov. 25, 2016. 
inflected language, it is claimed, Lithuanian cannot incorporate foreign proper nouns without endowing them with case endings, or else they would not be declinable. As a state contained basically within its ethnic boundaries today, relatively small compared to its size of a few centuries ago and with short history of independent statehood, Lithuania came to identify strongly with its language, which for many years was the mainstay of Lithuanian national identity. Lithuanians are proud of their ancient mother tongue with a rich derivation system and an abundance of inflections. It also seems that the old myth of Lithuanian having preserved the most similarity to Latin and Sanskrit is not dead yet. In fact Lithuanian is positioned by scholars within the Balto-Slavic group of languages, most closely related to Slavic - not to Latin, which is an Italic language, or to Sanskrit, which is classified within the Indo-Iranian group.

This feeling of the exceptionalness of the Lithuanian language has a long-standing tradition. As early as in the $15^{\text {th }}$ century Jan Długosz, a famous Polish chronicler, claimed that the speech of Lithuanians was Latin, with minor differences only ("Mowa Litwinów jest łacińska, z małymi tylko odmianami"). Further proof of the ennobling ancestry was allegedly the very name of Lithuania, believed in medieval times to have originated from the form L'Italia. Some claim that the conviction that Lithuanians are descendants of ancient Romans may have been the work of Teodor Narbutt ${ }^{560}$. However, already as early as the $16^{\text {th }}$ century Michalo(n) Lituanus (Michał Litwin) in his work De moribus tartarorum, lituanorum et moscorum [on the customs of Tatars, Lithuanians and Muscovites] suggested using Latin in public life as the authentic ancient language of Lithuanians (cf. Krzywicki 2005: 98, Kamusella 2009: 182, Kiełpiński et al. 2010: 23; Kiaupa et al. 2007: 191-193; Jurkiewicz 2005).

${ }^{560}$ Polish historian interested in the history of Lithuania, also active as engineer and archeologist (1784-1864). 
The conviction that Lithuanian is exceptional among the languages of the world has been carried over into modern times. "Renowned philologists have agreed that the Lithuanian language is not only the oldest language in the world today, but the language used by Aryans before the invention of evolution of Sanskrit," Theodore S. Thurston wrote in 1941 in his Lithuanian History, Philology, and Grammar, and he went on to quote in the same article Benjamin Woodbridge Dwight, who surmised that "if the value of a nation in the total sum humanity were to be measured by the beauty of its language, the Lithuanian ought to have the first place among the nations of Europe". Generally speaking, the above beliefs amount to what Smith et al. dub "the myth of primordiality," which is posited as one of the five language-extrinsic founding myths of nation-states ${ }^{561}$. More specifically, it corresponds to the myth of the Ursprache ("our language is the original language of mankind", Smith et al. 1998: 176).

However, "Surnames are not an issue of language, but of identity," Lithuania's Prime Minister Kubilius admitted in 2010 in an interview for a Polish daily ${ }^{562}$. The official stance of the Lithuanian authorities is a reflection of this conviction among the general populace. An opinion poll published in 2010 by the daily Lietuvos Rytas, in which 3677 respondents took part, revealed that 22 per cent of respondents support the prohibition to spell Polish surnames the Polish way since this would equal 'the beginning of erasing the Lithuanian character'. Further 24 per cent think that the ban on the Polish versions of names unnecessarily increases tensions between the two countries. Asked if accepting the Polish spelling of

${ }^{561}$ Incidentally, another language-extrinsic myth about the Lithuanian language, namely the so-called myth of foreign approbation ('foreigners want to learn the national language more than any other foreign language'), was dispelled by a Polish joke popular at the beginning of 1940 in the Vilnius area: optimists learn English, pessimists learn German, and idiots learn Lithuanian (cf. Łossowski 1985b: 108).

562 „Wiem, co trzeba litewskim Polakom” [I know what Poles in Lithuania need]. Gazeta Wyborcza, Nov. 4, 2010, p. 9. 
Polish names in Lithuania would improve the PolishLithuanian relations, 51 per cent of respondents gave the negative answer, agreeing with the opinion that 'Poles would soon come up with some new claims anyway' ${ }^{563}$. These figures are matched by the results of another opinion poll of 2011, which revealed that 63 per cent of Lithuanians are convinced that Polish language signs must disappear from streets in Lithuania at once, while 12 per cent think the signs should disappear, yet such an event is unlikely since Poles are too determined. Only 21 per cent of the respondents would let the Polish inscriptions stay since 'they do not disturb anybody,' and the remaining 4 per cent 'do not care about the PolishLithuanian relationships ${ }^{1564}$.

The Polish perspective, however, is diametrically opposed. In January 2012 a letter arrived to Kurier Wileński, a Polish daily that appears in Lithuania ${ }^{565}$. Its author, a Polish Lithuanian by the name of Adolf Kodź, complains:

Children have that nasty and unethical habit of, when running out of arguments, calling one another names so as to humiliate the opponent. Now we are officially called names thousands of times, in any state agency. Nobody calls us by our proper surnames.

When I completed primary school, I got my school report as Kuodysui Adolfui. Father lamented the fact that he'd lost the bearer of his and our ancestors' surname. After military service and upon graduating from two universities I went to court and thus regained my surname - though in Cyryllic alphabet, still it sounded decent.

563 „Litwini: 'Nazwiska? Nie ustępować. To nic nie da, Polska znów coś wymyśli'" [Lithuanians: 'Surnames? Concessions are of no use, Poland will come up with something else'] 2010. Gazeta Wyborcza, Nov. 3.

564 „Prawie 2/3 Litwinów przeciwko polskim tablicom informacyjnym” [almost 2/3 of Lithuanians against Polish topographical indications]. Gazeta Wyborcza, Jan. 20, 2011.

565 http://kurierwilenski.lt/2012/01/06/list-do-redakcji-o-prawo-bycsoba/, accessed Dec. 5, 2016. 
In independent Lithuania I became mutilated again. I am not myself, since even the name I am called is not mine... [...] We are fighting back since nobody wishes to be mutilated. We want and we have the right to be ourselves if this country is to be called democratic, civilised, European, and not some backwoodsy sticks [...]

I don't mind people calling themselves whatever suits them. It is none of my business. But my given name and my surname are my identification and my property. Just like my genes and my blood identify my lineage $[\ldots]$

I received a brand new passport and a new humiliation to go with it. Apart from my name being mutilated, there is no space for nationality in it. Why should I be an officially certified mankurt ${ }^{566}$ with no given name, no surname, no nationality or language $[. .$.$] In my passport there is only my number - a code$ - like in an Oflag ${ }^{567}$, and a nickname like in a clink, but no information on who I am or where I come from.

\subsection{The policy}

The Lithuanisation of the personal names of Poles in Lithuania is effected on the basis of certain principles that govern the mapping of the Polish spelling system onto the Lithuanian one. Both spelling systems being based on the Latin alphabet, the conversion can not be termed transliteration in the strict sense. Nevertheless, it is not a pure transcription either, even if it largely relies on approximating the pronunciation of the original. For instance, Polish geminates in given names like Anna, Emma, Izabella, Wioletta, are rendered in Lithuanian as single letters and pronounced accordingly. In a system based uniformly on the substitution of those letters only that do not appear in the target language, such a correspondence would not be possible. Thus the mapping is a mixture of transcription and

566 A synonym of a passive, torpid, obedient slave. The term is derived from the 1980 novel The Day Lasts More Than a Hundred Years by Ch. Aitmatov, in 1990 made into a film entitled Mankurt.

${ }^{567}$ A POW camp for officers (from the German word Offizierslager). 
transliteration, also taking into account the phonotactics of Lithuanian. The rules that follow ${ }^{568}$ are binding for writing Polish personal names in Lithuanian in documents. They also apply in cases where the passport of the Republic of Lithuania is issued on the basis of documents in Polish that do not have entries in Lithuanian. The rules specify only those Polish characters that do not match their Lithuanian counterparts. They are presented underneath in the following format: original form - Lithuanised form without Lithuanian endings / with Lithuanian endings.

\section{Vowels}

ą - om before b, p: Dąbrowski - Dombrovski / Dombrovkis

a - on in all other cases: Lątkowski - Lontkovski / Lontkovskis, Wądolski - Vondolski / Vondolskis, Mączyński Mončynski / Mončynskis, Wąsowicz - Vonsovič / Vonsovičius

ę-em before b, p: Dębski-Dembski / Dembskis, Kępski - Kempski / Kempskis

$\mathbf{e}$ - en in all other cases: Pędzelewski - Pendzelevski / Pendzelevskis, Lęcki - Lencki / Lenckis, Węžyk - Venžyk / Venžykas, Węgierski - Vengerski /Vengerskis

i (as a mark of softness ) before e, ę: Bielikowicz Belikovič / Belikovičius, Ciechanowski - Cechanovski / Cechanovskis, Dziekiewicz - Dzekevič / Dzekevičius, Mieczysław - Mečyslav / Mečyslavas, Niedzielska Nedzelska, Czekień - Čeken / Čekenis, Dzięgielewski Dzengelevski / Dzengelevskis

But before a: Białecki - Bialecki / Bialeckis, Hiacynt Hiacynt / Hiacyntas

ó - u: Wójtowicz - Vuitovič / Vuitovičius, Skórko - Skurko / Skurka, Piórko - Piurko / Piurka, Józef - Juzef / Juzefas, Judymówna - Judymuvna, Kaziów - Kaziuv / Kaziuvas

568 According to "Lietuvos lenkų pavardžių ir vardų rašymo Lietuvos Respublikos piliečio pase taisyklès" [the rules for writing Polish surnames and given names in Lithuanian in the passport of a citizen of the Republic of Lithuania], http://www.vlkk.lt/aktualiausios-temos/svetimvardziai/perrasais-lenku-kalbos, accessed Dec. 5, 2016. 


\section{Consonants}

j - i before consonants: Ajdukowicz - Aidukovič / Aidukovičius, Kajtoch - Kaitoch / Kaitochas, Ejsmunt Eismunt / Eismuntas, Chojnowski - Choinovski / Choinovskis, Domejko - Domeiko / Domeika

ć - c: Ćwikliński - Cviklinski / Cviklinskis, Ćywiński Cyvinski / Cyvinskis

1 - li before a, a, o, ó, u: Ladawski - Liadavski / Liadavskis, Lutowicz - Liutovič / Liutovičius, Ladecki Liondecki / Liondeckis, Grzela - Gželia, Ludmiła - Liudmila But (in the case of non-Polish origin of names): Jolanta Jolanta, Adelajda - Adelaida

1 - I: Pawet - Pavel / Pavelas, Wtadystaw - Vladyslav / Vladyslavas, Łęcki - Lencki / Lenckis, Mikłaszewicz Miklaševič / Miklaševičius

ń - n: Jasiński - Jasinski / Jasinskis, Iliński - Ilinski / Ilinskis, Czekień- Čeken / Čekenis

ś - s: Śniadecki - Sniadecki / Sniadeckis, Pieńkoś Penkos / Penkosis Vanda

$\mathbf{w}$ - v: Władystaw - Vladyslav / Vladyslavas, Wanda -

ź - z: Kuźmicki - Kuzmicki / Kuzmickis, Kuźma - Kuzma

$\dot{\mathbf{z}}$ - ̌̌: Żmijewski - Žmijevski / Žmijevskis, Żarnowski Žarnovski / Žarnovskis, Ważny - Važny / Važnas

\section{Diagraphs}

cz - č: Czestaw - Česlav / Česlavas, Czernecki - Černecki / Černeckis

$\mathbf{r z}-\check{\mathbf{s}}$ after $c h, k, p, t: K r z y w i c k i-K \check{s} y v i c k i$ / Kšyvickis, Przemystaw - Pšemyslav / Pšemyslavas, Trzebiński Tšebinski / Tšebinskis

rz - ̌̌ in all other cases: Rzecki-Žecki / Žeckis, Grzegorz - Gžegož / Gžegožas, Jarzyński - Jažynski / Jažynskis

sz - ̌s: Szejnicki - Šeinicki / Šeinickis, Szymon - Šymon / Šymonas 


\section{Double consonants}

H - l: Dowgiałto - Dovgialo / Dovgiala

nn - n: Anna - Ana

$\mathbf{t t}-\mathbf{t}:$ Violetta - Violeta

$\mathbf{m m}$ - m: Emma - Ema

Apart from the rules that reflect letter correspondences, there are also rules for adding endings to Polish names to make them inflectable in Lithuanian. Their addition is optional in personal documents but obligatory in newspapers and books. These rules are as follows:

1. Male given names and surnames that end with a consonant receive the ending -as, -is, -(i)us.

1.1. -as is added after a hard (unpalatalised) consonant:

Bohdan - Bohdanas, Hajduk - Haidukas, Kajtoch Kaitochas, Grzegorz - Gžegožas, Przemysław - Pšemyslavas, Józef-Juzefas, Czesław-Ceslavas, Jan-Janas

1.2. -is is added after a soft (palatalised) consonant, except -̌̌́:

Czekień - Čekenis, Pieńkoś - Penkosis, Rytel - Rytelis, Balciul-Balciulis, Giedrojć-Gedroicis, Karol-Karolis

1.3. -(i)us is added after - $\check{c}$ in surnames, and after $-\mathbf{j}$ in given names:

Wasowicz - Vonsovičius, Mikłaszewicz - Miklaševičius, Wójtowicz - Vuitovičius, Cytowicz - Cytovičius, Bielikowicz Belikovičius, Tomaszewicz - Tomaševičius, Chodkiewicz Chodkevičius, Andrzej-Andžejus, Maciej-Macejus

2. Feminine surnames ending with a consonant do not receive endings:

Czekień - Čeken, Balciul - Balciul, Wąsowicz - Vonsovič, Chodkiewicz-Chodkevič 
3. Masculine surnames ending with -o change it into -a:

Moniuszko - Moniuška, Matejko - Mateika, Skórko Skurka, Piórko - Piurka, Dowgiałto - Dovgiala, Surwiłto Survila

4. Feminine surnames ending with -o retain it:

Moniuszko - Moniuško, Piórko - Piurko, Surwitto Survilo

5. - $\mathrm{s}$ is added to masculine surnames ending with -i (after a soft consonant):

Lipiński - Lipinskis, Lisiecki - Liseckis, Wierzyński Vežynskis, Niedzwiecki - Nedzveckis, Rzecki - Žeckis, Chojnowski-Choinovskis

6. Masculine names ending with $-y$ (after a hard consonant) change it into -as, sometimes -is:

Ksawery - Ksaveras, Damazy - Damazas, Ważny Važnas. But: Jerzy - Ježis

7. Personal name ending -a corresponds to the Lithuanian ending -a:

Halina - Halina, Teresa - Teresa, Ewelina - Evelina, Jadwiga - Jadviga, Henryka - Henryka, Gumowska Gumovska, Przygodzka-P̌̌ygodzka, Gieczewska-Gečevska, Niedzielska - Nedzelska, Kuźma-Kuzma

8. The ending -ja in female given names remains unchanged, the ending -ia changes into -ija:

Felicja-Felicja, Lucja-Liucja, Maria-Marija 


\subsection{The practice 7.7.1. General remarks}

In order to examine the practice of the Lithuanisation of personal names, names in current use in Lithuania in the Polish-language version have been excerpted from Internet sources $^{569}$ and analysed; they are the names of schoolchildren, teachers and politicians from the Polish websites in Lithuania. Names have been listed only on condition that at the same time both the Polish-language version and the Lithuanianlanguage version of the full name of the same person was available.

\subsubsection{Given names}

The two tables in Appendix 1 present the excerpted given names in the Polish version (first column) and in the Lithuanised version (second column). For comparison, the third column shows standard Lithuanian forms of these names (after Kuzavinis \& Savukynas 2005). The comparison comprised 48 masculine and 40 feminine given names.

Some of the given names appeared in the excerpted material in non-standard spelling, and occasionally also in their diminutive versions, as the following table shows.

\begin{tabular}{|l|l|}
\hline \multicolumn{1}{|c|}{$\begin{array}{c}\text { The version of the Polish } \\
\text { minority in Lithuania }\end{array}$} & \multicolumn{1}{|c|}{ Standard Polish version } \\
\hline Ala (dim.) & Alicja \\
Anton & Antoni \\
Bogosława & Bogusława \\
Darek (dim.), Darjusz & Dariusz \\
Gelena & Helena \\
Hanka (dim.) & Hanna \\
Henirich & Henryk \\
\hline
\end{tabular}

569 The list of all surnames, as well as of the sources from which they were excerpted, is to be found in Appendix 2. 


\begin{tabular}{|l|l|}
\hline \multicolumn{1}{|c|}{$\begin{array}{c}\text { The version of the Polish } \\
\text { minority in Lithuania }\end{array}$} & \multicolumn{1}{|c|}{ Standard Polish version } \\
\hline $\begin{array}{l}\text { Jasia (dim.) } \\
\text { Kazmierz } \\
\text { Liusia (dim.), Lucijana } \\
\text { Vitolda (feminine) }\end{array}$ & $\begin{array}{l}\text { Janina } \\
\text { Kazimierz } \\
\text { Lucyna (dim. Lusia), Lucja } \\
\text { Witold (only the masculine form } \\
\text { exists in standard Polish) } \\
\text { Walenty }\end{array}$ \\
Waluś (dim.) & \\
\hline
\end{tabular}

Certain given names posed problems with the decision to which culture - Lithuanian, Polish or Russian - they belong: Milovita, Elina ${ }^{570}$, Euredyta, Aelita. There are instances of Lithuanian renderings of Russian given names: Aliona (Алёна), Antonij (Антоний). Also the name Anton, noted among the Poles, might be of Russian origin.

Some given names had identical Polish and Lithuanised forms: Eliza, Robert (though there also appeared the form Robertas), Alina, Agata, Aneta, Eleonora, Jolanta, Marek (though there also appeared the forms Marekas and Mark, while the Lithuanian form is Morkus), Lech, Arnold, Daniel (though there also appeared the form Danel), Inga, Beata, Ernest, Ilona, Karina, Renata, Karol, Albert. In the case of Lech, the suffixed form Lechas is common in Lithuanian periodicals, e.g. referring to the deceased Polish president Lech Kaczyński. Among Poles, there appear several unquestionably Lithuanian names or Lithuanian versions of those names that exist in Polish too: Vita, Nijole, Liucina, Simona, Jolita (Polish Jolanta).

Nevertheless, the most conspicuous are unusual forms of given names that are neither Polish nor Lithuanian, such as Rišard, Katažyna, Ježy, Agneška, Tomaš, Juzef. An even stranger side effect is the creation of forms that are not even properly Lithuanised, since despite the superficial appearance of Lithuanization they contain letters alien to Lithuanian:

570 According to the portal http://www.behindthename.com, it is a Swedish/Finnish version of Helen (Lithuanian Elena). 
Waldemaras, Edwardas, Jadwyga. Thus the analysis of the excerpted material proves that the guidelines laid down by the VLKK are not followed dutifully. To take another example: in the Lithuanised forms of the Polish given name Kazimierz, which are Kazimir, Kazmierz and Kazimiras (vis-a-vis the Lithuanian form Kazimieras), the letter $<\mathrm{i}>$ is preserved after $<\mathrm{m}>$, even though it signals palatalisation.

\subsubsection{Surnames}

The analysis of the Lithuanised names included in Appendix 2 reveals that the principles of Lithuanisation of personal names as set out by the VLKK are not always followed in practice. In particular, the transcription is not consistent - for instance, the grapheme $<\dot{c}>$ in the surnames Dudojć, Rekść is not rendered as $\langle\mathrm{c}\rangle$ but as $\langle\mathrm{t}\rangle$ (Dudoit and Rekst respectively). On the other hand, the VLKK guidelines occasionally diverge from the principle of transcribing a name according to its pronunciation. For instance the letter $\langle w\rangle$ in Tomaszewski becomes in Lithuanian $\langle\mathrm{v}\rangle$ and not $\langle\mathrm{f}\rangle$, even though it is actually pronounced as [f].

Bilingual name lists provide an interesting insight into the way surnames have been changed in a multi-cultural (PolishRussian-Lithuanian) setting, frequently leading to divergence from the usual Polish-language versions of surnames. Interestingly, names may manifest various degrees of Lithuanisation: on the list of electoral candidates there is Tadeuš Tučkovski alongside Tadeušas Pavlovskis. Thus the 'more Lithuanian' (i.e. suffixed) form of the latter surname seems matched by the 'more Lithuanian' form of the latter given name. However, it also happens that Lithuanised surnames are combined with typically Polish given names. Some names in their Polish-language version are morphologically Lithuanised already (Szpakauskas, Liachowiczius). Sometimes one name in a language corresponds to two variants in the other (e.g. Pol. Luksza, 
Łuksza - Lith. Lukša, Pol. Marcinkiewicz - Lith. Marcynkevič, Marcinkevic). The situation is complicated further by the Russification of personal names (which is usually the result of the name changes at the time of the USSR), visible in the Russian ending - $i j$, - $a j a$.

What is more, at the moment the accretion of incompatible laws regarding the names of Poles in Lithuania results in a legal muddle. Of the three sons of Barbara Orszewska from Vilnius, the eldest - born in the Soviet times - was registered as Оршеьский. The middle son, born in independent Lithuania in 1991, became officially Orševskis, while the surname of the youngest was recorded in documents as Orševski. It used to be extremely difficult to prove to the authorities abroad that they are siblings. Monika Urbanowicz, a Polish citizen who had married a Lithuanian Pole, had to face another problem. While at marriage her surname was recorded as Urbanovič, on the document confirming her permanent resident status in Lithuania, issued in January 2010, her surname is Urbanovic (i.e. without the caron over "c"). As an official explained to her, non-Lithuanians are not entitled to the letters of the Lithuanian alphabet in their names in documents. As a consequence, her married surname is now different from that of her husband and children (Mikulewicz 2011).

There may be even more than three forms of a surname. Ana Okuškaitè ${ }^{571}$, a Lithuanian Pole, recollected:

1) Okuszko was the surname that her grandmother used to sign herself with in Polish ${ }^{572}$;

2) Okuška was its Lithuanian equivalent;

3) alongside these, in the family there existed the parallel Polish version Okuszka;

571 Ana Okuškaite, personal communication, 2011.

572 According to K. Rymut, the surname comes from the Polish verb okusić sie 'to be tempted'; in this form it is borne today by over two hundred users throughout Poland (2001: 177, 2005: 7943). 
4) at the beginning of the 1970s, with Lithuania still part of the $\mathrm{USSR}^{573}$, the Cyrillic version of the surname was Акушко, in the Latin script Akuszka.

5) Okuškaité was Ana's surname after 1991;

6) Okuškiene was her mother's married surname at the time;

7) Okuszkienie is the way the above was spelt on the tombstone;

8) Okuskaite is the diacritic-free Lithuanised form that Ana uses as a university student in Poland.

Incidentally, Ana's given name testifies to Lithuania's name policy as well. It is neither Polish nor Lithuanian: the former would be Anna, and the latter - Ona. As a kind of hybrid, it marks Ana strongly neither as a Pole nor as a Lithuanian, but narrowly as a Lithuanian Pole.

\subsubsection{Non-Lithuanian letters and letter combinations in registered personal names}

As revealed in December 2012 by the European Foundation of Human Rights ${ }^{574}$, which applied to the Population Register Office by the Ministry of the Interior (Gyventojų registro tarnyba prie VRM) for statistical data concerning non-Lithuanian given names and surnames registered in Lithuania, in nearly 8800 cases it was possible to register such given names as Katarzyna, Ewa, Tadeusz, Matthew, Joanna and Odetta, as well as such surnames as for example Leszczynska, Szczerba, Szulc or Brown. Other instances of legally registered personal names included Agnieszka, Anna, Annika, Barzda, Brown, Czeslav, Ewa, Gannibal, Ivannikov, Joanna, Kaczor, Kerza, Katarzyna, Leszczynska, Litten, Malgorzata, Mattheo, Matthew, Odetta, Powell, Szczerba, Szulc, Tadeusz, Urszula, Violetta, Visznievski

573 1944-1990.

${ }^{574}$ Europos Žmogaus Teisių Fondas, a non-governmental organisation operating in Lithuania since 2010. http://en.efhr.eu/about-us/, accessed Dec. 5, 2016. 
and Vitte. Hence, the Foundation concluded, it might be inferred that using non-Lithuanian letters and such letter combinations as $r z, c z, s z, n n$ and $t t$ does not present danger for the Lithuanian statehood any more ${ }^{575}$. The website makes public the office's correspondence, which includes detailed information on the number of instances of particular letter combinations. The combination $r z$ appeared in names over three thousand times, $t t$ - almost a thousand times, the letter $w-123$ times, whereas over a hundred girls and women in Lithuania have been registered with the given name Anna spelt with double $n$.

It is also noteworthy that even though the Lithuanian alphabet does not contain the letters $Q, X$ and $W$, the biggest Lithuanian chain of supermarkets is named Maxima, and one of the biggest banks is named Swedbank. Moreover, as noted by the press in 2010, the distillery "Stumbras" in Kaunas launched a new brand of vodka, called "Wódka Jagiełło", which means that letters unacceptable in the Lithuanian language are present in both parts of the name $(w, o$ and $t)$. On the label, which is in Polish, it can be read that this vodka is "Polish in character, in a truly Polish spirit." The manufacturer does not conceal the fact that the product - despite the disclaimer in Lithuanian "Pardavimui Lietuvoje" ('to be sold in Lithuania') - is targeted at the Polish market576. All these examples appear in contravention of Article 16 of the Law on the State Language (January 31, 1995), which states that "names of all enterprises, establishments and organizations

575 "'W' na Litwie jednak zgodne z prawem" [and yet the letter 'W' is legal in Lithuania]. European Foundation of Human Rights, Dec. 28, 2012. http://www.efhr.eu/2012/12/28/w-na-litwie-jednak-zgodne-z-prawem/, accessed Dec. 5, 2016. The website contains a link to the office's correspondence with detailed information on the number of instances of particular letter combinations.

${ }^{576}$ Cf. Stanisław Tarasiewicz 2010. „, Dla pieniędzy i Witold może być Polakiem." [for money Vytautas can be a Pole too]. Kurier Wileński, Oct. 26, as well as Agnieszka Filipiak 2010. „Polskie nazwiska po litewsku” [Polish surnames in Lithuanian]. Gazeta Wyborcza, Dec. 17. 
functioning in the Republic of Lithuania shall be formed adhering to the norms of the Lithuanian language and the resolutions of the State Commission of the Lithuanian Language under the Seimas of the Republic of Lithuania."

An interesting example of a surname that made a full circle from Lithuanian into Polish and back to Lithuanian is that of a Lithuanian professional basketball player Robertas Javtokas. The original Lithuanian surname was Jautakas/-is/$o s$. As early as at least the $17^{\text {th }}$ century it was attested in the Polonised form Jawtok ${ }^{577}$. The athlete's present surname is evidently an awkward attempt at (re-)Lithuanisation, heedless of the fact that the resulting form does no justice to the late medieval original.

\subsubsection{Names of historical persons and of foreigners}

Personal names of living persons in identity and other official documents are not the only aspect of the name conflict between the Polish minority and the state of Lithuania. Equally heated debates are occasioned by the approach to names of historical figures on monuments, commemorative plaques and in books. For instance the ashes of Antoni Wiwulski (1877-1919), a Polish architect and sculptor, which had been moved in 1964 from their original burial place in the crypt under the Holy Heart of Jesus' Church in Vilnius to Rasos Cemetery ${ }^{578}$, lay for over 30 years there under the Lithuanised name of Antanas Vivulskis. Only in 1999 was a new inscription with the original version of his name put up. ${ }^{579}$

577 Source: own archival research.

${ }^{578}$ Pol. Cmentarz na Rossie, Lith. Rasu kapinès, a cemetery in Vilnius and one of the four Polish cemeteries-national monuments, where many famous Poles have been buried.

579 Cf. Jerzy Romanowicz 2005. „Wileńska Rossa” [the Rasos cemetery in Vilnius]. Mówią Wieki. Jan. 1. Incidentally, Wiwulski was one of the few Polish personages whose streets did not change name when Vilnius was taken over by Lithuania in 1939. Reportedly, the argument in favour of leaving in Vilnius a street named after him was put forward by sculptor 
Emilia Plater, a revolutionary who fought in the November Uprising of 1830-1831, to this day on Lithuanian monuments or commemorative coins is referred to as Emilija Pliateryte. The countess herself used the surname Platerówna, i.e. one with the traditional Polish feminine suffix -ówna denoting an unmarried woman. In September 2008 a case was brought before the European Court of Human Rights regarding the name of a Polish minority school in Lavoriškès (Ławaryszki) which was named after Emilia Plater and whose name, the Lithuanian state insists, should be in the Lithuanian form $^{580}$. In 2012 the Court rejected the application "for nonexhaustion of domestic remedies"581.

Such policy stands in contrast to the present official policy in Poland. On the wall of a manor house in the town Marki near Warsaw, there is a commemorative plaque devoted to the eminent Lithuanian composer and painter Mikalojus Konstantinas Čiurlonis, who died there in 1911. His name on the plaque is spelled in Lithuanian letters only.

Recent plans to name one of the streets in Gdynia after the famous Lithuanian poet of Polish-Lithuanian ancestry, Antanas Baranauskas, triggered the locals' protests against the name as too foreign and thus hard to remember. The authorities, however, were adamant. "The City Council of Gdynia decided

Petras Rimša, who claimed that Wiwulski must have greatly valued the role played by Lithuanians in the battle of Tannenberg if in the original version of a monument commemorating this battle he positioned Vytautas higher than king Jogaila; therefore he deserved his own street (cf. Łossowski 1985b: 102-103).

${ }^{580}$ Cf. Interpelacja $n r 5649$ do ministra spraw zagranicznych $w$ sprawie sprzeciwu władz litewskich wobec polskiej pisowni patrona szkoty średniej $w$ Ławaryszkach $w$ rejonie wileńskim (Oct. 9, 2008) [interpellation No. 5649 to Foreign Minister regarding Lithuania's objection to the Polish spelling of the name of the person after whom the Lawaryszki Secondary School is named]. http://orka2.sejm.gov.p1/IZ6.nsf/main/5B22CE02, accessed Dec. 50, 2016. http://biblioteka.wspolnotapolska.org.pl/artykul/22 /Przestrzeganie-praw-mniejszoci-polskiej-na-Litwie-Raport-Stowarzyszenia, accessed Dec. 5, 2016.

$581 \mathrm{http}: / /$ lrv-atstovas-eztt.lt/uploads/CYTACKA_2012_decision.pdf, accessed Dec. 5, 2016. 
to name one of the streets after bishop Antanas Baranauskas, a Lithuanian who rendered great service to Poland and to the cause of reconciliation between Poles and Lithuanians. Polonising his surname would in this situation be inappropriate," the city council replied to complaints. "If we want the name of Adam Mickiewicz to be written in Lithuania the Polish way, then on our part we have to obey the rules of Lithuanian," the council president added. The decision of the council was taken almost unanimously ${ }^{582}$. In a similar spirit, the statue of Antanas Baranauskas, erected in 1999 in Sejny (Seinai), Poland, has inscriptions with both the Lithuanian and Polish names of the bishop.

On the other hand, the same bishop as a personage after whom a street in Sejny might be named stirred up controversy. When the town mayor of Sejny expressed his opinion that Antanas Baranauskas actually never physically existed under that name, so the street might as well be named after Miś Uszatek $^{583}$, this met with a rebuke by Bronius Makauskas, a Polish historian of Lithuanian nationality, at a meeting of the Parliamentary Commission on National and Ethnic Minorities (Sept. 18, 2008). As Makauskas explained, though the bishop's signature in fact had always been Antoni Baranowski, yet he himself until recently signed his name as Bronisław Makowski, though for his Lithuanian compatriots he has always been known as Bronius Makauskas. As the example of Bronius Makauskas shows, since 2005, by virtue of Article 7 of the Act of 6 January 2005 on National and Ethnic Minorities and on the Regional Language, Lithuanians in Poland have been allowed, upon request, to adopt the Lithuanian spelling of their names in documents.

582 Klimowicz-Sikorska, Marzena 2010. „Mieszkańcy nie chcą nazwy ulicy, bo jest za trudna" [inhabitants reject street name as too difficult]. Portal Regionalny Trójmiasto.pl, Feb. 15. http://www.trojmiasto.pl/wiadomosci /Mieszkancy-nie-chca-nazwy-ulicy-bo-jest-za-trudna-n37004 .html?sort=down, accessed Dec. 50, 2016.

583 'Teddy the Floppy-Ear', a popular character of a Polish TV series for children. 
There are also more recent examples of the name-spelling conflict, which involve name cases other than the nominative. After the death of the Polish president Lech Kaczyński in a plane crash near Smolensk on April 10, 2010, there was a plan for one of the streets in Vilnius to be named after him. The name of the street would be Lecho Kacynskio in Lithuanian, which spelling the Polish minority in Lithuania found unacceptable. The controversy over the spelling of the name finally led to the abandonment of the idea. Ironically, it was exactly during Lech Kaczyński's visit to Lithuania, two days before the plane crash, that the Lithuanian Seimas rejected the government bill which allowed the original version of Polish names in official documents.

It must be noted that the Lithuanian language has had a long-standing tradition of phonetic adaptation of foreign names, which - coupled with suffixation - might render them unrecognizable. Votkinsas or Čerčilis (Watkins and Churchill respectively) may serve as a case in point. Similarly, foreign names are still Lithuanised in Lithuanian press. There is George'as W. Bushas (Džordžas $V$. Bušas), Bronislavas Komorovskis, Barakas Obama, etc. Occasionally this practice has unintended comical effects. Mel Gibson in the Lithuanian version would have as his first name Melas, which in Lithuanian means 'lie'. Latvian film star Girts Jakovlevs would in Lithuanian have his given name changed to Girtas - 'drunk'.

Yet there are exceptions in the press practice. Rimvydas Valatka, deputy editor-in-chief of an influential Lithuanian daily Lietuvos Rytas, stresses the fact that this newspaper makes a point of always using both $w$ and $c z$ instead of $v$ and $\check{c}$ in Polish surnames (Kiełpiński et al. 2010: 69).

\subsection{The Lithuanian context: names of companies}

Despite the rigid rules concerning the form of personal names in Lithuania, the rules concerning the names of companies do not appear as strict. Łukasz Wardyn, a Polish lawyer and the husband of the above-mentioned Małgorzata 
Runiewicz-Wardyn, who filed suit against Lithuania over the spelling of her name in Lithuanian documents, commented in Parliament:

You may have been to Lithuania [...] and you may have seen a big signboard of the most visible bank, it's the biggest bank in Lithuania, it's Swedbank. In the name Swedbank there are two instances of violating the constitutional order. On the one hand it contains the letter "w", which is considered to be violating the constitutional order, and on the other - it also contains the word "bank", whereas according to the requirements of the Lithuanian language it ought to be called "Svedbankas", and not "Swedbank", because there is no word "bank" in Lithuanian. What's interesting, apart from Swedbank there's also PAREX Bankas - such a bank, later acquired by another bank, used to exist - in whose name there is the letter "x", similarly absent from Lithuanian. Lithuanian citizens possess one milion three hundred and sixty thousand accounts in Swedbank. What's funny, this is as many as there as households in Lithuania. Thus one might conclude that every household in Lithuania has a bank account in a bank whose name violates Lithuania's constitutional and democratic order in two respects. Every third company and state institution, I repeat, state institution, has a bank account, so I wouldn't be surprised if the Constitutional Court, which ruled that such names should be forbidden, has a bank account in this bank too [...]

Lithuania has registered four hundred and fifty thousand such cars as BMW, VW and Daewoo - that is, there is one in every fourth household - which in the name have a letter that is detrimental to the constitutional order. Hundreds of thousands of cars have engine numbers with the letters "w", "q" and "x", which are also absent in the Lithuanian alphabet [...] At the promotional price of 600 euros you can purchase a registration plate where the word "Wilno" can be spelt with "w". ${ }^{584}$

584 Łukasz Wardyn, speech at the 78. meeting of the Senate's Emigration Affairs and Contacts with Poles Abroad Committee [Senacka Komisja Spraw Emigracji i Łączności z Polakami za Granica] on Feb. 15, 2011. Unauthorised shorthand transcript No. 2020. http://ww2.senat.p1/k7 /kom/ksep/2011/078sep.htm, accessed Dec. 5, 2016. 
In May 2013, stricter observance of the rules promoting the use of the Lithuanian language in such names was announced. According to the media, the companies would have to "choose either proper Lithuanian or at least Lithuanian-sounding words or, especially in the case of foreign-controlled entities, a name identical or similar to the founding party's name." ${ }^{585}$ However, the final decision will still be made by the Registration Centre (Registru centras), with VLKK only giving their opinion. According to Jūrate Palionytè, deputy chairman of VLKK, "the requirement for company names to follow Lithuanian language norms has been enacted for many years, only it hasn't been followed properly".

\subsection{The international context}

In the case of two dissimilar languages, there are basically two options in the rendering of names from the minority language in the majority one (assuming that the same script is used for both languages, as is the case with Lithuanian and Polish):

1) preserving the original spelling at the expense of the potentially distorted pronunciation,

2) approximating the original pronunciation of the minority language in the orthography of the majority language.

The legislation of the European Union as embodied in the Framework Convention for the Protection of National Minorities is not decisive on this point. Article 11 p. 1, which grants the members of national minorities the right to official recognition of their surnames (patronyms) and given names, leaves ample room for the state's own legislation and is in fact too general to provide any useful guidelines. The Explanatory

585 "Lithuania requires company names to be in Lithuanian", http://bnn-news.com/lithuania-requires-company-names-lithuanian-94847, accessed Dec. 5, 2016. 
Report, on the other hand, gives as an example only the second option (i. e. approximated pronunciation at the expense of distorted spelling):

In view of the practical implications of this obligation, the provision is worded in such a way as to enable Parties to apply it in the light of their own particular circumstances. For example, Parties may use the alphabet of their official language to write the name(s) of a person belonging to a national minority in its phonetic form. (Art. 11, § 1. p. 68.)

In the case of the European Charter for Regional or Minority Languages, it is similarly unclear what is understood by the notion of another writing system in which the most accurate possible phonetic transcription of [the minority] name is to be made. In particular, it is of relevance to the present discussion if a different system of diacritics within the same Latin script (e.g. German vs. Lithuanian, or French vs. Polish) qualifies as 'another writing system'. In the case of the Latin script versus another one - such as Cyrillic, Greek, Arabic, Hebrew, Georgian, or Armenian - it goes without saying that no preservation of the original (i.e. non-Latin) script is possible: "International documents [...] reveal the fact that the right of the members of a national minority to use names in their native language does not extend to the use of the script of that language in official documents" (Satkauskas 2008: 132).

There are states in Europe that adhere to the first of the two above mentioned options - as of 2008, Satkauskas (ibid.: 112) mentioned Italy, Denmark, Germany and Slovenia. In these countries, minority personal names are written according to the original minority spelling, complete with the diacritics. In Slovenia, for instance, by force of the Law on Personal Names, Italian and Hungarian names are written in the original Italian/Hungarian way, unless the individual desires otherwise. In the opinion of Satkauskas (ibid.: 114-115), the right of minorities to personal names in their original form, complete 
with diacritics, follows logically from several universal principles, including the principle of non-discrimination, the right to maintain and develop cultural identity (freedom from assimilation), and the protection of a person's private life. These values are generally safeguarded in various human rights agreements and instruments, of which Satkauskas listed the following:

1) the Universal Declaration of Human Rights - Art. 1 and 2 (1),

2) the European Convention for the Protection of Human Rights and Fundamental Freedoms (ECHR),

3) the International Covenant on Civil and Political Rights,

4) the Document of the Copenhagen Meeting of the Conference on the Human Dimensions of the CSCE (Conference for the Security and Cooperation in Europe),

5) the United Nations General Assembly Declaration on the Rights of Persons Belonging to National or Ethnic, Religious and Linguistic Minorities,

6) the Council of Europe Framework Convention for the Protection of National Minorities,

7) the European Charter for Regional or Minority Languages,

8) The Oslo Recommendations Regarding the Linguistic Rights of National Minorities.

However, as indicated above in the context of the FCNM, these documents are often more important in terms of the spirit than of the letter of the law, and the number of states that are parties to them seems proportional to the degree to which these agreements are general and non-committal in nature of their provisions. Still there exists an international agreement that deals with the actual practice of rendering minority personal names: the 1973 Bern Convention on the Recording of Surnames and Forenames in Civil Status Registers. 


\subsubsection{Poland}

In the Polish language both options (i.e. original spelling with potentially distorted pronunciation, or, alternatively, closely approximated pronunciation at the expense of spelling) have been used, as evidenced by such surnames of foreign origin as, on the one hand, those retaining the original foreign spelling (e.g. Schmidt, Baudouin de Courtenay, de Virion, Sacchetti, Dubois) and on the other hand, those whose spelling has been adapted to Polish (e.g. Sztajnberg, Cymerman, Wajs, Rozencwajg, Lelewel, Socyn). Sometimes there are two alternative variants: Chopin/Szopen, Rousseau/Ruso, Voltaire/Wolter, Shakespeare/Szekspir. Generally, however, Polonised versions are those that have been well established in Polish (for instance, but not exclusively, in historical names), whereas more recent acquisitions usually preserve the original spelling. Moreover, Bartmiński (cf. 1992: 12) noted that in contemporary times one can witness the return to the original forms: the $18^{\text {th }}$ and $19^{\text {th }}$ century forms Rasyn, Szyler, Wolter, Russo are nowadays usually replaced by Racine, Schiller, Voltaire, Rousseau respectively.

As Bartmińska and Bartmiński (cf. 1978: 96-103) observed, the problem of personal name adaptation has been hotly debated since the $19^{\text {th }}$ century. They went on to invoke Józef Mroziński, who in his 1830 article "O sposobie pisania nazwisk cudzoziemskich" [on the manner of spelling foreign surnames] deplored the distortions suffered by Hebrew, Greek and Latin personal names adapted throughout centuries into Polish, though he admitted that after so many years little can be done with those distortions. Nevertheless, in the case of surnames coming from modern languages, he strongly advocated preserving the original spelling intact, even at the expense of the pronunciation. Spelling-based pronunciation, he argued, is not so bad as to be avoided at all costs, especially that the native speakers themselves make mistakes in the pronunciation. On the plus side, doubts as to which personal 
name is referred to can thus be avoided. The debate, based generaally on the same arguments, continued in the years 1903-1904 and was resumed after the Second World War, when the persuasive argumentation by Zenon Klemensiewicz and Witold Doroszewski settled the issue in Poland. In other words, two features of foreign surnames are preserved by the Polish language system today: their foreignness and their nonassimilative nature (cf. Bartmiński 1992: 9).

Regarding loans (valid not only for proper but also for common nouns), Bartmiński (ibid.) developed and described a six-degree scale of their assimilation to Polish. For clarity, it has been depicted below in table form. The numbers in the first column correspond to the degree of assimilation.

\begin{tabular}{|c|c|c|c|c|c|c|}
\hline $\begin{array}{l}\text { 1. Degree of } \\
\text { assimilation }\end{array}$ & $\begin{array}{c}2 . \text { Is the } \\
\text { original } \\
\text { morphology } \\
\text { preserved? }\end{array}$ & $\begin{array}{c}\text { 3. Is the } \\
\text { original } \\
\text { spelling } \\
\text { preserved? }\end{array}$ & $\begin{array}{l}\text { 4. Is the } \\
\text { original } \\
\text { pronunciation } \\
\text { preserved? }\end{array}$ & $\begin{array}{l}\text { 5. Immunity } \\
\text { to Polish } \\
\text { derivation } \\
\text { (+ example) }\end{array}$ & $\begin{array}{l}\text { 6. Immunity } \\
\text { to Polish } \\
\text { declension }\end{array}$ & 7. Example \\
\hline 1 (quote) & yes & yes & yes & yes & yes & $\begin{array}{l}\text { Beecher- } \\
\text { Stowe }\end{array}$ \\
\hline $2 \mathrm{~A}$ & yes & yes & partly & yes & no & René \\
\hline $2 B$ & yes & yes & partly & no [arrasy] & yes & {$[\text { Arras] }]^{586}$} \\
\hline 3 & yes & yes & partly & $\begin{array}{l}\text { no } \\
\text { (Disneyowski) }\end{array}$ & no & Disney \\
\hline 4 & yes & yes & no & $\begin{array}{l}\text { no } \\
\text { (darwinizm) }\end{array}$ & no & Darwin \\
\hline 5 & yes & no & no & $\begin{array}{l}\text { no } \\
\text { (szopenowski) }\end{array}$ & no & Szopen \\
\hline 6 & no & no & no & no & no & $\begin{array}{l}\text { Wierzynek } \\
(<\text { Wierzing })\end{array}$ \\
\hline
\end{tabular}

The second option (pronunciation at the expense of spelling) in writing the names of minority members (including the Polish national minority), as well as of most foreigners, has been adopted by Lithuania. Considering the high level of Lithuanian/Polish bilingualism among the citizens of

586 The examples in parentheses or without any brackets are Bartmiński's, in square brackets - mine. 
Lithuania, there would probably be little danger of mispronouncing Polish names if the opposite choice had been made. Clearly it was not the potential problems with pronunciation that were the rationale behind such a choice. Applying the above mentioned scale to Polish surnames in Lithuania, one would obtain the following:

\begin{tabular}{|l|l|l|l|l|l|l|}
\hline $\begin{array}{l}\text { 1. Degree of } \\
\text { assimilation }\end{array}$ & $\begin{array}{c}\text { 2. Original } \\
\text { morphology }\end{array}$ & $\begin{array}{c}\text { 3. Original } \\
\text { spelling }\end{array}$ & $\begin{array}{c}\text { 4. Original } \\
\text { pronunciation }\end{array}$ & $\begin{array}{c}\text { 5. Immunity to } \\
\text { Lithuanian } \\
\text { derivation }\end{array}$ & $\begin{array}{c}\text { 6. Immunity to } \\
\text { Lithuanian } \\
\text { declension }\end{array}$ & 7. Example \\
\hline 2B/5 & yes & no & yes/partly & $?$ & yes & Mečislav \\
\hline 6 & no & no & no & $?$ & no & Mečislovas \\
\hline
\end{tabular}

To phrase it differently, the transcribed Polish surnames display characteristics of degree $2 \mathrm{~B}$ combined with degree 5 , whereas in the case of Lithuanised surnames with added Lithuanian suffixes ('grammaticalised'), the assimilation is complete (degree 6).

The letters acceptable in the spelling of personal names of Polish citizens are not explicitly enumerated and are rather a matter of practice. The data in Rymut (2005) indicate that e.g. umlaut vowels ä, ö, ü are used in surnames (Brandstätter, Kröger, Müller). Also Lithuanian diacritics have been accepted since 2004. ${ }^{587}$

\subsubsection{Latvia}

It is noteworthy that this country has a name policy similar to that of Lithuania. Names are regulated, among others, by Art. 19 of the Valsts Valoda Likums [state language law] of 1992, which states that

${ }^{587}$ Act on national and ethnic minorities and on the regional languages (Jan. 6, 2005) recognises nine national minorities in Poland: Belarusians, Czechs, Lithuanians, Germans, Armenians, Russians, Slovaks, Ukrainians and Jews; four ethnic minorities: Karaites, Lemkos, Roma and Tatars; and one minority using a regional language (Kashubian). Members of these minorities have the right to spell their names in the original (minority) form (transliteration in the case of non-Latin alphabets). 
(1) Names of persons shall be presented in accordance with the traditions of the Latvian language and written in accordance with the existing norms of the literary language, observing the provisions of Paragraph two of this Section.

(2) There shall be set out in a passport or birth certificate, in addition to the name and surname of the person presented in accordance with the existing norms of the Latvian language, the historic family name of the person, or the original form of the personal name in a different language, transliterated in the Roman alphabet, if the person or the parents of a minor person so wish and can verify such by documents.

(3) The written form and identification of names and surnames, as well as the written form and use in the Latvian language of foreign language personal names, shall be regulated by Cabinet regulations. ${ }^{588}$

In 2000, Regulations on Spelling and Identification of Names and Family Names were issued in Latvia, which stipulated, among others, that

3. When spelling and using name and family name in the Latvian language the following basic rules shall be observed in records:

3.1. A person's name (names) and family name (double family name) are the personal names that shall be written in Latvian language in the basic documents;

3.2. name and family shall be spelled according to the spelling norms of the Latvian language and Latvian alphabet letters;

3.3. every name and family name shall have an ending corresponding to the Latvian language grammatical system in masculine or feminine gender according to the person's gender (except common gender family forms with the feminine endings for persons of both genders);


$\mathrm{cd}=2 \& v e d=0$ ahUKEwj7042n093QAhWGWSwKHQ_wDPYQFggiMAE\&u $\mathrm{rl}=\mathrm{http} \% 3 \mathrm{~A} \% 2 \mathrm{~F} \% 2 \mathrm{Fwww} . v v c$. gov.lv$\% 2 \mathrm{Fexport} \% 2 \mathrm{Fsites} \% 2 \mathrm{Fdefault} \% 2 \mathrm{Fdo}$ cs\%2FLRTA\%2FLikumi\%2FOfficial_Language_Law.doc\&usg=AFQjCNH WxaFEJjO5reXKBCTpZtLMoal9IQ\&bvm=bv.139782543,d.bGg, accessed Dec. 5, 2016. 
3.4. Indeclinable in the Latvian language are names and family names of foreign origin ending with $-\overline{\mathrm{a}},-\overline{\mathrm{e}},-\mathrm{i},-\overline{\mathrm{i}},-\mathrm{O},-\mathrm{u},-\overline{\mathrm{u}}$.

4. Foreign names and family names shall be spelled in the Latvian language (expressed with Latvian language sounds and letters) as close as possible to their pronunciation in the original language and according to the rules for spelling foreign proper nouns as well as the norms given in Article 3 of these Regulations. ${ }^{589}$

Provision 3.3. of the above regulations meant in practice adding the endings $-s$ (for masculine names) and $-a /-e$ (for feminine names) to the names to mark the gender and allow declination. The following examples of English and German names transcribed into Latvian illustrate this:

- $\quad$ Tove Skutnabb-Kangas - Tuve Skutnaba-Kangasa

- Robert Phillipson - Roberts Filipsons

- Max van der Stoel - Makss van der Stūls

- Colin Baker - Kolins Beikers

- Andrew - Endrjū

- Mary - Mērija

- David - Deivids 590

In a 2001 Mentzen/Mencena case (in which a Latvian citizen after marrying a German citizen by the surname of Mentzen had her married surname in the passport changed to Mencena, against her wish) the Latvian Constitutional Court confirmed the constitutionality of this law (cf. Poggeschi 2004).

The updated, detailed rules of March 2, 2004, are contained in the "Regulation on Writing and Use of Person's Names in Latvian Language" $"$.

$589 \mathrm{http}: / /$ miris.eurac.edu/mugs $2 /$ do/blob.html type=html\&serial=1044 633488167, accessed Dec. 5, 2016.

${ }^{590}$ Cited after Druviete 1999: 271ff, who discusses the topic in more detail.

591 Ministru kabineta noteikumi Nr.114 (2004): Noteikumi par personvārdu rakstību un lietošanu latviešu valodā, kā arī to identifikāciju, http://likumi.lv/doc.php?id=85209, accessed Dec. 5, 2016. 
Brands-Kehris and Pūce (cf. 2005b: 55) mentioned cases when Registry Offices refused to register the names of children of non-ethnic Latvian origin (e.g. registering the name Daniels instead of the parents' claimed name Danila, and Nikola instead of Nikola).

\subsubsection{Germany}

In April 2010, there was a heated debate among German netizens over the spelling of non-German names in German when a news portal published information about the plane crash with the Polish president on board, referring to the head of the Polish state as Kaczynski instead of Kaczyński, i.e. without the Polish diacritic over $\mathrm{n}^{592}$. Many German forum users claimed that it was impossible for Germans - or at least troublesome and complicated - to use letters other than German. There are countless instances of German umlauts similarly ignored in European press, another commentator pointed out. "It is interesting that for example French, Portuguese, Danish, Norwegian names are always spelled correctly. But to see why it is so, one must go back a couple of centuries in history", a forum user replied. This comment in turn met with a rebuke: "your comments again stir up hatred against Germans; how can there at last be friendly relationships when Poles are forever against something?" In order to prove that German in fact can use non-German diacritics, another comment mentioned the name of a well-known German actor, Joachim Król, whose name is always spelled in German with the Polish diacritic.

The spelling of the names of Poles in Germany ${ }^{593}$ is regulated by the Treaty on Good-Neighborliness and Friendly

592 https://www.tagesschau.de/ausland/kaczynski114.html, accessed Dec. 10, 2016.

${ }^{593}$ In contrast with Germans in Poland, and despite their long-standing presence in this country (especially following their 19th and early 20th century immigration, for example to the Ruhr district), Poles in Germany are not legally recognised as a minority. Consequently, in the treaty they are described as "[p]ersonen deutscher Staatsangehörigkeit in der Bundes- 
Cooperation ${ }^{594}$ between Poland and the Federal Republic of Germany, which in Art. 20 (3) mentions the right of Poles "to use their first names and surnames in the form of the mother tongue" ${ }^{595}$. Until 2007, the situation of the ethnic minority (nationale Minderheit or Volksgruppe in German) of Lusatian Sorbs was not as fortunate: their names could be officially registered only in the German form (cf. Rzetelska-Feleszko et al. 2002: 272; Bott-Bodenhausen 1997: 40). For example, Stanisław Tilich, a German CDU politician of Sorbian extraction, officially went by the German name of Stanislaw Tillich (with double $l$ in the surname and with plain $l$ in the given name). Since 2007, however, minorities in Germany have had the following options with regard to their personal names (both given names and surnames):

Eine Person, auf die sowohl das Rahmenübereinkommen zum Schutz nationaler Minderheiten als auch deutsches Namensrecht Anwendung finden, kann durch Erklärung gegenüber dem Standesamt

1. eine in die Sprache der nationalen Minderheit oder Volksgruppe übersetzte Form ihres Namens annehmen, wenn ihr Name einer solchen Übersetzung zugänglich ist (begriffliche Übertragung),

2. einen durch Veränderung der Schreibweise ihres Namens an eine der Sprache der Minderheit oder Volksgruppe

republik Deutschland, die polnischer Abstammung sind oder die sich zur polnischen Sprache, Kultur oder Tradition bekennen."

594 Vertrag zwischen der Bundesrepublik Deutschland und der Republik Polen über gute Nachbarschaft und freundschaftliche Zusammenarbeit vom 17. Juni 1991, http://skgd.pl/de/o-nas/traktat-miedzyrzeczpospolita-polska-a-republika-federalna-niemiec-o-dobrym-sasiedztwiei-przyjaznej-wspolpracy-z-17-czerwca-1991-roku/, accessed Dec. 5, 2016.

595 "Die Vertragsparteien erklären, daß die in Absatz 1 genannten Personen insbesondere das Recht haben [...] ihre Vor- und Familiennamen in der Form der Muttersprache zu führen." The English translation after Satkauskas (2008: 122). The wording of the Polish version is more ambiguous: "prawo [...] używania swych imion i nazwisk w brzmieniu języka ojczystego" [emphasis added] - 'brzmienie' could mean both the sound, the reading, or generally the form. 
entsprechende Lautung angeglichenen Namen annehmen (phonetische Übertragung) oder

3. einen früher in der Sprache der nationalen Minderheit oder Volksgruppe geführten Namen annehmen, wenn dieser Name in eine deutsche Form übertragen oder in einen anderen Namen geändert worden ist; dabei reicht es aus, dass der oder die Erklärende die frühere Namensführung glaubhaft macht. ${ }^{596}$

Germany officially recognises as minorities only Sorbs and Danes; the provisions of the FCNM, by force of the German declaration of Sept. 10, 1997, apply also to two more groups - Frisians and the Sinti and Roma. On the other hand, regulations concerning given names allow diacritics ${ }^{597}$.

\subsubsection{Other countries}

Greece has a century-old tradition of forcible Hellenisation of minority personal names. As recounted by Pavlos Voskopulos, a Greek of Macedonian ethnicity who in 2006 started a legal battle against Greece for failing to let him return to his original Macedonian name Pavle Filipov:

${ }^{596}$ Artikel $2 \S 1$, Gesetz zur Ausführung des Artikels 11 Abs. 1 des Rahmenübereinkommens des Europarats vom 01. Februar 1995 zum Schutz nationaler Minderheiten (Minderheiten-NamensänderungsgesetzMindNamÄndG) in das Fassung des Gesetzes zur Reform des Personenstandsrechts vom 19. Februar 2007.

597 "Die Schreibweise des Namens ergibt sich aus den Regelungen der Rechtschreibungen. Ein Vorname aus einer fremden Kultur ist mit den entsprechenden Akzenten oder Sonderzeichen zu versehen." http://www.babycenter.de/a9996/namensrecht-welchen-vornamen-darf-ichmeinem-kind-geben, accessed Dec. 9, 2016. 
My great grand father's name was Kocho Filipov, born in 1891. Imagine, the Greek Government changed his name to Kostas Voskopoulos. They changed birth certificates of people who died after 1913. However, during the Ottoman Empire, here there were not a single last name ending in "is" or "os". That means the Greek Government falsified documents for people born prior to 1912, which is outright embarrassing and humiliating for a 'country' to do ${ }^{598}$.

Nevertheless, even though such practices in Greece took place before the Second World War, and despite the fact that under Greek law Macedonians are now free to assume their (or their ancestors') original names, in fact reclaiming the minority names is an arduous task:

Six years ago, four Greek citizens of ethnic Macedonian origin began a Court battle to return their family last names. Despite laws that allow them to return their Macedonian names, they continue to be stuck in Greece's labyrinth of a court system. What should have taken less than two days has turned into six years of legal battle of four Macedonians against official Athens ${ }^{599}$.

Northern Ireland. Name registration in this province of the United Kingdom used to follow the explicitly stated principle that "you can register your child's name in any language providing you use any unicode character" ${ }^{\prime 600}$. This information was displayed on the official government website as late as $2015^{601}$. However, as of Dec. 2016, there is no note about unicode characters any more. A forum with this thread started:

598 "2012 or 1912? Greece continues to force minorities to adopt 'Greek' sounding names." Macedonian International News Agency, Nov. 28, 2012. http://macedoniaonline.eu/content/view/22296/2/, accessed Dec. 5, 2016.

599 Ibid.

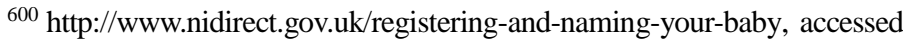
Nov. 18, 2013.

601 http://web.archive.org/web/20151019214055/http://www.nidirect.gov .uk/sm/registering-and-naming-your-baby, accessed Dec. 5, 2016. 
A friend of mine was tempted to see how far he could push that rule.

Could you really name your child U+2603 SNOWMAN or U+1F4A9 PILE OF POO or U+1D5EB MATHEMATICAL SANS-SERIF BOLD CAPITAL $X$ ?

[...] The original link appears no longer to be valid. Were people naming their kid U+1F4A9 PILE OF POO? The current rules do not mention the "any Unicode character" part. ${ }^{602}$

Sweden. The Swedish language uses the ISO basic 26-letter Latin alphabet enlarged by three extra vowels: å ä ö. However, as Frändén (2016: 235) emphasises,

there are [...] limitations to which letters can be handled by the Swedish population registration system. What you can register is the ordinary Swedish alphabet (a b c d e f g h i j k l m n o p q r s t u v w x y z å ä ö) alongside with some special characters, namely à á â ã è é ê ë ì î îi ò ó ô õ ù ú û ü ý æ $\varnothing$ ç ñ and ÿThus, many vowels can be registered, but only two consonants apart from those of the Swedish alphabet. This means that for example the letters ć č š ž $\breve{g} 1$ ş $\nmid$ ś and ź, which are all in use in some of the major immigrant languages in Sweden, cannot be registered.

The above means that some letters used to write the Sami languages used in Sweden are not officially accepted in Sweden.

France. Only the letters of the French alphabet may be used when registering the given name of a newborn baby («L'alphabet utilisé doit être celui qui sert à l'écriture du français. Les caractères alphabétiques étrangers ne sont donc pas autorisés (par exemple le « $\tilde{\mathrm{n}} ») »)^{603}$.

602 https://blogs.msdn.microsoft.com/oldnewthing/20161003-00/?p=9 4435, accessed Dec. 5, 2016.

${ }^{603} \mathrm{https} / / / \mathrm{www}$. service-public.fr/particuliers/vosdroits/F882, accessed Nov. 25, 2016. 
Italy. The Italian language uses only 21 letters, though the remaining five letters of the ISO Latin alphabet (j, k, w, x, y) are acceptable in loanwords and also in personal names of Italian citizens. As the law states, "where possible, also the diacritics characteristic of the alphabet of the language from which a name originated" 604 should be used if a foreign name is given to a child of Italian citizenship.

Slovenia. As a rule, personal and foreign geographical names are registered in their original form. ${ }^{605}$ The Slovenian language uses 22 letters of the ISO Latin alphabet plus č and ž, but the remaining four letters of the ISO Latin set (q, w, x, y) are acceptable in personal and geographical names. Also acceptable are the letters ä, ö, ü, ć, đ (which together with q, w, $\mathrm{x}, \mathrm{y}$ form an additional set of letters found in dictionaries of proper names, books and the press), as well as the following letters with diacritics: á, é, í, ó, ú, à, è, ì, ò, ù, ê, ô, ö, ü. Thus it is possible to record in their original form the names of the Hungarian and Italian minority in Slovenia, as well as preserve without name-change the names of Serbs and Croats ${ }^{606}$.

The USA. Interestingly and paradoxically, while this country is known for its extremely liberal approach to naming (as embodied by the nearly unlimited freedom to choose, modify, "spell creatively" or invent given names, there are restrictions on the use of diacritics in many states:

${ }^{604}$ D.P.R. 3 novembre 2000, n. 396 (1). Regolamento per la revisione e la semplificazione dell'ordinamento dello stato civile, a norma dell'articolo 2, comma 12, della L. 15 maggio 1997, n. 127, http://www.esteri.it/mae/doc/dpr 396_2000.pdf, accessed Dec. 5, 2016.

${ }^{605}$ Cf. http://www.uradni-list.si/1/objava.jsp?urlid=200540\&stevilka =1439, accessed Sept. 8, 2014 .

606 "Ti nabori znakov zagotavljajo možnost originalnega zapisa imen pripadnikov italijanske in madžarske narodnosti ter ne zahtevajo spremembe imena za osebe $\mathrm{z}$ imeni $\mathrm{s}$ področja srbske in hrvaške narodnosti" (http://www.uradni-list.si/files/RS_-2005-040-01439-OB P001-0000.PDF\#! /pdf, accessed Sept. 8, 2014) 
Prohibitions of accent marks and other diacritical marks are common. For example, the California Office of Vital Records provides a handbook to county vital records departments that states birth names can be recorded using only "the 26 alphabetical characters of the English language with appropriate punctuation if necessary." The handbook further specifies that "no pictographs, ideograms, diacritical marks" (including "é," " "ñ," and "ç") are allowed [...] Kansas imposes similar restrictions. In Massachusetts, the "characters have to be on the standard american [sic] keyboard. So dashes and apostrophes are fine, but not accent marks and the such." New Hampshire prohibits all special characters other than an apostrophe or dash (Larson 2011: 169).

\subsubsection{Technical problems in the recording of foreign names}

Despite the impressive advances in technology, sometimes technical problems may unexpectedly emerge despite the best efforts on the part of a state to accommodate the writing system of another state. That this problem might involve not only two different writing systems (such as e.g. Latin vs. Cyrillic, or Greek vs. Latin), but even different diacritics within the realm of the same Latin script, is proved by the following citation, which tells the story of an attempt of a Slovak in the Netherlands to register his daughter, Elisa Bil'ak.

As a descendant of the Slavic settlers of the Danube river basin, I have a surname with an accent: Bil'ak. The name has given me some trouble because of the accent over the L. When I first arrived in the Netherlands, another efficient public servant in his best effort to record my name wrote: Bil' ak. 'Pretty close,' I thought at the time. Charming even, how hard they try. Except that when I receive official mail, their software, programmed to capitalize all proper nouns, addresses it to P. Bil' Ak, which probably makes my neighbors wonder what African tribe I come from $[\ldots]$ 
After what seems like an eternity of searching, they finally find my records. But instead of relief, I feel concern: will Elisa have to go through this every time? I try to take action.

'Look, my name is not right in the database. It is not Bil' ak, it is Bilak.' The gathering of Dutch civil servants gives me a collective perplexed look.

'But that's just what we have, don't you see.' I try to remain calm and polite.

'Well, no it isn't.' I even have a convincing argument. 'Move the cursor one letter at a time. It should be 5 characters: B-i-l'-a$\mathrm{k}$, see, not B-i-l-apostrophe-space-a-k, as it is now.'

'The trouble is,' I say in the voice I use in my typography lectures, 'that instead of the small letter $\mathrm{L}$ with a caron, you used $\mathrm{L}$ and an apostrophe. L-caron is a character used only in the Slovak language, so perhaps your computer doesn't have access to it.'

'No, that's impossible, we recognize all accents - look.' The assembly of clerks shows off, scrolling through a collection of accented characters. I scan through them, dismissing Latvian L with a cedilla, Polish $\mathrm{L}$ with a stroke, Catalan $\mathrm{L}$ with a mid dot, another few L's whose uses I don't know [...]

In the meantime Elisa received her first official letters. Apparently not all official municipality's computers have the same fonts installed, and the L-caron is simply missing. On the recent letter her name was spelled Bi?ak. I guess one cannot beat the system. ${ }^{607}$

\subsubsection{The cases in supranational European courts}

The Court of Justice of the European Union has already dealt with several cases of similar nature to the Lithuanian Runevič-Vardyn case ${ }^{608}$ :

Case C-168/91 - Christos Konstantinidis v Stadt Altensteig, 1993. Mr Konstantinidis, a Greek national residing and married in Germany, at marriage in 1983 had his name

${ }^{607}$ Peter Bilak "In the Name of the Father (or the troubles with Lcaron)". https://www.typotheque.com/articles/lcaron, accessed Dec. 1, 2013.

608 The details of all the cases discussed below can be found on the website EUR-Lex, which is a multilingual platform providing access to the legislation of the European Union (http://eur-lex.europa.eu). 
registered as Konstadinidis. In 1990 he demanded rectification since the requested spelling "indicated as accurately as possible to German speakers the correct pronunciation of his name in Greek and that it was, moreover, the way in which his name was transcribed in Roman characters in his Greek passport." Upon the request, the court in Tübingen made a transliteration of his name as it appeared on his birth certificate, according to ISO Standard 18 as prescribed by the Convention on the Representation of Names and Surnames in Registers of Civil Status (Sept. 13, 1973, Art. 3), which resulted in the form Hréstos Kónstantinidés. In the opinion of Mr Konstantinidis, such a spelling distorts the pronunciation of his name. The court's ruling was in his favour since with his name transliterated "potential clients may confuse him with other persons". Matters of transliteration from Greek into languages using the Latin alphabet were also the subject of a written question E-0558/02 by a Greek MEP Alexandros Alavanos to the European Parliament Commission. In the example he gave, a Greek woman, married to a man named Weber, after transliterating her surname into Greek and then back into German became Vemper ${ }^{609}$.

Case C-148/02 - Carlos Garcia Avello v. Belgium, 2003. Mr Avello, a Spanish national, and Ms I. Weber, a Belgian national, married and live in Belgium. Their two children have dual Belgian and Spanish nationality. Under Belgian law, the children were registered by their father's surname of Avello only. Their parents requested that the children's surname be changed to Garcia Weber, since it is customary for children in Spain to have a surname consisting of the first surname of the father followed by that of the mother. The Court of Justice found Belgian regulations in contravention of the law of the European Union.

Case C-353/06 - Stefan Grunkin and Dorothee Regina Paul, 2008. The applicants were a married couple of German nationality residing in Denmark, where their son Leonhard

${ }^{609}$ Greek $B \varepsilon \mu \pi \varepsilon \rho$. 
Matthias was born in 1998 and given the surname GrunkinPaul, in accordance with the Danish law. However, Germany does not recognise double-barrelled surnames composed of the surnames of both the father and mother, so the German registry office refused to recognise the surname of the boy. The couple, who had both kept their individual surnames at marriage, in the meantime divorced, but refused to choose (as the German Civil Code, BGB, in Section 1617a would have them do) whose surname the child would bear: they wished for their son to have the double-barrelled surname. The court ruling was in favour of the parents: a member state of the European Union cannot refuse to recognise a child's surname, as determined and registered in a second member state.

Apart from the above cases in the European Court of Justice, in 2008 a verdict was given by the European Court of Human Rights in the case Güzel Erdagöz v. Turkey (No. 37483/02). The applicant, whose given name was recorded in registry of births, deaths and marriages as Güzel, has always been known to her family and friends as Gözel, which spelling reflected a regional pronunciation that was not in the dictionary of the Turkish language. The refusal on the part of the authorities to rectify the spelling of her name in the registry was considered by the court as a violation of human rights.

In 2002, in the written question (E-3287/02) to the European Parliament Commission, a Portuguese MEP Carlos Coelho mentioned a complaint of a Portuguese citizen married to a Spanish woman about the change of the order of elements within the surname of their child. The Spanish tradition puts the name of the father before that of the mother, whereas the Portuguese convention is the opposite. In consequence, "such children lose the father's last family name, which is the one transmitted to children in Portugal."

The general situation in the European Union seems to be the incompatibility of the laws of particular member states and the reluctance of the administrations of these states to recognise the superiority of the EU law over national laws. 


\section{Conclusions \\ Personal name policies - a summary}

My objective has been a detailed discussion of the validity of a postulated discipline of personal name policy. This discipline, it has been argued, is largely a subfield of LP by virtue of the fact that personal names constitute an inherent part of language, even though some regulations lie outside this realm. The illustrative material drawn from various cultures and various periods of history enables cross-cultural comparisons and justifies inferences that there are certain similarities in the agents, targets, objectives, implied assumptions, methods and effects of personal name policies, despite their different spatio-temporal setting. Still, the abundance of ways to control personal naming makes their categorisation only along the lines suggested by Cooper 1989 insufficient. For this very reason, a more detailed division of these policies, according to objects of name policies, into those related to given names, those related to surnames, and those connected with name changes (of given names and/or surnames) proved fruitful. Within each of these categories, corresponding here to separate chapters, further subdivisions of policies were made mostly according to their method. Next, a separate chapter was devoted to de jure policies only. Finally, the case study showed how a detailed analysis of a personal name policy might be performed in practice.

It has been shown that personal names can indeed be independent objects of study regarding the policies that relate to them. Practically every state, many agents that have some sort of power below state level, and even certain supra-state level agents (such as international organisations) develop policies with personal names as objects. Even in those states that profess complete liberty in personal naming, the resulting void may be partly occupied by agents of de facto policies such as employers, religious organisations and other bodies. Identity issues, as embodied and symbolised by personal names, are simply too important not to be interfered with. 


\section{The types and the directionality of name policies}

In the preceding chapters name policies were analysed from various angles (e.g. de jure vs. de facto policies) and according to their various parameters (such as the agents, the targets, the effects of name policies, the motivation, etc.). However, it is also possible to explore them from a more global perspective.

First of all, one should not overlook the relation of name policies to the cultural tradition of a nation or an ethnic group. Quite frequently the policies merely reflect the dominant trends in that respect. As long as there is relative consensus as to the acceptance of such trends, the policies that are the embodiment of these trends remain uncontroversial and uncontested. As Kaplan and Bernays put it, referring to the conventional practice of taking a husband's name at marriage, "what has always been done is what's generally deemed the correct thing, whether or not it defies reason" (1999: 139). As a case in point one might take the official Spanish surnaming convention, which combines the name of one's father with that of one's mother, both linked by the conjunction "y", and which is a reflection of the generally accepted usage. Perhaps in some situations the two, the policy and the prevailing custom, might be intertwined and feeding each other to the extent where it is not easy to establish which is the cause and which is the result. Such invisible, uncontested conventions have been referred to in the previous sections, invoking the concept of doxa.

It is different, however, when a policy goes against the grain. It might be that the policymakers wish to innovate (such actions often go by the name of modernisation), getting rid of the old ways which the population at large is still attached to. A case in point could be the imposition of obligatory surnames in societies in which these were hitherto unknown: the Ashkenazi Jews in the $18^{\text {th }}-19^{\text {th }}$ century Central Europe, or Filipinos under Spanish rule in the middle of the $19^{\text {th }}$ century. 
Conversely, old ways might be revived. Instances of these 'revival' policies are numerous too. For instance, in pre-war Poland traditional feminine forms of nominal-type surnames, indicative of a woman's marital status, were imposed on the citizens of a newly-emerged state, even though in large portions of the previously partitioned country they had by then largely disappeared. It would seem that the same applies to Latvia, where, reportedly, "the use [in surnames] of the feminine ending was not universal in the interwar years" 10 .

Second, some policies (such as encouraged or enforced name changes on a mass scale) might be systematic, allencompassing, well-planned and comprehensive, while others (such as prohibitions applying to individual names only, or individual changes of some - but not all - names at school) might seem random, discreet and idiosyncratic. Needless to say, the latter type is far more difficult to integrate satisfactorily into a general model, should one wish to construct it - and should this at all be possible. Since such policies often appear a chance side effect of a whim, they are by definition highly irregular. Moreover, the opposition between the two types (viz. systematic vs. individual) is not clear-cut either, since there could be intermediate stages (e.g. prohibitions could apply to particular groups of names).

Further, certain policies might be logically consistent, while others could be internally contradictory and could send conflicting signals to those affected. In Poland, for example, for several years after 1945 the only officially acceptable form of adjective-type surnames for women (other than those ending with $-s k i$ or $-c k i /-d z k i)$ was the masculine one, e.g. Wanda Bury (cf. Szober 1958: 310). Since 1957, by force of a circular of the Ministry of Interior of April 8, the only officially acceptable version became the - $a$-ending one (cf. Litwin 1961: 73, Doroszewski 1968: 501-2), and since the 1980 s both forms have been admitted as correct.

610 Dace Prauliņš \& Christopher Moseley 2010. Colloquial Latvian: The Complete Course for Beginners. London \& New York: Routledge, p. 2. 
Somehow similar to the above consistent - inconsistent dichotomy is another one: that of regularising policies vis-avis policies that foster exceptions. For example, numerous nation states promote or downright insist on name assimilation to the national language standard (regularisation). In a similar fashion some states apply the same regulations to all surnames without exceptions (so that e.g. any existing surname can be chosen by a person changing their surname), while other states protect historical surnames of limited circulation against nonrelated outsiders (thus fostering exceptions).

Last but not least, many policies are merely a section of a larger policy. Thus Lithuania's policy of Lithuanising the names of the Polish national minority constitutes only one aspect of the overall policy of Lithuanisation, which is also applied to other minorities (mainly the Russian minority, which is in size comparable to the Polish one) and manifested - with regard to Poles or to other nationalities - also in the obligatory presence of the national language in official usage, in the practical non-existence of bilingual place-name topographical indications, in the choice of the language of instruction in schools, in the effectively discouraged use of Polish or other languages which are not the state language (Lithuanian) in the workplace and in various official institutions.

So far the effects of name policies have been considered with respect to individual cases set in specific historical contexts. It would be interesting to attempt to answer the following question: is it possible to find in the diverse policies discussed here any common underlying patterns?

Given that names constitute a subset of a language's overall vocabulary, it can be observed that two contradictory forces act here. On the one hand, there is the tendency to expand this subset by adding new elements to the onomasticon - frequently at the expense of the distinctiveness of each element. To exemplify this, it might be emphasised that alongside the given name Catherine, in English there are also independent 
names, such as the following: Kate, Cathryn, Katheryn, Katharyn, Katherin, Catharine and many more, with the list ever-expanding due to borrowings from other languages (e.g. Karen from Danish, Kathleen from Irish). It is no coincidence that all these given name forms are so similar to one another and therefore easily confusable with one another. On the other hand, there exists the opposite tendency to reduce the number of elements (here: names) with the concomitant effect that the cognitive distance between such elements increases. By way of exemplification, one might invoke again the above mentioned $18^{\text {th }}$-century Croatia with its system of merely 40 masculine and 20 feminine given names (cf. Šimunovič 2002: 373).

It would seem that relatively numerous name policies appear to favour the second of the above two tendencies, i.e. a limit on the number of elements within the name system (e.g. via a list of allowed names), with the simultaneous preservation of the distinctiveness (and therefore higher predictability, or lower entropy, to employ the terminology of information theory) of these elements. For instance, language-regulating bodies appear unwilling to allow new names (be they invented ex nihilo, created by modifying the already existing names, or borrowed from other languages), or to admit diminutives in the function of independent names. These language regulators seem equally prone to standardise - in terms of morphology and orthography - given names by the exclusion of rivalling variants, with the same end effect.

Also instances of assimilative policies could be perceived as examples of the attempted reduction of diversity with the concomitant increase in the distinctiveness of the elements of the system. To put it simply. where foreign / minority names are not allowed, or where (as once used to be the case in Iceland) naturalised foreigners are forced to renounce their own names and assume those characteristic of the host country, the number of available variants is lowered, and at the same time each of the allowed names is more readily recognised as a name. 
Another frequently encountered aspect of various name policies is the tendency to let names reveal the maximum information on their bearers, which is, again, in line with the overall prevailing trend towards lower entropy. Thus, wherever possible (considering the background culture/tradition), policymakers frequently insist on separate feminine forms of surnames, and, what is more - sometimes also on feminine forms that allow identification of its bearer's marital status (as today in Lithuania, or in the years 1918-1939 in Poland) ${ }^{611}$. Possessing a large number of given names is obviously impractical and therefore usually forbidden or at least discouraged by state authorities, yet two given names instead of merely one allow for more precise identification and therefore are encouraged, if not expected (as for instance the "default" middle name in the USA). For this reason, the situation where only one given name is allowed is practically not encountered. It is in the interest of the policymakers who want to have "a legible people" to optimise the number of given names: not too many, but not too few either.

The above findings - which, it must be stressed, are merely the observed tendencies and not universally valid facts - harmonise well with the following observations by Osgood:

At all levels of units in a language, the competing alternatives will be organized hierarchically in terms of frequency of occurrence and with a relatively low-entropy distribution approximating the Zipf function. Greenberg's data on the relative frequencies of sentence types, on the relative frequencies of suffixing vs. prefixing vs. infixing, and so forth, based on a sample of 30 languages provide the beginnings for such an analysis at the syntactical level. Saporta's present data on the relative frequencies of alternative morpheme lengths in Spanish and his previous data on the relative frequencies of consonantal clusters in English provide suggestive beginnings at the phonological level. In some research of my own on the cross-

${ }^{611}$ Naturally, such policies might also be interpreted as maintaining the status quo. 
linguistic and cross-cultural generality of meaning systems (to which I will return later), we have found rather remarkable stability of the slope of the frequency-diversity functions for qualifiers elicited by standard associational procedures in some nine language/ culture communities. All of these "universals" suggest that when the human organism must choose repeatedly among a set of alternatives, it tends to choose a few alternatives with very high frequencies and many alternatives only rarely. And this pervasive law is not restricted to humans, either; rats tested in a "checkerboard" maze where all alternative routes are equally long and equally rewarded display the same lopsided distributions of preference. Living organisms seem to be antientropic in nature (1963: 240-241, emphasis added).

To sum up, it may be assumed that name policies could be classified, in a somewhat structuralist spirit, within the framework of the following binary systems as presented below $^{612}$.

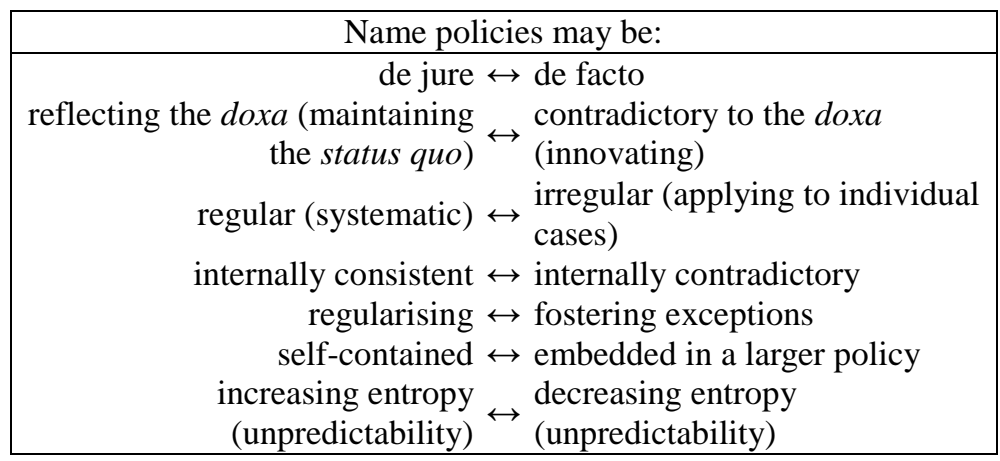

Besides the above divisions, a potential third factor comes into play: that of chance. In my opinion, this factor is not to be underestimated - on the contrary, it would be naïve not to

${ }^{612}$ Each line in the table represents the division along one dimension only, independently of other dimension. To put it differently, a policy may be at the same time e.g. de jure, innovating, self-contained and fostering exceptions (such was in fact the "Ignacy policy" in Poland, described earlier in this work). 
realise to what extent it is operative. In what follows, by chance shall be understood random decisions on the part of decision-makers that are based solely on idiosyncratic factors and not on any rational premises or on any analysis of the reality. As Chalmers put it:

Individual policy makers and practitioners are often certain about things that are a matter of opinion. But surveys of practice reveal that these individual certainties are often manifested in a very wide range of practices, not infrequently providing indirect evidence of mutually incompatible opinions. This evidence of collective uncertainty about the effects of policies and practices should prompt professionals and the public to find out which opinions are likely to be correct. A lack of empirical evidence supporting opinions does not mean that all the opinions are wrong or that, for the time being, policy and practice should not be based on people's best guesses. On matters of public importance, however, it should prompt efforts to obtain relevant evidence through evaluative research to help adjudicate among conflicting opinions (2003: 24).

In practical terms the above would mean that not all the decisions made by those in authority are logical or sensible by the sole virtue of the fact that they are official; to blindly assume otherwise equals holding to the fallacy of authority. As in other spheres of human activity, also in the sphere of name policies the decision-makers perceived as authorities may be driven by ignorance, whim, vested interest and other factors that have little to do with rational decision-making. As a case in point one might consider the name policy pursued in interwar Poland that effectively promoted the name Ignacy among newborn boys. As noted above in the present work, this name policy was an element of a more comprehensive social policy whose aim was promoting large families. It stands to reason that the impact of this policy on such families would have been as high without the element of naming: the financial incentives sufficed. Moreover, there seems no particular reason on the part of the Polish authorities to promote, of all 
the names, the name Ignacy, which was not symbolic in any historical or patriotic sense. No famous or symbolic personage in the history of Poland - other than the initiator of the policy himself, Ignacy Mościcki, Polish president at the time - ever bore that name. The only motivation then appears to have been the president's vanity.

There may be one more reason - apart from the influence of the doxa or the fallacy of authority - why people have a propensity to interpret random, directionless and chaotic activities on the part of those in authority as logical, consistent and sensible policies. In 2008 Shermer introduced the explanatorily fruitful concept of patternicity, which he defined as the human tendency to find meaningful patterns in meaningless noise. "Traditionally," Shermer points out, "scientists have treated patternicity as an error in cognition. A type I error, or a false positive, is believing something is real when it is not (finding a nonexistent pattern)" ${ }^{\text {"613. }}$. While there exists the opposite phenomenon - type II error, which equals not recognising an actually existing pattern - Shermer argues that type I is far more frequent in human thinking.

\section{Perspectives for the future}

Finally, the question remains to be discussed, which trends detectable in the diverse policies described here seem more universal - encompassing at least the states of Europe. In other words, can predictions of any generality be made for the future?

One of the decidedly universal palpable trends is that of continually expanding the lists of acceptable given names, wherever such official or semi-official lists exist. This might be due to the pressure exerted on respective local onomasticons by

${ }^{613}$ Michael Shermer 2008. "Patternicity: Finding Meaningful Patterns in Meaningless Noise." Scientific American, December. Online version of Nov. 25, 2008 at: http://www.scientificamerican.com/article.cfm?id= patternicity-finding-meaningful-patterns, accessed Dec. 10, 2016. 
those affected by policies. The decision-makers increasingly realise that in the age of globalisation it is difficult to control the choice of given names. Governments of states that previously kept loans and new coinages at bay are slowly yielding to powerful pressures both from within and from the outside. New names are admitted even in the most conservative of states. In most cases the name lists used for consultation by registries are continually expanded to accommodate new items ${ }^{614}$.

Restrictive surname policies are also being gradually relaxed. Iceland, with its now abandoned policy of domesticating the names of naturalised immigrants; the Czech republic that does not insist any more on all its women to add the feminine suffix to their surnames; or France, not as restrictive with regard to minority surnames as earlier, might serve as examples. Also technological progress, namely the use of computers in civil registration, contributes to the changes: barriers fall where there can be no more excuse that the use of a foreign / minority script is not possible for technical reasons.

On the other hand, certain trends that underscore the local, the regional, the native, the traditional (as opposed to the global, the international, and the novel) are visible as well. A case in point may be the more recent policies in Nordic countries, most of which readmitted in some form the onceabandoned and seemingly obsolete use of patronymics instead of inheritable family names. Since this policy provides an option without creating any obligation, only time will show how influential it will prove. Where there is no disciplinary coercion, a lot will naturally depend on how fashionable patronymics will be, how (and whether at all) they will be marketed, as well as to what extent citizens will be prone to

${ }^{614}$ A striking example comes from Denmark, where a new, more lenient 2006 name law led in the years 2006-2016 to the increase from 10,660 to over 33,000 names in use in that country. Christian W. "Huge spike in new names in Denmark". CPH Post Online, April 1, 2016. http://cphpost.dk/news/huge-spike-in-new-names-in-denmark.html, accessed Dec. 10, 2016. 
identify with their country's heritage and how willing they will be to manifest this identification through the use of patronymics.

The use of modern technology enriches name policies with a new, hitherto unheard-of dimension. Citing Algeo (1973: 6), I have already mentioned earlier in this book a computerised method of coining novel surnames in Sweden to increase their diversity and reduce the percentage of frozen patronymics in the function of surnames. As Willson noted,

Svensk namnbok 1964 takes the initiative of the 1921 version one step further. It actually provides a list of computergenerated Swedish surnames. The committee found that that the 80,000 compound names which were in use in Sweden in the early 1950s represented combinations of some 11,500 different first elements (förleder), but only 1,400 second elements or bases (slutleder). For generation of new names, the committee made use of ca. 200 of these bases, combining them mechanically with new prefixes. Some of these prefixes are themselves computer-generated, letter combinations filtered through rules which define phonotactic restrictions on Swedish words $[\ldots]$ The fact that many [...] elements are synchronically perceived as meaningless by many speakers is used to justify the creation of name elements that have no meaningful etymology [...] The combinatorical view of Swedish surnames has in recent years led to the approval of some names that do not appear traditional (2012:316-317).

In the promotion of trends in personal naming, not to be underestimated is the influence of well-known people, such as actors or sportspeople. Given the global-scale propagation of their naming choices by the media, celebrity names of today might become the trend-setters of tomorrow. By way of illustration, the so-called "name meshing" could be invoked. This term denotes the phenomenon which consists in fusing the surnames of newlyweds to obtain a novel surname to be borne by both spouses (sometimes, especially in the early days of this fad, the spouses retained their surnames, but created 
a 'meshed' surname for their offspring). For instance, Mr Pugh and Miss Griffin become after marriage Mr and Mrs Puffin. Name meshing was present in the USA on a very small scale as early as 1970 s, but became more popular only in the middle of the first decade of the 21st century, and was certainly reinforced in the 21 st century by the impact of such nicknames created by the media as Brangelina (Brad Pitt and Angelina Jolie) or Bennifer (Ben Affleck and Jennifer Lopez). As revealed in 2012, approximately 800 British newlyweds meshed their surnames in the first ten months of that year - as opposed to merely a handful in 2008 - which has meant that the UK Deed Poll Service have had to create a separate system to cope with the demand ${ }^{615}$. Further instances of 'meshed' surnames include:

- Westhafer \& Moore $=$ Westmoore (USA 1975)

- Weintraub \& Myrick = Weinrick (USA 1978)

- $\quad$ Silverman \& Flaherty = Flaherman (USA 1992)

- $\quad$ Porter \& O'Dowd = O'Porter (UK 2012)

- Chapman \& Werner-Allen = Challen (USA 2009)

- $\quad$ Hunt \& Palmer = Huntpalmer (USA 2010)

It is only natural that bottom-to-top pressure exerted on the policymakers ${ }^{616}$ may lead to certain relaxation of stringent laws. While such pressure provides some feedback on what is

${ }^{615}$ Anna Berrill "Keeping up with the Smones: 'Meshing' becomes the new wedding trend as more married couples are fusing surnames". Mail Online, Nov. 9, 2012. http://www.dailymail.co.uk/femail/article-2230419 /Meshing-new-wedding-trend-newlyweds-fuse-surnames.html\#ixzz2mFAz Eg91, accessed Dec. 1, 2013. Ben Zimmer "Keeping Up With the Smoneses: Are American newlyweds blending their last names?" Slate, Aug. 16, 2006. http://www.slate.com/articles/life/the_good_word/2006/08/keeping_up_with _the_smoneses.single.html, accessed Dec. 1, 2013.

${ }^{616}$ Remarkably, naming issues release strong emotions, as evidenced by the case of a Norwegian mother, Kristi Larsen, who was so desperate to name her son Gesher ('bridge' in Hebrew) that she spent some time in prison (Ashley Coates 2013. "Names banned around the world." The Telegraph, Aug. 12. http://www.telegraph.co.uk/news/newstopics/howaboutthat/10237 682/Names-banned-around-the-world.html, accessed Dec. 3, 2013). 
expected of lawmakers and other policy agents by the population at large, there also exists another type of feedback which merits a mention, namely the feedback provided by descriptive name dictionaries.

There are generally two kinds of name dictionaries: prescriptive ones and descriptive ones. The former are certainly more frequently met and they are also more useful to the layperson, to whom they offer onomastic information on the name's form, correctness, origin, etymology, etc. The latter register, usually synchronically ${ }^{617}$, all instances of the actual naming, regardless of its linguistic correctness or compatibility with respective laws. Let us consider an example from Poland. The data reflecting the naming habits of Poles, revealed to a wider audience as a result of the publication of such a dictionary in Poland (Rymut 1995), must have come as a surprise since the number of the various name forms and variants was about nineteen thousand ${ }^{618}$ (the number of given names in an average prescriptive name dictionary seldom exceeds one thousand). Evidently a descriptive dictionary, albeit not as valuable for prospective parents, might nevertheless be indispensable (if taken heed of) to policymakers since it reflects the actual rather than recommended name practices - thus testing the effectiveness of name policies, i.e. the degree to which these policies are actually observed.

On the basis of the analysed material, three major trends for the future can reasonably be outlined, as symbolically represented by the words diversity, identity, majority/minority:

${ }^{617}$ This requirement is not always followed. For example the biggest Lithuanian surname dictionary (Lietuviu pavardžiu žodynas, ed. by Aleksandras Vanagas, Vitalija Maciejauskienè and Marija Razmukaite, 1985) gathers data from a wide time bracket, so that already at the moment of its publication some surnames were long extinct (had no living bearers).

618 The information on how many names and their variants are contained in the dictionary in question is missing from the dictionary. However, in a review of the dictionary this number is given on the basis of the reviewer's interview with the author (cf. Włodzimierz Jurasz 1995. "Judasz mieszka we Wrocławskiem." Czas Krakowski 99, April 28, p. 10). 
1) diversity - a tendency towards the relaxation of the already existing rules, which fact in itself may promote embracing difference;

2) identity - rediscovering and reevaluating the tradition - on a voluntary basis, so that traditional naming patterns may exist alongside modern naming (incidentally, resulting in increase in diversity);

3) majority/minority - globalising trends, manifested on the one hand in the predominance of the Western cultural models (at the expense of indigenous naming), on the other - in the increasing pressure to reconcile the naming patterns of the migrants with those of the host countries. 


\section{Appendix 1: Lithuanised given names}

\section{Masculine names}

Polish

name

\begin{tabular}{l|l} 
Andrzej & Andžej, Andžejus, Andrej \\
Antoni & Antonij \\
Artur & Artūr \\
Bolesław & Boleslav \\
Czesław & Česlav \\
Dariusz & Dariuš, Darjuš, Darjusz \\
Edgar & Edgar(as) \\
Edward & Edvard, Edvardas, Edwardas \\
Franciszek & František, Francišek \\
Grzegorz & Gžegož ${ }^{619}$ \\
Henryk & Henrik \\
Jan & Jan, Janas \\
Janusz & Januš \\
Jarosław & Jaroslav, Jaroslavas \\
Jerzy & Jerzy, Ježy, Jurijus \\
Jędrzej & Jendžej \\
Józef & Juzef, Josifas \\
Kazimierz & Kazimir, Kazmierz, Kazimiras \\
Krzysztof & Kšyštof \\
Leszek & Lešek \\
Lukasz & Lukaš \\
Marian & Marijanas, Marjanas, Marian \\
Mariusz & Mariuš \\
Mieczysław & Mečislav \\
Mirosław & Miroslav, Miroslavas \\
Patryk & Patrik \\
Paweł & Pavel, Pavelas \\
Piotr & Piotras \\
Rafał & Rafael, Rafal \\
Rajmund & Raimund, Raimondas \\
Roman & Romanas \\
Ryszard & Rišard, Ryšard, Rišardas \\
Sławomir & Slavomir \\
Stanisław & Stanislav(as) \\
Sylwester & Silvestr \\
Tadeusz & Tadeuš, Tadeušas \\
Tomasz & Tomaš, Tomašas \\
Waldemar & Valdemar, Valdemaras, Waldemaras \\
Wiktor & Viktor \\
& \\
\hline
\end{tabular}

Standard Lithuanian version, if different from the Lithuanised form

Andrius

Antanas

Artūras

Boleslovas

Česlovas, Česys, Česius

Darijus, Darius

Edgaras

Eduardas, Edvardas

Pranciškus (Pranas)

Grigalius, Grigas

Henrikas, Enrikas, Henris

Jonas

$--$

Jurgis

$---$

Juozapas, Juozas

Kazimieras, Kazys

Krystupas (Kristapas)

---

Lukas

---

Marijus, Marijonas

Mečislovas

$---$

Patrikas, Patrys, Patris

Paūlius, Povilas

Petras

Rapolas

Raimondas, Raimundas

$--$

Rikardas

---

Stanislovas, Stasys

Silvestras

Tadas

Tomas

Valdemaras, Voldemaras, Valdas

Viktoras

${ }^{619}$ This name is sometimes also rendered in Lithuanian as Gžegošas, though that form did not appear in the excerpted material. 
Polish

name

Lithuanised version
Standard Lithuanian version, if different from the Lithuanised form

Vytautas

Vladislovas, Vladas, Vladys

$--$

$--$

$--$

$--$

Zenonas, Zenys, Zenis, Zenius

Zigmantas, Zigmas, Sigis(z)mundas

Feminine names

Polish version Lithuanised version

Original Lithuanian version, if it exists

Agnieszka Agneška, Agnieška, Agnesa, Agnija Agné, Agneté

Alicja

Anna Alicija

Ana

Andżelika

Bożena

Anželika

Božena

Czesława

Česlava

Edyta

Edita

Elvyra

Elžbieta

Elżbieta

Ema

Emma

Emilija

Eva

Ewa

Evelina

Ivona

Iwona

Jadwiga

Jadvyga

Alicija, Alisa

Ona

Angelè

Joanna

Joana

Julia

Julija

Julijana

Juliana

Justyna, Justina

Katažyna

Katarzyna

Kazimiera

Kazimira

Krystyna

Łucja

Kristina

Małgorzata

Lucija

Margarita

---

Edita

Elvyra

Elzbieta, Elžbieta

Ema

Emilija, Emilijona

Evelina

Ivona

Jadvyga

Joana

Julija

Julijona

Justina

Kotryna

Kazimiera

Kristina

Liucija, Lucija

Marija

Margarita

Marija

Mariola

Mariolia, Marijolia 
Polish version

Lithuanised version

\begin{tabular}{l|l} 
Marzena & Mažena \\
Natalia & Natalija, Natalja \\
Patrycja & Patricija \\
Stanisława & Stanislava \\
Sylwia & Silvija \\
& Tatjana \\
Tatiana & Tereza \\
Teresa & Uršulia \\
Urszula & Vaclava \\
Wacława & Vanda \\
Wanda & Viktorija \\
Wiktoria & Vladislava \\
Władysława & Zofija \\
Zofia & Zuzana \\
Zuzanna &
\end{tabular}

Original Lithuanian version, if it exists

Natalija

Patricija

Silvija, Silverija, Silva

Teresè

Uršulè

Vaclova

Vanda

Viktorija

Zofija

Zuzana 


\section{Appendix 2: Contemporary Lithuanised surnames}

The surnames have been excerpted from the following Internet sources, accessed in November 2016:

1. The School Council of Szkoła Średnia im. Szymona Konarskiego in Vilnius (Vilniaus Simono Konarskio vidurinė mokykla), http://www.konarskio.vilnius.lm.lt

2. Lists of student names in the Anna Krepsztul High School in Butrymańce (Butrimonių Anos Krepštul vidurinė mokykla), http://www.butrimonys.salcininkai.lm.lt

3. List of teachers' names in Szkoła Średnia im. św. Urszuli Ledóchowskiej w Czarnym Borze, http://www.leduchovskos .vilniausr.lm.lt

4. Szkoła Średnia w Zujunach (Vilniaus r. Zujūnų vidurinė mokykla) (http://www.zujunai.vilniausr.lm.lt) - teachers

5. Szkoła-Przedszkole 'Wilia' (Vilniaus darželis-mokykla "Vilija") (www.dmvilija.lt) - teachers

6. Lists of party members and candidates of Akcja Wyborcza Polaków na Litwie (the Electoral Action of Poles in Lithuania) for municipality and national elections, http://www.awpl.lt

If two different Lithuanised versions of Polish surnames are given, this means that at least two bearers of the Polish surname in question have been identified, each of whom had a differently Lithuanised surname. Inconsistencies (such as the existence of a Russian suffix in the Polish-language version but its lack in the Lithuanian-language one, or vice versa) have been left intact so as to illustrate the actual practice.

\begin{tabular}{|c|c|c|c|}
\hline The Polish version & $\begin{array}{c}\text { The Lithuanian } \\
\text { version }\end{array}$ & The Polish version & $\begin{array}{c}\text { The Lithuanian } \\
\text { version }\end{array}$ \\
\hline Abłom & Ablom & Andruszkiewicz & Andrušk(i)evič, \\
\hline Adamajtis & Adomajtis & & Andruškievič \\
\hline Adamowicz & Adamovič & Andrzejewski & Andžejevski \\
\hline Aleksandrowicz & Aleksandrovič & Anichowska & Anichovskaja \\
\hline Andruszaniec & Andrušanec & Astaszka & Astaška \\
\hline
\end{tabular}


The Polish version

Aszkielaniec

Ażelonis

Balcewicz

Bandalewicz

Baniukiewicz

Baranowska

Barkowska

Bartosewicz

Bartoszewicz

Bielan

Bielasz

Bierzańska

Blażewicz

Błaszkiewicz

Bogdanowicz

Bogdziewicz

Bordowska

Borkowski

Borowik

Bortkiewicz

Brzozowska

Bujnicki

Butrimowicz

Czerniawska

Czerniawskaja

Czernel

Czyszewicz

Dajlidko

Daszkiewicz

Dienowagis

Dierżyńska

Dobronravova

Dowal

Dudojć

Durowicz

Dziemieszko

Dzikewicz

Dzisiewicz

Filipowicz

Filistowicz

Franckewicz

Fursowa

Gajewski

Gierasimowicz

Giwielusz

Gołowacka

Gołubowska

Gornatkiewicz

Grigorowicz

Grodź

Grużewskaja

Gryniewicz

Grynkiewicz

Grzybowski
The Lithuanian version

Aškelianec

Aželionis

Balcevič

Bandalevič

Baniukevič

Baranovskaja

Barkovskaja

Bartosevič

Bartoševič

Belianas

Beliaš

Bieržanska

Blaževič

Blaškievic

Bogdanovič

Bogdevič

Bordovska

Borkovski

Borovik

Bortkevič

Bržozovskaja

Buinickas

Butrimovič

Černiavska

Černiavskaja

Černel

Čišèvič

Dailidko

Daškevič

Dienovagis

Deržinskaja

Dobronravova

Doval

Dudoit

Durovič

Demeško

Dzikevič

Dzisievič

Filipovič

Filistovič

Franckevič

Fursova

Gajevski

Gerasimovič

Giveliuš

Golovacka

Golubovska

Gornatkevič

Grigorovič

Grodz

Gruževskaja

Grinevič

Grinkevič

Gžybovski
The Polish version

The Lithuanian

version

Gudacz

Gudalewicz

Gulbinowicz

Ignatowicz

Ingielewicz

Jaglińska

Jakubcewicz

Jankiełajć

Jankowska,

Jankowski

Jarmołowicz

Jarosz

Jasielonis

Jasińska

Jasiulewicz

Jedziński, Jedzińska

Joczys

Juchniewicz

Jusiel, Jusel

Kaliużnaja

Kamiński

Kaniuszienienie

Karankiewicz

Karaźniewicz

Karpicz

Karpowicz

Kasperowicz

Kaszkiewicz

Kirkiewicz

Klimaszewski

Klimaszewska

Klimowicz

Koczan

Kodź

Kołoszewska

Kondracka

Kondratowicz

Korzeniewska

Koszewska

Kotłowska

Kotwicka

Kowalczuk

Kowalewska

Kozakiewicz

Krajewska

Kratkowska

Krawczonok

Krecuł

Krepsztul

Krzyrzewska

Ksiendzowa

Ksienzowa

Kułakowska

Kupcewicz
Gudač

Gudalevič

Gulbinovič

Ignatovič

Ingelevič

Jaglinska

Jakubcevič

Jankelait

Jankovska,

Jankovski(j)

Jarmolovič

Jaroš

Jaselionis

Jasinskaja

Jasiulevič

Jedinskij, Jedinskaja

Jočys

Juchnevič

Jusel

Kaliužnaja

Kaminski

Kaniušènienè

Karankevič

Karaznevič

Karpič

Karpovič

Kasperovič

Kaškevič

Kirkevič

Klimaševski

Klimaševska

Klimovič

Kočan

Kodz

Kološevska

Kondrackaja

Kondratovič

Koženevska

Koševska

Kotlovska

Kotvicka

Kovalčuk

Kovalevska(ja)

Krajevska

Kravčionok

Krecul

Krepštul

Kržiževska

Ksenzova

Ksenzova

Kulakovska

Kupcevč
Kozakevič

Kratkovska 
The Polish version

Kuźmicki

Kwiatkowski

Leonowicz

Leszczewski

Leszczynskij

Leszczyński

Liachowiczienie

Liachowiczius

Lisowska

Liszilenko

Litwinowicz

Lubin

Ludkowski

Luksza

Ładziato

Łapcun

Łastowska

Lawcel

Ławrynowicz

Łowczyk

Łuksza

Łukaszewicz

Maciejewski

Macinkiewicz

Macioł

Mackiewicz

Majewska

Makowska

Malinowskaja

Malkowska

Marcinkiewicz

Markiewicz

Markowska

Matusewicz

Michalkiawicziene

Michałkiewicz

Mikelewicz

Milewska

Miłosz

Miluszkiewicz

Mincewicz

Miroszniczenko

Monkiewicz

Możejko

Muchlajewa

Muszkiet

Narbutienie

Narkiewicz

Naruniec

Niedźwiecki
The Lithuanian version

Kuzmickas

Kviatkovski,

Kvetkovskij

Leonovič

Leščevski

Leščinski

Leščinskij

Liachovičienè

Liachovičius

Lisovska

Lišilenko

Litvinovič

Lubin, Liubin

Liudkovski,

Ludkovski

Lukša

Ladziato

Lapcun

Lastovska

Lavcel

Lavrinovič,

Lavrynovič

Lovčik

Lukša

Lukaševič

Maciejevski

Macinkevič

Maciol

Mackevič

Majevska

Makovska

Malinovskaja

Malkovska

Marcynkevič,

Marcinkevič

Markevič

Markovskaja

Matusevič

Michalkevičienė

Michalkevič

Mikelevič

Milevska

Miloš

Miliuškevič

Mincevič

Mirošničenko

Monkevič

Možeiko

Muchlajeva

Mušket

Narbutienè

Narkevič

Narunec

Nedveckis
The Polish version

The Lithuanian version

Niemiec Nemec

Niewierowicz Neverovič

Nowicka, Nowickaja Novicka, Novickaja

Obłoczyński Obločinski

Olenkovicz,

Olenkowicz Olenkovič

Oleszkiewicz Oleškevič

Olszewski Olševski

Osińska Osinska

Osipowicz-Bezuszko Osipovič-Bezuško

Ozarowskaja Ozarovskaja

Palewicz Palevič

Palul

Paszkowska

Pawliukowicz

Pawłowski

Piechockaja

Piechockij

Pieszko

Pieślak

Pietuchowa

Piórko

Poczobut

Poszew(i)eckaja

Prokopowicz

Prowłockaja

Pszczołowska

Pucz

Puncewicz

Raczyńska

Radulewicz

Ragielewicz

Rekść

Rimsza

Rodziewicz

Rogożinskaja

Romankiewicz

Romanowska,

Romanowski

Rożanowskij

Rudzis

Ruskań

Sakowicz

Salkewicz

Sawiel

Siemaszka

Sienkiewicz

Sinkiewicz

Siwicka

Skakowska

Skakunova

Sokolińska

Sokołowskaja

Stankiewicz
Paliul

Paškovska

Pavliukovič

Pavlovskis

Pechockaja

Pechockij

Peško

Pesliak

Petuchova

Piurko

Počobut

Poševeckaja

Prokopovič

Provlockaja

Pščolovska

Puč

Puncevič

Račinska

Radulevič

Ragelevič

Rekst

Rimša

Rodz(i)evič

Rogožinskaja

Romankevič

Romanovska,

Romanovskij

Rožanovskij

Rudis, Rudzis

Ruskan

Sakovič

Salkevič

Savel

Semaška

Senkevič, Sinkevič

Sinkevič, Senkevič

Sivicka

Skakovska

Skakunova

Sokolinskaja

Sokolovskaja

Stankevič 
The Polish version

\begin{tabular}{ll} 
Steckiewicz & Steckevič \\
Stefanowicz & Stefanovič \\
Suckiel & Suckel \\
Symonowicz & Symonovič \\
Szablinskaja & Šablinskaja \\
Szaranda & Šaranda \\
Szarejus & Šarejus \\
Szejbak & Šeibak \\
Szejnicka & Šeinickaja \\
Szełkowski & Šelkovski \\
Szileikienie & Šileikienė \\
Szot & Šot \\
Szpakauskas & Špakauskas \\
Szpilewskaja & Špilevskaja \\
Sztura & Štura \\
Szumska & Šumska \\
Szyłka & Šilka \\
Szyłobryt & Šilobrit \\
Szyszko & Šiško, Šyško \\
Taraszkiewicz & Taraškevič \\
Teliczan & Teličan \\
Tkaczenko & Tkačenko \\
Tomaszewicz & Tomaševič \\
Tomaszewski & Tomaševski \\
Treszczyński & Treščinski \\
Trifonowienie & Trifonovienė \\
Trusewicz & Trusevič \\
Trybocka & Tribocka \\
Trzeciak & Tšetiak \\
Tuczkowski & Tučkovski \\
Tuczynskij & Tučinskij \\
Tyszkiewicz & Tyškevič \\
Uczkuronis & Učkuronis \\
Urbanowicz & Urbanovič \\
Walenie & Valienė \\
& \\
\hline &
\end{tabular}

The Polish version

Wasilewski

Waszkowicz

Werykowska

Więckiewicz

Wierszycka

Wikło

Wiłkojć

Witkowskij

Wojciechowicz

Woiciechowska

Wojskunowicz

Wojsznis

Wojtkiewicz

Wojtukowicz

Wołkonowski

Wołochowicz

Wołodkowicz

Worszyński

Wysocki

Zacharewicz

Zadranowicz

Zdanowicz

Zdonczyk

Zenowicz

Zinkiewicz

Zubrickienie

Zujewicz

Zykowicz

Żdanowicz

Żeromski

Żuk

Żukowska

Żybort

Żyżniewskaja
The Lithuanian version

Vasilevski

Vaškovič

Verikovskaja

Venckevič

Veršicka

Wiklo

Vilkoit

Vitkovskij

Voitechovič

Voitechovska

Voiskunovič

Voišnis

Vojtkevič, Voitkevič

Voitukovič

Volkonovski,

Volkanovski

Volochovič

Volodkovič

Voršinski

Vysockij

Zacharevič

Zadranovič

Zdanovič

Zdončik

Zenovič

Zinkevič

Zubrickienè

Zujevič

Zykovič

Ždanovič

Žeromskij

Žuk

Žukovska

Žibort

Žižnevskaja 


\section{List of abbreviations}

Arm. Armenian

BUWiWM Biuro Uznawalności Wykształcenia i Współpracy Międzynarodowej [Bureau For Academic Recognition and International Exchange]

c. about

CILP Current Issues in Language Planning

CT Connecticut

CUP Cambridge University Press

dim. diminutive

DA a.F. die Dienstanweisung für die Standesbeamten und ihre Aufsichtsbehörden - alte Fassung

D.P.R. Decreto del Presidente della Repubblica [Decree of the President of the Republic of Italy]

Eng. English

FCNM the Framework Convention for the Protection of National Minorities

FN family name

GN given name

HRAF Human Resources Area File

ICCS International Commission on Civil Status

ICANN Internet Corporation for Assigned Names and Numbers

IDN Internationalized Domain Name

IJP Instytut Języka Polskiego [the Polish Language Institute]

LHR Linguistic Human Rights

Lith. Lithuanian

LP language policy

LPP language policy and planning

LTI Lingua Tertii Imperii [the language of the Third Reich]

M matronymic / metronym(ic)

MA Massachusetts

MIT Massachusetts Institute of Technology

MN middle name

NE Nebraska

NJ New Jersey

NP name policy 


\begin{tabular}{|c|c|}
\hline NY & New York \\
\hline OR & Oregon \\
\hline OUP & Oxford University Press \\
\hline $\mathrm{P}$ & patronym(ic) \\
\hline $\mathrm{PA}$ & Pennsylvania \\
\hline PAN & $\begin{array}{l}\text { Polska Akademia Nauk [Polish Academy of } \\
\text { Sciences] }\end{array}$ \\
\hline PIW & $\begin{array}{l}\text { Państwowy Instytut Wydawniczy [State Publishing } \\
\text { Institute] }\end{array}$ \\
\hline $\mathrm{PN}$ & personal name \\
\hline Pol. & Polish \\
\hline Port. & Portuguese \\
\hline PWN & $\begin{array}{l}\text { Państwowe Wydawnictwo Naukowe [State Scientific } \\
\text { Publishers] - in the years 1951-1991, Polskie } \\
\text { Wydawnictwo Naukowe [Polish Scientific } \\
\text { Publishers] - since } 1991\end{array}$ \\
\hline RJP & Rada Języka Polskiego [Polish Language Board] \\
\hline Rus. & Russian \\
\hline SNL & $\begin{array}{l}\text { Serviciu de Normalización Llingüística [the office of } \\
\text { (Asturian) language standardization in Spain] }\end{array}$ \\
\hline TS-LKD & $\begin{array}{l}\text { Tèvynès Sajunga - Lietuvos Krikščionys Demokratai } \\
\text { [Homeland Union - Christian Democrats of Lithuania] }\end{array}$ \\
\hline UCL & University College London \\
\hline Ukr. & Ukrainian \\
\hline URL & $\begin{array}{l}\text { Universal Resource Locator (also known as web } \\
\text { address }^{620} \text { ) }\end{array}$ \\
\hline UT & Utah \\
\hline VLKK & $\begin{array}{l}\text { Valstybine Lietuviu Kalbos Komisija [State } \\
\text { Commission of the Lithuanian Language] }\end{array}$ \\
\hline WAM & $\begin{array}{l}\text { Wydawnictwo Apostolstwa Modlitwy [a Polish } \\
\text { publisher of books connected with religion; the full } \\
\text { name was used by the publisher until 1993, since } \\
\text { then only the acronym has been in use] }\end{array}$ \\
\hline
\end{tabular}

$620 \mathrm{http}: / /$ en.wikipedia.org/wiki/Uniform_resource_locator, accessed Jan. 25, 2014. 
This page intentionally left blank 


\section{References}

Abramowicz, Zofia 1998. "Problemy konwersji polskich i rosyjskich antroponimów" [problems with the conversion of Polish and Russian anthroponyms]. In: Jakus-Borkowa \& Nowik, pp. 123-130.

Abramowicz, Zofia 2002. "Antroponimia Żydów białostockich jako zwierciadło kultury i historii narodu" [anthroponymy of Białystok Jews as a reflection of their culture and history]. Onomastica Slavogermanica 22, pp. 25-34.

Alford, Richard D. 1988. Naming and Identity: A Cross-Cultural Study of Personal Naming Practices. New Haven: HRAF Press.

Algeo, John 1973. On Defining the Proper Name. Gainesville: University of Florida Press.

Alia, Valerie 2009. Names and Nunavut. Culture and Identity in the Inuit Homeland. New York - Oxford: Berghahn Books.

Anderson, Benedict 2006. Imagined Communities. London: Verso.

Angelov, Angel G. [\&] David F. Marshall 2006. "Introduction: Ethnolinguistic Minority Language Policies in Bulgaria and Their Balkan Context." International Journal of the Sociology of Language 179, pp. 1-28.

Ashley, Leonard R. N. 1996. "Middle Names." In: Eichler et al. 2, pp. 1218-1221.

Avrutin, Eugene M. 2005. "The Politics of Jewish Legibility: Documentation Practices and Reform During the Reign of Nicholas I." Jewish Social Studies 11/2, pp. 136-169.

"Azerbaijan to Adopt New Law on Names" 2011. Today.Az. Jan. 21. http://today.az/news/society/79765.html, accessed Jan. 25, 2011.

Banach, Andrzej 1946. Nowe prawo o zmianie i ustalaniu imion i nazwisk [the new law on changing and determining given names and surnames]. Kraków: Księgarnia Powszechna.

Bandle, Oskar et al. (eds.) 2005. The Nordic Languages. An International Handbook of the History of the North Germanic Languages, vol. 2. Berlin: Walter de Gruyter.

Barnes, Michael P. 2005. "The Standard Languages and Their Systems in the $20^{\text {th }}$ Century II: Faroese." In: Bandle et al. (eds.), pp. 1574-1584.

Bartmińska, Izabela [\&] Jerzy Bartmiński 1978. Nazwiska obce w języku polskim [foreign surnames in Polish]. Warszawa: PWN.

Bartmiński, Jerzy 1992. "Nazwiska obce na tle kontaktów językowych i kulturowych" [foreign surnames in language and culture contact]. In: Język a kultura 7, Jolanta Maćkiewicz [\&] Janusz Siatkowski (eds.), pp. 9-13. Wrocław: Wydawnictwo „Wiedza o Kulturze.”

Bašić, Goran 2001. "Political and Legal Position of the Romanies in Central and South-Eastern Europe." Facta Universitatis 08, pp. 491-516. 
Bastardas, Albert 2004. "Sociolingüística versus política y planificación lingüísticas: distinciones entre los campos y nociones integradoras" [sociolinguistics versus language policy and language planning: field distinctions and elements of integration]. Revista de Llengua i Dret 41, pp. 175-194.

Bauer, Gerhard 1995. "Namenforschung im Verhältnis zu anderen Forschungsdisziplinen." In: Eichler et al. 1, pp. 8-23.

Bering, Dietz 1992. The Stigma of Names. Antisemitism in German Daily Life, 1812-1933. Ann Arbor: The University of Michigan Press.

Biskupski, Mieczysław B. 2000. The History of Poland. Westport: Greenwood Publishing Group.

Bobryk, Adam 2006. Odrodzenie narodowe Polaków w Republice Litewskiej 1987-1997. Toruń: Dom Wydawniczy DUET.

Boeri, David 1985. People of the Ice Whale: Eskimos, White Men, and the Whale. San Diego: Harcourt Brace Jovanovich.

Bojtár, Endre 1999. Foreword to the Past: a Cultural History of the Baltic People. Budapest: Central European University Press.

Bott-Bodenhausen, Karin 1997. Sprachverfolgung in der NS-Zeit: sorbische Zeitzeugen berichten. Bautzen: Domowina-Verlag.

Bourdieu, Pierre 1993. Outline of a Theory of Practice [orig. title: Esquisse d'une théorie de la pratique, précédé de trois études d'ethnologie kabyle]. Cambridge: CUP.

Brands-Kehris, Ilze [\&] Ilvija Pūce 2005a. "Nationhood and Identity". In: Rozenvalde, pp. 21-34.

Brands-Kehris, Ilze [\&] Ilvija Pūce 2005b. "Civil and Political Rights". In: Rozenvalde, pp. 45-62.

Breza, Edward 2008. „Standaryzowane imiona kaszubskie” [standardised Kashub names]. Biuletyn Rady Języka Kaszubskiego [yearbook of the Kashubian Language Board]. Gdańsk: Zrzeszenie KaszubskoPomorskie, pp. 30-73, 76-79.

Bruchnalski, Wilhelm 1926. „T. z. Kalendarz Świętych Słowiańskich w Polsce i ks. Franciszek Siarczyński” [so-called calendar of Slavic saints in Poland and Rev. F. Siarczyński]. Prace Filologiczne 12, pp. 18-29.

Brylla, Eva 2002. "Personal Name Planning in the Nordic Countries." Onoma 37, pp. 357-370.

Buchowski, Krzysztof 1999. Polacy $w$ niepodległym państwie litewskim 1918-1940 [Poles in the independent state of Lithuania 1918-1940]. Białystok: Instytut Historii Uniwersytetu.

Buchowski, Krzysztof 2006. Litwomani i polonizatorzy. Mity, wzajemne postrzeganie i stereotypy $w$ stosunkach polsko-litewskich $w$ pierwszej polowie XX wieku [myths, mutual perception and stereotypes in the Polish-Lithuanian relations in the first half of the $20^{\text {th }}$ century]. Białystok: Wydawnictwo Uniwersytetu w Białymstoku.

Bystroń, Jan Stanisław 1938. Księga imion w Polsce używanych [given names used in Poland]. Warszawa: Towarzystwo Wydawnicze "Rój". 
Bystroń, Jan Stanisław 1993. Nazwiska polskie [Polish surnames]. Warszawa: Książka i Wiedza.

Casier, Marlies [\&] Joost Jongerden (eds.) 2010. Nationalisms and Politics in Turkey: Political Islam, Kemalism and the Kurdish Issue. New York: Taylor \& Francis.

Chalmers, Iain 2003. "Trying to Do More Good than Harm in Policy and Practice: The Role of Rigorous, Transparent, Up-to-Date Evaluations". Annals of the American Academy of Political and Social Science 589, pp. 22-40.

Chłądzyńska, Joanna 2010. “Zmiany nazw miejscowości na Śląsku w świetle polityki językowej” [place-name changes in Silesia in the light of language policy]. In: Nazwy własne a społeczeństwo, edited by Romana Łobodzińska, vol.2, pp. 83-92. Łask: Oficyna Wydawnicza LEKSEM.

Cieślikowa, Aleksandra 2000. “Jednostkowość w onomastyce a system języka" [singularity in onomastics and the system of language]. In: Onomastyka polska a nowe kierunki językoznawcze, Magdalena Czachorowska [\&] Łucja Maria Szewczyk (eds.). Bydgoszcz: Wyd. Uczelniane WSP w Bydgoszczy, pp. 21-30.

Citko, Lilia 1998. "Adaptacja nazwisk wschodniosłowiańskich i bałtyckich w języku polskim (na materiale antroponimicznym Białostocczyzny)" [adaptation of East Slavic and Baltic surnames into Polish on the example of the anthroponyms of the Białystok region]. In: JakusBorkowa \& Nowik, pp. 117-122.

Cooper, Robert L. 1989. Language Planning and Social Change. Cambridge New York - Melbourne: Cambridge University Press.

Couretas, John 2008. "An Orthodox View of Contemporary Economics, Politics, and Culture". The Information Service of the Serbian Orthodox Church. http://www.spc.rs/eng/orthodox_view_contemporary _economics_politics_and_culture, accessed Dec. 11, 2016.

Creamer, Thomas B.I. 1995. "Chinese Place and Personal Names." In: Eichler et al. 1, pp. 906-912.

Crystal, David 1997. The Cambridge Encyclopedia of Language. Cambridge: CUP.

Cygański, Mirosław 1965. Z dziejów okupacji hitlerowskiej w Lodzi 19391945 [issues in the history of Nazi occupation in Łódź 1939-1945]. Łódź: Wydawnictwo Łódzkie.

Dacey-Fondelius, Elizabeth 2007. "Forbidden Names. Identity and the Law." The Local. Nov. 26. http://www.thelocal.se/20071126/9212, accessed Dec. 11, 2016.

Daniłowicz, Robert 2010. „Narodów pomieszanie” [confounding of nations]. Polityka, Dec. 18, pp. 50-53.

Darski, Józef [Jerzy Włodzimierz Targalski] 2008. "Stosunki polskolitewskie" [Lithuanian-Polish relationships]. Abcnet Fundacja 
Orientacja, Feb. 17. http://jozefdarski.pl/3822-stosunki-polskolitewskie, accessed Dec. 11, 2016.

Davies, Norman 2001. Heart of Europe. A Short History of Poland. Oxford: OUP. Online edition, limited view, no pagination. http://books.google.pl /books?id=yWi-WLvY_v0C\&printsec $=$ frontcover $\&$ hl=pl\&source $=$ gbs ge_summary_r\&cad=0\#v=onepage\&q\&f=false, accessed Dec. 5, 2016.

Davies, Norman 2005. God's Playground: A History of Poland in Two Volumes. Oxford: OUP.

Dimitrova, Donka 1998. "Bulgarian Turkish Immigrants of 1989 in the Republic of Turkey." In: Between Adaptation and Nostalgia: the Bulgarian Turks in Turkey, Antonina Zhelyazkova (ed.). Sofia: International Center for Minority Studies and Intercultural Relations. http://old.omda.bg/imir/studies/nostalgia_2.html, accessed Dec. 5, 2016.

Doroszewski, Witold 1968. O kulturę stowa [for proper language standards]. T. II. Warszawa: PIW.

Dorward, David Philip 1996. "Scottish Personal Names.” In: Eichler et al. 2, pp. 1284-1289.

Druviete, Ina 1999. "Language Policy in a Changing Society: Problematic Issues in the Implementation of International Linguistic Human Rights Standards." In: Language, a Right and a Resource, Miklós Kontra, Robert Phillipson, Tove Skutnabb-Kangas [\&] Tibor Várady (eds.). Budapest: Central European University Press, pp. 263-276.

Dzharylgasinova, Roza Shotaevna, Mikhail Vasiljevich Kryukov 1986. Sistemy lichnykh imen u narodov mira [personal name systems among the nations of the world]. Moskva: Izdatelstvo "Nauka" [orig. title: Джарылгасинова, Роза Шотаевна, Михаил Васильевич Крюков 1986. Системы личных имен у народов мира. Москва: Издательство "Наука"]

Eastman, Charles A. (Ohiyesa) 1915. The Indian Today. The Past and Future of the First American. Garden City - New York: Doubleday, Page \& Co.

Eberhardt, Piotr 2005. „Problematyka narodowościowa Bułgarii w XX wieku" [ethnic issues in Bulgaria in the $20^{\text {th }}$ century]. Sprawy Narodowościowe 27, pp. 53-70.

Eichler, Ernst, Gerold Hilty, Heinrich Löffler, Hugo Steger [\&] Ladislav Zgusta (eds.) 1995. Namenforschung: ein internationales Handbuch zur Onomastik, 1. Teilband. Berlin [\&] New York: Walter de Gruyter.

Eichler, Ernst, Gerold Hilty, Heinrich Löffler, Hugo Steger [\&] Ladislav Zgusta 1996. Namenforschung: ein internationales Handbuch zur Onomastik, 2. Teilband. Berlin - New York: Walter de Gruyter.

Eire, Carlos M. N. 1986. War Against the Idols. The Reformation of Worship from Erasmus to Calvin. Cambridge: CUP.

Farkas, Tamás 2007. "Changing names as abolishing the difference. Personal names as ethnic symbols, characteristics of name changes and the Magyarization of surnames in Hungary." Paper presented at XI 
International Conference on Minority Languages (Pécs, Hungary, 5-6 July).

Farkas, Tamás 2009. "Surnames of Foreign Origin in a Language Contact Situation. The Reasons and Ways of Their Changes and Their Influence on the Surname Stock in Hungary" In: Names in Multi-Lingual, MultiCultural and Multi-Ethnic Contact, Wolfgang Ahrens, Sheila Embleton [\&] André Lapierre (eds.), pp. 365-374. Toronto: York University.

Farkas, Tamás [\&] Péter Maitz 2008. "Der Familienname als Nationalsymbol. Über den Untergang deutscher Familiennamen im Ungarn des 19. Jahrhunderts". Zeitschrift für germanistische Linguistik 36, pp. 163-196.

Farkas, Tamás [\&] Mariann Slíz 2013. "Translating Family Names in Hungarian: A Diachronic Survey." AHEA: E-Journal of the American Hungarian Educators Association, 6/2013. http://ahea.net/e-journal /volume-6-2013/11, accessed Dec. 5, 2016.

Felecan, Nicolae 2014. "Nicknames or Collective Bynames?" In: Oliviu Felecan [\&] Daiana Felecan (eds.), pp. 122-132.

Felecan, Oliviu 2012. "Conformity and Nonconformity in Gypsy Names". In: Name and Naming: Synchronic and Diachronic Perspectives. Oliviu Felecan (ed.). Newcastle upon Tyne: Cambridge Scholars Publishing, pp. 129-146.

Felecan, Oliviu 2014. "Unconventional First Names: Between Onomastic Innovations and Illustrious Models". In: Oliviu Felecan [\&] Daiana Felecan (eds.), pp. 133-155.

Felecan, Oliviu [\&] Daiana Felecan (eds.) 2014. Unconventional Anthroponyms: Formation Patterns and Discursive Function. Newcastle upon Tyne: Cambridge Scholars Publishing.

Fercsik Erzsébet 2012. "The Legal Regulation of Married Name Use and Its Practice in Hungary". Onoma 47, pp. 57-80.

Fishman, Joshua A. 1972. Sociolinguistics. A Brief Introduction. Rowley, MA: Newbury House.

Frändén, Märit 2016. "Surnames in the Melting Pot: Presentation of a Project on Surnames and Immigration". In: Proceedings of the 25th International Congress of Onomastic Sciences, Carole Hough [\&] Daria Izdebska (eds.), pp. 233-237. Glasgow: University of Glasgow,

Fros, Henryk [\&] Franciszek Sowa 2002. Twoje imię. Przewodnik onomastyczno-hagiograficzny [an onomastic-hagiographical guide to given names]. Kraków: WAM.

Galley, Chris, Eilidth Garrett, Ros Davies [\&] Alice Reid 2011. "Living Same-Name Siblings and British Historical Demography." Local Population Studies 1, pp. 15-36.

Garibova, Jala [\&] Betty Blair 1996. "History in a Nutshell. 20th Century Personal Naming Practices in Azerbaijan.” Azerbaijan International 4/3, pp. 54-64. http://www.azer.com/aiweb/categories/topics/azeri/aboutaz /43_names_az.html, accessed Dec. 5, 2016. 
Gauß, Karl-Markus 2003. Die sterbenden Europäer. München: Deutscher Taschenbuch Verlag.

Gerritzen, Doreen 2007. "First Names of Moroccan and Turkish Immigrants in the Netherlands". In: Proceedings of the $21^{\text {st }}$ International Congress of Onomastic Sciences, Eva Brylla [\&] Mats Wahlberg (eds.), in collaboration with Rob Rentenaar, pp. 120-130. Uppsala: Institutet för språk och folkminnen.

Gorrochategui, Joaquin 1995. "Basque Names.” In: Eichler et al. 1, pp. 747-756.

Górski, Konrad 1995. Divide et impera [divide and rule]. Białystok: Towarzystwo Literackie im. Adama Mickiewicza, Oddział Białostocki.

Haar, Ingo [\&] Michael Fahlbusch 2006. German Scholars and Ethnic Cleansing, 1919-1945. Oxford [\&] New York: Berghahn Books.

Hametz, Maura 2005. Making Trieste Italian, 1918-1954. Woodbridge [\&] Rochester: Boydell \& Brewer.

Hametz, Maura 2012. In the Name of Italy: Nation, Family, and Patriotism in a Fascist Court. New York: Fordham University Press.

Hanks, Patrick W. 2003. "Americanization of European Family Names in the Seventeenth and Eighteenth Centuries." Onoma 38, pp. 119-154.

Hanson, Ann Meekitjuk [no date]. "What's in a Name? Names, As Well As Events, Mark the Road to Nunavut." http://www.nunavut.com/nunavut 99/english/name.html, accessed Dec. 5, 2016.

Harvalík, Milan 2013. "The Dynamism of the Development of Contemporary Czech Onymic Systems". In: Proccedings of the Second International Conference on Onomastics "Name and Naming”, ed. by Oliviu Felecan. Cluj-Napoca: Editura Mega/Editura Argonaut, pp. 44-51.

Haugen, Einar 1979. "Language Ecology and the Case of Faroese." In: Linguistic and Literary Studies in Honor of Archibald A. Hill, Mohammad Ali Jazayery, Edgar C. Polome [\&] Werner Winter (eds.), pp. 243-258. The Hague [\&] Paris [\&] New York: Mouton.

Haugen, Einar [no date]. "Names in a New World." http://nabo.nb.no/trip?_b=EMITEKST\&urn=\%22URN:NBN:no-nb_emidata _1136\%22, accessed Dec. 5, 2016. Excerpted from The Norwegian Language In America: A Study In Bilingual Behavior, Vol. I: The Bilingual Community. 1953. Philadelphia: University of Pennsylvania Press.

Hazen, Kirk 2011. "Labov: Language Variation and Change." In: The SAGE Handbook of Sociolinguistics, Ruth Wodak, Barbara Johnstone [\&] Paul E. Kerswill (eds.), pp. 24-39. London: SAGE Publications.

Hejger, Maciej 2008. Przeksztatcenia narodowościowe na Ziemiach Zachodnich $i$ Pólnocnych Polski $w$ latach 1945-1959 [national transformations in Poland's Recovered Territories in the years 19451959]. Słupsk: Wydawnictwo Naukowe Akademii Pomorskiej w Słupsku.

Herbert, Robert K. 1997. "The Politics of Personal Naming in South Africa." Names 45/1, Mar., pp. 3-17. 
Holland, Theodore, Jr. 1995. "Investigating Navajo Naming Practices." Names 43/4, pp. 275-293.

Holmberg, Bente 2005. "The Development of Personal Names from the $16^{\text {th }}$ to the End of the $18^{\text {th }}$ Century I: Denmark." In: Bandle et al., pp. 1314-1317.

Howard, Douglas Arthur 2001. The History of Turkey. Westport, CT: Greenwood Publishing Group.

Hudson, R.A. 1996. Sociolinguistics. Cambridge: CUP.

Ishida, Richard 2011. Personal names around the world. Last updated Aug. 17. http://www.w3.org/International/questions/qa-personal-names, accessed Dec. 5, 2016.

Jacob, James E. [\&] Pierre L. Horn 1998. "Comment vous appelez-vous? Why the French Change Their Names." Names 46/1, pp. 3-28.

Jakus-Borkowa, Ewa [\&] Krystyna Nowik (eds.) 1998. Najnowsze przemiany nazewnicze [the most recent naming changes]. Warszawa: Energeia.

Janužytė, Audronė 2005. "Historians as Nation State-Builders: the Formation of Lithuanian University 1904-1922." Dissertation, University of Tampere. http://tampub.uta.fi/search?query=Janu\%C $5 \%$ BEyt $\%$ C4\%97\&submit $=$ Hae $\&$ scope $=10024 \% 2$ F59337, accessed Dec. 5, 2016.

Jernudd, Björn H. 1995. "Personal Names and Human Rights." In: Linguistic Human Rights: Overcoming Linguistic Discrimination, Tove SkutnabbKangas, Robert Phillipson [\&] Mart Rannut (eds.), pp. 121-132. Berlin [\&] New York: Mouton de Gruyter.

Jóhannesson, Gudni Th. [\&] Gunnar Thór Pétursson 2010. EUDO Citizen Observatory. Country Report: Iceland. San Domenico di Fiesole: European University Institute. http://cadmus.eui.eu/bitstream/handle /1814/19617/Iceland.pdf?sequence $=1 \&$ is Allowed $=y$, accessed Dec. 5, 2016.

Joor, Johan 2009. "History and Myth of Dutch Popular Protest in the Napoleonic Period (1806-1813)." In: Myth in History, History in Myth: Proceedings of the Third International Conference of the Society for Netherlandic History, Laura Cruz [\&] Willem Frijhoff (eds.), pp. 175199. Leiden: Brill.

Judgement 3-4-1-6-01 of the Constitutional Review Chamber of 3 May 2001. Supreme Court of Estonia. http://www.nc.ee/?id=436, accessed Dec. 11, 2016.

Jurkiewicz, Jan 2005. ,Legenda o rzymskim pochodzeniu Litwinów w świetle historiografii. Czas powstania i tendencje polityczne" [the legend of Lithuanians' descent from Ancient Romans in the light of historiography; its time of origin and political tendencies]. In: Europa Środkowo-Wschodnia. Ideologia, historia a społeczeństwo. Księga poświęcona pamięci Profesora Wojciecha Peltza, pp. 335-350. Zielona Góra: Oficyna Wydawnicza Uniwersytetu Zielonogórskiego.

Kaleta, Zofia 1998. Nazwisko w kulturze polskiej [the surname in the Polish culture]. Warszawa: Slawistyczny Ośrodek Wydawniczy. 
Kamusella, Tomasz 2009. The Politics of Language and Nationalism in Modern Central Europe. Basingstoke: Palgrave.

Kaplan, Justin [\&] Anne Bernays 1999. The Language of Names. New York: Touchstone.

Karagiannis, Evangelos 2005. Flexibilität und Definizionsvielfalt pomakischer Marginalität. Wiesbaden: Harrassowitz Verlag.

Kiaupa, Zigmantas, Jūratė Kiaupienè [\&] Albinas Kuncevičius 2007. Historia Litwy [the history of Lithuania]. Warszawa: Wydawnictwo Naukowe PWN.

Kiełpiński, Jacek, Adam Luks [\&] Radosław Rzeszotek 2010. Pogoń za Litwa. Sześćset lat po Grunwaldzie [chasing Lithuania: 600 years after Tannenberg]. Warszawa: Państwowy Instytut Wydawniczy.

Klejn, Zbigniew 2004. „Losy Pomaków w Bułgarii” [the fate of the Pomaks in Bulgaria]. Studia z Dziejów Rosji i Europy Środkowo-Wschodniej 39, pp. 5-25.

Klemperer, Victor 2006. The Language of the Third Reich. London [\&] New York: The Athlone Press.

Klimas, Antanas 1983. "The Newest Lithuanian Spelling Reform.” Lituanus 29/4, pp. 17-23.

Knappová, Miloslava 2010. Jak se bude vaše ditě jmenovat? [what will your child be called?] Praha: Academia.

Kohlheim, Rosa 1996. "Typologie und Benennungssysteme bei Familiennamen: prinzipiell und kulturvergleichend.” In: Eichler et al. 2, pp. 1247-1259.

Krăsteva-Blagoeva, Evgenija 2006. "About the Names and Renamings of the Bulgarian Moslems (1912-2000)." Ethnologia Bulgarica. Yearbook of Bulgarian Ethnology and Folklore 3, 63-76.

Krzywicki, Tomasz 2005. Litwa. Przewodnik [a guidebook to Lithuania]. Pruszków: Oficyna Wyd. "Rewasz".

Kulov, Georgi 2007. "Suleyman, Who Used To Be Yulian, and His Grandson Michael." Balkan Investigative Reporting Network, July 17. http://www.balkaninsight.com/en/article/suleyman-who-used-to-beyulian-and-his-grandson-michael, accessed Dec. 5, 2016.

Kuzavinis, Kazimieras [\&] Bronys Savukynas 2005. Lietuviu vardu kilmés žodynas [etymological dictionary of Lithuanian given names]. Vilnius: Mokslo ir enciklopedijų leidybos institutas.

Laber, Jeri 1987. Destroying Ethnic Identity: The Turks of Bulgaria. A Helsinki Watch Report. New York [\&] Washington: Human Rights Watch.

Larson, Carlton F.W. 2011. "Naming Baby: The Constitutional Dimensions of Parental Naming Rights". The George Washington Law Review, 80/1, pp. 159-201.

Lévi-Strauss, Claude 1962. La pensée sauvage. Paris: Librairie Plon. Available online at: http://archive.org/details/lapenseesauvage00levi, accessed Dec. 5, 2016. 
Liberman, Mark 2008. "The Academy Strikes Back.” July 9. http://languagelog.ldc.upenn.edu/nll/?p=336, accessed Dec. 5, 2016.

Linek, Bernard 1997. Odniemczanie województwa śląskiego w latach 19451950 (w świetle materiatów wojewódzkich) [de-Germanizing the Silesian Voyvodeship 1945-1950 in the light of the voyvodeship's documents]. Opole: Państwowy Instytut Naukowy - Instytut Śląski w Opolu.

Litwin, Józef 1930. "Pseudonim wojskowy i jego legalizacja w Polsce" [nom de guerre and its legalisation in Poland]. Pamiętnik HistorycznoPrawny 8/3, pp. 1-65.

Litwin, Józef 1961. Prawo o aktach stanu cywilnego: komentarz [law on civil status: a commentary]. Warszawa: Wyd. Prawnicze.

Liulevicius, Vejas Gabriel 2000. War Land on the Eastern Front: Culture, National Identity and German Occupation in World War I. Cambridge: CUP.

Łossowski, Piotr 1985a. Po tej i po tamtej stronie Niemna [this and the other side of the Nemunas]. Warszawa: Czytelnik.

Łossowski, Piotr 1985b. Litwa a sprawy polskie 1939-1940 [Lithuania and Polish issues 1939-1940]. Warszawa: PWN.

Maass, Ernest 1958. "Integration and Name Changing among Jewish Refugees from Central Europe in the United States". Names 6, pp. 129-171.

Mac Giolla Easpaig, Dónall 1995. "Name Studies in Ireland." In: Eichler et al. 1, pp. 27-31.

Mackiewicz, Józef 1947. „, Jak to było z Litwinami” [the way it was with the Lithuanians]. Wiadomości r. II nr 33 (72), Aug. 17. London. http://kpbc.umk.pl/dlibra/doccontent?id=17976\&dirids=1, accessed Dec. 5, 2016.

Majewicz, Alfred F. 1989. Języki świata i ich klasyfikowanie. Warszawa: PWN.

Majewska, Ewa 2015. "Der Vorname Maria und seine Varianten im Namenschatz der Deutschen und Niederländer im 19. Jahrhundert." In: Proccedings of the Third International Conference on Onomastics "Name and Naming", ed. by Oliviu Felecan. Cluj-Napoca: Editura Mega/Editura Argonaut, pp. 202-213.

Malec, Maria 2001. Imię w polskiej antroponimii i kulturze [the given name in the Polish anthroponymy and culture]. Kraków: Wydawnictwo Naukowe DWN.

Mażul, Henryk 2005. „Kleczkowski czy Klečkovski?” [Kleczkowski or Klečkovski?] Tygodnik Wileńszczyzny 31, August 4-10 (online version No. 256), http://www.tygodnik.lt/200531/bliska1.html, accessed Dec. 5, 2016.

Mikulewicz, Irena 2011. „Niekończący się spór o polską tożsamość” [neverending dispute over Polish identity]. Tygodnik Wileńszczyzny, Jan. 6-12.

Mill, John Stuart 1882. A System of Logic, Ratiocinative and Inductive, Being a Connected View of the Principles of Evidence, and the Methods 
of Scientific Investigation. New York: Harper \& Brothers. Vol. I. http://www.gutenberg.org/files/27942/27942-h/27942-h.html, accessed Dec. 5, 2016.

MIRIS (Minority Rights Information System). http://miris.eurac.edu/mugs 2/browse.jsp, accessed Dec. 5, 2016.

Morava, Alexander H. E. 2003. "The Jurisprudence of the United Nations Human Rights Committee and Other Treaty Monitoring Bodies.” In: European Yearbook of Minority Issues.1, pp. 461-486. The Hague: Kluwer Law Int. (Martinus Nijhoff Publishers).

Neuburger, Mary 2004. The Orient Within. Muslim Minorities and the Negotiation of Nationhood in Modern Bulgaria. Ithaca, NY: Cornell University Press.

Nguyễn, Đình Hoà 1995. "Vietnamese Names.” In: Eichler et al. 1, pp. 893-897.

Nicolaisen, Wilhelm F. H. 1995. "Name and Appellative.” In: Eichler et al. 1, pp. 384-393.

Nyström, Staffan 2016. "Names and Meaning". In: The Oxford Handbook of Names and Naming, edited by Carole Hough, pp. 39-51. Oxford: OUP.

O'Keefe, Michael 2001. Francophone Minorities: Assimilation and Community Vitality. Department of Canadian Heritage. https://archive.org/details/ERIC_ED429461, accessed Dec. 5, 2016.

Osgood, Charles E. 1963. "Language Universals and Psycholinguistics." In: Universals of Language, Joseph H. Greenberg (ed.), pp. 236-54. Cambridge, MA: The MIT Press.

Osmańczyk, Edmund 1954. Pamiętniki Opolan [the memoirs of the inhabitants of the Opole Province]. Kraków: Wydawnictwo Literackie.

Paikkala, Sirkka 2002. "Surnames in Finland on the Threshold of the New Millenium.” Onoma 37, pp. 267-277.

Park, Nahm-Sheik 1989. "Language Purism in Korea Today." In: The Politics of Language Purism, Björn Jernudd [\&] Michael J. Shapiro (eds.), pp. 113-140. Berlin: Walter de Gruyter.

Pawłowski, Adam 2006. „Problemy polskiej polityki językowej w Unii Europejskiej" [the issues of the Polish language policy in the EU]. Socjolingwistyka [Kraków] 20, pp. 7-17.

Pizzi, Katia 2001. A City in Search of an Author: The Literacy Identity of Trieste. London [\&] New York: Sheffield Academic Press.

Poggeschi, Giovanni 2004. "Language Policy in Latvia." European Academy of Bolzano/Bozen. http://www.gencat.cat/llengua/noves/noves/hm04tar dor/docs/poggeschi.pdf, accessed Dec. 11, 2016.

Pollok, Ewald Stefan [c. 1998]. Legendy, manipulacje, kłamstwa prof. F. A. Marka $w$ "Tragedii górnośląskiej" a prawda o Śląsku i powojennej dyskryminacji jego mieszkańców [prof. F. A. Marek's legends, manipulations, lies in his Upper-Silesian Tragedy and the truth about Silesia and the post-war discrimination of its inhabitants]. Przedbórz: Wydawnictwo Żyrowa. 
Powell, Kimberly, 2012 (updated). "My Ancestor's Name Was Changed at Ellis Island - Dispelling the Myth of Ellis Island Name Changes." About.com / Genealogy. http://genealogy.about.com/od/ellis_island/a/ name_change.htm, accessed Dec. 5, 2016.

Puskás, Tünde 2009. We Belong to Them: Narratives of Belonging, Homeland and Nationhood in Territorial and Non-Territorial Minority Settings. Brussels: Peter Lang.

«Qu'y a-t-il dans un nom? » Time, Jan. 7, 1966.

Raag, Raimo 1999. Från allmogemål till nationalspråk: språkvård och språkpolitik $i$ Estland från 1857 till 1999 [from dialect to national language: language planning and policy in Estonia 1857-1999]. Uppsala: Acta Universitatis Upsaliensis.

Raátz Judit 2008. "Trends in the choice of first names in Hungary since the second half of the 20th Century." In: Proceedings of the XXII International Congress of Onomastic Sciences, Maria Giovanna Arcamone, Davide de Camilli [\&] Bruno Porcelli (eds.), pp. 195-207. Pisa: Università di Pisa. http://mnytud.arts.unideb.hu/nevtan /informaciok/pisa/rj-a.pdf\#page $=8 \&$ zoom $=$ auto,0,720, accessed Dec. 5, 2016 (pagination in quotes and references after the on-line edition).

Raátz Judit 2012. "The Giving and Usage of First Names in Hungary". Onoma 47, pp. 13-34.

Radczenko, Aleksander 2009. „O pisowni nazwisk raz jeszcze” [the spelling of surnames revisited]. Infopol, May 12. http://www.infopol.lt/pl /naujienos/detail.php?ID=1735\&PRINT=Y, accessed Sept. 20, 2012.

Radczenko, Antoni 2007. ,Zwycięstwo czy porażka? Projekt ustawy o pisowni nazwisk." [victory or defeat? The bill on surname spelling]. Nasz Czas, June. http://www.nasz-czas.1t/_NCZ_ARCHYVAS/706/w _trybie.html, accessed Dec. 11, 2016.

Rajkowski, Rudolf 1955. Zmiana nazwiska. Studium z zakresu prawa administracyjnego [change of surname. A study in administrative law]. Warszawa: Wydawnictwo Prawnicze.

Ramonienè, Meilutė 2007. "Language Planning and Personal Naming in Lithuania." CILP 8/3, pp. 422-436.

Rannut, Mart 2008. "Finno-Ugric Languages and Sustainable Development." The 5th World Congress of Finno-Ugric Peoples, Hanty-Mansiisk Russia, June 27-30. http://jabadaba.eki.ee/index.php ?id=15250, accessed Dec. 5, 2016.

Redmonds, George 2004. Christian Names in Local and Family History. Toronto: Dundurn Press.

Reisœter, Guro 2012. "Immigrants in Norway and Their Choice of Names: Continuation or Adaptation?" In: Botolv Helleland, Christian-Emil Ore [\&] Solveig Wikstrøm (eds.) Names and Identities. Oslo: University of Oslo, pp. 224-234.

Rennick, Robert M. 1969. "Hitler and Others who Changed Their Names and a Few who Did Not." Names 17, pp. 199-207. 
Rennick, Robert M. 1984. "On the Right of Exclusive Possession of a Family Name." Names 32, pp. 138-155.

Ricento, Thomas (ed.) 2006. An Introduction to Language Policy: Theory and Method. Malden: Blackwell Publishing.

Rix, Helmut 1995. "Romische Personennamen." In: Eichler et al. 1, pp. 724-732.

Rose, Margaret 2005. Baby Names for Dummies. Indianapolis: John Wiley $\&$ Sons.

Rospond, Stanisław 1947. „Repolonizacja śląskich imion i nazwisk” [rePolonisation of Silesian given names and surnames]. Komunikaty Instytutu Śląskiego, 9/1-4. Katowice: Instytut Śląski.

Rozenvalde, Inta 2005. How Democratic is Latvia? Democratic Audit. Latvijas Universitāte. www.president.lv/images/modules/items/PDF /item_498_Audit_of_democracy.pdf, accessed Dec. 11, 2016.

Rymut, Kazimierz 1995. Stownik imion współcześnie w Polsce używanych [dictionary of names currently used in Poland]. Kraków: IJP PAN.

Rymut, Kazimierz 1999. Nazwiska Polaków. Słownik historycznoetymologiczny, t. I [the surnames of Poles. A historical-etymological dictionary, vol. I]. Kraków: IJP PAN.

Rymut, Kazimierz 2001. Nazwiska Polaków. Słownik historycznoetymologiczny, $t$. II [the surnames of Poles. A historical-etymological dictionary, vol. II]. Kraków: Wydawnictwo Naukowe DWN.

Rymut, Kazimierz 2005. Słownik nazwisk użyanych w Polsce na poczatku XXI wieku. Wydanie drugie poprawione. CD-ROM. Kraków: PAN - IJP.

Rzetelska-Feleszko, Ewa, Aleksandra Cieślikowa [\&] Jerzy Duma 2002. Słowiańska onomastyka: encyklopedia. T. I [Slavic onomastics, vol. I]. Warszawa [\&] Kraków: Towarzystwo Naukowe Warszawskie.

Santos, Hector 1995-1998. "Katálogo ng mga Apelyidong Pilipino (Catalog of Filipino Names).” http://www.bibingka.com, accessed Dec. 5, 2016.

Sarnowska-Giefing, Irena 2003. „Imiona poznaniaków w latach 1939-1945” [the given names of the inhabitants of Poznan in the years 1939-1945]. Poznańskie Spotkania Językoznawcze 11, pp. 101-115.

Satinská, Lucia 2015. "Problematika rodovo citlivého vyjadrovania v mad'arčine (v Mad'arsku a na Slovensku)". In: Analýza významu a možností použivania rodovo vyváženého jazyka, ed. by Jana Cviková, NÁRODNÝ PROJEKT: Inštitút rodovej rovnosti. http://www .ruzovyamodrysvet.sk/chillout5_items/1/6/0/1/1601_5755f0.pdf, accessed Nov. 24, 2016, pp. 101-110.

Satkauskas, Rytis 2008. "Use of Diacritics: Towards a New Standard of Minority Protection?" Lithuanian Foreign Policy Review 21, pp. 112-135.

Saville-Troike, Muriel 2003. The Ethnography of Communication: An Introduction. Oxford: Blackwell.

Scherr, Arthur 1986. "Change-of-Name Petitions of the New York Courts: An Untapped Source in Historical Onomastics.” Names 34, pp. 284-302. 
Schiffman, Harold F. 1996. Linguistic Culture and Language Policy. London [\&] New York: Routledge.

Scott, James C. 1998. Seeing Like a State: How Certain Schemes to Improve the Human Condition Have Failed. New Haven \& London: Yale University Press.

Scott, James C., John Tehranian [\&] Jeremy Mathias 2002. "The Production of Legal Identities Proper to States: The Case of the Permanent Family Surname." Comparative Studies in Society and History 1/44, pp. 4-44.

Selimski, Ludwig 1998. "Zmiany w imiennictwie osobowym Bułgarów w okresie powojennym" [post-war changes in Bulgarian anthroponymy]. In: Jakus-Borkowa \& Nowik, 103-109.

Selimski, Ludwig 1999. Християнските имена у българските католици. Проблеми на усвояването [Christian names of Bulgarian Catholics. Problems with adaptation]. Katowice: Wydawnictwo Uniwersytetu Śląskiego.

Senn, Alfred 1945. "Lithuanian Surnames." American Slavic and East European Review 4/1-2, pp. 127-137.

Shohamy, Elana 2006. Language Policy: Hidden Agendas and New Approaches. London - New York: Routledge.

Šimunovič, Petar 2002. "Chorwacja" [Croatia]. In: Rzetelska-Feleszko, Cieślikowa \& Duma, pp. 369-377.

Skutnabb-Kangas, Tove, Robert Phillipson [\&] Mart Rannut (eds.) 1995. Linguistic Human Rights: Overcoming Linguistic Discrimination. Berlin [\&] New York: Mouton de Gruyter.

Skutnabb-Kangas, Tove [\&] Robert Phillipson 1995. "Linguistic Human Rights, Past and Present.” In: Skutnabb-Kangas et al., pp. 71-110.

Skutnabb-Kangas, Tove [\&] Sertaç Bucak 1995. "Killing a Mother Tongue How the Kurds Are Deprived of Linguistic Human Rights." In: Skutnabb-Kangas et al., pp. 347-371.

Skutnabb-Kangas, Tove 1997. "Human Rights and Language Policy in Education." In: Encyclopedia of Language and Education. Volume I: Language Policy and Political Issues in Education. Ruth Wodak [\&] David Corson (eds.), pp. 55-66. Dordrecht: Kluwer Academic Publishers. Smith, Elsdon C. 1970. The Story of Our Names. Detroit: Gale Research Co.

Smith, Graham, Vivien Law, Andrew Wilson, Annette Bohr [\&] Edward Allworth 1998. Nation-Building in the Post-Soviet Borderlands: the Politics of National Identities. Cambridge: CUP.

Smith-Bannister, Scott 1997. Names and Naming Patterns in England 15381700. Oxford: OUP.

Snyder, Timothy 2004. Reconstruction of Nations. New Haven: Yale University Press [Polish edition: Rekonstrukcja narodów: Polska, Ukraina, Litwa $i$ Biatoruś 1569-1999. Sejny: Fundacja Pogranicze, 2006].

Spolsky, Bernard 2004. Language Policy. Cambridge: CUP.

Spolsky, Bernard 2009. Language Management. Cambridge: CUP. 
Spolsky, Bernard 2010. "Review of Tomasz Kamusella's The Politics of Language and Nationalism in Modern Central Europe." Language Policy, 9/4, pp. 375-377.

Spolsky, Bernard 2012. "What Is Language Policy?” In: Spolsky 2012a, pp. 3-15.

Spolsky, Bernard 2012a (ed.). The Cambridge Handbook of Language Policy. Cambridge: CUP.

Spolsky, Bernard [\&] Elana Shohamy 1999. The Languages of Israel: Policy, Ideology and Practice. Clevedon [\&] Buffalo: Multilingual Matters.

Šrámek, Rudolf 2010. "Struktura relacji 'nazwa własna - rzeczywistośćc" [the structure of the relationship between a proper name and the reality]. In: Nazwy własne a spoleczeństwo, Romana Łobodzińska (ed.) 1, pp. 23-32. Łask: Oficyna Wydawnicza LEKSEM.

Stahl, Abraham 1994. "The Imposition of Hebrew Names on New Immigrants to Israel: Past and Present." Names 42/2, pp. 279-288.

Straczuk, Justyna 1999. Język a tożsamość czlowieka $w$ warunkach społecznej wielojęzyczności: pogranicze polsko-litewsko-biatoruskie [language and identity in a multilingual society: Polish-LithuanianBelarusian border]. Warszawa: Wydawnictwa Uniwersytetu Warszawskiego.

Subačius, Giedrius 1997. "Three Models of Standard Written Lithuanian Language in the $19^{\text {th }}$ Century: J. A. Pabrèža, J. Čiulda, S. Daukantas." Lituanus 43/1, pp. 13-25.

Subačius, Giedrius 2004. "Double Orthography in American Lithuanian Newspapers at the Turn of the Twentieth Century." In: Studies in Baltic and Indo-European Linguistics, Philip Baldi [\&] Pietro U. Dini (eds.), pp. 189-202. Amsterdam [\&] Philadelphia: John Benjamins.

Subačius, Giedrius 2005. "Development of the Cyrillic Orthography for Lithuanian in 1864-1904." Lituanus 51/2, pp. 29-55.

Superanskaja, Aleksandra V. 1995. "Eastern Slavic Names". In: Eichler et al. 1, pp. 812-816.

Szober, Stanisław (ed.) 1958. Stownik poprawnej polszczyzny [normative dictionary of Polish]. Warszawa: PIW.

Taszycki, Witold 1927. „O t. zw. kalendarzu imion słowiańskich” [on the socalled calendar of Slavic given names]. Język Polski 12, pp. 33-42.

Telkes, Simon 1977. How to Become a Hungarian. The Artificial Reproduction of a People. Roma: Edizioni Europa [includes a reprint of the 1898 ed. of S. Telkes' Hogy magyarositsuk a vezetékneveket? with its English translation].

Thompson, Riki 2006. "Bilingual, Bicultural, and Binominal Identities: Personal Name Investment and the Imagination in the Lives of Korean Americans." Journal of Language, Identity and Education 5/3, pp. 179-208. 
Tomasson, Richard F. 1980. Iceland, the First New Society. Minneapolis: University of Minnesota Press.

Türköz, Meltem 2007. "Surname Narratives and the State-Society Boundary: Memories of Turkey's Family Name Law of 1934." Middle Eastern Studies 43/6, pp. 893-908.

Umińska-Tytoń, Elżbieta 1988. „Imiona łodzian urodzonych podczas okupacji hitlerowskiej" [names of the inhabitants of Łódź born under the Nazi occupation]. Onomastica 32, pp. 121-140.

Valentine, Tim, Tim Brennen [\&] Serge Brédart 2002. The Cognitive Psychology of Proper Names: On the Importance of Being Ernest. London [\&] New York: Taylor \& Francis e-Library.

Valentová, Iveta 2016. "Prechyl’ovanie priezvisk a jeho vývin na Slovensku" [the feminine forms of surnames and their development in Slovakia]. In: Prechyl'ovanie: áno - nie? Jazykovedné štúdie 33, eds. Lucia Molár Satinská \& Iveta Valentová. Bratislava: Veda, 11-22.

Van Langendonck, Willy 1996. "Bynames”. In: Eichler et al. 2, pp. 1228-1232.

Van Langendonck, Willy 2007. Theory and Typology of Given Names. Berlin [\&] New York: Mouton de Gruyter.

Vasilevich, Hanna 2013. "Lithuania's Minority-Related Legislation: Is There A Legal Vacuum?" ECMI Working Paper\#70. European Centre for Minority Issues. https://www.files.ethz.ch/isn/170346/WP_70_ Final.pdf, accessed Dec. 9, 2106.

Wahlberg, Mats 1990. "Swedish soldiers' names. Official surnames given in the Swedish army 1682-1901". In: Proceedings of the XVIIth International Congress of Onomastic Sciences, Eeva Maria Närhi (ed.), vol. 2, 460-467. Helsinki: The University of Helsinki and the Finnish Research Centre for Domestic Languages.

Walczak, Bogdan 2010. "Jeszcze o przyszłości egzonimów" [the future of exonyms revisited]. In: Nazwy własne a społeczeństwo, edited by Romana Łobodzińska, vol. 2, pp. 263-273. Łask: Oficyna Wydawnicza LEKSEM.

Walkowiak, Justyna B. 2012. "Feminine Surnames in Polish: Two Policies and the Practice." Onoma 47, pp. 223-246.

Walkowiak, Justyna B. 2013. "Foreign branding in Poland: chrematonyms and anthroponyms". In: Proceedings of the Second International Conference on Onomastics "Name and Naming". Onomastics in Contemporary Public Space. Cluj-Napoca: Mega/Argonaut, pp. 218227. http://onomasticafelecan.ro/iconn2/proceedings/2_11_Walkowiak _Justyna_ICONN_2.pdf, accessed Dec. 10, 2016.

Walkowiak, Justyna B. 2014. "A name policy and its outcome: Programmatic names in the nineteenth-century Posen Province." In: Joan Tort-Donada [\&] Montserrat Montagut i Montagut (eds.) Els noms en la vida quotidiana. Actes del XXIV Congrés Internacional d'ICOS sobre Ciències Onomàstiques / Names in daily life. Proceedings of the XXIV ICOS International Congress of Onomastic Sciences, pp. 1745-1756. 
Barcelona. http://www.gencat.cat/llengua/BTPL/ICOS2011/180.pdf, accessed Dec. 6, 2016.

Wenzel, Walter 2008. "Das Schicksal slawischer Orts- und Personennamen in der Niederlausitz." In: Namen und ihr Konfliktpotential im europäischen Kontext, Nicole Eller, Stefan Hackl [\&] Marek L'upták (eds.), pp. 239-250. Regensburg: edition vulpes.

Wicherkiewicz, Tomasz 1997. "Do-Pyjter-Jaśka i cym-Hala-Mockja oraz inne zjawiska $\mathrm{z}$ antroponimii Wilamowic w dawnym Księstwie Oświęcimskim" [various phenomena in the anthroponymy of the town of Wilamowice in the former Duchy of Oświęcim]. In: Onomastyka $i$ leksykologia, Hanna Popowska-Taborska [\&] Jerzy Duma (eds.), pp. 307-316. Warszawa: Slawistyczny Ośrodek Wydawniczy.

Willms, Jennifer 2011. 10000 Vornamen. So soll unser Kind heißen. Augsburg: Weltbild.

Willson, Kendra 2002. "Political Inflections: Grammar and the Icelandic Surname Debate." In: Standardization: Studies from the Germanic Languages, Andrew Robert Linn [\&] Nicola McLelland (eds.), pp. 135-152. Amsterdam [\&] Philadelphia: John Benjamins.

Willson, Kendra 2009. "Name Law and Gender in Iceland." http://www.academia.edu/1166199/Name_law_and_gender_in_Iceland, accessed Dec. 5, 2016.

Willson, Kendra 2012. "Linguistic Models and Surname Diversification Strategies in Denmark and Sweden". Onoma 47, pp. 299-326.

Wilson, Stephen 1998. The Means of Naming. A social and cultural history of personal naming in western Europe. London [\&] Bristol, PA: UCL Press.

Wylie, Jonathan 1987. The Faroe Islands: Interpretations of History. Lexington: The University Press of Kentucky.

„Zalecenia dla urzędów stanu cywilnego dotyczące nadawania imion dzieciom osób obywatelstwa polskiego i narodowości polskiej” [guidelines for registry offices regarding names for children of Polish citizens of Polish nationality] 1996. Komunikaty Komisji Kultury Języka Komitetu Językoznawstwa PAN nr 1/4, http://www.rjp.pan.pl /index.php?option=com_content $\&$ view $=$ article $\& i d=611 \&$ Itemid $=58$, accessed Dec. 5, 2016.

Zawadzki, Jarosław Maciej 2002. 1000 najpopularniejszych nazwisk w Polsce [1000 most popular surnames in Poland]. Warszawa: Świat Książki.

Zax, David 2008. "How Jews Got Their Last Names." Moment Magazine, March - April, http://bechollashon.org/heart/index.php/articles/1999, accessed Dec. 5, 2016.

Zielińska, Anna 2002. Polska mniejszossć na Litwie Kowieńskiej. Studium socjolingwistyczne [Polish minority in the Kaunas Region of Lithuania. A sociolinguistic study]. Warszawa: Slawistyczny Ośrodek Wydawniczy. 
Zinkevičius, Zigmas 1998. The History of the Lithuanian Language. Vilnius: Mokslo ir enciklopedijų leidybos institutas.

Zorc, R. David 1995. "Philippine Naming Practices." In: Eichler et al. 1, pp. 925-928. 

Justyna B. Walkowiak, absolwentka poznańskiej anglistyki i podyplomowych studiów dziennikarskich oraz doktor językoznawstwa, jest adiunktem w Pracowni Polityki Językowej i Badań nad Mniejszościami Katedry Orientalistyki UAM. Naukowo zajmuje się onomastyka, szczególnie antroponomastyka w jej aspekcie komparatystycznym i normatywnym. Jest autorka dwudziestu artykułów i rozdziałów w monografiach, a także dwóch podręczników do nauki języka angielskiego dla studentów kierunków orientalnych. Od 2010 r. jest członkinią International Congress of Onomastic Sciences, a od 2015 - Komisji Onomastycznej przy Oddziale PAN w Poznaniu.

„Na wysoka ocenę zasługuje odwaga autorki, która podejmuje temat $\mathrm{w}$ istocie uniwersalny. Wskazuje na istnienie dziedziny ważnej dla każdego - każdy jest nosicielem swej nazwy osobowej, nawet jeśli sobie tego nie życzy. Każdy jako nosiciel imienia i nazwiska jest lub może być przedmiotem działań politycznych. Godna uznania jest wstrzemięźliwość autorki wobec tendencji ideologicznych [...].

Praca wskazuje ważna lukę w naszym obrazie zjawisk językowych i udowadnia, że lukę tę wypełniać moga studia interdyscyplinarne [...]. Zasługuje na miano nowatorskiej, dowodzi erudycji i zdolności analitycznych autorki."

dr hab. Witold Maciejewski, prof. Uniwersytetu Humanistycznospołecznego SWPS (fragment recenzji wydawniczej)
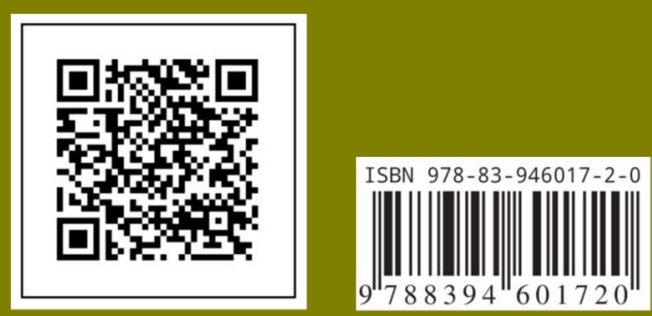

*DOI: $10.14746 / 9788394601720 *$ 